open 2 access

\title{
colloquium:
new philologies
}


Colloquium: New Philologies is edited by the Alpen-Adria-Universiät Klagenfurt.

Chief Editor: Nikola Dobrić

Section Editors: Cristina Beretta, Nikola Dobrić, Angela Fabris, Doris Moser, René Reinhold Schallegger, Jürgen Struger, Peter Svetina, Giorgio Ziffer

Technical Editor: Thomas Hainscho

Administrative Assistance: Mark Schreiber

\section{World Wide Web}

Visit Colloquium online at http://colloquium.aau.at

\section{Legal Information}

Colloquium is an Open Access Academic Journal. It is licensed under a Creative Commons Attribution 4.0 International License (CC BY 4.0).

Colloquium Logo by Gerhard Pilgram; Open Access Logo by Public Library of Science, from Wikimedia Commons (CC BY-SA 3.0); Title page: "Process4.reload()" by Alessandro Valentino from www.openprocessing.org (CC BY-SA 3.0).

2018 by Alpen-Adria-Universiät Klagenfurt

DOI: http://dx.doi.org/10.23963/cnp.2018.3.2

ISSN 2520-3355 


\section{Table of Contents}

Colloquium: New Philologies • Vol 3, No 2 (2018)

\section{Language and Linguistics: Results}

The Multiple Modality System in Southern Scotland: Levels of Acceptability of Double and Triple Modals in the $21^{\text {st }}$ century Scottish Borders region

ANTHONy R. Bour

Analysis of The Correlation Between Populist Discourse and Tweet Popularity 27 Fabio CARrella

Let's Stop The Enemy!

Natalia Borza

Dependency Structures and Beyond: Assembling Drawings of Sentence Construction

Mosang Zhang

Conceptual Metaphors in Donald Trump's Political Speeches:

Framing his Topics and (Self-)Constructing his Persona

Kateryna Pilyarchuk \& Alexander Onysko

\section{Literature and Culture: Results}

Srbohrvaški asimetrični deseterec v slovenskih prevodih

AleKsANDER BJELČEvič

Perspectives: Abstracts of the conference

Language.Literature.Politics

Language.Literature.Politics. 1918-2018.

(Un)doing Nationalism and Resistance

COlloquium Editorial BOARD 
The phenomenon of propaganda as reflected in Victor Pelevin's novel S.N.U.U.F

Tomas Cenys

Competitive Nationalism vs. Cooperative Nationalism:

Re-reading Rabindranath Tagore in Times of War

Debabrata Das

Resisting Nationalism: Postnational Visions in Thomas Pynchon's

Against the Day

Ali DehDarirad

Identity and Contemporary Fashion

ANa Gruic

Beyond Nationalism: Faith Movements as Transnational Communities

HimANi KAPOOR

Conceptual Blending in Social Issue Advertisements

Anela Mulahmetovic Ibrisimovic \& Nerma Pezerović-Ridić

Unification, Nationalism and/or Brexit? The impact of the Nationalisms and the Northern Irish Good Friday Agreement 1998-2018 on local media discourse

SARAH RitT

Neologisms at historical turning points: Czech example

TENa ŠINJORI

'The opposite of hatred': Undoing nationalism in Joyce's Ulysses

NATAŠA TuČEv

The Role of Language in the Definition of National Character:

A Case Study of Identity Discourse in Contemporary Japan

ELISA Vitali

(Un)doing nationalism through familial metaphors: a case of Taiwan 
Colloquium: New Philologies · Vol 3, No 2 (2018)

The Postmodern Turkish Novel's Resistance to the Return of Nationalism

Barı̧̧ YILMAZ

Ernst Bloch's Ungleichzeitigkeit then and now - About a political term and its reflection in literary texts of the past and present

Manuel TheophiL 


\title{
The Multiple Modality System in Southern Scotland: Levels of Acceptability of Double and Triple Modals in the $21^{\text {st }}$ century Scottish Borders region
}

\author{
Anthony R. Bour*
}

\begin{abstract}
This paper mainly aims to describe and analyse the current syntactic and semantic system of Multiple Modality spoken and written in the Scottish Borders region. The task of the questionnaire survey is to get further details as regards this dialectal reality in which hundreds of combinations are possible. In total, 231 informants participated in this field dialectal enquiry from 2010 to 2013. The data analysed in this paper stem from the 2011 survey that mainly took place in Kelso and Jedburgh. 73 informants completed the structured-type questionnaire at this time. How many combinatorial possibilities are allowed in this part of Scotland? What are the possible positions of modal expressions in these combinations? What types of semantic interpretations can these combinations generate in the Borders? What is (un)grammatically possible in the varieties of Scottish English spoken in the region? In contrast to the American South, where a number of projects (both theoretical and field studies-based) have been undertaken since the 1970s, there are, at this point only very few answers to these questions regarding the Scottish Borders region. It is time to reactivate the knowledge in this research field in order to obtain a general syntactic overview of these modal sequences which were born in Northern Europe.
\end{abstract}

Key words: combinations, modals, Scots, syntax, Scottish English, vernacular dialects

* Hermann Paul School of Linguistics, Freiburg im Breisgau; bour.anthony1@orange.fr 


\section{Introduction}

Research on this dialectal phenomenon has been conducted since the 1970s. It is quite complex because it contains hundreds of possible modal combinations, i.e. Double Modals (DMs, i.e. two adjacent modals) and Triple Modals (TMs, i.e. three adjacent modals), used in various territories of the Western-part of the Anglophone world. Authors such as Nagle $(1994,202)$ think that they are of recent use, based on the earliest attestations of Multiple Modals (MMs) found in two Scottish texts written by Calderwood (1756) and Alexander Ross (1768):

(a) If we get a German doctor, not one of us will can speak to him. (1756)

E R

(b) The youth himself may can to rule the rost. (1768)

E R

Each combination has its series of semantic sequences. In the field of modality, there are two main types of senses: the epistemic sense, corresponding to various levels of probability, and the root sense, referring to the other semantic interpretations, such as ability, obligation, permission, suggestion, warning, and necessity.

Epistemic-Root is the most common semantic ordering (Battistella 1995, 31) for modal combinations. Nevertheless, their diversity generates other orderings such as:

R-R (used to could)

1 You used to could do that in the old house (Butters 1996, 274)

E-E (may would)

1 I wonder if you may would help me (Mishoe's corpus 1991, 15)

R-E (ought to might)

1 Yes, we ought to might go now (Coleman 1975, 96)

A modal combination is above all a mishmash of modal expressions classified via a scale of auxiliaries sketched by Quirk in the mid-1980s (Quirk 1985, 137):

a) Central modals: can, could, may, might, must, will, would, shall, should.

b) Marginal Modals: used to, ought to, need, dare.

c) Semi Auxiliaries or Semi Modals: have to, would like to, be going to, be able to, be allowed to, be compelled to, be obliged to ...

d) Modal Idioms in which comparative modals are found: would rather, had (or would) better, would sooner, have got to, be to ...

Combinatorial possibilities are quite numerous, which implies that some of them can be written and spoken in Standard Englishes. That is indeed the case with the following constructions: 


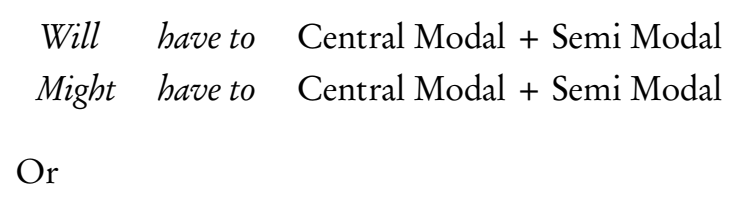

Mufwene (1994) noticed this assembling of modal expressions in mainstream Englishes. However, for unknown reasons, the terms MMs or modal combinations, DMs and TMs, are simply rejected from Standard English grammar. Unlike Scandinavian varieties (Nagle 1995) in which modal combinations are found as well on a daily basis and which are fully recognized and used in standard grammars of this part of the Germanic language family, anglophone combinations are only recognized and mostly found in vernacular or also called non-standard varieties.

Visser (1963-1973) and Traugott (1972) detected some ancestors of these current modal combinations which go back to the Old and Middle English periods:

Old English DMs (450-1100 AD):

Scule agan, sceal(l) agan for should ought

Mot, moten or moston agan for must ought

Middle English DMs (1100-1450 AD):

Shall moun or sall mow for shall may

Sall kunne for shall can

Must kunne for must can

The problem for Nagle $(1989,363)$ is the absence of auxiliarization of modals during these two periods, although he claims that shall, should, and must were already advanced in auxiliarization in Old English. These combinations were used in Anglian dialects and especially spoken in the domineering kingdom of the Middle Ages in Northern Great Britain, namely Northumbria. For this time, Nagles identifies them as combinations of verbs rather than of auxiliaries. What is more, most of these historical combinations, such as must ought, shall may, and shall can no longer exist as auxiliary combinations nowadays. Therefore, he does not define them as the direct precursors of today's MMs. Nonetheless, a complete disconnection of these two periods with late modern English cannot be proved yet.

Montgomery is in a kind of intermediary situation and asserts that today's MMs go back one century prior to the attestations in Calderwood's and Ross's texts:

Both of these (attestations) occurred some two centuries after the demise of the Middle English combinations. Montgomery (1989) reviews the historical link between the populations of Scotland, Northern Ireland and the 
American South, the three principal double modal regions and suggests that the origin of the double modals lies well before the first attested citations since speakers of Scottish English began to settle Northern Ireland in 1610. (Montgomery, cited in Nagle 1994, 203)

In order to obtain better clarification on the origin of this dialectical system, more diachronic research is necessary. However, this is not the main goal of the paper.

\section{Field Survey}

After this brief historical summary, the next sections of this paper will deal with the data obtained through a questionnaire survey distributed in April and May 2011 in the main towns of the Scottish Borders region: Kelso and Jedburgh, both located in the county of Roxburghshire.

The research focuses on the current types and uses of MMs in the region. For the survey, 73 respondents (46 women aged between 40 and 60 years and 27 men aged between 30 and 70 years) completed a structured-type questionnaire based on a dialectal methodology proposed by Louis Jean Calvet and Pierre Dumont (1999). This approach allows the preparation of questions that are termed in the jargon of social sciences as closed and semi-closed questions:

La plupart des chercheurs préfèrent élaborer un questionnaire structuré comprenant à la fois des questions fermées et semi fermées, plutôt qu'un questionnaire composé uniquement de questions ouvertes. (Calvet et Dumont 1999, 18)

Most researchers prefer preparing a structured questionnaire comprising both closed and semi-closed questions, rather than a questionnaire only made up of open questions. (Calvet and Dumont 1999, 18) (English translation by the author Anthony R. Bour)

A closed question consists of the informant simply answering yes or no to a series of two written questions. This represents the first task of the questionnaire:

1 Have you ever heard the type of structure underlined below? He'll can help us the morn.

2 Would you use it yourselves in a similar context?

$\mathrm{N}$

If the respondents answer no to the second question, they have to replace it with a grammatical construction that can be similar but not necessarily equal to the combination that, according to him/her, would fit better with the clause. 
In semi-closed questions, the respondents have to select one grammatical feature among four proposed options. This represents the second task of the questionnaire

I didn't tak them at aa.
A/ uisst tae could
B/ used to would
C/ use tae could
D/ used to could
E/ another similar construction

This paper will focus on the second task in which respondents can choose one modal combination out of four that best describes the sentence, or they can tick answer $\mathrm{E}$ and write their own grammatical construction that can be another modal combination or a completely different structure in a standard or vernacular syntactic environment. There are 8 sentences in total.

\section{Results}

This task comprises a series of 8 sentences in which respondents selected the appropriate DM or TM for each sentence based on their dialectal knowledge and personal grammatical preferences. They also made several morpho-syntactic and spelling modifications in the modal structures when none of the vernacular combinations could fit with the sentence. At the end of this task, a clear tendency is observed in the choice of the MMs and similar preferences can be traced by both genders.

\begin{tabular}{llrr}
\hline & & M & W \\
\hline A/ & might not can & 5 & 18 \\
B/ & might not could & 1 & 2 \\
C/ & used to couldn't & 0 & 2 \\
D/ & might used to couldn't & 1 & 0 \\
E/ & Other vernacular features & 1 & 4 \\
E/ & Other standard features & 16 & 19 \\
\hline
\end{tabular}

Table 1: $\mathrm{He}$ refuse.

As mentioned in the first table, the favourite combination is might not can, which is identified as a classical DM. 18 women and only 5 men ticked this structure for the 
first sentence. This DM is very often recognized and spoken throughout the Englishspeaking communities in their vernacular dialects. Unlike will can, it does not belong to a specific geographical area. The rest of the combinations were barely chosen. There are two main reasons that can explain this situation:

1) Two combinations contain a non-classical modal element, i.e. used to, which can be difficult for some respondents to decipher when it is accompanied by one or two modal expressions. The grammatical nature of used to is quite diversified even in standard English grammar. Most of the time, it can be identified as a Semi Modal (Macafee 1980, 19), a Quasi Modal (Labov 1968, 263 and Bauer 2002, 52-53), a Marginal Modal according to Quirk $(1985,236)$ or a true Modal Auxiliary like can, must, might by Collins $(2004,1)$. This confusion in the identity of used to casts some serious doubts for the respondents and for that reason they rather avoid it in DMs or TMs.

2) The second reason is the presence of a clitic negator attached to could in the last two combinations, which, contrary to the American South, is apparently still rare in vernacular Scottish English grammar.

However, might not could is a typical DM in Southern Scotland, which makes the fact that it was not chosen by more respondents quite a mystery.

Regarding the other non-standard constructions, three of them were chosen by female respondents:

(1) He maybe unable t refuse.

(2) He cannae refuse.

(3) He couldna refuse.

One man decided to separate the Central Scots negator nae after might, which is rare in vernacular grammatical rules of Scots:

(4) He might nae refuse.

According to Brown (1991) and Miller (1993), this negator should never be detached from its primary or modal auxiliary. However, the respondents' perception of grammar, especially in the oral medium, keeps changing, and written grammar rules, even in the vernacular environment, always change more slowly than oral vernacular grammar rules do.

The number of standard constructions is quite large. The rest of the tables will show a similar situation in which vernacular structures of replacement, including MMs, are minor. Listed below are the standard constructions by order of preference:

Standard structures of replacement mostly proposed by men: 
(5) He might not refuse.

(6) He couldn't refuse.

(7) He wouldn't refuse.

(8) He may not refuse.

Standard structures of replacement mostly proposed by women:

(9) He might not be able to refuse.

(10 He might refuse.

(11) He could not refuse.

Other modal expressions, essentially in the negative, were proposed by respondents only once:

(12) He (will, might not, won't, should, may, mightn't, wouldn't, may not be able to, cannot) refuse.

The following table is particularly interesting to analyse as there seems to be a greater tendency towards the choice of American MMs by some respondents.

\begin{tabular}{llrr}
\hline & & M & W \\
\hline A/ & might not couldn't & 2 & 1 \\
B/ & might couldn't & 0 & 1 \\
C/ & may not could & 1 & 9 \\
D/ & might will can't & 0 & 1 \\
E/ & Other vernacular features & 2 & 5 \\
E/ & Other standard features & 20 & 26 \\
\hline
\end{tabular}

Table 2: I better put it (a hearing aid) on or I understand you.

Over the past 30 years, Scottish-English dialects have undergone constant change, especially in the field of modality. In this second table, there is a net preference for may not could, which is not a typical modal sequence in the traditional grammar spoken and written in Southern Scotland. Combinations in which may is in first position belong to the American South. Miller (1993) does not take these contemporary changes of modals in Scotland into account: "Modal verbs occupy an important place in the grammar of any variety of English, and this is one area in which Scottish English is massively different from Standard English. The major differences are these: Broad Scots lacks SHALL, MAY and OUGHT." (116)

This difference keeps decreasing in the $21^{\text {st }}$ century since more and more Northern English, Ulster, and Southern American modal sequences appear in the Scots and Scottish-English dialects. In this sentence, the first modal of the combination is epis- 
temic, expressing equi-probability (Lapaire and Rotgé 2004, 205) whereas the second modal is root and expresses ability.

Five women wrote their own non-standard constructions, one of which proposed a similar sequence to may not could:

(13) Maybe I better put it on or I might not could understand you. (once)

(14) Maybe I better put it on or I might no understand you. (twice)

(15) Maybe I better put it on or I wouldnay understand you. (once)

(16) Maybe I better put it on or I would nae understand you. (once)

In these examples, two typical Scottish negators are present: nay and nae. Both are identified as enclitic negatives. Nae should be attached to would since it remains a wide scope negator unlike no which is a narrow scope negator. With nae, the sentence is completely negative whereas with no the sentence is partially negated. That is what the respondents wanted to create without paying attention to the spelling of the negator. This situation can also be explained by the lack of grammatical knowledge in Scots because in the field survey conducted in this part of the Roxburghshire county, some respondents asserted that they were not taught enough vernacular knowledge in their childhood.

As regards male respondents, one wrote a more American DM, while the other insisted on an assembling of a Central Modal and a Semi Modal:

(17) Maybe I better put it on or I might better understand you.

(18) Maybe I better put it on or I wouldnae be able tae understand you.

Many standard structures were again proposed by both genders. As regards male informants, the most proposed standard modals are as follows:

(19) Maybe I better put it on or I might not understand you. (proposed six times)

(20) Maybe I better put it on or I may not understand you. (three times)

(21) Maybe I better put it on or I won't understand you. (twice)

Furthermore, the contraction of might not was also found in two questionnaires:

(22) Maybe I better put it on or I mightn't understand you. (twice)

Each of the following modal expression in the negative couldn't, could not, will not, wouldn't, might not be able to, and might were mentioned only once in this second clause.

Regarding female respondents, 26 mainstream structures were written and again might not and may not are at the top of the classification of structures of replacement: 
(23) Maybe I better put it on or I might not understand you. (seven times)

(24) Maybe I better put it on or I may not understand you. (six times)

(25) Maybe I better put it on or I won't be able to understand you. (five times)

(26) Maybe I better put it on or I might not be able to understand you. (three times)

(27) Maybe I better put it on or I wouldn't understand you. (twice)

Couldn't and could not are rarely mentioned. It is the same case for mayn't which was proposed by one 65-year-old woman. For the latter it is quite understandable because, contrary to mightn't, most Anglophone speakers consider may in the negative as ungrammatical in any variety of English. The third clause presents some major differences due to the presence of TMs in the list.

\begin{tabular}{llrr}
\hline & & M & W \\
\hline A/ & should might better & 2 & 0 \\
B/ & will might can & 0 & 4 \\
C/ & 'll should could & 1 & 4 \\
D/ & 'll might can & 1 & 11 \\
E/ & Other vernacular fea-tures & 4 & 3 \\
E/ & Other standard features & 16 & 22 \\
\hline
\end{tabular}

Table 3: $\mathrm{He}$ do it for you.

In this third sentence, many more women than men preferred to select TMs, especially Il might can. Should might better is the odd one out in this table because, unlike the other three TMs that all belong in southern Scotland, it is American. Although very few men proposed a TM or another vernacular structure, two of them selected the American TM, something that the female respondents did not do at all. Four women selected the uncontracted will should can combination and four others chose the contracted $l l$ should could.

Four non-standard features were also proposed, two of which have the Semi Modal (Quirk 1985, 137) be able to that is not conjugated:

(28) He be able to do it for you. (proposed twice)

"Invariant be" or "be-levelling" processes are put into place in this case. The other structures are two traditional Scottish English DMs:

(29) He might can do it for you.

(30) He'll can do it for you.

Many standard structures were also found in this part of the questionnaire. Male respondents mostly chose the Single Modals might and should as constructions of replacement: 
(31) He might do it for you. (five times)

(32) He should do it for you. (twice)

The other structures were selected only once:

(33) He (may be able to, might be able to, would, didn't, could, may, will maybe, will, should be able to) do it for you.

Three of the female respondents proposed different alternative DMs, namely:

(34) He'll might do it for you.

(35) He may well do it for you.

(36) He should can do it for you.

It is interesting to notice here that might is in the second position in the DM, while is not typically found in a Scottish combination. Both will and might are epistemic, which was barely thinkable in the early research on DMs in the 1970s. Only a very limited number of combinations were studied at the time (Butters 1973) and only the semantic ordering Epistemic + Root $(E+R)$ was proposed to understand modal sequences. As further research has shown, especially in the 1990s (Brown 1991, Montgomery and Nagle 1994, De-La-Cruz 1995 and Battistella 1995), the ordering of each modal can vary greatly from place to place in the English-speaking world. For the first two clauses, the semantic ordering (Battistella 1995, 31) E+E is created in both sequences "ll might and may well. Well is orthographically and semantically similar to will but, contrary to will, it is never put in the first position. For both clauses, the paraphrases proposed by the author are the following:

(37) Maybe he will do it for you.

For the third sentence, this time with the $\mathrm{E}+\mathrm{R}$ semantic ordering, the paraphrase also contains an adverb followed by a Semi Modal:

(38) It is likely that he is able to do it for you.

As regards standard structures, there is a slight preference for could followed by should:

(39) He could do it for you. (five times)

(40) He should do it for you. (four times)

(41) He should be able to do it for you. (three times)

(42) He will probably do it for you. (twice)

(43) He might do it for you. (twice)

(44) He may be able to do it for you. (twice) 
The remaining structures were mentioned just once:

(45) He (may, will, would, might be able to) do it for you.

Since more newcomers dwell in southern Scotland for work or retirement, especially Northern English people, it was interesting to test typical Northumbrian DMs for this study. As expected in the next table, some Scottish respondents positively indicated that they have been using a few of these combinations on a regular basis for at least 30 years.

\begin{tabular}{llrr}
\hline & & M & W \\
\hline A/ & mustn't could've & 0 & 4 \\
B/ & must not could have & 2 & 3 \\
C/ & mustn't could have & 1 & 7 \\
D/ & might not could've & 2 & 1 \\
E/ & Other vernacular features & 6 & 11 \\
E/ & Other standard features & 13 & 18 \\
\hline
\end{tabular}

Table 4: The girls usually make me some toasted sandwiches but they made any today.

The first three DMs are quite similar, morpho-syntactically speaking. However, among the female respondents, there is a slight preference for mustn't could bave. They prefer contracting the negator belonging to must rather than the primary auxiliary located after could. Concerning male respondents, only five chose one of the four DMs and six others preferred writing their own vernacular constructions as follows:

(46) They cannae have made nay today.

(47) They m'anae could've made any today.

(48) They may not be able to made any today.

(49) They mustn't made any today.

(50) They were unable to made any today.

(51) They did not made any today.

The ellipsis of have occurred three times, maintaining the past participle of make after to and not. The first two clauses are Scots, in terms of spelling of the modals and the enclitic negator nae.

As regards standard features, some male respondents maintained the grammatical structure must have + past participle and the association of have with not: 
(52) They must not have made any today. (mentioned three times)

(53) They haven't made any today. (three times)

(54) They mustn't have made any today. (twice)

(55) They bave not made any today. (twice)

Women again proposed more vernacular and standard features than men in this fourth table:

(56) They didn't made any today. (four times)

(57) They did not made any today. (twice)

(58) They couldn't made any today.

(59) They might made any today.

(60) They have nae made any today.

(61) They mustnae could've made any today.

(62) They might no could've made any today.

The last two clauses are particularly interesting. They have two DMs, each containing one Central Scots negator, i.e. the enclitic negative nae and the independent negative no detached from might. These two informants wished to 'Scotticize' the DMs of the clause, which is also common in clauses containing one single modal. This really reflects the Modern Scots grammatical knowledge of the Borders inhabitants. This knowledge continues to be passed down, resisting to the pervasive influence of Southern Standard English-English. Nonetheless, the other forms of negation in Scots dialects fall more and more into oblivion over the Central Scots negative nae.

Standard answers given by the female informants were not significantly different from those given by male participants:

(63) They haven't made any today. (mentioned four times)

(64) They have not made any today. (three times)

(65) They must not have made any today. (three times)

There is an exception with the use of the past perfect instead of the present perfect:

(66) They had not made any today. (twice)

The following structure was just written once:

(67) They (could not make, mustn't have made, might not have made, won't be able to make, didn't make, were not able to make) any today. 
The next table includes the notion of hypothesis.

\begin{tabular}{llrr}
\hline & & M & W \\
\hline A/ & might would & 0 & 0 \\
B/ & may could & 1 & 2 \\
C/ & could might & 0 & 2 \\
D/ & might could & 4 & 7 \\
E/ & Other vernacular features & 0 & 5 \\
E/ & Other standard features & 17 & 27 \\
\hline
\end{tabular}

Table 5: If we get a piece of a car, things would be better.

The 'queen of combinations' might could was mainly selected by both genders for the fifth sentence. The reversed combination could might and the American combination may could were only chosen by five respondents. Every respondent who was familiar with the Multiple Modality system in the Anglophone world recognized and used might could. There is still no explanation for the pervasive influence of might could in the system. The earliest Scottish-English attestations go back to the $18^{\text {th }}$ century and they do not contain might could or similar structures, i.e. might would, might should or might can. This structure still represents the nerve centre of MMs already studied by Battistella in 1991. The extensive network of MMs in the English-speaking world makes me think otherwise. It is not guaranteed that the system does not hold without might could. In the field surveys conducted from 2010 to 2013, most respondents with some knowledge of MMs did not have might could in mind all the time or it was not necessarily identified as the pillar of the system. The possibilities to create modal combinations are so impressive that might could or one of the two modals of this classical combination could easily be replaced by many other modal expressions.

Regarding the other vernacular features, only five women proposed the following sentences:

(68) If we could've get a piece of a car, things would be better. (mentioned twice)

(69) If we cannae get a piece of a car, things would be better.

(70) If we maybe get a piece of a car, things would be better.

(71) If we were able get a piece of a car, things would be better.

In two clauses, the subordinate clause does not contain a preterit on the verb get and the modal in the negative cannae. This could be a levelling process in which Scottish English grammar does not require the preterit for both the main and subordinate clauses.

As observed before, many more mainstream constructions were proposed, 17 for men and 27 for women. Among the 27 female respondents, 17 mentioned could, interpreted here as indicating ability. This meaning is also present for can mentioned twice: 
(72) If we could get a piece of a car, things would be better. (mentioned 17 times)

(73) If we maybe could get a piece of a car, things would be better. (three times)

(74) If we can get a piece of a car, things would be better. (twice)

(75) If we could maybe get a piece of a car, things would be better. (twice)

Concerning the 17 standard features proposed by the male respondents, could was again the favourite modal, chosen by 14 men. Other modal expressions were proposed only once, such as be able to and can.

In the next clause, all the four DMs proposed in the list have might in first position.

\begin{tabular}{llrr}
\hline & & M & W \\
\hline A/ & might oughta should & 2 & 1 \\
B/ & might better & 2 & 7 \\
C/ & might should oughta & 0 & 1 \\
D/ & might ought to & 4 & 12 \\
E/ & Other vernacular features & 1 & 0 \\
E/ & Other standard features & 16 & 22 \\
\hline
\end{tabular}

Table 6: One of our goals be to encourage non-member involvement.

This series of combinations is much different from the classical one, in which only Central Modals are found. With the help of Quirk's tables of modal expressions, the four combinations proposed, i.e. the two TMs, the Comparative DM (containing better) and the Hybrid DM (containing ought to) are described as follows:

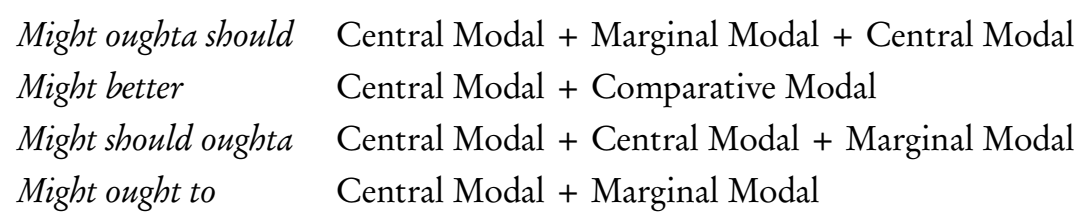

These hybrid forms represent combinatorial possibilities in which a minority of respondents did not remain insensitive to their presence in the questionnaire. 12 female respondents had a net preference for might ought to, directly followed by might better, which was selected by seven women. Very few male respondents selected these exotic combinations and they preferred replacing them by standard syntactic structures. Might better, coming from might had better, is typically American and its presence in the Southern Scottish territory seems to increase. The presence of Americans in the regions of the Lowlands for work or vacation probably has its effects, but bringing back this DM from the American South by Scottish tourists is not impossible either. The paraphrase for this type of DM is as follows: 
Maybe it would be better that one of our goals be to encourage non-member involvement.

The presence of the "mandative" subjunctive in this paraphrase is adequate. Regarding both TMs, they are too complex to be used on a regular basis. The respondents proved this very well in the table. The habitual semantic ordering for such constructions is $\mathrm{E}+\mathrm{R}+\mathrm{R}$. The presence of the two combinations should oughta or oughta should located after might in these exotic combinations reinforce the sense of suggestion expressed by both genders. When ought to is only present in a DM with might usually in the first position, the suggestion expressed by the individual is more personal. It does not reflect the common idea expressed by other individuals in a group. Since might is in first position here, the following semantic ordering for might ought to is $\mathrm{E}+\mathrm{R}$.

Only one man proposed a vernacular structure of replacement, namely the to-deletion in ought to:

(76) One of our goals ought be to encourage non-member involvement.

Ought is quite common in Australian and New Zealand Englishes, especially in the negative and the interrogative (Bauer 2002, 53). It is more colloquial in British or American Englishes, but its usage is not rare in the spoken medium.

Concerning male standard features of replacement, should was written seven times, followed by might, would, ought to and could.

Regarding female standard features, the order of preference of Single Modals remains the same, except that they included one more modal only once, which is may.

\begin{tabular}{llrr}
\hline & & M & W \\
\hline A/ & may might can & 3 & 0 \\
B/ & might could & 4 & 15 \\
C/ & should could & 0 & 1 \\
D/ & may should ought & 0 & 1 \\
E/ & Other vernacular features & 0 & 1 \\
E/ & Other standard features & 16 & 26 \\
\hline
\end{tabular}

Table 7: One of our goals be to encourage non-member involvement.

There is no doubt that might could remains a very recognisable and very common combination in the Anglophone world. More enquiries need to be carried out to understand this behaviour of the respondents. Both tables 5 and 7 clearly show a significant increase in the choice of this classical DM. The rest is barely taken into account by both genders. The two TMs are more American, which can explain this rejection. However, should could is a typical Scottish-English DM and the decrease in its frequency is more difficult 
to explain. Some informants were disturbed by the presence of the object pronoun me in the sentence because they found it to be too American. This additional element with a European modal combination does not fit very well for them.

By order of preference, the following standard clauses proposed by the 16 male respondents are as follows:

(77) I think I might have me a piece of cake. (nine times)

(78) I think I could have me a piece of cake. (twice)

(79) I think I may have me a piece of cake. (twice)

(80) I think I will have me a piece of cake. (twice)

(81) I think I would like a piece of cake.

Three of the 16 respondents preferred removing the object pronoun me to make the sentence less American and, in the last sentence, the respondent deleted the auxiliary have as well.

Only one vernacular structure of replacement was proposed by one female respondent:

(82) I think I ought have me a piece of cake.

Again, the removal of the to-infinitive was proposed in Scottish English, making ought a true modal auxiliary in the affirmative form. Should remains a more regular Central Modal than ought or ought to in Standard Englishes.

Standard features of replacement proposed by 26 female respondents display the same order of preference as for male respondents:

(83) I think I might have (me) a piece of cake. (proposed ten times and one respondent among the ten deleted $m e$ )

(84) I think I may have (me) a piece of cake (eight times and one respondent among the eight deleted $m e$ )

(85) I think I will have me a piece of cake. (four times)

(86) I think I might be able to have me a piece of cake. (twice)

(87) I think I should have a piece of cake.

(88) I think I could have a piece of cake. 


\begin{tabular}{llrr}
\hline & M & W \\
\hline A/ & might ought to should & 1 & 0 \\
B/ & may should & 1 & 3 \\
C/ & ought to should & 0 & 2 \\
D/ & should ought to & 5 & 10 \\
E/ & Other vernacular features & 1 & 1 \\
E/ & Other standard features & 17 & 28 \\
\hline
\end{tabular}

Table 8: You have the oil changed.

Should ought to remains the favourite DM that, according to 15 respondents, best corresponds to the clause. Although the meaning of a personal suggestion is expressed by the respondents in the clause, ought to should seems less natural for most respondents, due mainly to the first position that ought to takes in the DM. Furthermore, the grammatical meaning of ought to is sometimes blurred for some respondents. The other two MMs might ought to and may should are apparently not used much either, due to the morphological complexity for the TM and the American South origin for the DM.

In the table, one man and one woman each proposed a vernacular sentence:

(89) You ought have the oil changed.

(90) You might outta have the oil changed.

Battistella $(1995,22)$ lists might otta and shouldn't otta in his manuscript. He asserts that this spelling variant of ought to, based on a preference scale, is often used among citizens of the American South. Either this feature variant was brought to Scots and Ulster later in the $20^{\text {th }}$ century, or groups of Scots and Scotch-Irish immigrants brought the spelling variant outta into the new world, later changing into otta during the $18^{\text {th }}$ and $19^{\text {th }}$ centuries.

For both genders, should remains the most chosen standard feature in this last clause. Here are the standard features proposed by men:

(91) You should have the oil changed. (mentioned twelve times)

(92) You ought to have the oil changed. (three times)

(93) You must have the oil changed.

(94) You can have the oil changed.

Regarding the use of Central Modal must, the person is quite sure that the oil has been changed. Those who use the Marginal Modal ought to again have a more personal thought that is not necessarily linked with the general viewpoint.

The types of standard features proposed by female respondents a generally similar to those given by male respondents: 
(95) You should have the oil changed. (fifteen times)

(96) You ought to have the oil changed. (nine times)

(97) You maybe should have the oil changed.

(98) You could have the oil changed.

(99) You might have the oil changed.

(100) You will have the oil changed.

Could have $+N P+$ changed and might have $+N P+$ changed can generate different meanings. The sentence with could have has the following semantic interpretation:

(101) You could have had the oil changed, but you didn't do it.

The grammatical structure expresses an 'irrealis' or 'counter-factual' event, meaning that it has never occurred, unlike the other structure might have $+N P+$ past participle:

(102) You might have had the oil changed, don't you remember?

There is a slight chance that this event occurred in the past.

\section{Conclusion}

The results obtained for this section of the questionnaire show that the dialectal knowledge of MMs has not been completely lost and that some preferences in the use of these combinations have clearly been emphasised by both genders. The table below sketches the most frequent combinations selected by the respondents:

\begin{tabular}{ll}
\hline WOMEN & MEN \\
\hline might could (22 times) & might could (8 times) \\
might not can (18 times) & might not can (5 times) \\
might ought to (12 times) & should ought to (5 times) \\
'll might can (11 times) & might ought to (4 times) \\
should ought to (10 times) & may might can (3 times) \\
may not could (9 times) & should might better (twice) \\
mustn't could have (7 times) & must not could have (twice) \\
might better (7 times) & might not could've (twice) \\
\hline
\end{tabular}

Although more women participated in this study, both genders generated the same tendency in in the first two lines of the table above. They gave priority to the 'ubiquitous' might could as well as the DM in the negative might not can. DMs having might in first position remain the most understandable non-standard dialectal structures to be 
used essentially in the spoken medium. In total, both DMs were selected 40 times by women and 13 times by men. As regards the other modal sequences, might ought to is also regularly used, 12 times by women. However, it is only used four times by men. This result could have been different if more male respondents had participated in the survey. Should ought to also belongs to one of the favourite combinations of the informants in Kelso and Jedburgh. These first four sequences, i.e. the two classical ones with Central Modals could and can and the two hybrid ones with Marginal Modal ought to are quite common to both genders. Nevertheless, the remaining combinations in the table are hardly used. This table does not indicate Scottish MMs only. The field study reveals that some citizens of the Borders have extended their range of MMs over the past two decades since Brown's (1991) and Miller's (1993) research. Hearing American DMs, such as may not could and might better or DMs from North-Eastern England like mustn't could have and might not could've, in Kelso and Jedburgh is not peculiar any more. Furthermore, several respondents also proposed to write their own personal DMs, i.e. Il might or may well. Some Scots spellings for negative particles have also been suggested by some respondents, such as the Central Scots nae and the Broad Scots na. Their knowledge of MMs is far from vague. The pursuit of these dialectal enquiries generates further clarification in the Scottish Multiple Modality system. What has already been described by Brown continues to change and to be preserved 20 years later by Scottish-English respondents in the Borders. In the near future, it is necessary to continue this research in the other regions of the Lowland Scots area in order to obtain a complete status on the stability and morphosyntactic richness of the Multiple Modality system in this part of Europe.

\section{References}

Battistella, Edwin. 1991. “The Treatment of Negation in Double Modal Constructions.” Linguistic Analysis 21. 49-65.

Battistella, Edwin. 1995. “The Syntax of the Double Modal Construction.” Linguistica Atlantica 17: $19-44$.

Bauer, Laurie. 2002. An Introduction to International Varieties of English. Edinburgh: Edinburgh University Press.

Brown, Keith. 1991. "Double Modals in Hawick Scots." In Dialects of English Studies in Grammatical Variation, edited by Peter Trudgill and Jack Chambers, 74-103. London: Routledge.

Butters, Ronald. 1973. "Acceptability Judgments for Double Modals in Southern Dialects." In New Ways of Analyzing Variation in English, edited by Guy Bailey and Roger Shuy, 276-286. Washington, D.C.: Georgetown University Press.

Butters, Ronald, and Barbara Fennel. 1996. "Historical and Contemporary Distribution of Double Modals in English.” In Focus on the USA, edited by Edgar Schneider, 265-288. Amsterdam: John Benjamins Publishing Company.

Calvet, Louis-Jean, and Pierre Dumont. 1999. L'Enquête Sociolinguistique. Paris: Editions L'Harmattan. 
Collins, Peter. 2005. "The Modals and Quasi-Modals of Obligation and Necessity in Australian English and other Englishes." English World-Wide 26(3): 249-273.

Chomsky, Noam. 1957. Syntactic Structures. The Hague: Mouton.

Coleman, William. 1975. "Multiple Modals in Southern States English." PhD diss., Indiana University Bloomington.

De-La-Cruz, Juan. 1995. “The Geography and History of Double Modals in English.” Folia Linguistica Historica XVII1-2: 75-96.

Labov, William, P. Cohen, and J. Lewis. 1968. "Study of the Non-Standard English of Negro and Puerto Rican Speakers in New York City.” 2 vols. Office of Education Cooperative Research Project No. 3288. Eric Document 028423. New York: Columbia University.

Macafee, Caroline. 1980. Characteristics of Non-Standard Grammar in Scotland. http://www.abdn. ac.uk/ en1038/grammar.html.

Miller, Jim. 1993. “The Grammar of Scottish English.” In Real English, The Grammar of English Dialects in the British Isles, edited by James Milroy and Lesley Milroy, 99-138. Harlow: Longman.

Mishoe, Margaret, and Michael Montgomery. 1994. "The Pragmatics of Multiple Modal Variation in North and South Carolina." American Speech 69(1): 3-29.

Mufwene, Salikoko. 1994. "Double Modals in American Southern English: How Peculiar Are They?” Contemporary Linguistics 1: 89-104.

Nagle, Stephen. 1989. “Double Modals in Early English.” In Historical Linguistics 1989, Papers from the 9th International Conference on Historical Linguistics, edited by Henk Aertsen and Robert Jeffers, 363-370. Amsterdam: John Benjamins Publishing Company.

Nagle, Stephen. 1994. “The English Double Modal Conspiracy.” Diachronica XI. 2: 199-212. Amsterdam: John Benjamins Publishing Company.

Nagle, Stephen, and Michael Montgomery. 1994. "Double Modals in Scotland and the Southern United States: Trans-Atlantic Inheritance or Independent Development?” Folia Linguistica Historica XIV/1-2: 91-107.

Nagle, Stephen. 1995. “The English Double Modals: Internal or Change?” In Linguistic Change Under Contact Conditions, edited by Jacek Fisiak, 207-216. Berlin: De Gruyter Mouton.

Nagle, Stephen. 1997. "What is Double About Double Modals?" In Language History and Linguistic Modelling. A Festschrift for Jacek Fisiak, edited by Raymond Hickey and Stanislaw Puppel, 1513-1526. Berlin: De Gruyter Mouton.

Quirk, Randolph, Sidney Greenbaum, Geoffrey Leech, and Jan Svarvik. 1985. A Comprehensive Grammar of the English Language. London: Longman.

Traugott, E.C. 1972. A History of English Syntax: A Transformational Approach to the History of English Sentence Structure. New York: Holt.

Visser, Fredericus T. 1963-1973. An historical Syntax of the English language, Leiden: Brill. 


\section{Questionnaire of 2011 (Sociolinguistic Study)}

\section{Name:}

Forename:

Age:

Gender:

$\mathrm{M} / \mathrm{F}$

Employment:

Workplace:

\section{I}

1) I know I might could and should enjoy myself.

After reading the first sentence evoking a context, try to answer the following questions:

A/ Have you ever heard this kind of underlined structure?

B/ Would you use it yourselves in a similar context? If yes, would you use it regularly, occasionally or rarely?

C/ If not, try to replace it by another one which, according to you, would be more suitable in this context. Do the same for the other seven sentences.
A/
$\mathrm{B} /$
$\mathrm{C} /$

2) He willnae can come.

A/

$\mathrm{B} /$

$\mathrm{C} /$

3) He'll can help us the morn.
A/
B/
$\mathrm{C} /$

4) I was afraid you might couldn't find this address.
A/
B/
$\mathrm{C} /$ 
5) A good machine clipper would could do it in half a day.

A/

$\mathrm{B} /$

$\mathrm{C} /$

6) I think that we should have ought've done that yesterday.
A/
B/
$\mathrm{C} /$

7) He wouldn't could've worked, even if you had asked him.

A/

B/

$\mathrm{C} /$

8) He should can go tomorrow.
A/
$\mathrm{B} /$
$\mathrm{C} /$

II

Choose only one structure (by circling one letter) that, according to you, would be the best choice in the following clauses.

1) $\mathrm{He}$ refuse.
A/ might not can
B/ might not could
C/ used to couldn't
D/ might used to couldn't
E/ another similar construction (in this case, write it in the gap. It must be the same type of grammatical structure as the first four)


2) I thought maybe I better put it (a hearing aid) on or I understand you.
A/ might not couldn't
B/ might couldn't
C/ may not could
D/ might will can't
E/ another similar construction (in this case, write it in the gap)

3) $\mathrm{He} \longrightarrow$ do it for you.
A/ should might better
B/ will might can
C/ 'Il should could
D/ 'll might can
E/ another similar construction (in this case, write it in the gap)

4) The girls usually make me some toasted sandwiches but they made any today.
A/ mustn't could've
B/ must not could have
C/ mustn't could have
D/ might not could've
E/ another similar construction (in this case, write it in the gap)

5) If we get a piece of a car, things would be better.
A/ might would
B/ may could
C/ could might
D/ might could
E/ another similar construction (in this case, write it in the gap) 
6) One of our goals be to encourage non-member involvement.
A/ might oughta should
B/ might better
C/ might should oughta
D/ might ought to
E/ another similar construction (in this case, write it in the gap)

7) I think I have me a piece of cake.
A/ may might can
B/ might could
C/ should could
D/ may should ought
E/ another similar construction (in this case, write it in the gap)

8) You have the oil changed.
A/ might ought to should
B/ may should
C/ ought to should
D/ should ought to
E/ another similar construction (in this case, write it in the gap)

III

Add the question tag you wish to write after each underlined dialectal construction.

1) I might could do that,

2) He must wouldn't steal, ___ ?

3) He'll can do it, , ?

4) He might used to could run the marathon, ?

5) You might could see Uranus if you had a telescope, __ ? 


\section{Additional questions concerning these structures}

IV

In which other contexts do you use them? (Circle one or several letters)
A/ In family
B/ Between friends
C/ At work
D/ Alone
E/ Other suggestions:

V

How often do you use (orally) these types of grammatical constructions? (Circle only one letter)
A/ a lot
B/ often
C/ occasionally
D/ rarely
E/ not at all

You write these types of constructions: (Circle only one letter)
A/ a lot
B/ often
C/ occasionally
D/ rarely
E/ not at all

You write these structures: (Circle only one letter)
A/ When taking notes during meetings or conferences
B/ When leaving a note for a friend
C/ When writing a report
D/ When writing an e-mail to someone
E/ When doing something else (What would it be?): 


\section{To conclude}

Put each of the underlined dialectal constructions in the negative $\&$ in the interrogative.

1) I may can get it out tomorrow.

NEG:

INT:

2) He'll should can come the morn.

NEG:

INT:

3) You should ought to make the rules clear.

NEG:

INT:

4) He might can tell you.

NEG:

INT:

5) The children used to would kind of stay in the background, you know.

NEG:

INT:

Thank you for your cooperation! 


\title{
Analysis of The Correlation Between Populist Discourse and Tweet Popularity
}

Fabio Carrella*

\begin{abstract}
This paper analyses linguistic features present in populist discourse on Twitter, together with the relationship that these may have with the popularity obtained by the tweets. The preliminary part of this study was conducted on tweets collected from the official accounts of four European populist leaders, namely Luigi Di Maio, Matteo Salvini, Marine Le Pen, and Nigel Farage. This phase suggested that particular discursive elements often related to populism, such as emotionalization, simplistic rhetoric and intensified evaluations, are present on social media as well. However, the main focus was on the possible correlation between these aspects and the number of "likes" and "retweets" that a single tweet receives. Therefore, tweets were firstly classified by a popularity value, and then divided in two groups, creating a corpus of most and least popular tweets for each subject. Secondly, tweets were annotated using the Appraisal Framework (Martin and White 2005), in order to observe the existence of a peculiar linguistic behaviour by populist leaders. The same operation was conducted on a control group formed by three establishment politicians, namely Matteo Renzi, François Hollande, and David Cameron. Finally, the annotations of the most and the least popular tweets were compared to highlight features that were particularly frequent in popular tweets. This process showed how specific "populist" features, such as emotions, negative judgments, or intensified evaluations are related with the attention received by users on social media. Findings indicate that these features are positively correlated with the tweet popularity, both when considering populist and non-populist politicians. As a matter of fact, reference subjects were the ones who showed a stronger presence of populist-related features
\end{abstract}

* University for Foreigners Perugia; fabio.carrella@unistrapg.it 
in popular tweets. This leads to believe that the stylistic distance between establishment and populist parties is reducing, and that also non-populist leaders are taking advantage of particular discursive elements that better catch the attention of the social media audience.

Key words: Twitter analysis, populism, political discourse

\section{Introduction}

The surge of populist politicians and movements to the detriment of more established leaders and parties has been demonstrated by several recent events. In particular, two of these started at a national level, but then had a global effect: the decision by the United Kingdom to leave the European Union, also known as "Brexit", and the election of the businessman Donald Trump as the 45th President of the United States. The former was strongly encouraged by the actions of the British Eurosceptic and right-wing party named UKIP and its leader Nigel Farage; the latter surprised most of the media and the public, both rather sure about the victory of Trump's opponent, Hillary Clinton (Healy \& Peters 2016; Ingram 2016; Greenslade 2016; Tharoor 2016). In addition, further political outcomes confirmed the momentum of populist parties. In France, Marine Le Pen, leader of the nationalist party Front National, was the second most voted choice in the 2017 presidential election after Emmanuel Macron, who then became President of France. In Italy, the general election held in March 2018 showed the success of two populist parties, Movimento 5 Stelle and Lega Nord.

The spread of social issues, such as immigration, racism, terrorism, and economic crisis in the Western world could have played a major role in the rise of populist ideas during these last decades. However, ideological, social, and political conditions have to exist for populist parties to emerge (Taggart 2002; Laclau 2005; Pasquino 2008). In addition, as stated by several authors (Canovan 1999; Weyland 2001; Kriesi 2014), we could suppose that populism arises in the presence of charismatic leaders who use their personalities to gain consensus during political and social crises. Populist politicians are also able to pervade the media with a peculiar language that emotionally appeals to voters through simplistic rhetoric and spectacular claims (Heinisch 2008). In this context, it is interesting to observe the role that social media are having in spreading the populist message. Although politicians from all parties are increasingly using social media to communicate with the public, populist figures are the ones who seem to take more advantage from having a Twitter or a Facebook account. The use of these allows for populists to directly present their discourse without any kind of filter, with the possibility to enhance their texts with images or videos that may better appeal to the online audience. 
The aim of this study is to examine the language used by the leaders of four European populist parties (Movimento 5 Stelle, Lega Nord, UKIP, and Front National) on Twitter, and to observe a possible relationship between some prototypical features that may emerge from their discourse and the popularity of their messages (or "tweets") on the social network. The research tries to offer several important insights regarding not only the features of populist discourses, but also the effectiveness that these have on the dissemination of the message on social media. In order to investigate their linguistic behaviour, we analyse a relatively small corpus of 8,000 tweets collected from the accounts of the above-mentioned parties' leaders: Luigi Di Maio, Matteo Salvini, Nigel Farage, and Marine Le Pen. Next, we use the Appraisal Framework (Martin \& White 2005) to verify the existence of emotional, simplistic, and intensified features in populist discourse, whose presence is suggested by previous research (Canovan 1999; Heinisch 2008; Bos 2011). Finally, we compare the most and the least popular tweets for every account in order to observe a possible connection between the presence of specific linguistic features and the number of "likes" and "retweets" received by the message, which illustrate the number of people who liked and/or shared the tweet. Essentially, this paper draws from previous studies on political and populist language (Zappavigna 2011 and 2012; Wodak 2015; Ekstrom \& Morton 2017; Wirz 2018) and tries to define the role that social media may or may not have on the consensus received by populist parties in these years.

The paper has been structured in four parts. The first part gives an overview of the background studies that are relevant to the current research. The second part is concerned with a description of the methodology used. The third section presents the findings of the research. Finally, the paper offers conclusions, limitations, and directions for future studies.

\section{Literature Review}

Populism seems to be a complex phenomenon. This is probably due to its various manifestations all over the world, or maybe due to the fact that the word "populist" is often used to belittle political opponents, regardless of their beliefs. However, there is a large volume of published studies that describes the nature of populism (Gellner \& Ionescu 1969; Canovan 1981; Di Tella 1997; Taguieff 2002; Laclau 2005), and an interesting definition of it is given by Albertazzi and McDonnell (2008, 3) who describe populism as: "[...] an ideology which pits a virtuous and homogeneous people against a set of elites and dangerous 'others' who are together depicted as depriving (or attempting to deprive) the sovereign people of their rights, values, prosperity, identity and voice."

A similar perspective was already adopted by Taggart (2000) who underlined the importance of considering populism as "people-based" rather than "class-based", as other authors had suggested (Di Tella 1965; Conway 1978). Apart from its definition, it is 
also crucial to understand the circumstances that may facilitate the growth of populism. According to Pasquino (2008), the conditions that likely determine its rise can be of ideological, social, or political nature. Ideological conditions could be summarised with a rejection of "established" politics, politicians, and parties. In this context, populist leaders claim to understand the disappointment of the public towards traditional politics and promise to be the true representatives of the people's will once in charge. Social conditions refer to the possibility for the populist party to find individuals who feel isolated and alienated from politics and the community due to social issues such as unemployment, migration, or identity crises. Therefore, these people find reassurance in anyone who asserts to be different from the 'others' and who affirms to have solutions for their problems. Finally, political conditions include a profound crisis of the structures of political intermediation, the personalisation of political power, and the pervasiveness of media in political life.

In particular, this latter aspect seems to have played a crucial role in the recent surge of populist consensus, as suggested by the considerable number of studies related to it (Mazzoleni 2008; Bos et al. 2011; Moffit \& Tormey 2013; Ellis \& Riejos, 2018). However, most of these only focus on populist communication through traditional media, such as TV and newspapers, whereas it is interesting to investigate the function that social media are having in this context. This is evident in the case of Twitter which, according to Trump, played a decisive part during his presidential election campaign (cf. McCormick 2016): it is also worth noting that the President of the United States has written a total of 39,746 tweets, with an average of 12 tweets a day, and has 73 million followers ${ }^{1}$. Similarly, the social media users who supported leaving the EU during the Brexit campaign in 2016 were more numerous and generally more active than those who were in favour of remaining (cf. Polonski 2016; Hänska \& Bauchowitz 2017). It is not by chance that populist leaders such as Marine Le Pen, Matteo Salvini, and Nigel Farage publicly defined social networks as an important political and social resource, as shown by the following tweets:

\footnotetext{
1 The data refers to tweets written from 04/05/2009 to 11/04/2018. Both accounts (@realDonaldTrump and $@$ POTUS) have been considered when calculating number of tweets and followers.
} 
(1) "Les réseaux sociaux permettent de s'adresser directement au peuple. Ma campagne sera innovante en ce domaine.” (@MLP_Officiel, January 4, 2017)2

(2) "Je continuerai de monter en puissance dans ma relation directe avec les Français, sans intermédiaire, par les réseaux socianx.” (@MLP_Officiel, May 1, 2016)

(3) "Finché almeno su Twitter potremo essere LIBERI, ritwittiamo! Di cosa avranno paura nel clan Renzi? Confrontarsi è bello ma... \#boschiscappa” (@matteosalvinimi, October 7, 2016)

(4) "Without the internet, the development and growth of UKIP in Britain would have been far tougher.” (@Nigel_Farage, April 6, 2016)

On the other hand, it is worth noting what Matteo Renzi, former Prime Minister of Italy and member of PD (Democratic Party), stated about Twitter, suggesting that reality is more complex than social networks:

(5) “@KiaraFarigu i Social sono molto utili. Ma chi li conosce sa che la realtà è più complessa di una tempesta di tweet.” (@matteorenzi, May 12, 2015)

Against this backdrop, the body of literature investigating populism has been constantly growing. On the other hand, few studies have analysed the relationship between populism and social media (Engesser et al. 2017a). Although all parties benefit from the use of the internet when communicating with the electorate, populist groups are the ones who particularly take advantage of it (Bartlett 2014). Since they present themselves as representatives of the people (cf. Canovan 1999), they seek a direct connection with the public, aiming to bypass the elites and the journalistic gatekeepers, who are often depicted as untrustworthy (cf. Mazzoleni 2008). This function is granted by a direct, democratic, and rather uncontrolled channel of communication: the social media (cf. Engesser et al. 2017b; Esser et al. 2017). In addition, a further opponent of the people is represented by the "others" who, differently from the above-residing elites, are portrayed besides the people (cf. Jagers \& Walgrave 2007; Albertazzi \& McDonnell 2008). They typically consist of ethnic, religious, or sexual minorities whose existence both endangers the honest, ordinary, and hard-working people, and promotes in-group favouritism or out-group discrimination (cf. Reinemann et al. 2017). This homophilic behaviour is facilitated by the internet and social media, where users tend, on one hand, to select information and media content that only reinforce their own opinions, creating

2 Trans: "Social networks allow to speak directly to the people. My campaign will be innovative in this domain."

3 Trans: "I will continue to gain strength in my direct relationship with the French, without intermediaries, through social networks."

4 Trans: “As long as at least on Twitter we can be FREE, let's retweet! What are they afraid of in the Renzi clan? Confronting each other is nice but... \#boschiscappa”

5 Trans: “@KiaraFarigu Social media are very useful. But who is familiar with them knows that reality is more complex than a tweet storm." 
a so-called "filter-bubble" (cf. Pariser 2011), and on the other hand to be part of social groups who share the same views, amplifying political and social attitudes through an "echo-chamber" effect (cf. Jamieson \& Cappella 2008). Another aspect that exemplifies how convenient social media are to populist politicians is the possibility to create a personal account, which guarantees the capacity to provide a personalised communication that may involve users more than websites focused on the whole party (cf. Kruikemeier et al. 2013). Finally, several studies have defined the style of communication that characterises populism (Canovan 1999; Bos et al. 2011; Kramer 2014). As suggested by Engesser et al. (2017a), there are three major aspects that characterise populist discourse: simplification, emotionalization, and negativity. These three factors strongly benefit populist leaders since they allow to catch people's attention on the Internet, a place where users are often overwhelmed by the amount of information and content (cf. Shoemaker \& Cohen 2006).

Therefore, it is well established that there is a strong connection between social media and populists, and that the possibilities offered by the former are thoroughly exploited by the latter. However, the influence that the particular discursive features attributed to populism have on the spread of the populist message has not been fully investigated. Thus, the underlying question that this study tries to answer is whether the popularity of a tweet, intended as the sum of "likes" and "retweets" (the number of people who like and/or quote the message), is correlated to the presence of peculiar discursive aspects, such as emotional language, intensification, and simplified rhetoric.

\section{Methodology}

Although there are several social media websites on the Internet, this paper only focuses on the language present in messages written by populist leaders on Twitter. From a methodological point of view, Twitter allows to collect messages (or "tweets") rather easily, keeping at the same time a considerable amount of metadata such as creation date of the tweet, user name of the author, URLs present in the message together with a series of peculiar elements such as hashtags, mentions, and retweets. In order to analyse linguistic features in a wider spectrum of populist discourse, tweets were collected from the official accounts of Luigi Di Maio, Matteo Salvini, Marine Le Pen, and Nigel Farage. While the first three politicians are the institutional leaders of their parties (Movimento 5 Stelle, Lega Nord, and Front National respectively), Nigel Farage officially resigned from his role as leader of UKIP on 4 July 2016. However, he still has a significant authority both towards UKIP and "Brexiters" (cf. McCrum 2017; Lowles 2018; Cohen 2018). In addition, we noticed that his tweets were still far more popular than those of any other member of UKIP.

The four populist parties and their leaders were chosen for different reasons. Firstly, they meet the definition given by Albertazzi \& McDonnell (2008), as they praise the 
sovereignty of the people to the detriment of institutional politics. These groups also seem to be rather sceptical towards traditional mass media and are represented by leaders that shape how the parties appear and communicate with the public. Moreover, these parties seem to share a rather right-winged version of populism, since they criticise immigration and excessive taxation and prefer nationalism over socialism (cf. Otjes $\&$ Louwerse 2015). As a result, they differentiate themselves from left-wing populist parties in Europe, such as Podemos in Spain, the Linke in Germany, Syrisa in Greece, and the Socialist Party (SP) in the Netherlands.

Tweets were collected using FireAnt (Anthony \& Hardaker 2016), a software that uses Twitter API to gather messages from one or more accounts. Retweets were excluded as messages written by external authors might have invalidated the research. In addition, tweets included in the analysis do not represent the total number of messages written by an author on Twitter, as the API only allows for a limited number of tweets to be collected. However, the extent regarding the data should be sufficient to cover an acceptable time interval, as suggested by Table 1 :

\begin{tabular}{llccc}
\hline Politician name & User name & $\begin{array}{c}\text { Tweets } \\
\text { collected }\end{array}$ & $\begin{array}{c}\text { Earliest } \\
\text { tweet } \\
\text { collected }\end{array}$ & $\begin{array}{c}\text { Latest tweet } \\
\text { collected }\end{array}$ \\
\hline \hline Luigi Di Maio & $@$ luigidimaio & 2,117 & $11 / 06 / 2014$ & $02 / 03 / 2018^{6}$ \\
Matteo Salvini & $@$ matteosalvinimi & 2,871 & $26 / 05 / 2016$ & $16 / 02 / 2017$ \\
Marine Le Pen & $@$ MLP_officiel & 3,056 & $02 / 12 / 2015$ & $16 / 02 / 2017$ \\
Nigel Farage & $@ N i g e l \_F a r a g e$ & 2,321 & $04 / 04 / 2015$ & $16 / 02 / 2017$ \\
\hline
\end{tabular}

Table 1: Data for Accounts and Tweets of Populist Politicians

Next, in order to identify peculiar linguistic features, three reference corpora (one for each language) were created by gathering tweets from the official accounts of Matteo Renzi, François Hollande, and David Cameron. These three political leaders were chosen both because of their belonging to established parties and their former positions as Prime Ministers. As with populist messages, reference tweets were collected using FireAnt, filtering out retweets. Table 2 presents further data regarding the reference corpora.

\footnotetext{
6 Originally, the leader designed in this study for Movimento 5 Stelle was Alessandro Di Battista. He later left the party, forcing the authors to opt for an individual with the same position and popularity. Differently, Nigel Farage was still considered for the study although he had resigned, as nobody in UKIP has gained the same status and visibility he had, at least in the authors' opinion.
} 


\begin{tabular}{llccc}
\hline Politician name & User name & $\begin{array}{c}\text { Tweets } \\
\text { collected }\end{array}$ & $\begin{array}{c}\text { Earliest } \\
\text { tweet } \\
\text { collected }\end{array}$ & $\begin{array}{c}\text { Latest } \\
\text { tweet } \\
\text { collected }\end{array}$ \\
\hline \hline Matteo Renzi & @matteorenzi & 2,622 & $20 / 11 / 2012$ & $11 / 01 / 2017$ \\
François Hollande & @fhollande & 3,225 & $12 / 02 / 2012$ & $07 / 01 / 2018$ \\
David Cameron & @David_Cameron & 2,362 & $06 / 10 / 2012$ & $18 / 01 / 2017$ \\
\hline
\end{tabular}

Table 2: Data for Accounts and Tweets of Reference Politicians

The Appraisal Framework created by Martin \& White (2005) was adopted to determine to what extent the linguistic features implied by the literature are present in populist online discourse (Canovan 1999; Heinisch 2008; Bos 2011). The framework is based on Systemic Functional Theory (Halliday et al. 2004) and is designed to analyse levels of evaluation in a discourse. More precisely, it focuses on "exploring, describing and explaining the way language is used to evaluate, to adopt stances, to construct textual personas and to manage interpersonal positionings and relationships" (White 2001, 1). Moreover, UAM CorpusTool (O'Donnell 2011) was used to annotate tweets according to the three main features of the framework: attitude, which concerns emotional language, ethical judgements, and aesthetic evaluations; engagement, which describes how an author includes, excludes, or ignores external stances in his/her discourse; and graduation, which focuses on how degrees of evaluation are increased or decreased. Before the annotation, tweets of each author were classified by a popularity value, which represents the sum of both likes and retweets of a message, and only the first and the last thousand tweets were considered. These quantities are arbitrary, the reason for their choice being that the Twitter API limits the maximum number of tweets downloaded, amounting to approximately 3,000 tweets per account. In this way, each subject had 2,000 tweets, resulting in a total of 8,000 tweets for the populist group and 6,000 tweets for the reference group. Finally, UAM CorpusTool was also used to compare the annotations between popular and non-popular tweets: the results were classified by their propensity value (also known as relative frequency) in order to understand how great the difference is between two corpora for a particular keyword or feature (cf. Hardie 2014). However, statistical significance was guaranteed by deleting all features with a Chi square value below 3.84, which is the threshold value for significant data with $d f=1$ and $p<0.05$ (Gries 2013). 


\section{Results}

In this section, findings are first presented with a pie chart, which graphically compares the most frequent features of the appraisal framework when analysing popular tweets in the populist corpus and the control group. Secondly, detailed results for each author are shown via tables; this would allow for understanding possible inconsistencies in the tweets by one or more authors. As mentioned in the second chapter, the appraisal framework is formed by three main systems: attitude, engagement, and graduation. Considering that each of these items has several sub-nodes, we decided to consider only the most discrete features, incorporating some of the smallest sub-nodes (especially endnodes) to their parent items. For example, the "monoglossic" feature regards statements presented without any possible dialogical alternatives (i.e. "The government has failed.") and consists of two sub-nodes: "presupposition" and "argumentative". With the former, propositions are taken for granted, whereas with the latter, propositions are minimally justified. Since the difference between the two is not the focus of this study, and the frequency of "argumentative" propositions is often low, we only present results for the general "monoglossic" feature.

The following pie chart presents an overall analysis of the most frequent features of the framework in popular tweets when compared to non-popular tweets by the same author. Here, politicians were grouped in order to give a general idea of the differences between the two corpora.
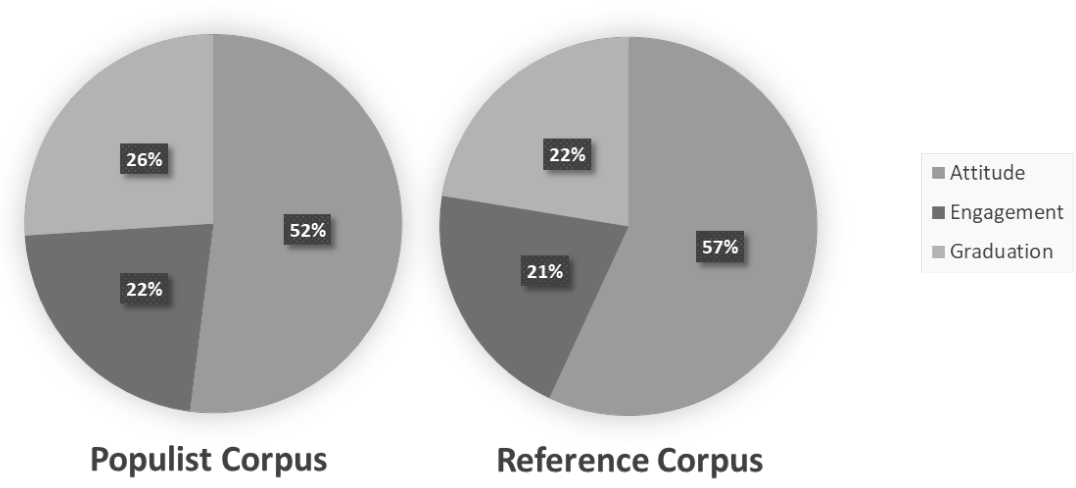

Figure 1: Frequent Features in Popular Tweets

The pie charts suggest that, in both corpora, more than $50 \%$ of the features that are more frequent in popular tweets when compared to non-popular messages belong to the attitude system. Figure 1 also shows a general similarity between the populist corpus and the reference groups, with a slightly major presence of attitude features in the establishment politicians' texts. Similarly, graduation elements are slightly more frequent in populist subjects, however only by $4 \%$. Finally, engagement percentages are nearly identical. 
Although the absence of considerable discrepancies between the corpora may be counterintuitive, the fact that attitude features are the most peculiar trait when differentiating popular and non-popular tweets was already suggested by previous research (Zappavigna 2011; Stieglitz \& Dang-Xuan 2013). In addition, we already observed overall similarities when investigating the differences between tweets by populist groups and establishment parties (Carrella 2017). However, findings in this study seem to confirm the relationship between emotionally connoted tweets and their popularity on Twitter.

Next, detailed results are presented in author-specific tables. All tables in this section present the most frequent features in the first thousand popular tweets for each author when compared to the last thousand popular tweets. Results are classified by propensity (or relative frequency), showing Chi square values as well. The relative frequency helps us to understand the degree of difference between two corpora when observing a word or a feature (Hardie 2014). A propensity value of 1 indicates no difference in the relative frequency of the same element in the two corpora, whereas a value of 2 shows that the feature is twice as frequent in the popular tweets compared to the non-popular tweets. On the contrary, a propensity value of 0.5 means that the item is half as common in the popular tweets. Finally, colours are used to facilitate the interpretation of our results: all features related to the attitude system are in grey, elements belonging to the engagement system are in dark grey, while all graduation sub-nodes are in light grey. 


\begin{tabular}{|c|c|c|c|c|}
\hline \multicolumn{5}{|l|}{ Nigel Farage } \\
\hline Features & Frequency (Pop) & Frequency (NonPop) & Propensity & Chi Square \\
\hline non-authorial-evaluation & 72 & 19 & 3.56 & 28.13 \\
\hline dis/inclination & 76 & 33 & 2.16 & 14.67 \\
\hline dis/satisfaction & 70 & 31 & 2.12 & 12.96 \\
\hline textual & 278 & 135 & 1.93 & 44.56 \\
\hline affect & 220 & 117 & 1.76 & 27.13 \\
\hline judgement & 449 & 272 & 1.55 & 38.51 \\
\hline negative-attitude & 526 & 341 & 1.45 & 34.62 \\
\hline authorial-evaluation & 148 & 98 & 1.42 & 7.61 \\
\hline attitude & 910 & 620 & 1.38 & 54.91 \\
\hline quantification & 243 & 167 & 1.37 & 10.55 \\
\hline mono-glossic & 167 & 118 & 1.33 & 5.94 \\
\hline positive-attitude & 384 & 277 & 1.30 & 12.9 \\
\hline upscale & 454 & 370 & 1.15 & 4.86 \\
\hline engagement & 1143 & 1349 & 0.80 & 65.1 \\
\hline hetero-glossic & 976 & 1231 & 0.74 & 85.8 \\
\hline mention & 240 & 338 & 0.67 & 26.52 \\
\hline focus & 25 & 40 & 0.59 & 4.54 \\
\hline reaction & 48 & 77 & 0.58 & 8.93 \\
\hline soften & 10 & 25 & 0.38 & 7,48 \\
\hline hashtag & 191 & 495 & 0.36 & 179.5 \\
\hline graphical & 10 & 35 & 0.27 & 15.68 \\
\hline
\end{tabular}

Table 3: Key Features in Farage's Popular Tweets

As can be seen from Table 3, the first nine positions, with the exception of "textual", are occupied by attitude features. Among these, "non-authorial-evaluation" represents the most distinctive element between popular and non-popular tweets written by Nigel Farage. The following tweet contains two examples of "non-authorial-evaluation", one of them also being an occurrence of "dis/inclination". The first element refers to the intention of an author to express others' emotions, while the second item is represented by words such as want, desire, unwanted, disinclined and other terms that indicate inclination or aversion.

(6) "People in Bolton sick of establishment scare tactics. They want to Leave EU \& get their country back \#BrexitBusTour” (@Nigel_Farage, May 25, 2016) 


\begin{tabular}{crrrr}
\hline Marine Le Pen & \multicolumn{5}{c}{} \\
\hline \hline Features & Frequency $($ Pop) & Frequency (NonPop) & Propensity & Chi Square \\
\hline graphical & 173 & 6 & 30.44 & 170.22 \\
\hline mono-glossic & 22 & 1 & 23.36 & 20.55 \\
\hline dis/satisfaction & 29 & 10 & 3.06 & 10.39 \\
\hline reaction & 36 & 19 & 2.00 & 6.28 \\
\hline authorial-evaluation & 116 & 70 & 1.75 & 14.46 \\
\hline dis/inclination & 60 & 38 & 1.67 & 6.31 \\
\hline intensification & 316 & 202 & 1.65 & 34.68 \\
\hline affect & 150 & 102 & 1.55 & 12.46 \\
\hline un/happiness & 53 & 37 & 1.51 & 3.84 \\
\hline judgement & 369 & 443 & 0.88 & 3.86 \\
\hline negative-attitude & 427 & 520 & 0.87 & 5.70 \\
\hline invoked & 313 & 385 & 0.86 & 4.58 \\
\hline social-valuation & 186 & 254 & 0.77 & 7.73 \\
\hline quantification & 162 & 287 & 0.60 & 30.70 \\
\hline repetition & 13 & 40 & 0.34 & 12.45 \\
\hline
\end{tabular}

Table 4: Key Features in Le Pen’s Popular Tweets

A similar trend is shown in Table 4, which regards tweets by Marine Le Pen. Although there are only nine features with a propensity value higher than 1 , six of these consist of attitude items. However, the first position is held by "graphical", a sub-node of graduation that indicate intensification of the message through the use of graphical elements such as emoticons or capital letters. The second element is "monoglossic", which is a feature related to engagement: it refers to non-dialogical statements of an author, as in the following tweet:

(7) "Dimanche rappelez-vous: le people est la seule chance pour la France! MLP" (@MLP_officiel, December 11, 2015) ${ }^{7}$

7 Trans: "Remember this on Sunday: the people are the only chance for France! MLP" 


\begin{tabular}{crrrr}
\hline Luigi Di Maio & \multicolumn{5}{l}{} \\
\hline \hline Features & Frequency (Pop) & Frequency (NonPop) & Propensity & Chi Square \\
\hline hashtag & 557 & 199 & 2.02 & 92.97 \\
\hline mention & 210 & 76 & 2.00 & 29.82 \\
\hline hetero-glossic & 1128 & 611 & 1.33 & 57.71 \\
\hline negative-attitude & 480 & 267 & 1.30 & 14.42 \\
\hline judgement & 514 & 288 & 1.29 & 14.90 \\
\hline engagement & 1204 & 687 & 1.27 & 45.62 \\
\hline positive-attitude & 257 & 232 & 0.80 & 6.92 \\
\hline mono-glossic & 76 & 76 & 0.72 & 4.22 \\
\hline appreciation & 125 & 140 & 0.64 & 13.81 \\
\hline social-valuation & 99 & 113 & 0.63 & 11.86 \\
\hline upscale & 344 & 409 & 0.61 & 58.15 \\
\hline intensification & 215 & 254 & 0.61 & 32.51 \\
\hline graduation & 421 & 520 & 0.58 & 89.24 \\
\hline textual & 95 & 118 & 0.58 & 16.73 \\
\hline quantification & 187 & 253 & 0.53 & 49.07 \\
\hline graphical & 78 & 127 & 0.44 & 35.51 \\
\hline downscale & 58 & 98 & 0.43 & 29.05 \\
\hline in/security & 7 & 14 & 0.36 & 5.30 \\
\hline
\end{tabular}

Table 5: Key Features in Di Maio's Popular Tweets

Table 5, concerned with Luigi Di Maio's tweets, shows slightly different results regarding key features. Findings indicate that hashtags and mentions are twice as common in popular messages than they are in non-popular tweets, whereas they are usually more frequent in non-popular tweets (cf. Table 3, 6 and 7). This may be explained by the fact that members of Movimento 5 Stelle tend to use social networks more than other parties and probably manage to maximise the spread of their messages through the use of particular conventions such as hashtags or mentions. However, it is interesting to notice that two attitude features, "negative-attitude" and "judgement", have a propensity higher than 1 . The first element indicates all occurrences of negative emotional language, while the second represents social and ethical judgements of human behaviour. The following tweet contains an example of an implicitly negative judgement:

(8) "Renzi ci ha svenduto per $80 €$ : ha autorizzato sbarchi migranti nei porti italiani in cambio della flessibilità europea per dare i suoi bonus" (@luigidimaio, July 12,2017$)^{8}$

\footnotetext{
8 Trans: "Renzi sold us out for $80 €$ : he authorised migrant landings in Italian ports in exchange for European flexibility to give his bonuses"
} 


\begin{tabular}{crrrr}
\hline Matteo Salvini & \multicolumn{5}{c}{} \\
\hline \hline Features & Frequency $($ Pop) & Frequency (NonPop) & Propensity & Chi Square \\
\hline distance & 106 & 12 & 8.98 & 77.77 \\
\hline un/happiness & 55 & 18 & 3.11 & 19.57 \\
\hline soften & 42 & 14 & 3.05 & 14.58 \\
\hline in/security & 24 & 8 & 3.05 & 8.30 \\
\hline acknowledge & 43 & 15 & 2.91 & 14.09 \\
\hline judgement & 579 & 217 & 2.71 & 193.43 \\
\hline negative-attitude & 594 & 236 & 2.56 & 182.82 \\
\hline non-authorial-evaluation & 20 & 9 & 2.26 & 4.37 \\
\hline focus & 47 & 22 & 2.17 & 9.56 \\
\hline proclaim & 36 & 17 & 2.15 & 7.18 \\
\hline attitude & 792 & 380 & 2.12 & 183.57 \\
\hline affect & 116 & 61 & 1.93 & 18.47 \\
\hline authorial-evaluation & 96 & 52 & 1.88 & 14.11 \\
\hline quantification & 180 & 101 & 1.81 & 24.53 \\
\hline mono-glossic & 56 & 37 & 1.54 & 4.25 \\
\hline positive-attitude & 198 & 143 & 1.41 & 10.30 \\
\hline graduation & 1066 & 819 & 1.32 & 50.68 \\
\hline upscale & 981 & 754 & 1.32 & 45.11 \\
\hline intensification & 839 & 696 & 1.22 & 20.38 \\
\hline graphical & 718 & 636 & 1.15 & 7.98 \\
\hline engagement & 1473 & 2187 & 0.68 & 281.32 \\
\hline hetero-glossic & 1417 & 2150 & 0.67 & 296.53 \\
\hline hashtag & 955 & 1732 & 0.56 & 353.95 \\
\hline mention & 40 & 0.23 & 84.46 \\
\hline
\end{tabular}

Table 6: Key Features in Salvini’s Popular Tweets

Table 6 provides the key features for Matteo Salvini's popular tweets. Although the majority of key elements is represented by attitude features, graduation is present with 7 items having a propensity higher than 1 . In addition, "distance" is the most distinctive feature characterising popular in relation to non-popular tweets and belongs to the engagement system. It indicates the will by an author to quote others' texts while discrediting them, as shown below:

(9) "Napolitano sul libero voto degli inglesi: 'Un azzardo sciagurato'. L'anziano comunista è sempre allergico alla Democrazia. Ritirati! \#Brexit” (@matteosalvinimi, June 24, 2016) ${ }^{9}$

\footnotetext{
9 Trans: "Napolitano on the free vote of the English people: 'A deplorable hazard'. The elderly communist is always allergic to Democracy. Retire! \#Brexit”
} 
Turning now to the results obtained with the reference corpora, we could notice a surprising similarity between the key features in populist tweets and the texts by David Cameron, François Hollande, and Matteo Renzi.

\begin{tabular}{crrrr}
\hline David Cameron & \multicolumn{3}{c}{} \\
\hline \hline Features & Frequency (Pop) & Frequency (NonPop) & Propensity & Chi Square \\
\hline distance & 14 & 3 & 4.37 & 6.44 \\
\hline negative-attitude & 327 & 83 & 3.69 & 140.27 \\
\hline repetition & 33 & 9 & 3.43 & 12.29 \\
\hline un/happiness & 92 & 33 & 2.61 & 24.70 \\
\hline authorial-evaluation & 255 & 100 & 2.39 & 61.96 \\
\hline dis/inclination & 51 & 21 & 2.27 & 10.76 \\
\hline disclaim & 122 & 53 & 2.16 & 23.65 \\
\hline affect & 276 & 127 & 2.04 & 49.43 \\
\hline intensification & 328 & 152 & 2.02 & 58.70 \\
\hline textual & 267 & 148 & 1.69 & 28.99 \\
\hline dis/satisfaction & 116 & 66 & 1.65 & 11.03 \\
\hline contract & 173 & 102 & 1.59 & 14.72 \\
\hline upscale & 587 & 437 & 1.26 & 16.29 \\
\hline judgement & 383 & 288 & 1.25 & 9.06 \\
\hline attitude & 1036 & 799 & 1.21 & 25.63 \\
\hline graduation & 666 & 520 & 1.20 & 12.36 \\
\hline engagement & 1134 & 1337 & 0.79 & 59.40 \\
\hline hetero-glossic & 995 & 1219 & 0.76 & 66.63 \\
\hline reaction & 94 & 136 & 0.65 & 11.15 \\
\hline hashtag & 289 & 447 & 0.61 & 52.10 \\
\hline mention & 221 & 487 & 0.42 & 135.76 \\
\hline
\end{tabular}

Table 7: Key Features in Cameron's Popular Tweets

As with Salvini, the "distance" feature is distinctive in Cameron's popular tweets as well. Next, we find "negative-attitude", which connotes all occurrences of negative emotional language, while the third position is occupied by "repetition", which represents all instances of intensification achieved by the repetition of the same lexical items or by lists of closely related terms, as in the following tweet:

(10) "The Labour party is now a threat to our national security, our economic security and your family’s security.” (@David_Cameron, September 13, 2015) 


\begin{tabular}{|c|c|c|c|c|}
\hline \multicolumn{5}{|l|}{ François Hollande } \\
\hline Features & Frequency (Pop) & Frequency (NonPop) & Propensity & Chi Square \\
\hline mono-glossic & 174 & 7 & 26.65 & 171.63 \\
\hline graphical & 16 & 1 & 17.17 & 14.37 \\
\hline composition & 10 & 1 & 10.72 & 8.03 \\
\hline dis/satisfaction & 68 & 8 & 9.11 & 52.41 \\
\hline un/happiness & 102 & 17 & 6.43 & 68.30 \\
\hline distance & 8 & 2 & 4.29 & 4.04 \\
\hline judgement & 390 & 132 & 3.17 & 161.15 \\
\hline mention & 87 & 30 & 3.11 & 32.60 \\
\hline negative-attitude & 250 & 101 & 2.65 & 79.05 \\
\hline reaction & 49 & 21 & 2.50 & 13.42 \\
\hline attitude & 842 & 383 & 2.36 & 262.37 \\
\hline non-authorial-evaluation & 72 & 33 & 2.34 & 17.68 \\
\hline proclaim & 17 & 8 & 2.28 & 3.92 \\
\hline intensification & 251 & 119 & 2.26 & 60.78 \\
\hline positive-attitude & 592 & 282 & 2.25 & 156.98 \\
\hline affect & 275 & 145 & 2.03 & 53.87 \\
\hline upscale & 430 & 233 & 1.98 & 82.85 \\
\hline authorial-evaluation & 203 & 112 & 1.94 & 35.00 \\
\hline repetition & 52 & 30 & 1.86 & 7.66 \\
\hline appreciation & 177 & 106 & 1.79 & 24.35 \\
\hline graduation & 491 & 299 & 1.76 & 70.97 \\
\hline social-valuation & 118 & 84 & 1.51 & 8.66 \\
\hline quantification & 237 & 170 & 1.49 & 17.47 \\
\hline engagement & 1406 & 2254 & 0.67 & 399.63 \\
\hline hetero-glossic & 1232 & 2247 & 0.59 & 593.76 \\
\hline hashtag & 662 & 1715 & 0.41 & 681.99 \\
\hline
\end{tabular}

Table 8: Key Features in Hollande's Popular Tweets

We can find further similarities comparing results from Marine Le Pen and François Hollande. In fact, the first two positions are held by the same features, "graphical" and "monoglossic". "Composition" occupies the third position, representing all occurrences of evaluations regarding things and objects. The tweet below contains both "monoglossic" and "composition" features (the latter in bold).

(11) "Chers amis, je suis venu vous dire ces mots simples que sont la fierté, la reconnaissance et la bienveillance.” (@fhollande, May 14, 2017) $)^{10}$

10 Trans: "Dear friends, I came to tell you these simple words that are pride, recognition and benevolence." 


\begin{tabular}{|c|c|c|c|c|}
\hline \multicolumn{5}{|l|}{ Matteo Renzi } \\
\hline Features & Frequency (Pop) & Frequency (NonPop) & Propensity & Chi Square \\
\hline mono-glossic & 76 & 4 & 18.25 & 62.96 \\
\hline distance & 14 & 1 & 13.45 & 10.79 \\
\hline dis/satisfaction & 42 & 8 & 5.04 & 22.00 \\
\hline un/happiness & 65 & 15 & 4.16 & 29.75 \\
\hline judgement & 332 & 88 & 3.62 & 144.23 \\
\hline acknowledge & 11 & 3 & 3.52 & 4.27 \\
\hline hashtag & 915 & 252 & 3.49 & 456.98 \\
\hline non-authorial-evaluation & 28 & 8 & 3.36 & 10.40 \\
\hline negative-attitude & 185 & 66 & 2.69 & 54.47 \\
\hline attitude & 718 & 294 & 2.35 & 201.78 \\
\hline positive-attitude & 533 & 228 & 2.25 & 130.05 \\
\hline affect & 142 & 65 & 2.10 & 26.74 \\
\hline reaction & 84 & 41 & 1.97 & 13.45 \\
\hline authorial-evaluation & 114 & 57 & 1.92 & 17.37 \\
\hline appreciation & 244 & 141 & 1.66 & 25.53 \\
\hline social-valuation & 152 & 89 & 1.64 & 14.74 \\
\hline quantification & 195 & 123 & 1.52 & 14.45 \\
\hline upscale & 312 & 236 & 1.27 & 8.65 \\
\hline graduation & 354 & 287 & 1.18 & 5.23 \\
\hline engagement & 1483 & 1874 & 0.76 & 189.93 \\
\hline hetero-glossic & 1407 & 1870 & 0.72 & 246.93 \\
\hline textual & 93 & 144 & 0.62 & 13.78 \\
\hline disclaim & 228 & 388 & 0.56 & 55.04 \\
\hline graphical & 20 & 49 & 0.39 & 13.58 \\
\hline mention & 125 & 1053 & 0.11 & 1005.67 \\
\hline
\end{tabular}

Table 9: Key Features in Renzi's Popular Tweets

Finally, the first two positions in Renzi's popular tweets are held by "distance" and "monoglossic", two engagement features that respectively contract and ignore different dialogical alternatives. Next, we find "dis/satisfaction", which exemplifies all instances of positive or negative emotions related to personal satisfaction. The following tweet is an example of a "monoglossic" statement containing a positive non-authorial "dis/satisfaction" occurrence (in bold).

(12) “Alex Zanardi, un uomo e un atleta di cui tutta l'Italia è orgogliosa.” (@matteorenzi, September 14, 2016) ${ }^{11}$

11 Trans: "Alex Zanardi, a man and an athlete who makes all Italy proud." 


\section{Conclusion}

This study was designed to examine the presence and possibly determine the effect of specific discursive features that are said to characterise populist discourse (Canovan 1999; Heinisch 2008; Bos 2011). More specifically, the aim was to investigate particular elements such as emotional language, simplistic rhetoric, and intensified discourse, and to observe whether these features are related with the popularity and with the diffusion of a message on social media. The Appraisal Framework, a tool designed by Martin \& White (2005) to study evaluation in discourse, was used to analyse the most and the least popular messages of four European populist leaders on Twitter, namely Luigi Di Maio, Matteo Salvini, Marine Le Pen, and Nigel Farage. The same operation was conducted on a reference group constituted by three European democratic leaders, specifically Matteo Renzi, François Hollande, and David Cameron.

\subsection{Summary of findings}

The first major finding was that the linguistic elements that the literature attributes to populist discourse are also present in the social media context. Additionally, these seem to be strictly related to the popularity of a tweet, that is how much a tweet is liked or shared by other users on Twitter. Instances of attitude features, represented by emotions, judgements, or aesthetic evaluations, represent the most distinctive trait when comparing popular and non-popular tweets. This result confirms previous findings which suggested a positive relationship between the presence of emotional language and the popularity of a message on social media (Zappavigna 2011; Stieglitz \& DangXuan 2014). Examples of simplistic rhetoric, particularly illustrated by a framework item called "monoglossic", are usually more frequent in popular tweets, with the exception of Movimento 5 Stelle's leader, Luigi Di Maio. Other instances of detrimental language used to discredit political opponents, such as the "distance" feature, are only present in findings regarding Matteo Salvini. Finally, elements of graduation that suggest a tendency to intensify or decrease degrees of evaluation, such as "quantification", "graphical", or "soften", are found in all populist subjects, again with the exception of Luigi Di Maio.

The second major and more surprising result was found in the analysis of the reference corpora, consisting of tweets collected from Matteo Renzi, François Hollande, and David Cameron. From a quantitative point of view, the analysis of the most prominent features in the popular tweets showed strong similarities between the populist and the reference corpora, even indicating a higher number of attitude features in the establishment politicians' messages. From a qualitative perspective, a detailed observation of the more frequent features in the popular tweets also presented a considerable affinity between the two corpora. Items related to emotional language are substantially more frequent in popular tweets, with the "negative-attitude" feature having a higher propensity values in all three reference subjects. Popular tweets by Renzi and Hollande have a 
high presence of "monoglossic" and "distance" features, both ideally linked to populist discourse. Although the "monoglossic" item is absent in Cameron's findings, we find "distance" and "disclaim" having a high propensity value, this latter representing the will by an author to reject contrary dialogical positions. Lastly, graduation features are distinctive for all reference subjects, with sub-nodes such as "graphical", "quantification", and "repetition".

Several conclusions can be drawn from the present study. On one hand, findings regarding populist tweets complement those of earlier studies: populist politicians chosen for this research confirmed the presence of emotional language, simplistic or dichotomist rhetoric, and outrageous or spectacular claims in their tweets (cf. Heinisch 2008). Furthermore, these elements seem to be more frequent in popular tweets when compared to non-popular tweets, especially when considering instances of emotional language.

On the other hand, findings regarding members of establishment parties raised relevant questions. It seems that linguistic features often related to the populist style are not only present in non-populist discourse, but they are also considerably frequent in tweets with a high popularity. The fact that "populist" elements are present in non-populist politicians' tweets may suggest that the boundaries defining the populist style are more blurred than it is believed, at least on social media. The context chosen for this study probably plays a key role in the implications: it could be hypothesised that particular discursive features, usually linked to populism, easily attract users' interest on social media (Shoemaker \& Cohen 2006). Paradoxically, non-populist politicians seem to take more advantage from these dynamics, maybe because their use of populist linguistic features, such as emotionalization, simplification, and intensification is seen as exceptional and, consequently, worth considering.

Overall, the evidence from this study confirms the existence of particular discursive characteristics present in the populist discourse and their relationship with the popularity of the texts on social media. However, it also supports the idea that, at least on the Internet, establishment parties are adapting their style, gaining online popularity and becoming increasingly similar to those populist politicians from whom they usually distance themselves.

\subsection{Limitations and directions for future research}

The major limitation of this study is probably represented by the small sample of subjects taken into consideration, both for the corpus of interest and the control group. Therefore, the generalisability of these results is relatively restricted. Furthermore, the fact that we chose to consider only 2,000 tweets per author probably excluded further insights regarding the linguistic features used. Finally, there were several ambiguous cases that posed some problems when annotating tweets with the Appraisal Framework, especially considering that the annotation was conducted by a single author. 
Notwithstanding these limitations, this paper offers some observations regarding the linguistic behaviour of populist and establishment politicians on social media. Future research may choose to include more subjects in order to broaden or reject findings offered by this paper. In addition, authors may focus on one particular aspect of the Appraisal Framework in order to offer more detailed results. Additionally, other social media may be considered: for example, Facebook offers more space to write and therefore more context in comparison to Twitter. Finally, statistical methods could be used to find significant relationships between the number of likes or retweets obtained by a tweet and the linguistic features present in the text.

\section{References}

Albertazzi, Daniele, and Duncan McDonnell. 2008. Twenty-first Century Populism. The Spectre of Western European Democracy. Basingstoke, UK: Palgrave Macmillan.

Anthony, Laurence, and Claire Hardaker. 2017. Fireant (Version 1.1.4). Computer Software. Tokyo, Japan: Waseda University. Accessed 22 November 2018. http://www.laurenceanthony. net/software

Bartlett, Jamie. 2014. "Populism, Social Media and Democratic Strain.” In European Populism and Winning the Immigration Debate, edited by Clara Sandelind, 99-114. Accessed 22 November 2018. http://eprints.whiterose.ac.uk/104297/1/Korr\%20igen.pdf

Bos, Linda, Wouter van der Brug, and Claes de Vreese. 2011. "How the Media Shape Perceptions of Right-Wing Populist Leaders.” Political Communication 28(2): 182-206. https://doi:10.1080/ 10584609.2011.564605.

Cameron, David (@David_Cameron). 2015. “The Labour Party is now a threat to our national security, our economic security and your family's security.” Twitter message. 13 September 2015. https://twitter.com/david_cameron/status/642984909980725248

Canovan, Margaret. 1981. Populism. New York: Harcourt Brace Jovanovich.

Canovan, Margaret. 1999. “Trust the People! Populism and the Two Faces of Democracy." Political Studies 47(1): 2-16.

Carrella, Fabio. 2017. “Tweets Across the Borders: an Interlingual Study on European Populism.” I-Land Journal 2: 121-145. https://doi:10:26379/1074.

Cohen, Nick. 2018. “Don't mock the 'hapless' Brexiters - they are still pulling all the strings.” The Guardian. 24 March 2018. Accessed 22 November 2018. https://www.theguardian.com/commentisfree/2018/mar/24/dont-mock-hapless-brexiters-try-to-change-their-minds

Conway, John F. 1978. "Populism in the United States, Russia and Canada: Explaining the Roots of Canada's Third Parties.” Canadian Journal of Political Science 11(1): 99-124.

Di Maio, Luigi (@luigidimaio). 2017. "Renzi ci ha svenduto per 80€: ha autorizzato sbarchi igrant nei porti italiani in cambio della flessibilità europea per dare i suoi bonus.” Twitter message. 12 July 2017. https://twitter.com/luigidimaio/status/885108608857509888

Di Tella, Torcuato S. 1965. "Populism and Reform in Latin America." In Obstacles to Change in Latin America, edited by Claudio Véliz, 47-74. London: Oxford University Press. 
Di Tella, Torcuato S. 1997. "Populism into the Twenty-first Century." Government and Opposition 32 (2): 187-200. https://doi.org/10.1111/j.1477-7053.1997.tb00157.x.

Ekström, Mats, and Andrew Morton. 2017. "The Performances of Right-Wing Populism: Populist Discourse, Embodied Styles and Forms of News Reporting." In The Mediated Politics of Europe, edited by Mats Ekström and Julie Firmstone, 289-316. Basingstoke, UK: Palgrave Macmillan.

Ellis, Victor, and Ana Roldán-Riejos. 2017. "Exploring the Current Treatment of Populism in European Media: A Linguistic Case Study.” I-Land Journal 2: 45-65. https://doi:10.26379/1070.

Engesser, Sven, Nayla Fawzi, and Anders Olof Larsson. 2017a. "Populist Online Communication: Introduction to the Special Issue.” Communication E Society 20(9): 1279-1292. https://doi: 10.1080/1369118X.2017.1328525.

Engesser, Sven, Nicole Ernst, Frank Esser and Florin Büchel. 2017b. "Populism and Social Media: How Politicians Spread a Fragmented Ideology." Information, Communication E Society 20(8): 1109-1126. https://doi:10.1080/1369118x.2016.1207697.

Esser, Frank, Agnieszka Stępińska, and David N. Hopmann. 2017. "Populism and the Media: Cross-national Findings and Perspectives.” In Populist Political Communication in Europe, edited by Toril Aalberg, Frank Esser, Carsten Reinemann, Jesper Strömbäck and Claes De Vreese, 365-380. London: Routledge.

Farage, Nigel (@Nigel_Farage). 2016. "People in Bolton sick of establishment scare tactics. They want to Leave EU \& get their country back \#BrexitBusTour.” Twitter message. 25 May 2016. https://twitter.com/Nigel_Farage/status/735481410790817792

Farage, Nigel (@Nigel_Farage). 2016. "Without the internet, the development and growth of UKIP in Britain would have been far tougher." Twitter message. 6 April 2016. https://twitter. com/Nigel_Farage/status/717672818423566337

Geller, Ernest, and Ghita Ionescu. 1969. Populism. Its Meanings and National Characteristics. London: Weidenfeld and Nicolson.

Greenslade, Roy. 2016. "UK Press Registers its Profound Shock at a Trump Victory." The Guardian. 10 November 2016. Accessed 22 November 2018. https://www.theguardian.com/ media/greenslade/2016/nov/10/donald-trumps-victory-the-uk-press-registers-its-profound-shock Gries, Stefan Th. 2013. Statistics for Linguistics with R. Berlin: De Gruyter Mouton.

Halliday, Michael Alexander Kirkwood, Christian Matthiessen, and Michael Halliday. 2004. An Introduction to Functional Grammar, revised by Christian Matthiessen. London: Hodder Arnold.

Hänska, Maximillian, and Stefan Bauchowitz. 2017. "Tweeting for Brexit: How Social Media Influenced the Referendum." In Brexit, Trump and the Media, edited by John Mair, Tor Clark, Raymond Snoddy, and Richard Tait, 31-35. Suffolk: Abramis.

Hardie, Andrew. 2014. "Log Ratio - an Informal Introduction.” Accessed 30 April 2018. http:// cass.lancs.ac.uk/?p=1133

Healy, Patrick and Jeremy W. Peters. 2016. "Donald Trump's Victory is Met with Shock Across a Wide Political Divide.” The New York Times. 9 November 2016. Accessed 22 November 2018. https://www.nytimes.com/2016/11/10/us/politics/donald-trump-election-reaction.html

Heinisch, Reinhard. 2008. "Austria: The Structure and Agency of Austrian Populism." In Twenty-first Century Populism, edited by Daniele Albertazzi and Duncan McDonnell, 67-83. Basingstoke, UK: Palgrave Macmillan. 
Hollande, François (@fhollande). 2017. “Chers amis, je suis venu vous dire ces mots simples que sont la fierté, la reconnaissance et la bienveillance. ” Twitter message. 14 May 2017. https://twitter.com/fhollande/status/863694520348758016

Ingram, Mathew. 2016. "Here's Why the Media Failed to Predict a Donald Trump Victory." Fortune. 9 November 2016. Accessed 22 November 2018. http://fortune.com/2016/11/09/mediatrump-failure/

Jagers, Jan, and Stefaan Walgrave. 2007. "Populism as Political Communication Style: An Empirical Study of Political Parties' Discourse in Belgium.” European Journal of Political Research 46 (3): 319-345.

Jamieson, Kathleen H., and Joseph Cappella. 2008. Echo chamber: Rush Limbaugh and the Conservative Media Establishment. New York, NY: Oxford University Press.

Krämer, Benjamin. 2014. "Media Populism: A Conceptual Clarification and some Theses on its Effects.” Communication Theory 24: 42-60. https://doi: 10.1111/comt.12029.

Kriesi, Hanspeter. 2014. “The Populist Challenge". West European Politics 37(2): 361-378. https://doi:10.1080/01402382.2014.887879.

Kruikemeier, Sanne, Guda van Noort, Rens Vliegenthart, Claes De Vreese. 2013. "Getting Closer: The Effects of Personalised and Interactive Online Political Communication” European Journal of Communication 28(1): 53-66. https://doi: 10.1177/0267323112464837.

Laclau, Ernesto. 2005. On Populist Reason. London: Verso.

Le Pen, Marine (@MLP_officiel). 2015. "Dimanche rappelez-vous: le peuple est la seule chance pour la France! MLP.” Twitter message. 11 December 2015. https://twitter.com/mlp_officiel/ status/675404274457800706

Le Pen, Marine (@MLP_officiel). 2016. “Je continuerai de monter en puissance dans ma relation directe avec les Français, sans intermédiaire, par les réseaux sociaux.' \#1erMaiFN.” Twitter message. 1 May 2016. https://twitter.com/MLP_officiel/status/726778536699285508

Le Pen, Marine (@MLP_officiel). 2017. “'Les réseaux sociaux permettent de s'adresser directement au peuple. Ma campagne sera innovante en ce domaine.' \#VoeuxMLP.” Twitter message. 4 January 2017. https://twitter.com/mlp_officiel/status/816588935711379456

Lowles, Nick. 2018. "Ukip Is Finished After Electing Gerard Batten, but Nigel Farage Is Set to Make a Comeback.” The Independent. 19 February 2018. Accessed 22 November 2018. https://www.independent.co.uk/voices/ukip-new-leader-gerard-batten-nigel-farage-return-henrybolton-a8218006.html

Martin, James R., and Peter R. White. 2005. The Language of Evaluation. Basingstoke, UK: Palgrave Macmillan.

Mazzoleni, Gianpietro. 2008. "Populism and the Media." In Twenty-first Century Populism, edited by Daniele Albertazzi and Duncan McDonnell, 49-64. Basingstoke, UK: Palgrave Macmillan.

McCormick, Rich. 2016. "Donald Trump says Facebook and Twitter 'helped him win." The Verge. 13 November 2016. Accessed 22 November 2018. https://www.theverge.com/2016/11/ 13/13619148/trump-facebook-twitter-helped-win

McCrum, Kirstie. 2017. "Nigel Farage Is Still King Ukip - But Paul Nuttall Is Learning Fast.” New Statesman. 17 February 2017. Accessed 22 November 2018. https://www.newstatesman.com/ politics/staggers/2017/02/nigel-farage-still-king-ukip-paul-nuttall-learning-fast

Moffit, Benjamin, and Simon Tormey. 2013. "Rethinking Populism: Politics, Mediatisation and Political Style.” Political Studies 62(2): 381-397. https://doi.org/10.1111/1467-9248.12032 
O’Donnell, Mick. 2011. UAM CorpusTool (Version 2.8.7). Computer Software. Accessed 22 November 2018. http://www.corpustool.com/index.html

Otjes, Simon, and Tom Louwerse. 2015. "Populists in Parliament: Comparing Left-Wing and Right-Wing Populism in the Netherlands.” Political Studies 63(1): 60-79. https://doi: 10.1111/1 467-9248.12089.

Pariser, Eli. 2011. The Filter Bubble: What the Internet Is Hiding From You. New York, NY: Penguin.

Pasquino, Gianfranco. 2008. "Populism and Democracy." In Twenty-first Century Populism, edited by Daniele Albertazzi and Duncan McDonnell, 15-29. Basingstoke, UK: Palgrave Macmillan.

Polonski, Vyacheslav. 2006. "Impact of Social Media on the Outcome of the EU Referendum” Accessed 30 April 2018. https://www.referendumanalysis.eu/eu-referendum-analysis2016/section-7-social-media/impact-of-social-media-on-the-outcome-of-the-eu-referendum/

Reinemann, Carsten, Toril Aalberg, Frank Esser, Jesper Strömbäck and Claes De Vreese. 2007. "Populist Political Communication. Toward a Model of Its Causes, Forms, and Effects." In Populist Political Communication in Europe, edited by Toril Aalberg, Frank Esser, Carsten Reinemann, Jesper Strömbäck and Claes De Vreese, 365-380. London: Routledge.

Renzi, Matteo (@matteorenzi). 2015. “@KiaraFarigu i Social sono molto utili. Ma chi li conosce sa che la realtà è più complessa di una tempesta di tweet.” Twitter message. 12 May 2015. https://twitter.com/matteorenzi/status/598148373867278337

Renzi, Matteo (@matteorenzi). 2016. “Alex Zanardi, un uomo e un atleta di cui tutta l'Italia è orgogliosa.” Twitter message. 14 September 2016. https://twitter.com/matteorenzi/status/7760 61035786756096

Salvini, Matteo (@matteosalvinimi). 2016. "Finché almeno su Twitter potremo essere LIBERI, ritwittiamo! Di cosa avranno paura nel clan Renzi? Confrontarsi è bello ma... \#boschiscappa.” Twitter message. 7 October 2016. https://twitter.com/matteosalvinimi/status/784357546429 652992

Salvini, Matteo (@matteosalvinimi). 2016. “Napolitano sul libero voto degli inglesi: ‘Un azzardo sciagurato'. L'anziano comunista è sempre allergico alla Democrazia. Ritirati! \#Brexit.” Twitter message. 24 June 2016. https://twitter.com/matteosalvinimi/status/746474103750729729

Shoemaker, Pamela, and Akiba A. Cohen. 2006. News Around the World Content: Practitioners, and the Public. New York, NY: Routledge.

Stieglitz, Stefan, and Linh Dang-Xuan. 2013. "Emotions and Information Diffusion in Social Media-Sentiment of Microblogs and Sharing Behavior." Journal of Management Information Systems 29(4): 217-248.

Taggart, Paul. 2000. Populism. Buckingham: Open University Press.

Taguieff, Pierre André. 2002. L'Illusion Populiste. De l'Archaïque an Médiatique. Paris: Berg International.

Tharoor, Ishaan. 2016. “World Media Reacts to Trump's Victory With Shock, Dread.” The Washington Post. 4 May 2016. Accessed 22 November 2018. https://www.washingtonpost.com/ne ws/worldviews/wp/2016/05/04/this-is-how-media-around-the-world-reacted-to-madman-trum mps_victory/?noredirect $=$ on\&utm_term $=$. a01cfbf0912a

Weyland, Kurt. 2001. "Clarifying a Contested Concept: Populism in the Study of Latin American Politics.” Comparative Politics 34(1): 1-22. https://doi:10.2307/422412.

White, Peter R. 2001. “Appraisal: An Overview.” Accessed 22 November 2018. http://www.lang uageofevaluation.info/appraisal/appraisalguide/framed/frame.htm 
Wirz, Dominique S. 2018. "Persuasion Through Emotion? An Experimental Test of the EmotionEliciting Nature of Populist Communication.” International Journal of Communication 12(25): 1114-1138.

Wodak, Ruth. 2015. The Politics of Fear: What Right-Wing Populist Discourses Mean. Los Angeles: Sage.

Zappavigna, Michele. 2011. “Ambient Affiliation: A Linguistic Perspective on Twitter." New Media E Society 13(5): 788-806. https://doi.org/10.1177/1461444810385097.

Zappavigna, Michele. 2012. Discourse of Twitter and Social Media. London: Continuum. 


\title{
Let's Stop The Enemy!
}

\section{A Critical Discourse Analytical (CDA) Case-Study of the Rhetoric of a State-Conducted Survey in Hungary, April 2017}

\author{
Natalia Borza*
}

\begin{abstract}
In April 2017, the Hungarian government launched a national consultation entitled 'Let's stop Brussels!' focusing on topical issues such as Brussels' prohibition of reductions in household utility charges; illegal immigration; foreign attempts to influence the domestic political scene; Brussels' attacks on tax reductions and job creation programmes in Hungary. The ruling party's intention of conducting the consultation was to gain alleged public support for the government's implementation of measures the EU has been concerned about. The present paper investigates the extent of the presence of manipulation in the rhetoric of the questionnaire of the consultation sent to Hungarian eligible voters by using van Dijk's (2006) triangulated Critical Discourse Analytical (CDA) approach. Van Dijk's three-layered approach to the investigation of manipulation in discourse is an integrated theory that establishes links between three different dimensions of manipulation: society, cognition and discourse. The findings of the study show that in all the three dimensions various rhetorical tools of manipulation were applied in the text of the national consultation.
\end{abstract}

Key words: Critical Discourse Analysis (CDA), rhetoric, manipulation

*nataliaborza@gmail.com 


\section{Introduction}

In April 2017, the Hungarian government launched a national consultation ${ }^{1}$ entitled 'Let's stop Brussels!' to ask the opinion of the Hungarian electorate about economic and legal issues. The consultation, whose cost of conducting rose to 29 million Euros, ${ }^{2}$ covered topics such as public utility charges, illegal immigration, the transparency of international organisations, and Brussels' alleged attacks on tax reductions and job creation programmes in Hungary. The Hungarian Prime Minister found it crucial to conduct the consultation "on the five dangers" ${ }^{3}$ Hungary was claimed to face that year by arguing that external forces were trying to "take rights away in many fields from the member states [of the European Union], endangering national sovereignty". ${ }^{4}$ In the consultation, the threatening external force was named to be Brussels.

The present study investigates whether there is any level of manipulation applied in the questionnaire of the national consultation sent to eligible Hungarian voters in April 2017. The qualitative analysis was carried out by applying van Dijk's (2006) triangulated method of Critical Discourse Analysis (CDA). Van Dijk's three-layered CDA approach to the investigation of manipulation in discourse is an integrated theory that establishes links between three different dimensions of manipulation: society, cognition, and discourse. The CDA framework goes beyond examining mere textual elements that occur in the discourse, thus allowing a text to be evaluated as manipulative in terms of its context categories.

In the first part of the study, the terms 'manipulation' and 'rhetoric' are clarified in order to illuminate the scope of their use in the present analysis. Next, it is argued why the CDA approach was chosen as the framework of the current inquiry. More specifically, the threefold model by van Dijk (2006) is presented in detail with the aim of showing the dimensions on which the investigation rests. Subsequently, the presence of manipulation in the discourse of the national consultation is explored by examining the balance in its participants and in the information shared; by considering its influence on social cognition; and by revealing the rhetorical techniques applied in the discourse of the set of questions. Since Prime Minister Orbán is regarded as the leader "who

\footnotetext{
1 Between May 2010 and December 2017, the Orbán government commissioned the conduct of seven national consultations (Körösényi 2018, 12).

2 The direct cost of conducting the consultation was 3 million Euros; however, the Hungarian governments spent another 26 million Euros on campaigning against Brussels. (Source: Cabinet Office http://www.kormanyhivatal.hu/download/b/9a/b3000/vállalkozásiszerződés.pdf; Magyar Nemzet, 29 September 2017. Accessed 23 November 2018. https://mno.hu/belfold/felrevezeto-az-uj-konzultaciosorosrol-es-terverol-2419168;)

3 Source: Cabinet Office of the PM, MTI (Hungarian State News Agency), 21 February 2017. Accessed 23 November 2018. http://www.kormany.hu/en/the-prime-minister/news/national-consultation-to-belaunched-on-threats-faced-by-hungary

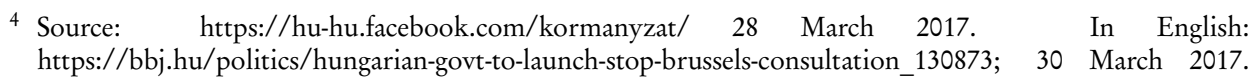
Accessed 23 November 2018.
} 
transformed Hungary into a textbook case of authoritarian populism" (Ádám 2018, 2), populist traits of the manipulative elements of the text of the consultation are shown as well. The text of the questionnaire can be found in Appendix 1.

\section{Review of the Literature}

\subsection{The Nature of Manipulation}

In the broad sense of the word, manipulation, understood as a social phenomenon, is the act of controlling and influencing people and situations in a skilful manner. In this sense, no value judgement can be attached to it. Manipulation, the power to influence others through interactions and typically through a communicative practice, ${ }^{5}$ can be seen as neither good nor bad. Simons et al. $(2001,7)$ suggest that manipulation, based on the notion of persuasion, is "a dialogue between two parties," thus it is not a one-way, forceful coercion of power. In a similar manner, Parker $(1972,74)$, who defined manipulation as an action which includes the intention or "desire to fortify or to alter the existing behavior of another," considered most human actions to be manipulative in nature. With such an understanding, Parker (1972) explicitly sought to dispense with the usual pejorative connotation attached to manipulation. In this broad sense of the term, manipulation, the use of one's power to influence others, is viewed as an ethically neutral action. To justify this position, Parker listed several situations where manipulation is appropriate and even beneficial to society. People suffering from emotionally or mentally distressing conditions voluntarily bring themselves as patients under the control of a psychologist or a psychiatrist; students eager to acquire knowledge allow themselves to be manipulated by the instructions of professors; also, a marriage relationship or a parent-child relationship is based on the continuous effort of exercising power on the partner or the family member in the relationship. Manipulation in settings where manipulators are willingly solicited for their expertise, knowledge, or experience conforms to social norms, thus such type of manipulation can evidently be viewed as a socially legitimate form of manipulation (Dillard and Pfau, 2002).

In the narrower sense, however, the term manipulation carries negative connotations by denoting an unethical form of behaviour. Walton $(2007,21)$ condemns manipulation as a dishonest course of action that uses "deceptive argumentation tactics to unfairly get the best" of an opponent or to "deceive a mass audience" (ibid., 1). In a similar vein, Simpser (2014), who analyses why governments manipulate elections, defines manipulation as an instrument of political control. Van Dijk (2006) characterises the manipulator

\footnotetext{
5 The present study deals with the notion of manipulation in the symbolic sense, not in the physical sense. That is, the case study investigates discursive influences in social interactions rather than the various physical forms of handling or operating objects skilfully by one's hands, as the etymology of the word implies.
} 
from two different aspects. On the one hand, a manipulator is an agent who exercises control over other people against their will or fully conscious will. In cases of illegitimate manipulation, the participants of the dialogue are not free to believe or act as they please. This stands in contrast with legitimate forms of manipulation, where the interlocutors are not under control as to their beliefs and actions. In the various forms of socially legitimate manipulation the interlocutors themselves seek assistance. However, the victims of manipulation tend to lack essential resources to resist, to avoid or even to detect being manipulated as they are unaware of the real intentions of the manipulator. On the other hand, according to van Dijk (2006), a manipulator dominates other people against their best interest. Thus, manipulation in the narrower sense definitely involves the abuse of power.

Approaches characterising manipulation in the narrower sense along similar aspects proposed by van Dijk (the lack of willingness on the part of the victim and the lack of benevolence on the part of the manipulator) have a long history in the philosophy of persuasion. Kastely $(2015,5)$ warns that in Plato's Republic manipulation should be distinguished from persuasion. The purpose of the former is to change "the audience by imposing an outside order" on it, while the aim of persuasion is to "allow the audience to understand and embrace the order that is proposed to it." In other words, persuasion for Plato enables internalisation, while manipulation does not. The difference between the two actions stems from the different nature of persuasion and manipulation. Persuasion in the Republic is the act of a two-way collaborative effort, while manipulation is the one-way imposition of arguments on a party (ibid., 225). Besides the lack of internalisation, manipulation can be further discerned from persuasion by the intention of the interlocutor who attempts to introduce the order on the other party. While persuasion seeks to guide people in the "care of their souls" (ibid., 208), manipulation does not have such a noble aim. In the case of persuasion, internalisation combined with the genuine goodness of the persuader results in the shaping of fundamental values, beliefs and desires of the persuaded, who, in consequence, becomes ethically more refined for Plato. ${ }^{6}$ In contrast, manipulation does not bring morally appreciable fruits in the person manipulated.

Keeping the negative connotations of the term manipulation in focus, the present study uses the term in the narrower sense, maintaining its historically conventional undertone filled with the pejoratives described above.

\footnotetext{
6 The same can be observed in the Apology, where Socrates names his principal activity as the persuasion of his fellow citizens that leads to the good of the city. "For I spend all my time going about trying to persuade you, young and old, to make your first and chief concern not for your bodies nor for your possessions, but for the highest welfare of your souls, proclaiming as I go, wealth does not bring goodness, but goodness brings wealth and every other blessing, both to the individual and to the state." (Plato, 30b)
} 


\subsection{The Means of Manipulation: Rhetoric}

Since manipulation is typically a communicative practice, the means of manipulation is the art of verbal persuasion, rhetoric (McLean 2001). Conventionally, it is rhetoric that makes an argument effective in persuading the target audience (Tindale 2004). Van Eemeren and Houtlosser (2001) also propose the view that rhetoric is a persuasive effort in order not to lose a discussion. More than five decades ago, Kennedy $(1963,7) \mathrm{em}-$ phasised that whenever persuasion is the purpose, "rhetoric is present." Thus, rhetoric, "the collection of techniques of manipulation" (Parker 1972, 78), appears to be a neutral term. To effectively reach one's aims through communication does not entail a deprecatory connotation.

However, the term rhetoric is not without heavily charged, negative connotations in the history of philosophy. Since the $4^{\text {th }}$ century BC, rhetoric has been depreciated and even rejected by philosophers. Plato, whose condemnation of rhetoric is noticeable in many of his dialogues (Krabbe 2000), denied in the Gorgias that rhetoric was an art at all (454b1) and explained it was mere flattery (kolakeia), a fake counterpart of justice (463a6). Plato's fierce criticism of rhetoric was targeted against its feature of not having any subject matter of its own, for which reason Plato argued that rhetoric cannot present truth. In Plato's language, rhetoric deals with illusion and belief rather than true knowledge. For Plato, the notion of rhetoric became connected with shallowness, deception and immorality. Kennedy $(1963,23)$ insists that modern readers of Plato cannot side with rhetoric since it appears to be mere "verbal dexterity, empty pomposity," a communicative activity which bears moral ambivalence. The rhetorician who is capable of achieving any sort of end by the means of his skilful eloquence is easy to be disapproved of morally. Plato's objection to the rhetorician attacks the sophists, itinerant teachers who taught rhetorical techniques of argumentation. Traveller teachers who gave instruction in public speaking were infamous for teaching rhetorical tricks rather than philosophical truth or justice. Despite teaching the practicalities of oratory, the sophists were criticised for using fallacious arguments and for trading on the biases of audiences. Due to their lack of moral rectitude, the art of the sophists is depicted as "a seriously tainted and practically compromised knack” (Hohmann 2000, 234). Sophists were claimed to teach how to exercise power by deception, by making the worse argument appear to be the stronger to the audience. Eloquence without a righteous character was treated suspiciously since the ability to display erroneous actions in an attractive manner has the power to pose a potential danger. In the Phaedrus, ${ }^{7}$ Plato's harsh disparagement of rhetoric became less rough. In this dialogue, rhetoric is at least considered as a faculty of persuasion. It was Aristotle who lessened the hostility against rhetoric. Aristotle acknowledged the usefulness of rhetoric as a tool, which he defined as "the faculty of discovering the possible means of persuasion in reference to any subject what-

7 Plato, 260a-277a 
ever" (Rhetoric 1355b2). Aristotle did not find rhetoric to be the diametric opposite of philosophy but treated the two in a gently compromising union by claiming that those who expose truth have an obligation to be persuasive as well.

The present study adopts the Aristotelian view on rhetoric in so far as the analysis does not treat rhetoric as an unworthy or suspicious subject but appreciates it as the art of engaging the audience with a greater power of persuasion. Yet, the case study investigates the presence of manipulation in the narrower sense in the discourse of a $21^{\text {st }}$-century national consultation, thus the rhetorical techniques applied skilfully in this context bear negative connotations.

\section{Methods}

\subsection{The Approach of Analysing Discourse: Critical Discourse Analysis}

The conceptual contours between manipulative discourse and persuasive discourse do not appear to be entirely distinct. What deepens the fuzziness of the terms is the fact that the difference between the two often depends on the situation in which they were articulated. Thus, the mere analysis of a text on its own cannot result in definite answers about the extent of manipulation in it. For this reason, a discourse analytical approach was applied in the present investigation which allows for a more complex inquiry. Critical Discourse Analysis (CDA), which particularly aims to reveal relations between discourse and society, sets out to examine "group relations of power, dominance and inequality, and the ways these are reproduced or resisted by social group members through text and talk" (van Dijk 1995, 18). The typically inter- or multidisciplinary CDA approach investigates not only discourse but its functions in society as well by dealing with "the discursive conditions, components and consequences of power abuse by dominant (elite) groups and institutions" (ibid., 24). The last two decades have seen the exploration of various relations regarding the abuse of power by discursive means. ${ }^{8}$ The CDA approach, whose foundation rests on the ethics of discourse (van Dijk 2006), is particularly appropriate for the present study as the CDA framework uncovers the various strategies of manipulation, the manufacture of consent, and other discursive techniques powerful groups use to influence people against their best interest.

\footnotetext{
8 To mention the most prominently researched fields within the CDA approach, Fairclough analysed the relations between language and power; Chilton worked on critical studies of political discourse; Wodak studied institutional power, male dominance, racism, anti-Semitism; van Dijk considered racism, media, relations between discourse and ideology; while Fisher \& Todd investigated professional language and discourse.
} 


\subsection{The Method of Analysing Manipulation in Discourse}

Strictly speaking, the CDA approach is not a method but a framework which gives space to the application of various analytical methods in the exploration of different layers of discursively enacted dominance. Van Dijk's (2006) threefold approach was chosen for the present analysis as it has the potential to yield more precise answers about the extent in which a text is manipulative. The three layers in van Dijk's (2006) model are society, cognition, and discourse. Emphasising the integrated nature of the CDA approach, all the three layers are recommended by van Dijk (2001) to be examined in an analysis.

The first layer, society, recognises the fact that discourse takes place between groups, not between individual actors. In van Dijk's (2006) model, manipulation is a form of social domination in public discourse, which reproduces inequality. The social aspect of manipulation refers to the act of "elite power reproduction that is against the best interest of dominated groups" (ibid., 364) carried out via the abuse of power. The model deals with the exploration of the ways of social control of less powerful groups by dominant groups, that is, by people in positions of power. Yet, the examination of influential psychological factors, such as the personality of the manipulator, is beyond the scope of the analysis. Focusing on the social aspect of manipulation, the manipulative actions of individual social actors are not analysed, either. It is also important to note that the presence of manipulation in a discourse is not evaluated on the basis of the intention of the speaker but on that of the social consequences of the discourse. Socially speaking, the manipulation of public discourse is characterised by the lack of balance regarding both the participants and the information shared. Typically, the manipulative control of participants in public discourse takes the form of disproportionate control of mass media, which marginalises alternative voices; while the lop-sidedness in the control of information means providing a) incomplete, $\mathrm{b}$ ) biased, or $\mathrm{c}$ ) distorted information rather than duly adequate information.

The second layer in van Dijk's (2006) CDA model for the analysis of manipulation concerns the manipulation of cognition. The basic analytical categories of cognition in the model involve 1) short-term memory (STM) processing, 2) episodic memory, and 3) social cognition. The processing of discourse in the STM results in understanding, thus manipulation at this level means either the impairment of understanding of the discourse or the unbalanced facilitation of understanding of certain parts of the information which will result in a biased understanding of a text or talk. In contrast, episodic or personal memory constitutes part of our long-term memory (LTM), which is noteworthy as our knowledge, attitudes, and ideologies are constructed in relation with our personal mental models. Manipulation at this level denotes the promotion of the formation of subjective mental models preferred by a powerful group, which results in the limitation of the freedom of interpretation for the individual. Social cognition, however, refers to general and abstract beliefs, such as knowledge, attitudes, ideologies, norms, and values shared by a social group. Van Dijk (2006) ranks the manipulation of social cognition as the "most influential form" (ibid., 368) of the three categories. 
First, socially shared representations or beliefs are "far more stable" than specific, individual mental models of a person as they stay the same for a relatively long period of time. Second, socially shared beliefs influence the individual personal mental models and attitudes, thus with their manipulation the costly multiple manipulation of individuals remains unnecessary for the dominant manipulative social group. Among the discursive strategies of manipulating social cognition, van Dijk lists a) generalisations, b) strong polarisation and c) the distribution of partial, misguided, and biased knowledge. In the case of generalisation, a specific case is generalised to attitudes or ideologies in the interest of a powerful group. Strong polarisation involves the creation of a sense of community where the group denoted as 'we' is depicted as innocent, while 'the other' social group is shown as guilty. The third type of strategy aims at adopting a specific social representation by impeding people to acquire critical general knowledge.

The third layer in van Dijk's (2006) model concerns manipulative discourse strategies. According to the CDA framework, the discourse strategies of a text or talk are assessed as manipulative along their context categories and not merely along their textual structures. To produce a biased record of events, the means of creating a positive self-representation and a negative other-representation appears to be an effective manipulative strategy. Van Dijk (2006) offers a range of discourse levels at which polarisation patterns can be analysed: macro speech act, local speech act, semantic macrostructure, local meaning, lexicon, local syntax, rhetorical figures, and expressions. The list of potentially manipulative discourse strategies is not exhaustive, and van Dijk (2006) proposes that it is the choice of the analyst to consider which ones are worth examining.

In the present study, I will both implement the theoretical CDA background of van Dijk's (2006) model and employ its qualitative methods, the three-layered model used for the analysis of UK Prime Minister Tony Blair's speech of March 2003, which gave legitimation for the UK to enter into war against Iraq. As emphasised by van Dijk (2006), social representations have a crucial importance in the course of manipulation, thus manipulation most typically focuses on social cognition. The current analysis examines the discursive tools used in the national consultation which have the power to manipulatively influence shared knowledge of the people. That is, within the second layer of van Dijk's (2006) model the third category (social cognition) is investigated; while manipulation of the short-term memory or that of personal mental models does not form part of the inquiry. Table 1 summarises the items from Van Dijk's (2006) triangulated model which were applied in the present research to reveal the extent of the presence of manipulation in the national consultation conducted in April 2017 in Hungary. 


\begin{tabular}{lll}
\hline LAYERS & Characteristics of manipulation & \\
\hline \hline 1) Society & A) Lack of balance: participants & \\
\cline { 2 - 3 } & B) Lack of balance: information & $\begin{array}{l}\text { a) incomplete information } \\
\text { b) biased information } \\
\end{array}$ \\
& & c) distorted information \\
\hline 2) Cognition & Social cognition & a) generalisations \\
& & b) strong polarisation \\
& & c) the distribution of partial, \\
& & misguided and biased knowledge \\
\hline 3) Discourse & Rhetorical techniques & Lexicon: \\
& & a) verbs and actions \\
& & b) adjectives and adverbs \\
\hline
\end{tabular}

Table 1: The items from Van Dijk's (2006) triangulated model characterising manipulation that were applied in the present study.

\section{Results and Discussion}

\subsection{Layer 1: Society}

\subsubsection{Participants}

From the social aspect, manipulation of public discourse can be characterised by strengthening inequality by means of creating an absence of balance regarding the participants. In the case of the Hungarian national consultation conducted in April 2017, imbalance in terms of the participants was highly typical. The governing party held a national consultation rather than calling for a referendum. One of the major differences between the two forms of voting lies in the degree in which the opinion of the citizens bears consequences. The second most important distinguishing feature of the two types of public expression of opinion is the level of transparency. In the case of a referendum, citizens vote for or against a measure proposed by a legislative body. A group of legally responsible counting officers conduct the verification and the count of the votes. The transparency of the voting process is ensured by supervising bodies, who pay special attention to guaranteeing that no unlawful steps are taken during the conduct of the referendum. Since the result of the referendum is binding, the electorate can reach the adoption of a new law.

In marked contrast, the nature of a national consultation offers the possibility of increasing one-sidedness in the process of recording the opinion of the people. In the April 2017 national consultation, none of the six questions in the consultation initiated 
by the government contained specific measures. As a result, the electorate could not express their opinion about an explicit legislative plan to be introduced. Also, the way of conducting the voting process gave rise to serious concerns about the trustworthiness of the result at several points. First, casting a vote in the consultation was possible by either sending the questionnaire back to the government by post or by electronically answering the questions on the government website. ${ }^{9}$ The electronic version of the consultation, however, allowed citizens to register their votes multiple times. In fact, voters could express their opinion electronically as many times as they pleased. ${ }^{10}$ Second, verification and counting of the votes were not carried out by legally accountable officers. ${ }^{11}$ Third, the data were not made available to the public. The government website failed to make the results of the consultation open to public scrutiny. ${ }^{12}$ Moreover, the government refused to answer official letters requesting public data, e.g. the raw statistical data of the consultation ${ }^{13}$ or even the number of votes cast electronically or that of questionnaires sent back by post. ${ }^{14}$ Fourth, no supervising body was set up to observe the quality of conducting the consultation. Thus, the transparency of the voting procedure was not safeguarded by any means whatsoever.

The act of conducting a national consultation on matters of public policy bears the trait of populism. Mudde $(2004,543)$ defines populism as "an ideology [...] which argues that politics should be an expression of the volonté générale (general will) of the people." However, as Müller $(2016,101)$ warns, calling for referenda does not necessarily mean the initiation of "an open-ended process of democratic will-formation among citizens." The fact that a consultation and not a referendum was held to delineate the will of the people indicates that the government did not encourage people for more participation in politics but endeavoured to confirm what they had "already determined the will of the real people to be" (ibid., 101).

The two cardinal principles of populism according to Shils (1956), the supremacy of the will of the people and the concept of the direct relationship between people

\footnotetext{
9 http://www.kormany.hu/hu/hirek/matol-interneten-is-kitoltheto-a-nemzeti-konzultacios-kerdoiv

${ }^{10}$ An investigative TV programme tested the same electronic voting system of the next national consultation conducted between October and December 2017. It was possible to register votes to an unlimited extent, and the investigative journalists cast 81 votes within an hour. Yet, the government announced there were no serious problems with the reliability of the electronic voting system. https://mno.hu/belfold/nemzetikonzultacio-konnyu-kijatszani-a-rendszert-2420433

11 The paper questionnaires sent back to the government by post were processed by the $\mathrm{Na}$ tional Infocommunications Service Company Ltd., an ICT provider in the public sector. https://kimittud.atlatszo.hu/request/nemzeti_konzultacio_2? unfold = 1\#incoming-14045

12 After conducting the consultation, the government website contained no precise information about the answers given to the six questions. Not until eight months later, data was hyperlinked to the official website of the consultation by the Cabinet Office of the PM. Confusingly enough, these hyperlinked data reveal information about another consultation conducted between October and December 2017 and the results of the consultation conducted in April cannot be reached. http://www.kormany.hu/hu/hirek/matol-internetenis-kitoltheto-a-nemzeti-konzultacios-kerdoiv; http://nemzetikonzultacio.kormany.hu

13 https://kimittud.atlatszo.hu/request/2017_evi_nemzeti_konzutacio_adat\#incoming-13876

14 https://kimittud.atlatszo.hu/request/nemzeti_konzultacio_2? unfold=1\#incoming-14045
} 
and the government, are manifestly present in the national consultation. Conducting the consultation meant the reinforcement of a direct, personal relationship with the electorate by sending each eligible voter a letter signed by the Prime Minister. Asking the opinion of the people individually promoted the notion of the paramountcy of the will of the people.

Furthermore, Körösényi (2018) reveals that the Prime Minister's apparent direct link to the people by sending letters to the electorate is an element of the plebiscitary character of the regime. Körösényi $(2018,12)$ also emphasises the marked difference between national consultations and referenda, the former lacking "formal legal regulation, transparency, and controllability" and whose "outcomes place no obligation on the government.” Such a plebiscitary tool, Körösényi (ibid., 12) argues, allows for its arbitrary use by the Prime Minister to "legitimise his politics and public policy."

In conclusion, launching a national consultation rather than conducting a referendum meant the choice of carrying out a one-way social communication procedure, the onesided imbalance of which regarding the participants of the communication is a clear sign of social manipulation. Despite the fact that Hungarian voters were asked, the opinion of the electorate was not considered for the adoption of new laws or regulations. The questionnaire of the consultation contained no planned future measures at all. In accordance with the nature of consultations, the final result bore no legal consequences. Yet, the consultation results were used by the government as a means to promote and apparently legitimise their previous moves. However, the complete lack of transparency of the voting procedure gave rise to obvious worries about the reliability of the survey and presented a cause for concern about the trustworthiness of the result.

\subsubsection{Information}

In social terms, the dissemination of imbalanced information is another sign of manipulation of public discourse in van Dijk's (2006) model. The questionnaire of the April 2017 consultation is structured in such a way that each of the six questions is preceded by one or two statements which depict an alarming situation. Apparently, these disturbing accounts of the state of affairs gave the incentive for the government to ask the questions from the electorate. According to Albertazzi $(2008,5)$, the act of evoking a sense of imminent crisis along with the notion of the distressing urgency to solve or avoid the catastrophe is a distinguishing feature of populism. In questionnaires, prefacing a question with a descriptive statement places the question in a particular context, which then can no longer be treated as neutral. In the text of the national consultation, an emphatic danger is stressed in each descriptive account. Walton considers the creation of context in polling as giving the question a "spin" $(2007,240)$, thus categorising this manipulative technique under the fallacy of the question structure bias.

Regarding the balance of transmitting factually correct information to the public, the April 2017 consultation spread not only unbalanced, incomplete, or biased information, but even factually distorted allegations, which the European Commission in 
its document entitled 'Facts Matter' ${ }^{15}$ officially assessed as "highly misleading." In each context-creating account preceding the six questions, the European Commission found and explicitly warned about a false claim which lacked truthful information. The first question falsely claimed that "Brussels wants to force us to abolish the reduction in public utility charges" despite the fact that the Commission strives to ensure affordable energy prices for households. The second question gave a false account of the European Union's migration policy by stating that "Brussels wants to force Hungary to let in illegal immigrants" even if the EU obviously fights irregular migration and provides aid to its member states to successfully protect their external borders from illegal trespassers. The third question disseminated distorted information about the EU's policy regarding human trafficking by declaring that "Illegal immigrants heading to Hungary are encouraged to illegal acts by not just the human traffickers but also by some international organisations," whereas, in reality, the EU does not at all tolerate human trafficking and overtly takes stern measures in order to eliminate such criminal activity. The fourth question mislead the public about the EU's responsibility regarding the activities of non-governmental organisations by affirming that "More and more organisations supported from abroad operate in Hungary with the aim to interfere in Hungarian internal affairs in a non-transparent manner". In fact, it is the responsibility of each member state to create the legal environment in which non-governmental organisations operate in that member state. ${ }^{16}$ It is the national legislation and not the EU that defines the exact conditions of operation. Moreover, the EU is firm about maintaining strict rules on transparency. The fifth question spread incorrect information about the EU's employment policy by maintaining that "Brussels is attacking our job-creating measures," despite the fact that neither the Commission, nor the European Union was doing so. As the 'Facts Matter' document pinpoints, the last question created a false image about the EU's taxation policies by asserting that "Brussels is attacking our country because of tax cuts." The claim is evidently false as the European Commission makes no interference in national taxation policies. EU taxation rules, in practice, must be agreed by all member states unanimously, that is, all current EU taxation rules were approved by the Hungarian government as well.

The government was asked in writing ${ }^{17}$ to support the six allegations disseminated in the consultation by quoting the appropriate rules, regulations, or resolutions of the EU which the government interpreted as dangerous. In their answer, the Cabinet Office of the PM failed to make mention of any EU legislation. ${ }^{18}$ Instead, the government

\footnotetext{
${ }^{15}$ First published 27 April 2017 https://ec.europa.eu/commission/publications/stop-brussels-europeancommission-responds-hungarian-national-consultation_en

${ }^{16}$ At the time of conducting the consultation, NGOs operating in Hungary were already obliged to make their budget transparent on their websites in order to continue their operations. Thus, the government's call for transparency is beyond comprehensibility.

17 https://kimittud.atlatszo.hu/request/a_nemzeti_konzultacio_2017_kerde

${ }^{18}$ http://www.kormany.hu/download/3/8d/01000/NK_2017_A4_v05.pdf
} 
denounced the European Commission's response to the national consultation ${ }^{19}$ to be a "highly misleading opinion, which conceals or distorts fundamental facts." 20

In conclusion, the transition of balanced information was not characteristic of the questionnaire at all. On the contrary, all the questions of the national consultation were based on distorted or false information. The act of placing statements before the consultation questions, which create a one-sided and uneven context, is another technique which contributes to manipulation. Moreover, the fact that each account preceding the questions failed to spread truthful claims is an indubitable sign of the heavy presence of manipulation in the consultation.

\subsection{Layer 2: Social cognition}

\subsubsection{Generalisation}

The second layer in van Dijk's (2006) model focuses on the manipulation of cognition. Among the three analytical categories, the abusive influence of social cognition, i.e. the authoritative domination of general and abstract beliefs such as knowledge, attitudes, ideologies, norms and values shared by a social group, is considered to be the most powerful. The national consultation launched in April 2017 was not without examples of generalisations. Rather than focusing on clear, specific examples, the consultation made use of more abstract, generalised notions. It is important to note that the application of generalisations is a rhetorical technique characteristic of non-manipulative and legitimately manipulative discourse as well. However, in such cases the use of generalisations helps the better understanding of a situation or a process through the introduction of general terms which distinctly focus on the main features required to be comprehended. As van Dijk (2006) warns, generalisation is considered to be manipulative when it creates socially shared fears and/or increases the sense of threat.

In the national consultation, five of the six accounts of the troublesome situations prefacing the questions include generalisations. All the five instances of generalisations manipulate citizens into believing that their lives are exposed to imminent perils. In question two, voters get to know that "in recent times terror attack after terror attack has taken place in Europe". Question three imparts the information that "there are international organisations which, without any consequences, urge the circumvention of Hungarian laws". Question four allegedly claims that "more and more foreignsupported organisations operate in Hungary with the aim of interfering in the interna-

\footnotetext{
19 'Facts Matter' First published 27 April 2017 https://ec.europa.eu/commission/publications/stop-brusselseuropean-commission-responds-hungarian-national-consultation_en

${ }^{20}$ http://www.kormany.hu/hu/hirek/nemzeti-konzultacio-kormanyzati-reakcio-az-europai-bizottsagallasfoglalasara
} 
tional affairs of our country in an opaque manner." ${ }^{21}$ While question five asserts that "Brussels is attacking our job-creating measure."

What all the five threatening generalisations have in common is that none of the inferences refer to any specific incident, and neither of them are concluded from the analysis of particular events. The claims of the generalisations are insufficiently factual, thus they cannot be subject to analysis. Due to the lack of relying on any specific examples, the accurateness of the statements and that of the conclusions of the accounts cannot be investigated at all. The evasion of resorting to exact cases creates the possibility of a sciamachy, where arguments are directed at an imaginary opponent. As the shadowy adversary figures are lacking all explicitness, people themselves cannot directly take part in the debate challenging the threatening enemies. This inertness can evoke the feeling of helplessness in the people and thus increases a sense of dependence on a protective power. Ágh (2019, TBC) underscores the tendency of the Orbán government to strengthen its position by creating enemy images through skilful "negative communication strategies."

In sum, the questionnaire contains a plethora of generalisations which all aim to mount socially shared tensions and fears. The generalisations create intangible enemies that catalyse a feeling of helplessness and dependence. None of the generalisations help the better understanding of a situation by purposefully focusing on its main features. Thus, the use of generalisations is a pronounced rhetorical technique of manipulation in the consultation.

\subsubsection{Strong Polarisation}

Apart from the use of generalisations, van Dijk (2006) lists strong polarisation among the discursive strategies of manipulating social cognition. The national consultation abounds in instances of disseminating polarised perspectives to the electorate. All of the accounts of the distressing situations which introduce the six questions heavily rely on a polarised, dichotomous worldview. According to the questionnaire, the two parties of the polarised world are Brussels and the conductor of the consultation, the Hungarian government. The two are illustrated as entirely different from each other. Brussels is portrayed as a powerful enemy of the Hungarian nation, while the ruling Hungarian party is represented as a conscientious, independent force that takes care of its nation by conducting a consultation which, in the government's narrative, could prevent Brussels' abuse of power.

The polarised view of the questionnaire makes mention of other agents besides Hungary and Brussels, who make the division between the two powers even sharper. The agents connected to Brussels are characterised by the ability to cause harm and commit

\footnotetext{
${ }^{21}$ It is a rightful question to ask why the compiler of the questionnaire did not take legal action against the unknown agents of the specific criminal acts rather than conducting a national consultation about the alleged illegal activities.
} 
actions which are not authorised by law. The agents supporting Brussels in the accounts of the consultation are criminal subjects, such as illegal immigrants (Q2, Q3), human traffickers (Q3), international organisations which help illegal immigration (Q3), and international organisations which interfere in Hungarian internal affairs and jeopardise Hungarian independence (Q4). Additionally, large companies (Q1) also appear as agents giving assistance to Brussels by inflicting injury on the Hungarian nation through their abuse of power in increasing Hungarian public utility charges. As it appears in the narrative of the consultation, Brussels is not without allies, with five different types of agents backing them in committing alarming deeds forbidden by law. In comparison, the consultation construes the view that Hungarian people can rely on nothing else but Hungarian authorities (Q2). The dichotomous, polarised nature of the narrative of the consultation can be identified as a populist feature. In Albertazzi's $(2008,117)$ definition of populism, the populist ideology contrasts "virtuous and homogeneous people" with “dangerous 'others' who are together depicted as depriving (or attempting to deprive) the sovereign people of their rights, values, prosperity, identity, and voice." In a similar manner, when characterising populism, Panizza $(2005,3)$ also stresses the importance of the "other that is deemed to oppress or exploit the people."

The narrative applies such a polarised view where Hungary is left alone, and apart from the Hungarian authorities, not even one single powerful agent supports the people of Hungary, who are in danger of imminent, serious criminal attacks. Hungarians are represented as vulnerable yet unassisted, without the support of cooperating powers. Rather than being backed by allying agents, the Hungarian government is linked with agentless, indefinite notions in the questionnaire. Each of the six situations preceding the questions in the consultation contains a concept which attaches a positive, yet abstract idea to the Hungarian agent: reduction of public utility charges (Q1); safety (Q2); responsibility and consequences (Q3, Q4); independence (Q4); job creation (Q5); own strategies (Q5); and tax cuts (Q6). These ideas depict the Hungarian authorities in a favourable light and increase the tension between the two extremes of the pole: an exceptionally powerful Brussels, backed by criminal allies, that attacks a helpless but responsible government, which aims to increase the standards of living of its nation against all adversities. The mission of the promotion of public good against dangerous "others" is another characteristic feature of populism (Albertazzi 2008, 84).

The strongly polarised worldview of the consultation does not serve the better understanding of the troubling situations by reducing their complexity to a stable but simple binary, since the seemingly impassable division (Brussels vs. Hungary) relies on a false dichotomy. By the use of a false dichotomy, an artificial binary choice is presented, where two options are shown despite the fact that many other alternatives exist. The nature of a false dichotomy is well characterised by its other names, "the black and white fallacy" or "the fallacy of simplistic alternatives" (Walton 2007, 244). A false dichotomy typically offers the two options as mutually exclusive, either black or white. The choice between the alternatives often poses no severe dilemma since they 
are depicted as extremes, one of them as a solution, while the other is shown as an obviously unattractive ruin. Van Dijk's (2006) model does not identify the construction and the application of false dichotomies as a manipulative discourse strategy. Since false dichotomies powerfully manipulate cognition, I consider it worthwhile to distinguish this discursive strategy as a special class of creating strong polarisation, thus I apply an extension to van Dijk's (2006) taxonomy within the cognition layer.

In the case of the consultation, a false dichotomy was created by opposing Brussels with Hungary. Such a binary is evidently false, since the EU is definitely not a conquering power and its member states decided democratically to join the Union. ${ }^{22}$ Moreover, contrary to what the false dichotomy of the consultation suggests, decisions in the EU are not made irrespective of the member states' decisions and votes. For this reason, the allegedly opposed parties are definitely not mutually exclusive but form a part-whole relationship.

In sum, the questionnaire of the consultation extensively applies generalisations. All the six questions are contextualised in a polarised world, where the narrative of the polarisation strengthens the sense of threat and increases the feeling of fear and vulnerability. Thus, the discourse of the consultation manipulates people into believing that they need a protecting agent.

\subsubsection{Partial, Misguided and Biased Knowledge}

Among the discourse strategies that manipulate social cognition, apart from the use of generalisation and strong polarisation, van Dijk (2006) enumerates the distribution of partial, misguided and biased knowledge. The questionnaire of the national consultation clearly distributes partial knowledge from a one-sided perspective since it completely avoids disseminating balanced arguments. All the six alarming situations preceding the questions are presented without listing even one single counterargument. Only that approach which is in the best interest of the government in terms of justifying their actions in the past is presented. Offering various and potentially differing aspects for public analysis is completely omitted in the accounts of the questionnaire. Thus, the recipients are not adequately informed, i.e. manipulation resides in the lack of providing potentially critical general knowledge. Absolute partiality and the complete lack of balance in the argumentation blocks any debate of the alleged problems.

Sunstein (2007) argues that in a democracy, as long as it is a well-functioning system of free expression, people should face unexpected and specifically unselected encounters of topics and opinions. Even if people find the presented points of view irritating, the "unanticipated encounters enrich $[\ldots]$ the public sphere by creating a kind of shared text of issues and information that in turn facilitates [...] dialogue amongst citizens"

\footnotetext{
${ }^{22}$ Hungary joined the EU in 2004 , when $83.76 \%$ of the voters expressed their will for the country to become a member state. (Source: https://europa.eu/european-union/about-eu/countries/membercountries/hungary_en)
} 
(Sunstein 2007, 5). The argument warns that one-sidedness in the selection of topics, points of view, and arguments enhances extremism in society and, in turn, undermines democracy. Spreading partial information might be an effective tool of manipulation, yet it is troubling for democracy. As Ágh (2019, TBC) observes, the decline of democracy and "the damages done to democratisation in Hungary by the ruling hard populist party" after the elections in 2010 was noted by international ranking institutes. ${ }^{23}$ In defence of supporting one-sidedness, the Hungarian Prime Minister gave reasons why he himself refused dialogues and discussions by stating that "What needs to be done is obvious; no debate about values or weighing of empirical evidence (sic!) is required" (Orbán, as cited in Müller 2016, 26). Since the PM's avoidance of debates did not occur once as a singular, isolated case but forms a habitual disposition, his conscious refraining from public debates is treated as a sign of populism by Müller (2016).

In conclusion, the omission of facts and points of view unfavourable to the powerful social group results in a biased body of knowledge in the consultation, which manipulatively hinders discussion, prevents a better understanding of the proposed situations, and manipulates people into believing that the government's policies are justified.

\subsubsection{Layer 3: Discourse: Lexicon: Verbs and Actions}

The third layer in van Dijk's (2006) triangulated model for the analysis of manipulation in public discourse regards manipulative rhetorical strategies. The present analysis examines the rhetorical strategies which create a positive self-representation and a negative other-representation at a lexical level both by investigating the implications of the choice of verbs and actions and by exploring the connotations of the use of the adjectives and adverbs in the text of the consultation. In the questionnaire, all the verbs connected to Brussels express actions and none of them are static verbs referring to states or mere existence. The excessive use of active verbs creates the image that 'the Other' is deliberately engaged in activities to achieve its aim. Besides conveying the impression of the capability of the pursuit of action, all the verbs used in relation to Brussels suggest aggression. The activities of Brussels in the narrative of the consultation appear to be violent. 'The Other' is depicted as an agent capable of confrontation, one who is likely to attack Hungary. The majority of the aggressive actions carry the alarming message that the hostile intent of Brussels is planned to be carried out illegally. As the consultation claims, Brussels "wants to force us to let in illegal immigrants" (Q2), it "encourages" immigrants to illegal acts (Q3), supports international organisations to "urge the circumvention of Hungarian laws" (Q3); gives them "support with the aim to interfere in

\footnotetext{
${ }^{23} \mathrm{BF}$, Bertelsmann Foundation (2017) Hungary country report, http://www.sginetwork.org/docs/2017/country/SGI2017_Hungary.pdf EIU, Economist Intelligence Unit (2017) Democracy Index 2016, http://www.eiu.com/public/topical_report.aspx?campaignid=DemocracyIndex201 FH, Freedom House (2017) Breaking Down Democracy: Goals, Strategies, and Methods of Modern Authoritarians, https://freedomhouse.org/report/special-reports/breaking-down-democracy-goals-strategies-andmethods-modern-authoritarians
} 
Hungarian internal affairs" (Q4). The rest of the aggressive actions associated with Brussels might be considered as lawful, yet they still express an obvious, impending threat. The consultation narrates Brussels as if it was "planning to take a dangerous step" (Q1) to "force us to abolish the reduction in public utility charges" (Q1). Aggression is joined with the image of war, where Brussels is repeatedly depicted as attacking Hungary for serving the interest of its people. Brussels allegedly launched attacks against Hungary for its job creating measures (Q5) and also against the reduction of taxes (Q6). Aggression is also represented in the form of oppression. The consultation depicts Brussels as disproportionately exercising its power to keep Hungary under control by "jeopardizing our independence" (Q4) and by "dictating tax rates" (Q6). In the narrative of the consultation, Brussels' evil activities generate reaction from the Hungarian government. The anti-EU feature in one's politics is regarded by Panizza $(2005,69)$ as a populist trait, since European integration is typically identified in populist discourse with the "authoritarian strategy of the elites," which stands in contrast with the will of the people.

In marked contrast, the verbs and actions used in the national consultation depict the Hungarian government as a benevolent power acting in support of its people. The caring attitude of the government is created by the very first question, which distributes the information that the government "reduced public utility charges" (Q1). The next question in the consultation couples this caring attitude with a sense of legal responsibility. A lawful image is disseminated about the government, which is supposed to encourage the reliance on official decisions in the case of asylum seekers. The law-abiding character of the government is further underlined by the third question, which promotes the punishment of both the assistance and the popularisation of illegal immigration. The fourth question further strengthens the image that the government keeps its legal obligations in high esteem by its effort to require organisations to register and take responsibility for their actions and objectives. Besides legal responsibility, the other notion connected to the government's caring attitude through the particular use of verbs and actions in the questionnaire is autonomy. The consultation implies that the Hungarian government can initiate and implement measures as long as it is autonomous and independent. In the framework of the narrative of the consultation, the government would not be able to reduce public utility charges without independence, for which reason the consultation attempts to persuade voters to "insist to determine" the prices in Hungary (Q1). According to the accounts of the questionnaire, job creation has been successful in Hungary. This success is attributed to the autonomous operation of the government in Question 5, which imparts the idea that Hungary can reach its desired aims, provided it "follows its own strategy" (Q5) and "continues to make decisions" on its own (Q5). Independent decision making is emphasised in the case of the apparent success of tax-cuts as well (Q6). If the Hungarian government's autonomy, which results in an effectively caring attitude, is threatened by external forces, such as Brussels, it is ready to defend its independence. According to the text of the consultation, Hungary needs to be defended from "Brussels's plans" (Q 1, Q5, Q6), and from illegal immigrants by 
"placing them in detention" (Q2). Emphasising the impending loss of sovereignty and autonomy of the nation is a crucial feature in populist discourse. Panizza $(2005,4)$ considers the concept of the sovereign people imagined as being in "antagonistic relation with the established order" to be the core element of populism, while McNight $(2018,14)$ also views the foregrounding of the conflicting opposition of the people and the oppressive elite as a typical characteristic of populism. Ágh (2019, TBC) notes that the ruling party in Hungary has been "using the mantra of national sovereignty as the freedom fight against the EU, in which 'Brussels' appears as 'Moscow."”24

The questionnaire of the consultation is structured along a straightforward pattern. Each short context-creating situation is followed by the same question: What do you think Hungary should do? The voter is given the choice to mark either of two answers, $\mathrm{A}$ or B. By choosing answer A, the voter supports the government in the protection of Hungary from the supposed attacks, while the choice of answer B promotes the maintenance of the threatening situation described before the question. The verbs in answer B seem to fulfil a specific function. These actions aim to break down trust. The narrative of the questionnaire tries to convince the electorate that large companies are not to be trusted (Q1), "Brussels' plan" is not to be accepted (Q1, Q6), international organisations are not to be accepted either (Q3), and consequently they should not be allowed to continue their activities (Q4). The questionnaire supports these suggestions by drawing out the supposedly dangerous, risky, and illegal nature of the agents. As the electorate is implied to withdraw their belief in the reliability of the decisions of the EU and those of international organisations and companies, the tone of the manipulation in the consultation is rather incendiary. Shortly after the publication of the 'Facts Matter' document, the European People's Party (EPP) warned the Hungarian Prime Minister to comply with the EU laws and EPP values as the Party found "the blatant anti-EU rhetoric of the 'Let's stop Brussels!' consultation unacceptable." ${ }^{25}$ The EPP press release insisted on the fact that "the constant attack on Europe, which Fidesz has launched for years, have reached a level" 26 they could not tolerate.

The analysis of the verbs and actions in the questionnaire reveals that the rhetorical strategy of the consultation follows the fear and threat appeal argument in each of the six questions. Fear appeal arguments propose that the state of affairs is dangerous to the respondent, typically suggest that his safety is at risk, and imply a course of action which will result in averting catastrophe by avoiding the alleged peril. The use of threats and force in argumentation is categorised under the fallacy 'argumentum ad baculum,'

${ }^{24}$ Moscow refers to Hungary's past when the country was ruled by the Communist Soviet Union (until 1989). During the Communist regime it was impossible to make important decisions at a national level; instead, orders were sent from Moscow.

${ }^{25}$ Source: http://www.epp.eu/press-releases/prime-minister-orban-to-comply-with-eu-laws-and-epp-valuesfollowing-meeting-with-epp-presidency/ 29.04.2017

${ }^{26}$ Source: http://www.epp.eu/press-releases/prime-minister-orban-to-comply-with-eu-laws-and-epp-valuesfollowing-meeting-with-epp-presidency/ 29.04.2017 
or the appeal to the stick. Using the threat of losing safety in order to bring about the acceptance of a conclusion is not only fallacious but heavily manipulative as well. The use of the argument ad baculum fallacy is often considered to be an element of populist rhetoric. Albertazzi $(2018,5)$ clarifies that while populists "preach impending doom, they also offer salvation."

To summarise, at the lexical level, a positive self-representation and a negative otherrepresentation is noticeably present in the discourse of the consultation. 'The Other' is illustrated to be active, violent, aggressive and unlawful, while those who govern Hungary are portrayed as benevolent and respectful of law and order. The application of the argumentum ad baculum manipulates the electorate into believing that the alleged imminent threats can only be avoided by supporting the claimed protector.

\subsection{Layer 3: Discourse}

\subsubsection{Lexicon: Adjectives and Adverbs}

Regarding the use of adjectives and adverbs in the consultation, the same positive selfrepresentation and negative other-representation can be observed. The adjectives connected to Brussels convey a threatening image. Brussels intended step is dangerous (Q1), the international organisations it supports are risky and non-transparent (Q4), while the people it forces to be let into the territory of Hungary are illegal (Q2, Q3). The seemingly neutral adjective 'international' (Q3) also appears to be a threat in the discourse of the consultation. The text insinuates that whatever is international is the enemy of the country, a serious danger to national interests. The national consultation creates the image of serving the protection of the nation against external, international forces. In this way, those who do not accept the narrative or the argumentation of the national consultation at any point can be accused of being unpatriotic and disloyal to the nation, which is a manipulative way of silencing the opposition. A renewed interpretation of the notion of patriotism is noticed by Ágh (2019) in the rhetoric of the present Hungarian ruling party. As a skilfully planned strategy of a value war, which "redefines the societal division lines," the political opponents of the government are labelled as "traitors," while the loyal followers of the ruling party are recognised as "patriots" (ibid., 366). Palonen $(2018,313)$ also noted that the Hungarian Prime Minister's claims unveil the idea of the "exclusive ownership of the nation."

Quite contrary to the image created about Brussels, the adjectives linked to the Hungarian government convey a completely different image. The consultation makes the impression that the government is successful (Q5) and committed to the people (Q6). Both of these positive characteristics are related to the interest of the nation: job creations and tax cuts.

Besides the two main agents, the dangerously threatening Brussels and the successful and caring Hungarian government, there is one more agent connected to Brussels whose action is modified with an adverb. In the account of the consultation, illegal immigrants 
are described as moving freely (Q2). That is, freedom becomes associated with criminality and danger in the questionnaire. Through directly being connected to dangerous and illegal activities, freedom is depicted as if it was obviously needed to be restricted by the Hungarian authorities. It is striking to what extent the language of the consultation aims at legitimising the restrictive measures of the government.

In conclusion, the manipulative discourse strategy of a positive self-representation and, in turn, a negative other-representation is distinctly observable at a lexical level. 'The Other' is narrated as illegal, non-transparent, and threating, while self-representation boasts of success and commitment to making society flourish.

\section{Conclusion}

\subsection{Findings}

To reach an answer to the research question, to what extent the April 2017 national consultation can be described as manipulative, let us summarise briefly the findings of each layer of the van Dijkean (2006) model as applied to the national consultation. From the social point of view, the lack of balance characterises the discourse of the national consultation with regard to both the participants and to the information shared. Social cognition is also manipulated by creating socially shared fears through generalisations, strong polarisation, the use of false dichotomies, as well as through the lack of disseminating balanced arguments or potentially critical general knowledge. Positive self-representation and negative other-representation is heavily present at a lexical level, regarding both the use of verbs and that of adjectives. The excessive use of the fallacious argumentum ad baculum also increases the manipulative power of the discourse of the consultation. The application of the various rhetorical tools of manipulation at all three levels builds up a strengthened, combined effect of manipulation in the consultation.

\subsection{Further research}

In April 2018, general elections were held in Hungary. The governing party, not having a manifesto, refused to participate in any public debate discussing their own political aims and planned policies. Their not taking part in public discussions has a long and successful history in Hungarian politics. Namely, the Prime Minister already decided not to participate in public debates both before the 2010 and 2014 elections (Müller 2016), both of which he succeeded to win. In Körösényi's $(2018,12)$ observation, the lack of a party manifesto is interpreted to be an alarming sign of the "unambiguous shift from a program-oriented competition towards a personalised campaign". The absence of a policy statement resulted in the governing party's campaigning with the simple slogan 'We continue!' During the campaign of the general elections in 2018, one single 
topic was communicated to the electorate. The singular campaign topic focused on the threatening concerns raised via the issues of the April 2017 national consultation (Qs 2-4). In order to maintain their power, dominant social groups are in dire need of knowledge about the nature of the themes that successfully resound with the public. Agenda setting can close down or open up political dimensions, and the manipulation of issue dimensions can effectively ensure stable results in elections (McLean 2001). The results of the present study about the extensive presence of manipulation in the discourse of the consultation suggest the necessity of further investigations into the issue of whether the consultation itself may have served as a means of ranking the topics and messages the public strongly resonated with.

\subsection{In retrospect}

The CDA method does not investigate whether the intentions of the discourse producer were manipulative but focuses on the social consequences of the discourse. However, State Secretary, Csaba Dömötör's announcement stating that the result ${ }^{27}$ of the survey "clearly shows ${ }^{28}$ that Hungarians do not want Brussels to take away Hungary's right to make strategically important decisions" ${ }^{29}$ reveals that the government's aim of conducting the survey was to gain alleged public support for the implementation of previous and new measures. Keeping in mind the extent of the lack of transparency regarding the conduct of the consultation, reference to solid results can be viewed as a manipulative act, too.

\section{References}

Albertazzi, Daniele, and McDonnell, Duncan. 2008. Twenty-first Century Populism. The Spectre of Western European Democracy. NY: Palgrave Macmillan.

Ádám, Zoltán. 2018. "Authoritarian Populism at Work: A Political Transaction Cost Approach with Reference to Viktor Orbán's Hungary." UCL Centre for Comparative Studies of Emerging Economics (CCSEE) Working Paper Series 2: 1-21.

Ágh, Attila. 2009. “The Hungarian Party System from Soft to Hard Populism.” In Party System Change, The European Crisis and the State Democracy, edited by Marco Lisi, 137-154. New York: Routledge, 2009.

\footnotetext{
${ }^{27}$ According to MTI (Hungarian State News Agency), 1,680,933 people took part in the consultation and ninety-nine (sic!) percent of the respondents backed the government's standpoint of maintaining the country's sovereignty against Brussels. http://abouthungary.hu/news-in-brief/national-consultationproves-hungarian-government-is-going-in-the-right-direction/

${ }^{28}$ In view of the fact that the public has grown sceptical about surveys (Witt 2001) and knowing that "in most real-life situations there will be critical, sceptical, cynical, incredulous or dissident people” (van Dijk 2006, 375), a 99-percent outcome is less than plausibly convincing.

${ }^{29}$ Source: http://abouthungary.hu/news-in-brief/national-consultation-proves-hungarian-government-isgoing-in-the-right-direction/
} 
Aristotle. 1991. Rhetoric. Translated by George A. Kennedy. New York: Oxford University Press.

Dillard, James Price, and Pfau Michael. 2002. The Persuasion Handbook: Developments in Theory and Practice. Thousand Oaks, CA: Sage.

Hohmann, Hans. 2000. "Rhetoric and Dialectic: Some Historical and Legal Perspectives." Argumentation 14: 223-34.

Kastely, James. 2015. Rhetoric of Plato's Republic. Democracy and the Philosophical Problem of Persuasion. Chicago: University of Chicago Press.

Kennedy, George. 1963. Art of Persuasion in Greece. Princeton, NJ: Princeton University Press.

Körösényi, András. "The Theory and Practice of Plebiscitary Leadership: Weber and the Orbán Regime." East European Politics and Societies and Cultures (EEPSC) (2018) DOI: 10.1177/088832 5418796929

Krabbe, Erik C. 2000. "Meeting in the House of Callias: Rhetoric and Dialectic." Argumentation 14: 205-17.

McLean, Iaian. 2001. Rational Choice and British Politics. An Analysis of Rhetoric and Manipulation from Peel to Blair. Oxford: Oxford University Press.

McNight, David. 2018. Populis Now. The Case for Progressive Populism. Sydney: University of New South Wales Press.

Mudde, Cas. 2004. “The Populist Zeitgeist." Government and Opposition 39 (4): 541-563.

Müller, Jan-Werner. 2016. What is Populism? Philadelphia: University of Pennsylvania Press.

Palonen, Emilia. 2018. "Performing the Nation: The Janus-Faced Populist Foundations of Illiberalism in Hungary.” Journal of Contemporary European Studies 26 (3): 308-320 DOI: 10.1080/14782804.2018.1498776

Panizza, Franciso. 2005. Populism and The Mirror of Democracy. London: Verso.

Parker, Douglas H. 1972. "Rhetoric, Ethics and Manipulation." Philosophy E Rhetoric 5 (2): 69-87.

Plato. 1966. Apology. Translated by Harold North Fowler. Vol. 1. 12 vols. Cambridge, MA: Harvard University Press.

Plato. 1967. Gorgias. Translated by W. R. Lamb. Vol. 3. 12 vols. Cambridge, MA: Harvard University Press.

Plato. 1925. Phaedrus. Translated by Harold North Fowler. Vol. 9.12 vols. Cambridge, MA: Harvard University Press.

Plato. 1969. Republic. Translated by Paul Shorey. Vol. $5 \&$ 6. 12 vols. Cambridge, MA: Harvard University Press.

Shils, Edward A. 1956. The Torment of Secrecy: The Background and Consequences of American Security Policies. London, The Free Press.

Simons, Herbert W., Joanne Morreale, and Bruce Gronbeck. 2001. Persuasion in Society. Thousand Oaks, CA: Sage.

Simpser, Alberto. 2014. Why Governments and Parties Manipulate Elections. New York: Cambridge University Press.

Sunstein, Cass. 2007. Republic 2.0. Princeton: Princeton University Press.

Tindale, Christopher W. 2004. Rhetorical Argumentation. Thousand Oaks, CA: Sage.

van Eemeren, Frans H., and Peter Houtlosser. 2001. "Managing Disagreement: Rhetorical Analysis with in a Dialectical Framework." Argumentation and Advocacy 37: 150-57.

van Dijk, T. A. 1995. “Aims of Critical Discourse Analysis.” Japanese Discourse 1: 17-27. 
van Dijk, T. A. 2001. "Multidisciplinary CDA: A Plea for Diversity." In Methods of Critical

Discourse Analysis, edited by Ruth Wodak and Michael Meyer, 95-120. London: Sage.

van Dijk, T. A. 2006. "Discourse and Manipulation." Discourse and Society 17 (3): 359-83.

Walton, Douglas. 2007. Media Argumentation. Dialectic, Persuasion, and Rhetoric. Cambridge:

Cambridge University Press.

Witt, Evans. 2001. "People Who Count." The Public Perspective 12 (July/August 2001): 1-5.

\section{List of Electronic Sources}

Websites of the Hungarian government

http://www.kormanyhivatal.hu/download/b/9a/b3000/vállalkozásiszerződés.pdf

http://www.kormany.hu/en/the-prime-minister/news/national-consultation-to-be-launched-on-

threats-faced-by-hungary

https://hu-hu.facebook.com/kormanyzat/

http://www.kormany.hu/hu/hirek/matol-interneten-is-kitoltheto-a-nemzeti-konzultacios-kerdoiv

http://nemzetikonzultacio.kormany.hu/

http://www.kormany.hu/download/3/8d/01000/NK_2017_A4_v05.pdf

http://www.kormany.hu/hu/hirek/nemzeti-konzultacio-kormanyzati-reakcio-az-europai-bizottsag-allasfoglalasara

http://abouthungary.hu/news-in-brief/national-consultation-proves-hungarian-government-isgoing-in-the-right-direction/

\section{European Union}

https://ec.europa.eu/commission/publications/stop-brussels-european-commission-respondshungarian-national-consultation_en

https://europa.eu/european-union/about-eu/countries/member-countries/hungary_en http://www.epp.eu/press-releases/prime-minister-orban-to-comply-with-eu-laws-and-eppvalues-following-meeting-with-epp-presidency

\section{Reports on Hungary}

BF, Bertelsmann Foundation (2017) Hungary country report, http://www.sgi-network.org/ docs/2017/country/SGI2017_Hungary.pdf

EIU, Economist Intelligence Unit (2017) Democracy Index 2016, http://www.eiu.com/ public/topical_report.aspx?campaignid=DemocracyIndex2016

FH, Freedom House (2017) Breaking Down Democracy: Goals, Strategies, and Methods of Modern Authoritarians, https://freedomhouse.org/report/special-reports/breaking-downdemocracy-goals-strategies-and-methods-modern-authoritarians

\section{Official Requests for Transparency}

https://kimittud.atlatszo.hu/request/nemzeti_konzultacio_2?unfold=1\#incoming-14045 https://kimittud.atlatszo.hu/request/2017_evi_nemzeti_konzutacio_adat\#incoming-13876 https://kimittud.atlatszo.hu/request/a_nemzeti_konzultacio_2017_kerde

\section{Online Newspapers}

https://bbj.hu/politics/hungarian-govt-to-launch-stop-brussels-consultation_130873

https://mno.hu/belfold/nemzeti-konzultacio-konnyu-kijatszani-a-rendszert-2420433

https://mno.hu/belfold/felrevezeto-az-uj-konzultacio-sorosrol-es-terverol-2419168 


\section{Appendix 1}

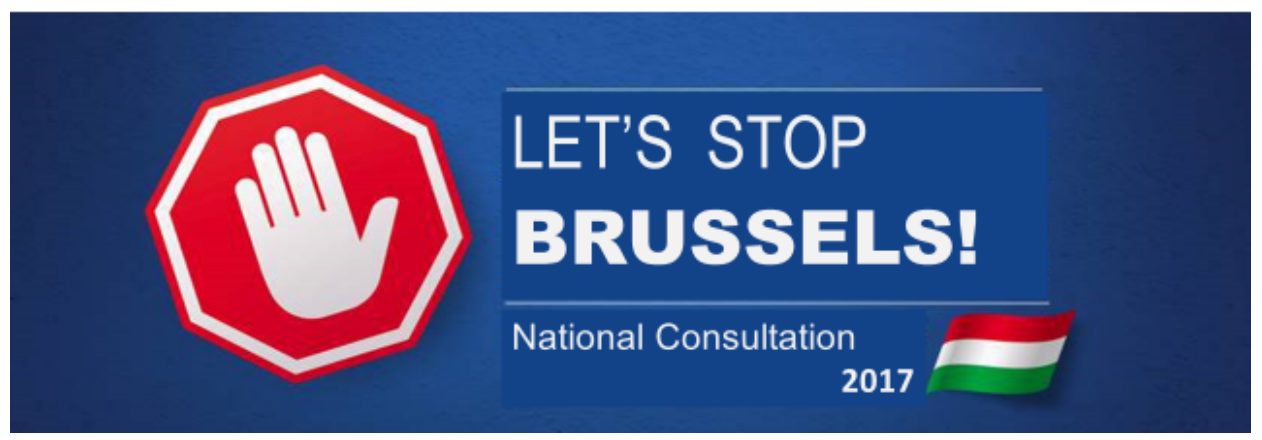

Please, fill in the questionnaire.

1. Brussels is planning to take a dangerous step. It wants to force us abolish the reduction in public utility charges. What do you think Hungary should do?

(a) Defend the reduction in public utility charges. We should insist that the Hungarian price of utilities must be determined in Hungary.

(b) We should accept Brussels' plan and trust large companies with fixing utility prices.

2. In recent times, terror attack after terror attack has taken place in Europe. Still, Brussels wants to force Hungary to let in illegal immigrants. What do you think Hungary should do?

(a) For the sake of the safety of the Hungarian people, illegal immigrants should be placed in detention until authorities decide in their cases.

(b) We should allow illegal immigrants to move freely in Hungary.

3. By now it has become clear that illegal immigrants heading to Hungary are encouraged to illegal acts by not just human traffickers but also by some international organisations. What do you think Hungary should do?

(a) Activities assisting illegal immigration such as human trafficking and the popularisation of illegal immigration should be punished.

(b) We should accept that there are international organisations which, without any consequences, have the right to urge the circumvention of Hungarian laws. 
4. More and more organisations supported from abroad operate in Hungary with the aim to interfere in Hungarian internal affairs in a non-transparent manner. The operation of such organisations could jeopardise our independence. What do you think Hungary should do?

(a) We should oblige them to register and take responsibility for the country or organisation on whose behalf they act and also for their objectives.

(b) We should allow them to continue their risky activities without any supervision.

5. In the last few years Hungary has been successful at job creation because we followed our own strategies. But Brussels is attacking our job-creating measures. What do you think Hungary should do?

(a) We, Hungarians, should continue making decisions about the future of the Hungarian economy.

(b) Brussels should decide what to do in the sphere of economics.

6. Hungary is committed to tax cuts. Brussels is attacking our country because of it. What do you think Hungary should do?

(a) We should insist that we, Hungarians, decide about tax cuts.

(b) We should bow to Brussels dictating tax rates.

Sending the questionnaire back by post is free of charge. 


\title{
Dependency Structures and Beyond: Assembling Drawings of Sentence Construction
}

\author{
Mosang Zhang*
}

\begin{abstract}
This paper aims at proposing a concise system of symbols to be used for assembling drawings in order to illustrate sentence constructions. The assembling drawings, purporting as a supplementary yet more linearized notation of dependency structures, reveal the dynamic process of how chunks are attached step by step according to their semantic dependency relations to form a partial structure which ultimately develops into the complete structure. It is identified by previous researchers that two movements exist within a sentence: the subjective movement and the objective movement, with the former being related to word order, while the latter is related to semantic dependency relations. Concepts of semantic stream and attachment are proposed and symbolised to represent semantic dependency relations and word order respectively, thus the assembling drawings can also represent both movements within a sentence. Sentence construction is ultimately accomplished when all the chunks in the sentence can be integrated, and the semantic streams merge together. The performance of the assembling drawings is investigated and exemplified via a selection of Mandarin Chinese and English sentences.
\end{abstract}

Key words: chunking, dependency, semantic stream, attachment, assembling drawing

* Peking University, Beijing Institute of Technology; zms118@pku.edu.cn 


\section{Introduction}

In this paper, chunks occurring in a sequential order assemble together according to their semantic dependency relations to form partial structures. The partial structure is the processor's interpretation of the uttered language string, presenting the current state, while a transition of the state can be represented by the attachment of another chunk to the current chunk, causing change to this partial structure. A chunk can be a morpheme, word, phrase, or sentence segment.

In sentence analysis, both sentence producer and recipient rely on partial structures. Take the "tip-of-the-tongue", hesitation and regression situation, for instance, when the producer temporarily gets stuck, he/she tends to repeat the previous segment until the next occurs to him/her.

This paper attempts to analyse a number of Chinese sentence constructions, including those with flexible word order and special sentence patterning, as well as English sentences, including those with long sentence patterning.

Previously, much work has been done on dependency parsing. While most of this research is more focused on the relations between words, in a slightly different light, this paper delves into the inner workings of various inter-chunk relationships and creates a concise assembling drawing to illustrate this process.

\section{Basic concepts}

We first attempt to identify some key concepts brought forward in this study, including attachment, semantic stream, subjective and objective movements within sentences, etc. Their features are elaborated as a preparation for proposing a system of symbols and the assembling drawing of sentences.

\subsection{Attachment of chunks}

Attachment: Attachment in this paper refers to the action of attaching a chunk composed of word(s) or morpheme(s) to a partial structure. Since it causes a transition of states, the attachment of a chunk represents a transition.

The precondition of attachment is that there should be a semantic dependency relationship among the components within the two chunks. Furthermore, the posterior chunk could attach to a previous chunk even in such a situation where there are other chunks located in-between without participating in or being affected by their attachment.

Position of Attachment: When a chunk attaches at a certain position to the partial structure, this position is designated as the position of attachment. The position of attachment could span over a certain chunk or a combination of chunks. 
Direction of Attachment: The direction of assembling the current chunk to the partial structure is deemed as the direction of attachment. Attachment itself is an action. The direction of attachment always points from the posterior chunk to a certain previous chunk in the partial structure. It indicates the direction of the movement of ideas which is related to the word order. In English and Mandarin Chinese, it is from the right to the left.

Target of Sentence: If we cut a sentence into two segments at a dividing point, the previous segment, represented by the partial structure, is the target of sentence. The posterior segment attaches to the previous part to form complete structure. The target of sentence is subjective in essence, which relates to the word order. It is always positioned before the dividing point, no matter whether the previous segment imports or exports semantic stream. The target of sentence is the partial structure which the processor pays the most attention to. Typically, within a sentence there is one target of sentence.

\subsection{Semantic stream}

A key concept proposed in this paper is the semantic stream, which indicates the dependency relations among the components within a sentence. Attachment of chunks occurs at the surface, while semantic stream reveals the underlying structure of meaning.

In a sentence, semantic stream flows from modifier to head; from direct object to predicate verb; from indirect object to the combination of predicate verb and direct object. Yet, differing from previous research on dependency relations, this paper has implemented some modifications: semantic stream is one which leads from patient to predicate verb; and from predicate verb to agent. Due to the need of distinguishing the notions of agent as opposed to patient in our system, this regulation differs from previous studies which regard both agent and patient as dependencies to the predicate verb. We hold that since the agent is the cause or initiator of an event, the relationship it bears to the predicate verb is different from that of the patient to the predicate verb. Therefore, distinctions are clarified.

Since the precondition of attachment between two chunks is that there is a semantic dependency relationship between them, to put it otherwise, the attachment chunk should either import or export semantic stream to a previous chunk.

\subsection{Subjective movement and objective movement}

According to Henri Weil in his influential thesis of 1844, syntactic movement is not equal to the movement of ideas. He argues that the movement of ideas is characterised in terms of word order: "the forward movement of our ideas is the natural basis of the order of words" (Weil 1844, 21-22). The movement of ideas is termed subjective movement and the syntactic movement is termed objective movement (Jiang, 2008).

Therefore, in sentence processing, the two simultaneously-occurring movements are in existence: the subjective movement and objective movement. Subjective movement is 
the movement of ideas, which relates to the word order, while the objective movement is characterised in terms of semantic relations between sentence components, which relates to lexical dependency.

\section{Representation of subjective movement: Attachment}

Since the subjective movement is termed by the word order, it can be represented as the sequence of the attachment of chunks to the partial structure. The direction of subjective movement is from the posterior chunk to a certain preceding chunk, thus in English and Mandarin Chinese it is always pointing left.

\section{Representation of objective movement: Semantic stream}

Since objective movement is termed by dependency relations, the semantic relations between sentence components, it can be characterised in terms of semantic stream between chunks. Its direction is in accordance with the direction of semantic stream.

\subsection{Recognition of chunks}

Ever since the word "chunking" was proposed by George Miller in his 1956 work, a tremendous amount of research has been conducted on that topic. In this paper, chunking refers to organising items into familiar and manageable units. A chunk varies from as large as a clause, to as small as a morpheme. The similarity of this system to that of Abney (1995) is that it has been so mediated that no orphan words exist after parsing, and all the words in a sentence can be merged into their corresponding chunks. And after merging, all the chunks are non-overlapping and exhaustive.

The segmentation of a sentence into chunks hinges on the individual long-term memory patterns, as well as the specific task of analysing certain sentence patterning. Sentences can be parsed in varied ways. In fact, a trial parsing can take place during the processing. If the processor fails at a certain point, regression and reparsing take place, which are typical in garden-path sentences.

The success of parsing in this case is marked by the completion, such that the partial structure grows into a complete structure: the assembling drawing contains at least one main chunk with the predicate verb; all chunks can be integrated; and the semantic streams merge together.

\subsection{Constructional elements of assembling drawings}

This paper proposes a system of symbols for the graphic analysis of the relations between chunks within a sentence, namely via assembling drawings. In the drawings, arrows are used to represent the direction of attachment, with the arrow head always pointing to the position of attachment. The tag of semantic stream behind each arrow represents the direction of semantic stream. The tag of semantic stream together with the arrow can represent the attachment and the semantic dependency relations, or to 
put it in another way, the subjective movement and the objective movement. Creating the assembling drawing firstly involves segmenting the sentence into chunks, with state points by each side of the chunk; then numbering each state point from 0 on in a sequential order; the number of a certain chunk is the same as the state point number on its right side. Then the chunk numbers are connected with arrows and other symbols in accordance with their semantic dependency relations, thus the assembling drawing takes shape, revealing the sentence structure as well as the assembling procedure.

\section{System of Symbols}

Having discussed the basic concepts, this section proceeds to propose a system of symbols which serves as a basic set of components for the assembling drawing. In the system of symbols, arrows and tags are applied to denote the previously-mentioned concepts.

\subsection{Chunking and attachment symbols}

Serial number of chunks: The serial number of chunks is defined as follows: the numbers in parentheses denotes the state point, and the numbers without parentheses denotes the chunk. The symbol $(0)$ denotes the state point at the beginning of a sentence, the number of the state point to the right of the first chunk is (1) ... and the number of the state point to the right of the nth chunk is (n). The chunk on the left side of state point (1) is chunk 1; the chunk on the left side of state point (2) is chunk $2 \ldots$ and the chunk on the left side of state point $(n)$ is chunk $n$. Take the sentence "I believe she has come" as an example. A pause is located between "believe" and "she". The sentence is segmented and numbered as follows:

(0) I believe (1) she has come (2).

In this case, chunk 1 is "I believe" and chunk 2 is "she has come".

For combined chunks, take as an example the combination of three chunks (chunk 1, chunk 2 and chunk 3), which is denoted as: $1 \sim 3$.

Main chunk: The chunk carrying the predicate verb is designated as the main chunk, which is signified by a single quotation mark ' appending to its right upper corner. In the previous example, if chunk 1 "I believe" contains the predicate verb, then the symbol 1 ' denotes the main chunk of the sentence.

Direction of attachment: For languages whose writing system is from left to right, such as English and Mandarin Chinese, the direction of an attachment points from the present chunk to a previous chunk in the partial structure. The direction of attachment is denoted by the left arrow $\leftarrow$. 
Main attachment: The vast majority of sentence processing encounters the situation that there is one main attachment in a sentence, denoted by the thick arrow $\leftarrow$ pointing at the target of sentence, which could be a chunk or a combination of chunks, and the segment following the thick arrow is the add-on. Therefore, the attachment in the sample sentence "I believe she has come" can be represented as 1' $\leftarrow 2$

Position of attachment: According to its definition, position of attachment refers to a certain point at which a chunk attaches to partial structure. The position of attachment could be a certain chunk or a combination of chunks to which the left arrow is pointing.

Hierarchy: Square brackets [] are introduced to indicate the boundaries of hierarchical relations among chunks.

\subsection{Tag of semantic stream}

The tag of semantic stream proposed in this system is placed to the right of the arrow.

Export: $\leftarrow \mathrm{e}$ is applied when the posterior chunk exports semantic stream to a previous chunk. The tag of exporting semantic stream is: e.

Import: $\leftarrow \mathbf{i}$ is applied when the posterior chunk imports semantic stream from a previous chunk. The tag of importing semantic stream is: $\mathbf{i}$.

As for the aforementioned sample sentence, the object clause "she will come" is exporting semantic stream to the predicate "believe". Thus, the sentence can be further represented as: $1^{\prime} \leftarrow \mathrm{e} 2$

\subsection{Background chunk and Foreground chunk symbols}

Background chunk reflects a situation where a particular chunk is inserted without participating in or being affected between two adjacent chunks, which directly import or export semantic stream from each other. Yet, this particular background chunk exports semantic stream to both of these two adjacent chunks. The symbolic representation of background chunk is: $\mathbf{b}$. Specific sample sentences will be provided in the next section.

Suppose there are three chunks 3, 4, and 5 lined up in sequence, with chunk 4 acting as a background chunk. Then b4 shall export semantic stream to the combination of 3 and 5 . Suppose chunk 5 exports the semantic stream to chunk 3 in this case.

The assembling drawing is: $3 \leftarrow \mathrm{b} 4 \leftarrow \mathrm{e} 5$

Its equivalent drawing is: $[3 \leftarrow e 5] \leftarrow e 4$

Conversely, foreground chunk reflects a situation where a particular chunk is inserted between two adjacent chunks which directly import or export semantic stream from each other. Yet, this particular foreground chunk imports semantic stream to the two adjacent chunks. The symbolic representation of foreground chunk is: $f$.

Suppose chunks 3,4 , and 5 are lined up in a sequence, with chunk 4 being a foreground chunk. Then $\mathrm{f} 4$ shall import semantic stream to the combination of 3 and 5 . Suppose chunk 5 exports the semantic stream to chunk 3 in this case. 
The assembling drawing is: $3 \leftarrow \mathrm{f} 4 \leftarrow \mathrm{e} 5$

Its equivalent drawing is: $(3 \leftarrow e 5) \leftarrow i 4$

\subsection{Parallel connection and serial connection symbols}

Parallel connection: Parallel connection refers to the parallel relation of two chunks which import or export semantic stream equally to a third chunk. Parallel connection is denoted by the symbol: + . Therefore, the parallel connection of chunk 3 and chunk 4 is designated as: $[3+4]$

Take this sentence as an example:

Sue lent Joe a book, and Ben a paper. (cf. Milward 1991, 28)

This sentence can be segmented and numbered as follows:

(0) Sue (1) lent (2) Joe (3) a book (4), and Ben (5) a paper (6)

After attachment and tagging, it can be designated as:

$$
1 \leftarrow 2^{\prime}[\leftarrow \mathrm{b} 3 \leftarrow \mathrm{e} 4+\leftarrow \mathrm{b} 5 \leftarrow \mathrm{e} 6]
$$

In this sample sentence, background chunk 3 and background chunk 5 are indirect objects in the sentence. The semantic streams gather to chunk 1 by the end. The items of parallel connection in the brackets obey distributive rules, as in Mathematics.

Serial connection: Serial connection refers to two chunks in a sequential order, exporting semantic stream to another preceding chunk, which functions as the cause of their events. Serial connection of chunks is denoted by the symbol ^. Serial connection is applicable in typical Mandarin Chinese sentence patterns, such as the serial predicate construction. For example,

他 怕 麻烦, 马上 走了。

Ta pa mafan, mashang zuole

He fears trouble, immediately left.

This sentence can be segmented and numbered as:

(0) 他 (1) 怕 (2) 麻烦 (3), 马上走了 (4)

After attachment and tagging, the sentence is analysed as follows:

$1 \leftarrow \mathrm{e} 2 \leftarrow \mathrm{e} 3^{\wedge} \leftarrow \mathrm{e} 4^{\prime}$ 
This is a sentence with sequential serial verb construction; with the actions of “走了” following “怕”, which is also the cause of the action “走了”, “怕” and “走了” constitutes the serial predicate construction and the serial connection symbol ${ }^{\wedge}$ is applied in-between.

\subsection{Bracket lock, specific word location, attention cursor symbols}

Bracket lock: The dot at the left side of a semantic tag is intended as a lock of the left bracket, ensuring the integration of the components within the brackets, which as a

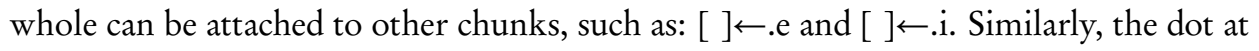
the right side of semantic tag locks up the right bracket, such as: $\leftarrow$ e. [ ] and $\leftarrow$ i. [ ]

Location of word in a chunk: In the assembling drawing, pointing out the location of a particular crucial word in a chunk is occasionally required, for which purpose the denotation of this location is exemplified as follows:

In the sample sentence "I believe she has come", the location of the word "believe", which is the second word in chunk 1 , is designated as: $1 / 2$.

Attention cursor: Attention cursor refers to the indicator showing the current position at which the processor arrives. When the attention cursor reaches a certain state point, the part of the sentence to its left becomes the partial structure representing the state at this point. In the assembling drawing, the symbol @ is used to indicate the current position of the attention cursor.

\section{Application of a system of symbols in the assembling drawing}

We are now in a position to illustrate the interpretation of sentence structures via the assembling drawings of typical examples discussed by previous researchers. The key to illustrate a sentence structure is to demonstrate the attachment of chunks as well as the flow of semantic stream.

Steps for the assembling drawing:

1. Chunking and numbering: the sentence is segmented into chunks, with state points tagged beside each chunk.

2. Attachment of chunks: each state point is assigned a serial number, and the chunk on its left side is assigned the same serial number.

3. Assigning tags of semantic stream: the serial numbers of chunks are connected through tags indicating the inter-chunk relations.

4. Checking for the overall connectedness of the structure: The outcome of this assembling drawing should be one in which all the chunks can be integrated into one, in other words, no isolated chunks exist, and all semantic streams merge together at certain chunk(s) in the end. 
In this system, with the assembling of each chunk into the existing partial structure, the arrow points from right to the left, from the larger-numbered to the smaller-numbered chunk.

Consider the following sentence adapted from Abney (1994), a typical example of parsing by chunks in sentence processing:

1.) When I read a sentence, I read it a chunk at a time.

\section{a. Dependency graph:}

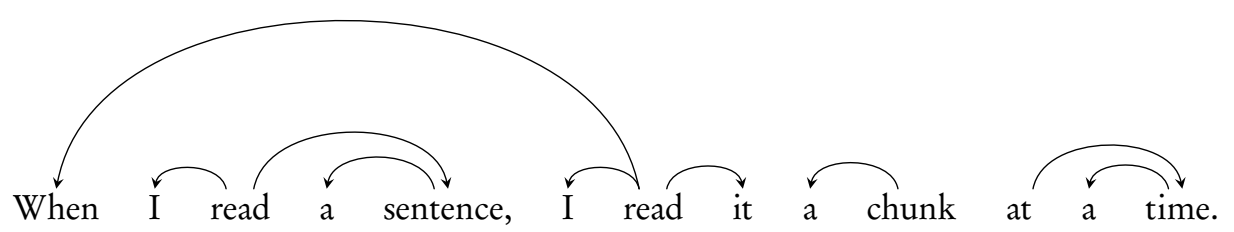

\section{b. Assembling drawing:}

Step one: chunking and numbering

According to Abney (1994), the sentence is segmented as follows:

(0) When I read (1) a sentence (2) I read it (3) a chunk (4) at a time (5)

The words in each pair of round brackets comprise one chunk.

Steps two and three: After attachment of chunks and tagging, the assembling drawing is as follows:

$$
[1 \leftarrow e 2] \leftarrow \mathrm{i} 3^{\prime} \leftarrow \mathrm{e}[4 \leftarrow \mathrm{i} 5]
$$

This assembling drawing indicates that the main chunk 3 "I read it" imports semantic streams from both the combination $[1 \leftarrow \mathrm{e} 2]$ and the combination [ $4 \leftarrow \mathrm{i} 5]$. It reveals the process of parsing by chunks, facilitating sentence comprehension. The more detailed representation of this sentence is:

$$
[1 / 3 \leftarrow e 2] \leftarrow \mathrm{i}^{\prime} \leftarrow \mathrm{e}[4 \leftarrow \mathrm{i} 5]
$$

"a sentence" in chunk 2 is the object of the verb "read" in chunk 3 , the precision of this drawing is specific to the word, with $1 / 3$ denoting the $3^{\text {rd }}$ word in chunk 1: "read".

Step four: Checking for the overall connectedness of the structure:

The outcome of this drawing is one in which all orphaned words are swept into adjacent chunks, all the chunks are integrated, and all semantic streams merge together in chunk 3 at the end. Thus, the analysis is completed. 
Compared with the dependency graph, the assembling drawing presents a concise and linearized representation, which avoids putting arrows on specific words, thus providing more room for illustrating the complex, flexible sentence patterning in a dynamic way.

\section{Semantic streams for resolving ambiguities:}

The following typical examples are intended to present the applications of semantic stream to the resolution of ambiguities. The concept of semantic stream is proposed to enable the concise representation of the inter-chunk relations.

2.) Flying planes can be dangerous. (cf. Chomsky 1965, 21)

Step one: chunking and numbering

(0) Flying (1) planes (2) can be dangerous (3)

Steps two and three: Attachment and tagging

There are two possible assembling drawings for this structurally ambiguous sentence:

A. $[1 \leftarrow e 2] \leftarrow e 3$

B. $[1 \leftarrow \mathrm{i} 2] \leftarrow \mathrm{e} 3$

As Chomsky has pointed out in Aspects of the Theory of Syntax, if the processor can detect the ambiguity of this sentence, his/her intuitive knowledge of the language is such that both of the interpretations (corresponding to "flying planes are dangerous" and "flying planes is dangerous") are assigned to the sentence by the grammar he/she has internalised in some form (Chomsky 1965, 21).

Assembling drawings reveal that the problem lies in the relations between "flying" and "planes": in 'assembling drawing A', the "planes" exports semantic stream to "flying", making "flying" the more weighted part, an action in this case; with "plane" being the patient. In 'assembling drawing B', the "planes" imports the semantic stream from "flying", thus the word "planes" is the more weighted part in this case, and "flying" becomes its modifier, gaining an adjective attribute.

3.) Put the frog on the napkin into the box. (cf. Felser et al 2003)

This is a typical sample sentence in Psycholinguistics to test children's processing of ambiguous sentences. Two possible interpretations can be generated by the attachment of the second proposition phrase, the differences of which can be illustrated with the following assembling drawings: 
Step one: chunking and numbering

(0) Put (1) the frog (2) on the napkin (3) into the box (4)

Steps two and three: Attachment and tagging

Two possible assembling drawings for this sentence are:

A. $1^{\prime} \leftarrow \mathrm{e}[2 \leftarrow \mathrm{e} 3] 1 \leftarrow \mathrm{e} 4$

B. $1^{\prime} \leftarrow \mathrm{e} 211^{\prime} \leftarrow \mathrm{e} 33 / 3 \leftarrow \mathrm{e} 4$

In structure A, the verb "put" takes the big NP "the frog on the napkin", then takes CP "into the box" which indicates the destination of the action. The other interpretation in structure B indicates that both "on the napkin" and "into the box" act as destinations of the verb "put" in a sequential order.

\section{Background chunk:}

Advantageous over dependency graphs, our system gives a specific account of the interrelations among three chunks. The concepts of background chunk and foreground chunk are proposed.

Background chunk is located between two adjacent chunks, which both import semantic streams from the background chunk. The following can be deemed as typical examples involving background chunks.

4). 病人是个近七十岁的老人, 老病加新病, 走路都困难。( cf. Lü 1986)

Bingren shi ge jin qi shi sui de lao ren, lao bing jia xin bing, zoulu dou kunnan.

The patient is an about seventy-year-old person; new disease adding to old disease, even walking is difficult. The patient is an old person about seventy years old, new disease plus old disease makes him in great difficulty even in terms of walking.

Step one: chunking and numbering

(0) 病人 (1) 是个近七十岁的老人 (2), 老病加新病(3), 走路都困难(4)

\section{Steps two and three:}

After attachment and tagging, the assembling drawing is as follows:

$$
1 \leftarrow \mathrm{e} 2^{\prime} \leftarrow \mathrm{b} 3 \leftarrow \mathrm{e} 4
$$

Without chunk 3 , the sentence still has a complete structure. Chunk 3 is inserted in the sentence as a background chunk. 
5). 不过这个过程 有人 长有人 短 罢了。 (cf. Lü 1986)

Buguo zhege guocheng you ren chang you ren duan bale.

Yet this process for someone long for someone short then.

Yet for someone, this process is long; while for the others it is short.

Step one: chunking and numbering

(0) 不过 (1) 这个过程 (2) 有人 (3) 长 (4) 有人 (5) 短 (6) 罢了 (7)

Steps two and three: Attachment and tagging

$$
[1 \leftarrow \mathrm{e}[2 \leftarrow[\mathrm{b} 3 \leftarrow \mathrm{e} 4+\mathrm{b} 5 \leftarrow \mathrm{e} 6]]] \leftarrow \mathrm{e} 7
$$

There is a parallel connection in this sentence structure: “有人长” and “有人短”, in which “有人” is the background chunk in either of these fragments.

\section{Foreground chunk:}

Foreground chunk, however, is located between two chunks which both export semantic stream to it.

\begin{tabular}{|c|c|c|c|}
\hline $\begin{array}{l}\text { 我们 } \\
\text { Women }\end{array}$ & $\begin{array}{l}\text { 路上 } \\
\text { lushang } \\
\text { on the way }\end{array}$ & $\begin{array}{l}\text { 整整 } \\
\text { zhengzheng } \\
\text { entirely }\end{array}$ & $\begin{array}{l}\text { 走了 } \\
\text { zoule } \\
\text { have walked }\end{array}$ \\
\hline
\end{tabular}

We have walked for an entire month on our way.

Step one: chunking and numbering

(0) 我们 (1) 路上(2) 整整 (3) 走了 (4) 一个月 (5)。

Steps two and three: Attachment and tagging

$$
1 \leftarrow \mathrm{b} 2 \leftarrow \mathrm{e}\left[3 \leftarrow \mathrm{f} 4^{\prime} \leftarrow \mathrm{i} 5\right]
$$

This sentence has “整整” emphasised by moving it in front of “走了”. Chunk 4 “走了”, containing the main verb, is the foreground chunk. Chunk 4 imports semantic stream from the combination of both chunk 3 and chunk 5 “整整一个月”.

7). 甭着急, 仗有你们打的。(Lü 1986)

Beng zhaoji, zhang you nimen da de.

Do not worry, battles there will be for you to fight.

Do not worry, there will be battles for you to fight. 
Step one: chunking and numbering

(0) 仗 (1) 有 (2) 你们打的 (3)

Steps two and three: Attachment and tagging

$$
1 \leftarrow \mathrm{f} 2^{\prime} \leftarrow \mathrm{e} 3
$$

Chunk 3 exports semantic stream to chunk 1. Then they export semantic stream to foreground chunk 2, which contains the verb “有”. “仗” is moved to the very beginning of the sentence in order to be emphasised and, in this inverted sentence, chunk 1 is the target of sentence.

\section{Parallel connection:}

Another advantage of assembling drawings is the clarity in representing the parallel structures and serial connection.

Parallel connection refers to the relation between two chunks that import or export semantic stream equally to a third chunk. The following assembling drawing signifies a typical example for parallel connection:

8). 大象 鼻子 长耳朵大。(Lü 1990)

Daxiang bizi chang, erduo da.

Elephant trunk long, ears big.

Elephant has long trunk and big ears.

Step one: chunking and numbering

(0) 大象 (1) 鼻子 (2) 长 (3), 耳朵 (4) 大 (5)

Steps two and three: Attachment and tagging

$$
1 \leftarrow e[2 \leftarrow e 3+4 \leftarrow e 5]
$$

Chunks [2 3] compose a subject-predicate phrase; similarly, chunks [4 5] compose another subject-predicate phrase; [2 3] and [4 5] equally modify chunk 1, the target of this sentence. Therefore, they are parallel structures, connected by the symbol "+”.

\section{Serial connection:}

Serial connection of two chunks refers to a kind of connection in which both chunks in a sequential order export semantic stream to another preceding chunk. The following is the sample sentence for serial connection: 
9). 旧社会, 穷人生了病, 小病抗, 大病躺, 根本得不到医治。(Lü 1986)

Jiu shehui, qiong ren sheng le bing, xiao bing kang, da bing tang, genben de bu dao yizhi.

In the old society, the poor fall ill, a minor illness (they) struggle against, a serious illness (they) lie down, cannot afford any medical treatment at all.

In the old days, when the poor fall ill, they have to struggle against minor illnesses, lie down when they are seriously ill, but they can never have access to medical treatment.

Step one: chunking and numbering

(0) 旧社会 (1), 穷人 (2) 生了病 (3), 小病 (4) 抗 (5), 大病 (6) 躺 (7), 根本得不到医 治 (8)

Steps two and three: Attachment and tagging

$$
1 \leftarrow \mathrm{i}\left[2 \leftarrow \mathrm{e} 3^{\prime}\right]^{\wedge} \leftarrow \mathrm{e}\left[4 \leftarrow \mathrm{i} 5^{\prime}+6 \leftarrow \mathrm{i} 7^{\prime}\right]^{\wedge} \leftarrow \mathrm{e} 8^{\prime}
$$

This is another sample sentence typical of Chinese flexible sentence patterning. Both parallel and serial connections arise in this sentence. [4 5] and [6 7] are parallel structures, connected by the symbol "+". As a whole, [4 7] constitutes a serial connection with [2 3], happening in a sequential order and being caused by the latter; similarly, chunk 8 also results from [2 3], creating another serial connection relationship.

\section{Bracket lock:}

10). 王冕死了父亲。(Shen 2006)

Wang Mian si le fuqing.

Wang Mian died father.

Wang Mian's father died.

Step one: chunking and numbering

(0) 王冕 (1) 死了 (2) 父亲 (3)

Steps two and three: Attachment and tagging

The assembling drawing is as follows:

$$
1 \leftarrow . e\left[2^{\prime} \leftarrow \mathrm{i} 3\right]
$$

In this sentence, the dot on the left side of the semantic stream tag "e" is a bracket lock, indicating that chunk 2 and chunk 3 jointly export semantic stream to chunk 1, since [2 3] “死了父亲” as a whole explains what happens to the person named “王冕”, Chunk 1, placed preceding the thick arrow, is the target of sentence. 


\section{Analysing long English sentences:}

English long sentence patterning is another language phenomenon which the dependency graphs shall find it difficult to cope with, yet this problem can easily be solved with assembling drawings. Consider this example:

11). It may, however, not be out of place to call to it the attention of the teachers of modern languages in secondary schools who, desiring to insure a good pronunciation for their pupils, will find Mr. Passy's book an invaluable handbook and guide with which to broaden and deepen out of their own knowledge the usually rather perfunctory phonetically introductions of the elementary modern language textbooks. Step one: Chunking and numbering

Step one: chunking and numbering

(0) It may (1), however, (2) not be out of place (3) to call (4) to it (5) the attention (6) of the teachers of modern languages in secondary schools (7) who, (8) desiring to insure a good pronunciation for their pupils, (9) will find Mr. Passy's book an invaluable handbook and guide (10) with which to broaden and deepen (11) out of their own knowledge (12) the usually rather perfunctory phonetically introductions (13) of the elementary modern language textbooks (14).

Steps two and three: Attachment and tagging

$$
1 \leftarrow \mathrm{b} 2 \leftarrow \mathrm{e} 33^{\prime} 1 / 1 \leftarrow \mathrm{e} 4 \leftarrow \mathrm{b} 5 \leftarrow \mathrm{e} 6 \leftarrow \mathrm{e} 77 / 3 \leftarrow \mathrm{e} 8 \leftarrow \mathrm{b} 9 \leftarrow \mathrm{e} 1010 / 10 \leftarrow \mathrm{e} 11 \leftarrow \mathrm{b} 12 \leftarrow \mathrm{e} 13 \leftarrow \mathrm{e} 14
$$

The assembling drawing of this long English sentence is composed of three interconnected parts, with the same number indicating the same chunk that is being overlapped. The inter-chunk relations are explicit. Specific words can be indicated in this drawing, "7/3" referring to "teachers", and "10/10" referring to the word "guide" are cases in point. A chunk can comprise only one single word, as is the case with chunk 8 , for example. Therefore, chunking should comply with specific tasks.

\section{Analysing garden paths sentence:}

Garden paths sentences have received much attention for the fact that they lure the processor into a parse that turns out to be a dead end. When used in Psycho-Linguistics, garden path sentences illustrate the fact that when human beings read, they process language one word at a time (cf. Harley 2014). Previous studies on dependency graphs show that they generally provide a static representation. Due to the fact that the processing of the complexity of a garden paths sentence is incremental, the following samples are intended as an investigation into dynamic parsing of garden paths sentences by chunks with assembling drawings: 
12). The complex houses married and single students and their families. (Jurafsky 1991)

In their initial parsing, as Jurafsky (1991) has noted, most readers interpret "the complex houses" as a noun phrase that meets the strong frequency expectation.

Chunking and numbering the part of the sentence at this point provides this:

(0) The complex houses (1)@

The symbol @ denotes the present position of the attention cursor.

Here, the assembling drawing is: $1 @$

Next, as the cursor moves on, it presupposes the word "married" as a verb. At this point, houses cannot get married, a semantic incorrectness arises, and chunk 2 cannot directly attach to chunk 1 , so the attention cursor leaves a question mark (?) between the words "houses" and "married".

At this point, chunking and numbering is as follows:

(0) The complex houses (1) married (2)@

The assembling drawing is: 1 (?) 2

Moving on, the cursor encounters the word "single", "married and single" can modify "students"; hence these three words are encoded into one chunk. Chunk 2 is expanded into "married and single students". Yet it still cannot directly attach to chunk 1 , hence the question mark (?) is retained.

Chunking and numbering at this point provides this:

(0) The complex houses (1) married and single students (2)@

The assembling drawing is as follows: 1 (?) 2

Next, the cursor moves on and encounters "and their families".

Chunking and numbering at this point is as follows:

(0) The complex houses (1) married and single students (2) and their families (3) @

Here, the assembling drawing is as follows: 1 (?) $2+3$

Now that the attention cursor has come to the end of the sentence, no following chunk could possibly rescue the initial partial structure, the question mark (?) is still retained. Chunks cannot be assimilated into one complete structure, signifying that an error exists in the initial parsing. 
At this point, the cursor backtracks from the initial mis-parse to locate the problem and restarts parsing:

"Complex" takes its second meaning as a noun. The string "The complex" is regrouped as a chunk.

The state of chunking and numbering is such:

(0) The complex (1)@

Next, the processor realises that the intended interpretation of "houses" is the thirdperson singular form of the verb.

Chunking and numbering thus are:

(0) The complex (1) houses (2)@

At this point, the assembling drawing is as follows:

$1 \leftarrow 2^{\prime}$

Next, "married and single students" can be encoded it as chunk 3.

Chunking and numbering here becomes:

(0) The complex (1) houses (2) married and single students (3)@

The assembling drawing is:

$$
1 \leftarrow e 2 \leftarrow e 3
$$

Next, "and their families" is identified as chunk 4.

Chunking and numbering becomes:

(0) The complex (1) houses (2) married and single students (3) and their families. (4)@

The attention cursor has arrived at the end of sentence. The final assembling drawing is:

$$
1 \leftarrow e 2^{\prime} \leftarrow \mathrm{e}[3+4]
$$

This drawing indicates that all the chunks have been completely integrated, with the semantic streams merging together. Chunk 2 is the main chunk; and chunk 1 is the target of sentence. The interpretation of the sentence structure has been accomplished. 
While dependency graphs mainly provide static representations, the assembling drawings reveal the step-by-step process of applying dynamic parsing by chunks to garden paths sentences.

\section{Conclusion}

This paper arises from an attempt to provide a concise system of symbols for assembling drawings to give an account of sentence construction in a more linearized fashion than is possible with dependency structures. The concept of semantic stream proposed in this paper is intended as a representation of the semantic dependency relations between chunks, which depicts how the meanings of sentence components are merged together.

Symbols serve as the basic elements for the assembling drawings: arrows and semantic stream tags together embody the attachment relation and the semantic dependency relation between chunks, which are also referred to as the objective movement and the subjective movement; chunk with apostrophes denote the main chunk with the predicate verb; thick arrows point to the target of sentence; square brackets are used to indicate the hierarchy of the sentence; serial connection and parallel connection are also denoted respectively; and the attention cursor symbol is intended to reflect the dynamic process of parsing by chunks. The following table summarises the basic symbols proposed in this study. 


\begin{tabular}{|c|c|c|}
\hline Symbol & Name & Explanation \\
\hline$(0),(1), \ldots(n)$ & Serial number of chunks & $\begin{array}{l}\text { Parenthesis denotes the state point, and the number without paren- } \\
\text { thesis denotes the chunk }\end{array}$ \\
\hline ' & Main chunk & the chunk carrying the predicate verb \\
\hline$\leftarrow$ & Direction of attachment & $\begin{array}{l}\text { The direction of an attachment points from the present chunk to } \\
\text { a previous chunk in the partial structure. }\end{array}$ \\
\hline$\leftarrow$ & Main attachment & $\begin{array}{l}\text { The thick arrow points at the target of sentence, the chunk or com- } \\
\text { bination of chunks to which the processor pays most attention. }\end{array}$ \\
\hline [ ] & Hierarchy & $\begin{array}{l}\text { Indicator of the boundaries of hierarchical relations among } \\
\text { chunks. }\end{array}$ \\
\hline$\leftarrow \mathrm{e}$ & Exporting semantic stream & $\begin{array}{l}\leftarrow \mathrm{e} \text { is applied when the posterior chunk exports semantic stream } \\
\text { to a previous chunk. }\end{array}$ \\
\hline$\leftarrow \mathrm{i}$ & Importing semantic stream & $\begin{array}{l}\leftarrow \mathrm{i} \text { is applied when the posterior chunk imports semantic stream } \\
\text { to a previous chunk. }\end{array}$ \\
\hline $\mathrm{b}$ & Background chunk & $\begin{array}{l}\text { a particular chunk inserted in-between, yet without being affected } \\
\text { by its two adjacent chunks, it exports semantic stream to both of } \\
\text { these two adjacent chunks }\end{array}$ \\
\hline $\mathrm{f}$ & Foreground chunk & $\begin{array}{l}\text { a particular chunk inserted in-between, yet without being affected } \\
\text { by its two adjacent chunks, it imports semantic stream to both of } \\
\text { these two adjacent chunks }\end{array}$ \\
\hline+ & Parallel connection & $\begin{array}{l}\text { the parallel relation of two chunks which import or export seman- } \\
\text { tic stream equally to a third chunk }\end{array}$ \\
\hline$\wedge$ & Serial connection & $\begin{array}{l}\text { two chunks, in a sequential order, exporting semantic stream to } \\
\text { another preceding chunk, which functions as the cause of their } \\
\text { events }\end{array}$ \\
\hline . & Bracket lock & $\begin{array}{l}\text { a lock of the left/right bracket that ensures the integration of the } \\
\text { components within the brackets and, as a whole, can be attached } \\
\text { to other chunks, such as: }[] \leftarrow . \text { e and }[] \leftarrow \text {.i or } \leftarrow \text { e. [ ] and } \leftarrow \text { i. [ ] }\end{array}$ \\
\hline / & Location of word in a chunk & the fifth word in chunk 3 is designated as: $3 / 5$ \\
\hline$@$ & Attention cursor & $\begin{array}{l}\text { the indicator showing the current position at which the processor } \\
\text { arrives }\end{array}$ \\
\hline
\end{tabular}

A comparison between dependency graph and assembling drawings:

1. Assembling drawings are more concise and linearized representations than dependency graphs. In the assembling drawing, chunks are represented through numbers in accordance with the word order, in order to avoid the great complexity of having to tag and create arcs directly on the original sentence.

2. Dependency graphs are basically static analyses, while assembling drawings are dynamic. 
3. Dependency graphs are decoder-oriented while assembling drawings are neutrally oriented between decoder and encoder.

4. Dependency graphs are more word-specific, while assembling drawings are more focused on chunks.

5. In the sample sentences, assembling drawings can more easily represent the semantic relationships among three chunks using labels, such as foreground chunk and background chunk.

Assembling drawings are relatively easy to produce, both in terms of manual charting as well as as computer-based images, via typing in Microsoft Word, for example. For instance, in order to create the arrow which occurs frequently as a representation of the attachment of chunks, it only takes a few steps with an English keyboard. Firstly, you type in the symbol "<", then follow this by typing "- -", which automatically creates the symbol " $\leftarrow$ "; alternatively, if one types in " = =" after the " $<$ ", the thick arrow " $\leftarrow$ " is created.

Building assembling drawings involves four steps: chunking and numbering; attachment of chunks; tagging the semantic streams; and checking for the overall connectedness of the structure. In the final drawing, at least one main chunk with a predicate verb, as well as one target of sentence is involved; all the chunks are finally integrated in one and all the semantic streams merge together at the end.

The system of symbols requires further expansion, defining chunks as specific types representing various special sentence patterns.

The application of assembling drawings provides a fertile ground for sentence analysis, which is left open to be explored in future studies.

\section{References}

Abney, S. 1994. "Partial Parsing.” ANLP-94. Stuttgart.

Abney, S. 1995. "Chunks and Dependencies: Bringing Processing Evidence to Bear on Syntax." Computational Linguistics and the Foundations of Linguistic Theory. CSLI.

Chomsky, N. 1965. Aspects of the Theory of Syntax. Cambridge: MIT Press.

Felser, C., T. Marinis, and H. Clahsen, H. 2003. "Children's Processing of Ambiguous Sentences: A Study of Relative Clause Attachment.” Language Acquisition, 11: 127-63.

Harley, T.A. 2014. Psychology of Language, from Data to Theory, 4th edition. Hove, UK: Psychology Press.

Jiang, W.Q. 2008. "Transmutations of the Concept of Theme.” Contemporary Linguistics II (In Chinese). Beijing: Foreign Language Teaching and Research Press.

Jurafsky, D. 1991. “An On-line Model of Human Sentence Interpretation.” Proceedings of the 13th Annual Conference of the Cognitive Science Society (COGSCI-91): 449-454.

Kempson, R. 2001. Dynamic Syntax: The Flow of Language Understanding. Oxford: Blackwell. 
Lü, S.X. 1986. "Flexibility of Chinese Sentence Patterns." Studies of the Chinese Language (In Chinese). Changsha: Hunan University Press.

Lü, S. X. 1990. "Formation and Elimination of Ambiguities." Collected Essays by Lü ShuXiang (in Chinese), Vol 3. Beijing: The Commercial Press.

Ma, X. Z. and F. Xia. 2014. "Unsupervised Dependency Parsing with Transferring Distribution via Parallel Guidance and Entropy Regularization.” ACL: 1337-1348.

Miller. A. G. 1956. "The Magical Number Seven, Plus or Minus Two: Some Limits on our Capacity for Processing Information.” The Psychological Review, 63(2): 81-97.

Milward, D. 1991. Axiomatic Grammar, Non-Constituent Coordination, and Incremental Interpretation. $\mathrm{PhD}$ thesis, Cambridge: University of Cambridge.

Milward, D. 1994. "Dynamic Dependency Grammar." Linguistics and Philosophy, 17: 561-605.

Nivre, J. 2008. “Algorithms for Deterministic Incremental Dependency Parsing.” Computational Linguistics, 34: 513-553.

Purver, M. \& R. Kempson. 2004. “Incremental Parsing, or Incremental Grammar?” Proceedings of the ACL Workshop on Incremental Parsing: Bringing Engineering and Cognition Together: 74-81.

Shen, J.X. 2006. "Generation of the Sentence 'Wangmian sile fuqing': On the Blending of New Patterns of Chinese Sentence Construction.” Studies of the Chinese Language (In Chinese), 4: 291-300. Changsha: Hunan University Press.

Tiedemann, J. 2015. "Improving the Cross-lingual Projection of Syntactic Dependencies." Nordic Conference of Computational Linguistics NODAL-IDA 2015: 191.

Wang, L. 1956. "Definition of Subject and its Application in Mandarin Chinese." Chinese Learning (In Chinese): 271-285. Shanghai: Central China Book Company.

Weil, H. 1844. De Vordre des Mots Dans les Langues Anciennes Comparées aux Langues Modernes. Thèse Principale Française, Paris. 


\title{
Conceptual Metaphors in Donald Trump's Political Speeches: Framing his Topics and (Self-)Constructing his Persona
}

Kateryna Pilyarchuk* \& Alexander Onysko**

\begin{abstract}
This study investigates the use of conceptual metaphors by Donald Trump in three important political speeches on his way to the US presidency: the acceptance speech of his candidacy, the victory speech on election night, and his inaugural address as president of the US. The consistent analysis of all the metaphors in the speeches shows that Trump relies almost exclusively on conventional conceptual metaphors that are expressed by conventionalised metaphorical expressions. Nevertheless, a range of metaphors appears as constitutive to his framing of political topics, such as immigration and the economy. In addition, Trump metaphorically constructs his political persona as that of a repairman, builder, healer, and warrior, among others.
\end{abstract}

Key words: conceptual metaphor, political discourse, Donald Trump, political speeches

\footnotetext{
* Alpen-Adria-Universität Klagenfurt; kabiletska@edu.aau.at

** Alpen-Adria-Universität Klagenfurt, Department of English; alexander.onysko@aau.at
} 


\section{Introduction}

Trump creates the aura of a super-male talking in abrupt sentences, 'barking', recycling the same words over and over again; he bullies and wants everything that is 'number one'. (Lakoff R. 2017, 598)

The year 2016 has witnessed the success of a highly controversial and unusual political persona - Donald Trump - who became the $45^{\text {th }}$ President of the US. His populist ideas, presumed closeness to the average citizen, and loud statements, such as "I alone can fix it", propelled him to the presidency despite only few political experts believing that he would have serious chances against Hillary Clinton. Trump seems to fit the now popular assumption that people no longer care about politics and instead prefer to be entertained (De Landtsheer et al. 2008, 228). Considering Trump's anti-intellectual use of language (cf., e.g., Degani 2016) questions arise whether metaphors play a role in his political speeches, and, if so, to what extent and in which functions he uses them.

According to Santa Ana (1999), metaphors encountered in political discourse are reminiscent of the now classical love metaphors described in detail by Lakoff and Johnson (1980, 195): they facilitate human understanding of complex concepts by explaining them via bodily experiences and the physical senses. As such, conceptual metaphors in political discourse help to both direct and constrain the audience's understanding by drawing on certain metaphorical themes. Since it is now a widely known fact that people's voting decisions are frequently linked to mental heuristics, or shortcuts, where an individual attends to only one aspect of a problem while ignoring others (Lau \& Redlawsk 2001), aptly used metaphors may help a politician to have the public focus only on those shades of the issue that are favourable for him or her (cf. Bougher 2012, 146). For instance, when deciding whether to vote for Donald Trump, a person may use analogy and resort to one's own experience and background knowledge about the Republican Party that this candidate represents, evaluating the policy of this party and assessing previous Republican presidents. This background knowledge is then enhanced by how a particular candidate presents him- or herself and what her/his political persona looks like. In the case of Trump, metaphors can help to influence voter preferences as in TRUMP IS A WARRIOR ("I will fight for you, and I will win for you; I will fight for you with every breath in my body" ${ }^{\prime 1}$ ), which conceptualises him as a strong, decisive leader and as a warrior who will stand for his people.

In general, metaphor in political discourse has previously been described to bear the following functions: supporting political positioning and ideology, creating a 'myth', increasing emotional effects, and establishing the speaker as a desirable candidate (CharterisBlack 2006, 567). Metaphor can reverberate the rhetorical dimensions of logos, pathos and ethos. The communication of a political ideology is not necessarily based on purely

\footnotetext{
1 This and other illustrative sentences are taken verbatim from Trump's acceptance speech (AS), victory speech (VS), and inauguration address (IA).
} 
factual reasoning. Instead, it overlaps with the pathos component so that reason is framed in a discourse that can leverage particular emotions. In Trump's case, this happens when he applies ANIMAL metaphors (see Section 4.1.3) to evoke fear and distrust towards all immigrants, presenting them as dangerous, wild, and uncontrolled.

According to Mio (1997, 122), one of the major aims of metaphors is to connect the logical (logos) with the emotional (pathos). If a politician embeds metaphors into his or her discourse, they are seeking to frame problems and advocate for a certain course of solutions (Stone 1988). Thus, when Trump, in his acceptance speech (AS), says "Middle-income Americans and businesses will experience profound relief" (metaphor: TAXES ARE PAIN), he understands that it would resonate with the group of citizens tired of paying high taxes. In this case, as well as in the metaphor IMMIGRANTS ARE ANIMALS (see Section 3), Trump diverts attention from other issues and hyperbolises the frames of suffering and fear. According to Van Dijk (2006, 365-66), this is how manipulation in discourse works: since short-term memory is mostly involved in interpreting the meaning of clauses, sentences, and texts when listening to or reading a message, one can easily influence the order of this processing by selecting a bigger font or reiterating certain ideas many times. Trump's constant reference to the same domains ensures that his listeners pick up these metaphors as central. While short-term memory is involved in deciphering the meaning of a text, long-term memory plays a role in the formation of attitudes and opinions (ibid., 367). Thus, if people hear that IMMIGRANTS ARE ANIMALS many times, they are likely to build this ideological model in their mind.

As these initial examples indicate, this article discusses Donald Trump's use of metaphors in his political speeches at the dawn of his presidential career and analyses how they contribute to framing his statements, to influencing his voters, and to building his political image. The study first discusses the data and methodological concerns regarding conceptual metaphors found in the corpus. This is followed by a section on general findings, which includes a discussion on the number and types of metaphors as well as on their significance in the selected speeches. Section 4 focuses on how certain metaphors in Trump's discourse are employed to frame important topics that are on his political agenda. The last section is concerned with how Trump metaphorically constructs his political persona.

\section{Data and methodology}

Virtually every election campaign is characterised by public speeches, during which candidates outline their plans, present their vision for the country's future, and try to persuade the audience to vote for them. The first important address that the candidates deliver to the citizens in the US is their acceptance speech. This speech is crucial as it defines to a considerable extent whether the orator is perceived as competitive and whether she or he has something better to offer than the opponents. Further important 
speeches for incumbent US presidents are the victory speech and the inaugural address. By and large, these are key moments of image construction and persuasion, and they usually abound with various rhetorical strategies and figures of speech, such as repetition, inversion, anti-thesis, and allusions, to name just a few (Schoor 2015, 82-83). Since this paper is concerned with conceptual metaphors, other rhetorical elements will only be taken into account if they are important for the discussion of metaphors.

As mentioned above, our analysis focuses on three key speeches delivered by Donald Trump in the 2016 presidential race: at the beginning of his election campaign, upon his victory, and when he was inaugurated as president. The speeches were obtained from the $\mathrm{CNN}$ website: ${ }^{2}$

1. Donald Trump's Nomination Acceptance Speech (22 July, 2016);

2. Donald Trump's Victory Speech (9 November, 2016);

3. Donald Trump's Inaugural Address (21 January, 2017).

These key moments serve as a basis to examine Trump's use of metaphors in terms of their frequency, uniqueness, and context of occurrence. The particular aim of the study is to find out whether metaphors help to define his dominant political themes and whether they are constitutive to his identity as a politician. How Trump shapes his persona and agenda metaphorically is crucial since, in political discourse, metaphors are known to be powerful persuasive tools (e.g. Charteris-Black 2006, 565; Van Dijk 2006, 361). From a more general perspective, conceptual metaphor analysis in political discourse fits in the wider frame of discourse analysis (cf. Van Dijk 2006) as political persuasion is situated in the interplay of text and language (the discourse aspect) with the social context and its representation in the mind (the cognitive aspect).

In order to identify metaphors in the three speeches, we adopted Conceptual Metaphor Theory (CMT) and applied the Pragglejaz method (Pragglejaz Group 2007; Steen 2007). Conceptual metaphors were described by partly drawing on already established sourcetarget domain descriptions and by postulating new ones as contextually appropriate. In detail, our methodological procedure consisted of the following steps: The speeches were first read without trying to identify the metaphors, rather focusing on the context, tracking Trump's ideas and establishing his message and rhetorical strategies. During the second reading, each article was divided into what Steen $(2007,21)$ refers to as "discourse units". Focusing only on content words, the third step consisted of identifying metaphorical phrases and going through the 5 -step procedure suggested by the Pragglejaz Group (2007). Finally, metaphors were postulated and divided into respective

\footnotetext{
2 - Acceptance Speech (AS):

https://edition.cnn.com/2016/07/22/politics/donald-trump-rnc-speech-text/index.html

- Victory Speech (VS):

https://edition.cnn.com/2016/11/09/politics/donald-trump-victory-speech/index.html

- Inaugural Adress (IA):

https://edition.cnn.com/2017/01/20/politics/trump-inaugural-address/index.html

All last accessed in August 2018
} 
categories, such as person/object/building/machine metaphors. All metaphors were inserted into a table along with the discourse units in which they occurred and the speech in which they were found (see Appendix B). For the general analysis, a frequency table was designed, which shows the total number of metaphors in the three speeches, the number of metaphors in each speech, the number of metaphors that occur only once, and the frequency of metaphors per number of words (see Appendix A and Figure 1). These basic figures summarise the findings and provide an overview of the results. The conventionalised or 'dead' metaphors are not paid much attention to in the qualitative analysis, which focuses on themes in Trump's speeches and on the (metaphorical) construction of his political image.

\section{Findings and General Discussion}

The conceptual metaphors found in the three speeches were categorised according to their source domain, and a basic frequency analysis was conducted. The total number of metaphors amounts to 346, of which 235 (67.9\%) are hapax legomena (i.e. used only once in all the three speeches). In detail, the acceptance speech (AS) contains 211 metaphors, the victory speech (VS) 65 metaphors, and the inaugural address (IA) 70 metaphors. When normalising the frequency of the metaphors according to text length, there is not much of a difference between the speeches: 1 metaphor per 24.2 words $(4.13 \%)$ in AS, 1 metaphor per 24.9 words (4.02\%) in VS, and 1 metaphor per 20.63 words (4.85\%) in IA (see Appendix A). 
Figure 1 shows the 17 categories of conceptual metaphors and their share in the total pool of metaphors.

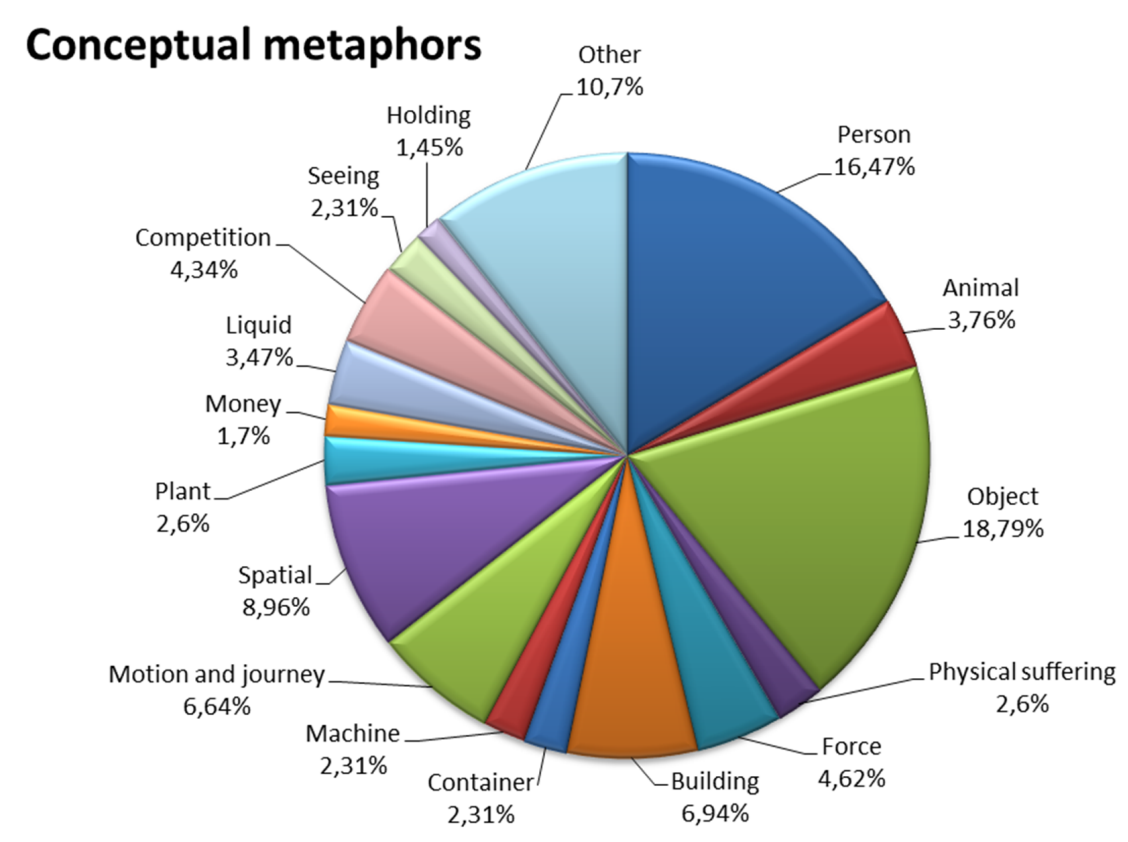

Figure 1: Types of conceptual metaphors (by source domain) in the three speeches

As Figure 1 shows, the biggest groups comprise conventional metaphors with person, object, building, and motion as source domains. The entire list of 346 metaphors is included in the Appendices to provide a general overview of the collected data. While analysing every metaphor clearly lies beyond the scope of the study, it also makes more sense to pay attention to those metaphors that carry a specific purpose in the discourse, in line with Charteris-Black's (2012) notion of 'purposeful' metaphor. Since the political speeches are carefully planned, the metaphors should be discussed in light of the potential aims they pursue such as influencing the audience's attitudes and beliefs, establishing rapport with the public, criticising an opponent, creating an image of a certain type of political persona, and so on. In this sense, it is only of secondary importance whether a metaphor is conventional or not as long as it can be tied to a function in the political speech. According to Pawelec $(2006,118)$, conventional metaphors can be "revitalized" in discourse (cf. Van Dijk 2006 for a cognitive approach in discourse analysis). In our study, some of the person and object metaphors indeed contribute to the construction of Trump's political persona (see Section 5).

Returning to Figure 1, the rest of this section will provide a brief overview of the 17 source-domain categories of conceptual metaphors found in Trump's speeches, beginning with the most frequent types. 


\section{(1) Oвject Metaphors}

In total, 65 metaphors in the data involve instances of objectification, which is arguably one of the most basic types of conceptualisations. Some of the metaphors in this category (e.g., AN OATH IS AN OBJECT) are highly conventionalised, and it is quite unlikely that Trump pursues any particular communicative goal when he uses this metaphor as in "when I take the oath of office" (AS) or "The oath of office I take today" (VS).

On the other hand, the statement "We cannot afford to be so politically correct anymore" (AS), where POLITICAL CORRECTNESS is AN EXPENSIVE ITEM, implies Trump's image of a business person. Similarly, the metaphorisation of PEOPLE AS OBJECTS in "to put the great miners and steel workers of our country out of work" (AS) and "we will put millions of our people to work" (VS) contributes to creating an image which shows that he is in control and can "move" people back into employment.

\section{(2) Person Metaphors}

In this category, the most frequent metaphor is NATION IS A PERSON (26 instances). This can be regarded as a conventional metaphor in political discourse (cf. e.g., Musolff 2010) that reflects basic beliefs about the concept of the nation as a human body and it influences how we perceive messages that contain this metaphor. When Trump says "A nation in mourning" (AS) or "Trade deals that strip us of our jobs, and strip us of our wealth as a country" (AS), he evokes the image of a nation as a sad person; and when he says "We will always put America's interests first" (VS) and "We will seek friendship and goodwill with the nations of the world" (IA), he proposes solutions regarding how to make this ‘sad person' happy again.

In other examples, the physicality of the body (see Ferrari 2007: 615) is at the centre of the metaphor. In expressions such as "Now it is time for America to bind the wounds of division" (VS), and "the crime and violence that today afflicts our nation" (AS), the nation appears as a body experiencing pain, wounds, and mutilation. The same level of conceptualisation is also evident in the metaphor MILITARY IS A PERSON, for which Trump uses the recurrent image of depletion: "our depleted military" (AS), and "depletion of our military" (IA). These metaphors are effective in the emotional dimension as they picture a suffering, bleeding, and wounded body - something that can impress the audience more deeply than an inanimate object or an abstract concept.

Finally, drawing on the POLITICIANS ARE SERVANTS metaphor, Trump frames politics as service to the people. Interestingly, he does not explicitly picture himself as a servant but rather draws on the discursive 'we versus them' dichotomy, like in "My opponent would rather protect bureaucrats than serve American children" (AS). In such a way, he kills two birds with one stone: he positions himself as a servant (which, in his view, Clinton is not) and accuses Clinton of being with 'the elite' rather than the people. 


\section{(3) Spatial Metaphors and (4) Motion and Journey Metaphors}

SPACE and MOTION occur as further fairly frequent source domains in the data. This is not surprising since spatial orientation, just like motion, are very basic image schematic experiences that can play a role in complex conceptualisations. The metaphors CHANGE IS MOTION, FUTURE IS AHEAD, and MORE IS UP are some of the most frequent in the data. Further examples draw on the conceptualisation of sUPPORT IS PROXIMITY (e.g., "Tonight, this candidate and the whole nation stand in their corner to support them", AS), which implies the metaphor of a POLITICAL CONTEST is A BOXING MATCH. Spatial and motion metaphors can also underlie highly conventionalised, idiomatic expressions, such as "I will never, ever let you down" (IA), which expresses the metaphor of DISAPPOINTMENT Is DOwN. In general, these highly conventionalised spatial and motion metaphors can contribute to building Trump's image as a political persona (see Section 5).

In the acceptance speech, Trump uses the metaphor of cyclical motion to talk about human trafficking and violence as well as poverty:

(1) HUMAN TRAFFICKING AND VIOLENCE IS A CYCLICAL MOTION ("the cycle of human smuggling and violence"; AS)

(2) POVERTY IS A CYCLICAL MOTION ("to escape the tremendous cycle of poverty that they're going through"; AS)

These metaphors are close to journey metaphors, which in this article are seen as a subcategory of motion metaphors. LOVE IS A JOURNEY is probably the most well-known metaphor postulated by Lakoff and Johnson (1980). The fact that we imagine life, love, and progress in general as motion in space does not need further comment here. Trump does not draw on the source domain of JOURNEY particularly often in the three speeches. There are three conventionalised references to life is a journey (e.g., "the way of life"; AS) which are accompanied by the genre-specific common metaphorical theme of AN ELECTION CAMPAign IS A JOURNey (e.g., "this 18-month journey"; VS).

\section{(5) Building Metaphors}

The $5^{\text {th }}$ most frequent category of metaphors relying on BUILDING as a source domain emerges from another habitual way of metaphoric thinking. In political discourse, the NATION IS A BUILDING metaphor is a popular rhetorical figure. In the context of Trump's speeches, the BUILDING source domain is of particular importance as it contributes to the construction of his political persona (see Section 5).

\section{(6) Animal Metaphors}

In the data, animal metaphors may be subdivided into three categories:

1. when talking about immigrants and terrorists as in IMMIGRANTS ARE ANIMALS (e.g., "Illegal immigrants with criminal records (ordered deported from our country) are tonight roaming free"; AS). This metaphor is repeatedly used by Trump (see Appendix A). 
2. directed against his opponent: "They are throwing money at her" (AS), implying the metaphor of WASTING IS THROWING A PRECIOUS OBJECT TO AN ANIMAL.

3. in relation to success and hard work: e.g., "I will harness the creative talents of our people" (VS). In this case, TALENTS are metaphorised as DRAFT HORSES.

Among these metaphors, IMMIGRANTS ARE ANIMALs has been analysed in a different context by Santa Ana (1999), who concludes that political discourse generally lacks positive metaphorisations of immigrants. Charteris-Black $(2007,565)$, on the other hand, finds a dichotomy of immigration metaphors: either relating to the positive phenomenon of an increasing birth rate and of helping to overcome the problem of an ageing population or in relation to negative scenarios as leading to unemployment and danger. Since these categories will serve as a point of analysis in the subsequent section, no detailed discussion will be offered here.

\section{(7) Physical Suffering Metaphors}

This category is used by Trump to portray certain issues as painful in his discourse, such as immigration (IMMIGRATION IS PAIN in e.g., "relieffrom uncontrolled immigration"; AS), high taxes (TAXES ARE PAIN in e.g., "Middle-income Americans and businesses will experience profound relief"; AS), bad economic decisions (FINANCIAL LOSS IS BLEEDING in e.g., "subsidized the armies of other countries while allowing for the very sad depletion of our military"; IA), and social division (SOCIAL DIVISION IS A WOUND in e.g., "Now it is time for America to bind the wounds of division"; VS).

Among these metaphors, the term relief is particularly conventionalised. The expression tax relief has dominated Republican political discourse since the Bush (senior) administration and has turned into an emblematic phrase of Republican moral politics (Degani 2015, 181).

\section{(8) Force Metaphors}

The dominant metaphor in this category is DIFFICULTIES ARE OPPOSING FORCES ("the growing threats we face from outside the country"; AS and "We will face challenges"; IA). This is another example of a conventional metaphor that is verbalised in very common expressions. The source domain of FORCE shares some similarity to that of PHYSICAL SUFFERING in Trump's speeches. In both cases, he creates negative metaphoric references to immigrants (3) and to problems supposedly created by his predecessors (4):

(3) "They are being released (by the tens of thousands into our communities) with no regard for the impact on public safety or resources" (AS)

(4) "Not only have our citizens endured domestic disaster, but they have lived through one international humiliation after another" (AS)

By contrast, the source domain of FORCE bears positive metaphoric implications in relation to patriotism (PATRIOTISM IS A FORCE), which Trump claims for his political agenda: 
(5) “A new national pride will stir our souls, lift our sights, and heal our divisions" (IA)

This phrase is mentioned close to the end of Trump's brief inaugural address, where he portrays patriotism (symbolically captured by the American flag) as a uniting power that holds for Americans of all origins and creeds ("we all enjoy the same glorious freedoms, and we all salute the same great American Flag”; IA). What might superficially appear as a message of egalitarianism, is actually tied to the image of all Americans saluting their national flag, i.e. being united by a common action of greeting a symbol of authority. This is not egalitarianism that grows among the people but reinforces a generally Republican vision of authority in governance (i.e. Strict Father Morality, see Lakoff G. 1996).

\section{(9) Container Metaphors}

As one of the 'root metaphors', the container metaphor implies boundaries that separate the inside from the outside of a container. In politics, this image is often applied in the sense that something is closed and needs to be kept this way; any leakage or spill overs have to be prevented (cf. Stone 1988). Chilton $(2004,118)$ discusses the conceptualisation of a country as a closed container (NATION/COUNTRY IS A CONTAINER) where everything that is inside is presumably good, and anything on or from the outside is bad. In Charteris-Black's (2007) point of view, the CONTAINER metaphor is particularly persuasive because it blends the concepts of TIME and SPACE implying that CONTROL OVER SOCIAL CHANGE IS CONTROL OVER MOVEMENT OF PEOPLE, something that holds true in the case of 'refugees' and 'drugs' in our data:

(6) "existing massive refugee flows coming into our country"; (AS)

(7) "to stop the drugs from pouring into our communities"; (AS)

The movement of people and harmful substances from the outside 'weakens' the walls of the container (cf. Charteris-Black 2007: 577). Examples (6) and (7) show that Trump uses the CONTAINER metaphor to say that it is safe inside the container of the US and threatening outside, which underlies the physical manifestation of building a wall to "protect” the US (cf. Chilton 2017, 585).

More rarely, Trump uses the THE US IS A CONTAINER metaphor in the reverse sense. This is the case when beneficial substances (as valuable possessions) are said to flow into the nation (e.g., "trillions of dollars will start flowing into our country"; AS).

\section{(10) Machine Metaphors}

The MACHINE metaphor is often applied to describe the unity and integrity of components. An example of that is the clock, which is a self-regulatory system where the tiniest parts are in harmony (Ezrahi 1995, 312). In his acceptance speech, Trump evokes the SOLVING PROBLEMS IS FIXING A MACHINE metaphor 5 times, using the lexical expression 
of fixing something (e.g., "we are going to fix the system", and "we can fix this problem so quickly"). Describing a nation as a machine, a mechanism where every single part matters, is likely to have strong influential power on the people, who want to participate in growth of their nation and feel their own value. This metaphor contributes to Trump's image as discussed in Section 5.

\section{(11) Plant Metaphors}

Trump conceptualises money as a plant to speak about abundance: MONEY ARE CROPS ("A small group in our nation's Capital has reaped the rewards of government"; IA), or A LOT OF MONEY IS AN ABUNDANCE OF LEAVES ("Secretary of State rakes in millions and millions of dollars"; AS). He also falls back on the conventional metaphor of weeds to refer to unwanted entities that are conceptualised as being invasive: TERRORISM IS A WEED (e.g., "radical Islamic terrorism, which we will eradicate completely"; IA). Some other metaphors in this domain contribute to the building of his image as a politician (see Section 5).

\section{(12) Money Metaphors}

The source domain of MONEY is used to present Trump as a business mogul, who measures everything for its financial value. Examples in this category emphasise once more his discursive reliance on conventional metaphorical themes, which are expressed by highly conventional lexical means. This is evident in the use of the metaphor TIME Is MONEY (e.g., "time I have spent with the mothers and fathers"; AS, or "spent my entire life in business"; VS), which is deeply rooted in the US culture (see Lakoff \& Johnson 1980, 7-9), in PERSONAL RELATIONS ARE BUSINESS (e.g., "we will deal fairly with everyone"; VS), and in GRATITUDE IS MONEY ("we owe her a major debt of gratitude"; VS). In addition, Trump uses the money domain non-metaphorically to establish an analogy between his own persona as a "successful" business man and his function as head of state ("I have made billions of dollars in business making deals - now I'm going to make our country rich again" in AS is just one out of many examples).

\section{(13) Liquid Metaphors}

Our study is in line with the findings by Charteris-Black (2007: 569), who observes that 'fluids', like natural disasters, frequently shape the theme of immigration and that the FLUID and the CONTAINER domains interact in that imagery. In Trump's discourse the country is conceptualised as a container that needs to be protected from WATER/FLOOD from the outside, which is instantiated in the metaphor VIOLENCE IS AN OVERFLOwING LIQUID (e.g., "violence spilling across our border"; AS).

\section{(14) Competition Metaphors}

As Gibbs $(2015,279)$ observes based on the results of empirical studies, people perceive politics as a competitive sport, in particular as a boxing match. This is most of all true 
of political debates during election campaigns. While our data also contains a number of metaphors that draw on the imagery of competition, we only pay close attention to those metaphors that concern the self-representation of Trump, as in TRUMP IS A WARRIOR (e.g., "I will fight for you with every breath in my body"; IA).

\section{(15) Seeing Metaphors and (16) Holding Metaphors}

The source domains of SEEING and HOLDING give rise to metaphors that structure basic conceptualisations of mental states. In our data, however, metaphors such as BELIEving IS SEEING Or UNDERSTANDING IS HOLDING do not contribute to the framing of themes or to building Trump's image. They are listed in the Appendices as part of the complete analysis but will not be discussed further.

\section{(17) Other Metaphors}

This last category accommodates the metaphors that only occur once or a couple of times so that they do not form separate groups in the data. Since the scope of this article does not allow for a detailed analysis of each of these 37 items, the most important ones will be incorporated into the further analysis of themes and the self-representation of Trump's political persona in the sections that follow.

In general, the overview of the different metaphor types (classified by their source domains) that occur in Trump's three key political speeches on his way to the US presidency indicates that his discourse relies on conventionalised metaphors which are often conventionally expressed. In this sense, Trump's use of metaphors falls in line with a common characteristic of political discourse as already observed some time ago by Edelman (1964, 124-125). He notes that politicians tend to repeat "clichés and stale phrases" which reinforce latent beliefs or reference frames (also see Mio 1997 for a discussion of conventionalised metaphors in political discourse). Among the range of metaphors that can be detected in Trump's speeches, those are of particular interest which reflect his framing of certain political ideas and which help to create the image of his political persona. Sections 4 and 5 will focus on these aspects.

\section{Themes in Trump's Discourse}

This section analyses dominant themes that Trump addresses in the selected speeches with a particular focus on the metaphors he uses. Trump's discourse is in line with the Strict Father Morality characteristic of Republican moral politics (cf. Lakoff G. 1996, 187-194) when he talks negatively about immigration and taxes (see Section 4.1). His messages also reflect populist ideas (cf. Wodak 2015; Oliver \& Rahn 2016), and some of the metaphors discussed in the following are further examples of that. Chilton (2017, 592) defines populism as "a discourse that works by activating emotion-laden and valueladen schematic concepts and concomitant emotions, rather than using overt argument 
and evidence". Metaphors can contribute to populist discourse since they help to create emotions and to evoke value-laden associations in the audience.

\subsection{Otherness: Other Nations and Immigration}

\subsubsection{The Frame of Fear}

The populist discourse in Europe and America is currently associated with threats coming from 'others', immigration as a negative phenomenon, and the need to prioritise citizens over immigrants when distributing jobs (cf. Wodak, 2015). Thus, 'we' is always strongly emphasised and 'they' are demonised as part of a nationalist agenda (Oliver \& Rahn 2016, 191). Trump conceptualizes America as a contained entity that has to beware of enemies from the outside. He metaphorises other nations as thieves when he says in his IA, "we must protect our borders from the ravages of other countries" and "other countries stealing our companies and destroying our jobs". Both terrorism and immigration are related to the frame of fear (Charteris-Black 2006, 574). They are often combined in populist reasoning, giving rise to the implication that terrorists arrive in a country along with immigrants seeking asylum. An illogical assumption is built up: the fact that some immigrants come illegally to the nation means that they might be terrorists, leading to the more general assumption that all immigrants are potential terrorists (Charteris-Black 2006, 574). In his speeches, Trump constructs the frame of fear towards immigrants, who can 'steal' jobs from the American citizens, turn out to be terrorists, and kill everyone (e.g., 11, 12, 15). Trump himself does not draw a clear line between the two groups, and his discourse at the macro-level points to his racist views, where anyone who is not American should be feared and viewed as non-human (e.g., 13, 16). These people are depicted by him as inferior and lacking morality (cf. Shafer, 2017).

\subsubsection{Container and Liquid Metaphors}

The theme of immigration is not unique to the US. As Montgomery (2017, 622-623) puts it, the recent concern was initiated by the UK planning to leave the EU and 'sealing' the country as a container (Charteris-Black 2006). Conceptualising immigrants as a disaster that threatens the inside of the 'container' (i.e. the US) encourages people to dissociate with immigrants (8). More so, the immigrants are not conceptualised as agents in Trump's discourse. They are 'water' or a 'flood'. This dehumanised lexicalisation can hardly evoke any empathy in the audience.

(8) A COUNTRY Is A CONTAINER ("This is not believable, but this is what's happening - refugees on top of existing massive refugee flowes coming into our country under President Obama"; AS)

In Trump's metaphors, the frame of containment is associated with that of liquids because a container can be filled, and liquids can overflow. It can also be ruined by an 
excessive amount of liquid (9). Given the US history of hurricanes and frequent warnings of floods, the issue of 'flooding' becomes even more ominous.

(9) IMMigRATION IS A FLOOD ("existing massive refugee flows coming into our country"; AS)

By comparing immigration to a flood, Trump also contributes to the myth that immigration is as extensive and uncontrollable as a natural catastrophe. As Demata (2017, 282-283) points out, the flood metaphor is a frequent figure of speech in populist political discourse, and Trump uses it as his major topos when referring to immigration as a threat.

While the word 'immigrant' or 'immigration' is not always explicitly mentioned, it can be read between the lines or emerges in the larger context in some instances. Social vices, such as drugs and violence, are associated with 'others' coming from across the border, as shown in (10) and (11).

(10) COMMUNITIES ARE CONTAINERS / DRUGS ARE AN UNCONTAINED FLOW OF WATER ("We are going to build a great border wall to stop illegal immigration, to stop the gangs and the violence, and to stop the drugs from pouring into our communities"; AS)

Example (10) is yet another case where containment and liquids make a mutual contribution to the frame of fear. A specific instance of the CONTAINER metaphor is the CASTLE metaphor, as proposed by Santa Ana $(1999,206)$. The image of a castle highlights the notions of ownership, preciousness, and protection as strong walls separate the inside from the outside. There is also a connection to another possible metaphor IMMIGRANTS ARE CONQUERORS: they come with bad intentions (drugs and violence) and take possession of the territory.

In the case of 'overflowing water' that is uncontrollable, Trump positions himself as a warrior standing on the same side of the barricades as his audience resisting the 'violence as liquid' that is supposedly threatening the US (11).

(11) VIOLENCE IS AN OVERFLOWING LIQUID ("who have lost their children to violence spilling across our border"; AS)

In terms of the 'we versus them' dichotomy (see Van Dijk 1998; 2006), the illegal penetration into the country is a symbolical entering of 'them' into 'us' because 'we' are inside the container. Charteris-Black (2006, 576-577) compares NATION IS A CONTAINER to BODY IS A CONTAINER. He says that humans are in a position to consciously control what comes in and out of the container. Similarly, Trump calls for controlling the 'national container' by erecting a wall (12), an idea that runs like a red thread through his discourse. In this frame of fear, Trump emerges as a saviour of the container, protecting it from penetration. 
OPEN BORDERS ARE AN ALTAR FOR RITUAL SACRIFICE ("One more child to sacrifice on the order and on the altar of open borders"; AS)

The fact that some immigrants indeed come to the US by water might have reinforced the occurrence of the metaphors in (8) to (12). Charteris-Black $(2006,572)$ makes a similar point about discourse on immigration during the elections in Britain in 2005. In general, the use of such metaphors on immigration both simplify the audience's understanding of the complex problem and trigger the cognitive frame of fear from a natural disaster. As Ferrari (2007, 617-619) claims, there is always a counterbalance in the fear frame: whereas the outside is portrayed as dangerous and filled with monsters, the inside is a safe haven. In other words, a political candidate that evokes the frame of fear can, at the same time, present him/herself as the protector from that fearful thing to happen. This is a frequent strategy of populist discourse and Trump is no exception to that.

\subsubsection{Animal Metaphors}

Santa Ana (1999, 196) claims that political discourse frames problems by means of metaphors, which can highlight certain aspects while blinding out others. Calling immigrants 'animals', both in the texts of his speeches and via his Twitter account (which is not the focus of this research but reinforces the point), Trump aims at building a strong association in the minds of his potential voters. The metaphor IMMIGRANTS ARE ANImALs (13) is very frequent in Trump's discourse and also in the three key speeches analysed in this study. Among others, it testifies to his xenophobic attitudes.

(13) IMMIGRANTS ARE ANIMALS

13.1 "Illegal immigrants with criminal records ordered deported from our country are tonight roaming free"; AS

13.2 "They are being released (by the tens of thousands into our communities) with no regard for the impact on public safety or resources"; AS

13.3 "One such border-crosser was released"; AS

13.4 "On Monday, we heard from three parents whose children were killed by illegal immigrants. Mary Ann Mendoza, Sabine Durden, and my friend Jamiel Shaw. They are just three brave representatives of many thousands who bave suffered so gravely. Americans who have been so brutally murdered, and who have suffered so so horribly"; AS

When he speaks about 'releasing' immigrants, one readily accesses the frame of a cage, which, once opened, lets out wild animals that pose danger to people (13.2) and (13.3). Once released, these immigrants are 'roaming freely', which reinforces an image of fear. The place where wild animals can roam freely is typically a jungle rather than an inhabited city (13.1).

The brutal and savage nature that Trump ascribes to 'others' (e.g., 13.4, 15, 16) again draws on the frame of the wild: a brute cannot be tamed. This metaphorical mapping 
is prevalent in the description of terrorism as well and emphasises that Trump does not draw a clear line between terrorists and immigrants (for a similar observation drawn on different data, see Demata 2017, 284).

(14) TERRORISM IS AN ANIMAL ("brutal Islamic terrorism"; AS)

(15) A TERRORIST IS AN ANIMAL ("Americans were savagely murdered by an Islamic terrorist"; AS)

(16) TERRORISTS ARE INSECTS ("stamping out Islamic terrorism"; AS)

That people can be conceptualised as animals is not a new metaphorical mapping. Lakoff and Turner $(1989,166-180)$ took the theoretical basis from Aristotle and Plato and discussed how the Great Chain of Being may serve as a model of metaphorical mappings. The Great Chain of Being, which is particularly rooted in western cultures, consists of 5 levels: God - humans - animals - plants - inorganic matter. They are located hierarchically one after the other, with God at the highest level and inorganic matter at the lowest. Since animals are located lower than humans, it is clear that such a mapping implies the superiority of humans. The comparison of terrorists to insects in one instance exemplifies this superiority relation. Insects are small invertebrates that can be 'stamped out' easily and destroyed (16) according to Trump.

\subsubsection{Disease and Murder Metaphors}

When operating within the frame of disease, physical wounds and pain are immediate associations. They form part of the impressive (and in political terms persuasive) power of metaphors that draw on the source domain of disease. (17) and (18) show how Trump uses this metaphor to present himself as a healer who is going to prevent immigration and crime metaphorised as pain and disease.

(17) IMMIGRATION IS PAIN ("relief from uncontrolled immigration"; AS)

(18) CRIME AND VIOLENCE IS A DISEASE ("The crime and violence that today afflicts our nation will soon - and I mean very soon - come to an end"; AS)

The physical aspects (cf. Ferrari 2007) of disease and pain give rise to further metaphors (19 and 20), which underline Trump's exploitation of that imagery.

(19) SERIOUS PROBLEMS ARE SLAUGHTER ("This American carnage stops right here and stops right now"; IA)

(20) Emotional SUFFering is a PHysical wound ("wounded American families"; AS)

(19) occurs in the context of Trump accusing immigrants of killing peaceful residents. The same implicit reference to the brutality of immigrants and pain inflicted by them is expressed in (20), in which the emotional suffering over the loss of family members is equated with being physically wounded. 


\subsection{Opponents and Previous Presidents}

In populist political discourse, opponents are a crucial theme. They are not only conceptualised as 'others' with a different agenda and values, but they also tend to be seen as a threat (Kreis 2017, 609). The way that Trump talks about his predecessors and his main rival in the election - Hillary Clinton - is reminiscent of his conceptualisation of immigrants and terrorists: they rob people, they prey on their wealth and happiness, and they threaten their peace and stability. Thus, the dichotomy of 'we versus them' is again meant to influence the audience's mental model (see Van Dijk 2006, 370). Trump is searching for culprits, and he proposes easy answers: 'others' have done it to the country (21). He is engaged in blaming these 'others' for conspiracy, an aspect that Wodak $(2015,20)$ defines as key in political populism. Similarly, Oliver and Rahn (2016, 200-201), comparing the voters of different 2016 presidency candidates, claim that Trump's supporters are inclined to believe in conspiracy scenarios and appear financially pessimistic - the opposite of what Clinton's voters are.

(21) BAD POLITICS Is CHAINS ("we must break free from the petty politics of the past”; AS)

While (21) shows an indirect blame - the blame put onto 'the past' politicians without mentioning concrete names - Trump does not mind pointing fingers and 'scapegoating' others saying that they bear responsibility for all the social woes (cf. Kreis 2017, 616). Thus, (22) to (24) are examples which demonstrate that he assigns a concrete fault to a specific politician, at the same time alluding to his own political work as an attempt to mend the mistakes made by the others.

(22) A TRADE DEAL IS A DESTRUCTIVE FORCE ("America has lost nearly-one third of its manufacturing jobs since 1997, following the enactment of disastrous trade deals supported by Bill and Hillary Clinton”; AS)

(23) A MISTAKE IS A DESTRUCTIVE FORCE ("She supported NAFTA, and she supported China's entrance into the World Trade Organization - another one of her husband's colossal mistakes and disasters"; AS; "her bad instincts and her bad judgments are what caused so many of the disasters unfolding today"; AS)

(24) OBAMACARE IS A DESTRUCTIVE FORCE ("We will repeal and replace disastrous Obamacare"; AS)

Examples (22) to (24) demonstrate what Van Dijk $(1998,2006)$ refers to as conceptualdiscourse self-presentation, which happens both on macro- and micro- levels. The overall theme of otherness is shaped by Trump demonising 'them', de-emphasising their merits or erasing them altogether. At the same time, he hyperbolises his own merits and presents his actions as the only possible way out. In this context, it is also the lexical choice that relates to the metaphorical source domain of a destructive force, which influences the audience to visualise the scope of 'their' negative sides and his positive 
sides. In (22) - (24) the noun 'disaster' and the adjective 'disastrous' allude to natural catastrophes, all-mighty forces, and destruction that can sweep away everything. The US history of hurricanes creates a contextual setting that can further build up fear among the audience: they have to beware of the politicians who bring about disaster and follow the one - i.e. Trump - who "knows" how to prevent this disaster.

Interestingly, Trump does not only depict Obama and the Clintons as a Destructive FORCE, but also blames them for fuelling immigration (25). In this way, he creates a common frame of 'others' who are either conceptualised as a threat or as misguided and inferior politicians.

(25) immigrants ARE A DeStRUCtive ForCe ("They are being released (by the tens of thousands into our communities) with no regard for the impact on public safety or resources"; AS)

In his criticism of political opponents, Trump falls back on metaphors involving physically threatening imagery (cf. Ferrari 2007, 615). This makes the presumed danger associated with his opponents more tangible (26).

(26) AUTHORITY IS PHYSICAL POWER ("the powerful can no longer beat up on people"; AS)

In (26), Trump plays with the connotation of the word 'powerful'. The 'powerful' aspect of his leadership is positive (since it makes him a strong head of state capable of protecting the poor), whereas the 'powerful' aspect of the others is negative (since it implies their intention to cause suffering and impose their power on the poor). What is also striking in Trump's discourse is how he makes 'others', especially Hillary Clinton, responsible for all the problems in the US. He insinuates that Hillary Clinton's actions depend on some higher authority who tells her what to do and which decisions to take. Trump calls Clinton a puppet $(27,28)$ without mentioning any names of the supposed puppet masters and without explaining what exactly he refers to, i.e. without any proof whatsoever (also see Lakoff R. 2017, 597).

(27) BEING UNDER CONTROL IS BEING A PUPPET ("She is their puppet"; AS)

(28) MANIPULATING Is PULLING STRINGS OF A PUPPET ("They pull the strings"; AS)

Trump accuses Clinton of being manipulated by the wealthy elite, who is the biggest enemy of the populist politician, and it is quite striking that Trump gets away with that while being a billionaire himself. In this context, it is worth mentioning that Trump speaks of 'the people', the definite article presupposing that he is referring to the citizens of the US. They have been betrayed, and he is now here to give them his helping hand (cf. Chilton 2017, 589, for a comparison with Obama's discourse about 'people' in general). Trump's framing of Clinton as a toy in the hands of the elite is emphasised 
in another metaphor that is targeted at decrying his opponent. The elite are wasting money by investing in her (29).

(29) WASTING is throwing a PRECIOUS OBJECT to AN ANIMAL ("They are throwing money at her"; AS)

The metaphor in (29), is evoked by a conventional idiomatic phrase (related to the Biblical proverb of 'casting pearls before swine', Matthew 7:6) which can be read as an implicit comparison of Clinton with an animal. This is yet another example of Trump's populist discourse, which is characterised by indecency or, as Oliver and Rahn (2016, 191) put it, by behaving "like a drunken guest" disrupting a party with "bad manners".

\subsection{Economy, Business, and Trade}

Given Trump's financial wealth, his conceptualisation of the economy is intrinsically linked to his way of doing business. He talks about the economy and trade by drawing comparisons to his making of business deals. While he emerges as a good and righteous person in these affairs, other politicians, such as his opponent, are blamed for striking bad and thus immoral deals (30).

(30) A TRADE DEAL IS AN IMMORAL PERSON

30.1 "trade deals that strip us of our jobs, and strip us of our wealth as a country"; AS

30.3 "borrible and unfair trade deals"; AS

30.3 "job killing trade deal"; AS

The theme of the economy is addressed in three major topics: the depleted economy, revitalisation of the economy, and products. To conceptualise what he deplores as a decaying state of the country because of his predecessor and opponents, Trump's metaphors again draw on physical source domains (31-33).

(31) FINANCIAL LOSS IS BLEEDING ("subsidized the armies of other countries while allowing for the very sad depletion of our military"; IA)

(32) TAXES ARE PAIN ("Middle-income Americans and businesses will experience profound relief"; AS)

(33) BAD AGREEMENTS ARE PAIN ("agreement that hurts our workers"; AS)

The metaphor on the topic of the depleted economy and economic problems is another example that relies on the source domain of FLOOD as an uncontrolled and harmful flow of water. Similar to his discourse on immigration (see Sub-section 4.1.2), Trump uses the frame of a flood to conceptualise all kinds of events. In his announcement speech, Trump employs the idiomatic phrase "to drown in debts" to evoke a metaphor based on water as a harmful substance (34). 
(34) DEBTS ARE A DEADLY FLOOD ("students who are drowning in debt"; AS)

When analysing Trump's rhetoric, it becomes evident that he relies on the same conceptual frames for presenting different issues. Water, for instance, not only serves to conceptualise danger (immigrants, terrorists, drugs, and violence) but also money as in (35) and (36). Trump's discursive role changes accordingly. When talking about immigration, he promises to safeguard the 'container' (i.e. his country) and not let anyone in (because the 'container' cannot accommodate "dangerous" foreigners). The money of foreigners, on the other hand, is seen as a welcome 'penetration' because the container has room for investment.

(35) MONEY IS FLOWING WATER ("trillions of dollars will start flowing into our country"; AS)

(36) MONEY IS WATER ("flush with cash"; IA)

Trump's business approach is also noticeable in other issues that he measures in terms of costs and value. Political correctness, for example, is given a price tag, too (37).

(37) POLITICAL CORRECTNESS IS AN EXPENSIVE ITEM ("We cannot afford to be so politically correct anymore"; AS)

Shafer (2017) believes that what has come to be known as Trump's 'political incorrectness' is an expression of neoliberal progress closely related to the supremacy of hegemonic whiteness and fear of other races. For Trump, being polite and tolerant to other people appears as a too expensive product and time consuming behaviour. He sells a lack of sensitivity for human concerns to his audience by drawing on the capitalist conceptualisation of time as money. Wasting time on looking for the appropriate words to discuss sensitive topics means losing time that could otherwise be spent on more important, and 'less expensive', problems.

Trump's substitute for political correctness is being straightforward and direct, as shown in (38) and (39). He also implicitly opposes Clinton's 'feminised' political correctness (cf. Johnson 2017). This plainness and directness falls in line with a STRICT FATHER $^{3}$ morality of Republican discourse, in which the voice of authority speaks without trying to sugar-coat facts.

\footnotetext{
3 For more on the STRICT FATHER vs NURTURANT PARENT models of Republican vs. Democratic political morality see Lakoff G. (1996), and for applications Cienki (2005) and Degani (2015).
} 
(38) TRUTH IS STRAIGHT ("It is finally time for a straightforward assessment of the state of our nation"; AS)

(39) TRUTH IS PLAIN

39.1 "I will present the facts plainly"; AS

39.2 "I will tell you the plain facts"; AS

The metaphor TRUTH IS STRAIGHT also implies that the opponent does not tell the truth. For Trump, political correctness is synonymous to lies while his 'incorrectness' is an expression of honesty.

\section{Trump's Political Image}

In political discourse, a politician does not solely aim at persuading her/his audience but pursues a number of other goals, such as representing the course of action, taking position in relation to certain topics, expressing attitudes towards political opponents, and, finally, shaping one's own political identity (Martin 2013, as cited in Schoor 2015, 84-85). Experts in political marketing have become aware of the fact that a distinct profile of the political candidate is of primary importance for winning elections (De Landtsheer et al. 2008, 218). De Landtsheer et al. (2008, 220) also talk about modern politics as "perception politics", in which style and personality play more important roles than lines of argumentation. This claim is supported by Degani (2016, 131), who states that voters tend to base their preferences of a particular candidate not so much on what they promise but rather on the image they create for themselves. This, in turn, goes back to Aristotle's model and the primacy of ethos and pathos over logos, which explains to a certain extent why the latest US elections yielded such a result. Donald Trump managed to present himself in a way that made him more appealing than Hillary Clinton to large parts of the electorate. The last section of this article aims at exploring how Trump uses metaphors to self-construct his political identity in the three key speeches. The different metaphorical self-images will be discussed in individual sub-sections.

\subsection{ENGINEER and REPAIRMAN}

Gibbs $(2015,265)$ suggests that the audience not necessarily recognises every single metaphoric concept in a political speech. It is rather the case that listeners will catch the overall symbolic idea and "allegorical themes" that are constructed in the narrative of a politician. The FIXING domain, expressed in Trump's stock phrase "I alone can fix it" (AS), has become what De Landtsheer et al. (2008) refer to as "a sound bite" or a recognisable catchphrase (40). By using that expression, Trump does what Montgomery $(2017,627)$ calls "turning up the discursive volume". According to the 
function of amplification in discourse, the speaker should indeed make strong, perhaps even hyperbolised, statements to convey a message effectively. Trump's rhetoric leaves no room for 'turning the volume up further'. Although he slightly adjusts the phrase in his speeches, sometimes replacing 'I' by 'we', in order to create the impression that his voters are also engaged in the decision making, the underlying metaphor works for his own image - Trump emerges as an engineer that knows how machines work and how to detect malfunctions that (only) he can mend.

(40) SOLVING PROBLEMS IS FIXING A MACHINE

40.1 "Nobody knows the system better than me, which is why I alone can fix it"; AS

40.2 "we will fix this biggest single issue"; AS

40.3 "we can fix this problem so quickly"; AS

40.4 "to fix our inner cities"; AS

Operating with the frame of MACHINE, Trump achieves yet another aim - he conceptualises the US as a horizontal rather than a hierarchical structure. According to Ezrahi (1995, 316-317), a MACHINE metaphor gives the impression of egalitarianism, harmony, and order, where the movement of every part pre-defines the movement of another part, like in a clockwork (41-42).

(41) THE POLITICAL SYSTEM IS A MACHINE ("to fix the system so it works justly for each and every American"; AS)

(42) TRANSPORTATION SECURITY ADMINISTRATION IS A MACHINE ("we will fix TSA at the airports"; AS)

As part of his image as a repairman, Trump promises to solve problems whereas his opponents fail to do so. By implication they are bad engineers since their system is malfunctioning.

\subsection{Constructor and Controller}

Apart from the job of an engineer and repairman, Trump also promises to take on the related role of a constructor. A NATION IS A BUILDING (43) is a very common metaphor. It builds on a primary CONTAINER metaphor as it conveys the idea of protection and the image of a walled structure, where the inside is home and the outside is alien. Trump frequently uses the BUILDING source domain in the sense of rebuilding the nation. 
(43) A NATION IS A BUILDING

43.1 "On the economy, I will outline reforms to add millions of new jobs and trillions in new wealth that can be used to rebuild America"; AS

43.2 "We will get our people off of welfare and back to work - rebuilding our country with American hands and American labor"; IA

43.3 "we will begin the urgent task of rebuilding our nation"; VS

Using the term 'restore', Trump evokes the building theme in reference to abstract concepts such as peace, safety, and law, as in (44) to (46). This reification creates associations to stability and resistance. By implication, he once again creates a dichotomy of 'we versus them' since the others have left these metaphorical buildings in such a bad state.

(44) PEACE IS A BUILDING ("It won't be happening very much anymore. Believe me. Peace will be restored"; AS)

(45) SAFETY IS A BUILDING ("Beginning on January 20th of 2017, safety will be restored"; AS)

(46) LAW AND ORDER IS A BUILDING ("I will restore law and order to our country"; AS)

Trump's political persona as a constructor and controller is also evident in the way he talks about people, who can be moved around just like objects (47).

(47) PEOPLE ARE OBJECTS

47.1 "we will put millions of our people to work"; VS

47.2 "We will get our people off of welfare and back to work"; VS

Similarly, jobs are conceptualised as objects, and Trump assumes the role of the one who can bring these objects back into existence (48).

(48) A JOB IS AN OBJECT

48.1 "I am going to bring our jobs back to Obio and Pennsylvania and New York and Michigan and all of America"; AS

48.2 "We will bring back our jobs"; VS

Overall, his metaphorical image as a constructor and controller adds to his appearance as a confident and independent agent - as the one who decides and acts.

\subsection{Healer}

Quoting Falkowski and Wojciech (1999), De Landtsheer et al. $(2008,220)$ say that people do not vote with their mind but with their heart. Since health is a prerequisite of happiness and wealth for everyone, it appeals strongly to people's emotions. Conceptualising the nation as sick evokes strong adverse reactions from the public, more so if 
the supposedly guilty ones are named. In his speeches, Trump emerges as a healer of the nation and its citizens (49-52).

(49) A NATION IS A PERSON ("We Will Make America Strong Again"; AS, IA)

(50) SOCIAL DIVISION IS A WOUND ("Now it is time for America to bind the wounds of division"; VS)

(51) EMOtional SUfFering Is A PHYSical wound ("These wounded American families have been alone. But they are alone no longer"; AS)

(52) TAXES ARE PAIN ("Middle-income Americans and businesses will experience profound relief”; AS)

These statements do not offer any concrete solutions, but they attempt to be persuasive by way of promise as in (49) and (52), by making an appeal for action (50), and by stating a change of conditions supposedly brought about by the speaker. These utterances are also examples of what Mio $(1997,124)$ calls "pseudo-deductive reasoning". Trump introduces a point which is made believable by using a metaphor that appeals to the cognitive frame of pain. While pain is bad, Trump turns into a 'healer' as he offers a solution to this painful state. The source domains of PAIN and PHYSICAL SUFFERING give rise to further metaphors that relate to the theme of immigration (53) and the economy (54). In (55) Trump's partaking in the pain of others is metaphorised by the conventional mapping of depth to intensity.

(53) PROBLEMS ARE PHYSICAL SUFFERING ("We are one nation - and their pain is our pain"; IA)

(54) BAD AGREEMENTS ARE PAIN ("She supported the job killing trade deal with South Korea. She has supported the Trans-Pacific Partnership [... I I pledge to never sign any trade agreement that burts our workers"; AS)

(55) EMOTIONAL INTENSITY IS DEPTH ("Nothing has affected me more deeply than the time I have spent with the mothers and fathers who have lost their children"; AS)

In (54) Trump not only constructs his persona as a healer, but he also puts blame on his opponent. Clinton becomes responsible for the workers' state of sufferance.

\subsection{SAVIOR / WARrior}

According to Wodak (2015), a populist politician always presents him- or herself as a charismatic leader who assumes the role of a modern-day Robin Hood and cares about the welfare of the people. In the discursive construction of his image as a politician, Trump claims this role as well. He talks about difficulties and resistance, implying that he will save the US and its citizens from these problems, as in (56) and (57). 
(56) DIFFICULTIES ARE OPPOSING FORCES

56.1 "The growing threats we face from outside the country"; AS

56.2 "We will confront hardships"; IA

(57) RESISTANCE IS REMAINING UPRIGHT ("I have a different vision for our workers. It begins with a new, fair trade policy that protects our jobs and stands up to countries that cheat"; AS)

Hyperbolising the problems and conceptualising them as either chains (58) or dangerous locations (59), Trump further contributes to the frame of fear and places the blame on those before him (cf. Johnson 2017). In (59) he addresses a particularly sensitive topic that appeals to emotions. Children need protection and shelter, and they are the future of the nation. Anxiety is further enhanced as Trump refers to suffering children in his framing of immigrants as criminals (e.g., "One more child to sacrifice on the order and on the altar of open borders"; AS) and his reference to poverty (e.g., "Mothers and children trapped in poverty"; IA). This prepares the ground for him to emerge as a saviour.

(58) BAD POLITICS IS CHAINS ("We must break free from the petty politics of the past"; AS)

(59) BAD SCHOOLS ARE A DANGEROUS LOCATION ("We will rescue kids from failing schools"; AS)

Trump's image as a warrior is most evident in relation to the election campaign. While the rivalry with an opponent during election campaigns is frequently conceptualised as a belligerent strife in US politics (cf. Gibbs 2015, 265 for the metaphor of POLITICAL DEBATES ARE BOXING MATCHES), Trump verbally enhances the image when he promises to fight with "every breath in my body" (62.2).

(60) ELECTIONS ARE A WAR

60.1 "Let's defeat her in November"; AS

60.2 "We love defeating those people"; AS

(61) POLITICS IS A COMPETITION

61.1 "We don't win anymore, but we are going to start winning"; AS

61.2 "I can be your champion in the White House"; AS

(62) TRUMP IS A WARRIOR

62.1 "I will fight for you, and I will win for you"; AS

62.2 "I will fight for you with every breath in my body"; IA

Built on the source domains of WAR and COMPETITION, the metaphors in (60) and (61) are examples of the conventionalised conceptualisation of elections and politics as an extension of the ARGUMENT IS WAR metaphor proposed in Lakoff and Johnson (1980, 79-81). 


\subsection{GARdener / FARMER}

Apart from conceptualising the nation as a building, which is constitutive to his image as a constructor, some metaphors draw on the source domain of PLANT, which makes Trump appear as a gardener or farmer of the nation (63). The major lexical expression that evokes the PLANT domain is 'growth', which is also applied to the economy (64). However, the term 'growth' is highly conventionalised when talking about the economy, as in the collocation 'economic growth', which could reduce the rhetorical flagging of the metaphorical image of Trump as gardener in that context.

(63) a NATION IS A PLANT

63.1 "We will embark upon a project of national growth and renewal"; VS

63.2 "Our country will thrive and prosper again"; IA

(64) ECONOMY IS A PLANT ("We have a great economic plan. We will double our growth"; VS)

Trump employs a few more source domains from the plant frame to refer to terrorism (65), to blame the elite (66), and to denounce his opponent Clinton for supposed monetary gains (67). Particularly in (66) and (67) these metaphors are part of his positioning as one of the ordinary citizens who need to stand up against the exploitative establishment. Once more Trump uses this theme to make Clinton appear as a member of the political elite (i.e. as removed from the ordinary people).

(65) TERRORISM IS A WEED ("radical Islamic terrorism, which we will eradicate completely"; IA)

(66) MONEY ARE CROPS ("A small group in our nation's Capital has reaped the rewards of government”; IA)

(67) A LOT OF MONEY IS AN ABUNDANCE OF LEAVES ("Secretary of State rakes in millions and millions of dollars"; AS)

The metaphors that purvey the role of gardener are examples of the fact that the billionaire relies on simple and conventional language to evoke certain metaphorical themes that become constitutive of his political persona.

\subsection{Tamers of Animals}

Finally, there is another small group of metaphors that add yet a further nuance to Trump's image. In a few cases, he uses members of the ANIMAL source domain to underline his quality as a tamer of these animals. The verb 'harness', in particular, evokes the source domain of DRAFT HORSES, which is used with reference to people's talents (69) as well as to economic and technical progress (70). 
(68) COMPANIES ARE LIONS ("companies and new jobs to come roaring back into our country"; AS)

(69) TALENTS ARE DRAFT HORSES ("I will harness the creative talents of our people"; VS)

(70) ENERGIES, INDUSTRIES, AND TECHNOLOGIES ARE DRAFT HORSES ("to harness the energies, industries and technologies of tomorrow"; IA)

Ironically, the source domain of DRAFT HORSES is reminiscent of the allegorical Animal Farm by Orwell. In the novel, pigs try 'to harness' the talents of the horse Boxer. This is not for the latter's benefit, but for the financial gain of the pigs. It remains doubtful though whether Trump is aware of that intertextual reference.

\section{Final Reflections and Conclusion}

This study has examined the occurrence of conceptual metaphors in three important speeches of Trump's political career - his acceptance of the nomination, his victory speech, and his inaugural address as $45^{\text {th }}$ president of the US. All the metaphors in the speeches were elicited (see Appendix A) with the aim of exploring how they contribute to the framing of political topics and to the construction of his political persona. Considering the metaphors in general, it is striking to see that almost all instances emerge from highly conventionalised lexical expressions. This underlines Trump's plain and uncreative use of language (cf. Degani 2016) and is consistent with his self-ascribed discursive stance that he is an ordinary person ('we') that stands against the elite ('them').

In a first classification, the metaphors were categorised according to their source domains. This yields 17 different categories, from which object metaphors, personification, space and motion metaphors with its subtype of journey metaphors, building metaphors, and animal metaphors stand out as the most frequent types. Trump applies them to three major topics that are pervasive in the selected key speeches: 1) economy, business, and trade, 2) his opponents and former presidents, and 3) immigration and other nations. The latter topic of immigration is the most prevalent one, and Trump uses the conceptual metaphors of IMMIGRANTS ARE ANIMALS and IMMIGRANTS ARE A FLOOD extensively throughout his discourse. Gibbs (2015) refers to such metaphors as "extended metaphors" since they structure the entire discourse and become allegoric to the extent that they might lead to the permanent conceptualisation of a theme in the audience's minds, i.e. in Trump's case: immigrants as dangerous people and criminals. Indeed, there is not a single instance in the three speeches where this theme appears in a positive light. The conceptualisations of immigrants are always pejorative and dehumanising.

When talking about his opponents, Hillary Clinton and former presidents are frequently conceptualised as destructive forces and as being responsible for inflicting pain 
onto the nation. Business and the economy, on the other hand, are presented as a way forward for the country's future once the current state of the nation as a depleted and wounded body (in Trump's metaphorical terms) is overcome.

In addition, a range of conceptual metaphors contribute to Trump's strong focus on ethos in his speeches. By talking about himself, Trump aspires to be a charismatic leader, who will 'fix it all alone' and 'seal the country from evil and enemies' (also see Montgomery 2017). He tries to construct an image of a successful leader and worthy candidate, and conceptual metaphors point to his political persona as that of a warrior, engineer, repairman, healer, saviour, constructor, gardener, and even tamer of animals. These metaphorical personae overlap to some extent. Thus, engineer, repairman, and constructor pertain to the domain of construction which, perhaps unsurprisingly so, emerges as the most prevalent characteristic of his image as a politician. Warrior, saviour, and healer are further related facets of his self-ascribed personality, which depict him as a "Robin Hood" of the US citizens. In general, these conceptualisations share the implication of him being in control and acting upon other entities, which is very much in line with a Strict Father morality (cf. Lakoff G. 1996).

As a final note, the examples of metaphors throughout the article have made it clear that Trump's discourse is largely built on set phrases and straightforward idiomatic collocations that give rise to many conventionalised conceptual metaphors. This raises two questions which emerge as limitations of the current study. First of all, it is difficult to assess to which extent the high level of conventionalisation in both his language and the underlying conceptual metaphors triggers the rhetorical effects that have emerged from the close analysis of his speeches. Secondly, this investigation only focussed on conceptual metaphors and how they contributed to Trump's discussion of political topics and to the construction of his political persona. A comprehensive analysis taking into account other rhetorical strategies as well would give a more complete picture of Trump's discursive practices.

\section{References}

Bougher, Lori D. 2012. "The case of metaphors in political reasoning and cognition". Political Psychology 33 (1): 145-163.

Charteris-Black, Jonathan. 2006. "Britain as a container: Immigration metaphors in the 2005 election campaign.” Discourse E Society 17 (5): 563-581.

Charteris-Black, Jonathan. 2012. "Forensic deliberation on 'purposeful metaphor". Metaphor and the Social World 2 (1): 1-21.

Chilton, Paul. 2004. Analyzing political discourse. London: Routledge.

Chilton, Paul. 2017. “'The people' in populist discourse. Using neuro-cognitive linguistics to understand political meanings". Journal of Language and Politics 16 (4): 582-594.

Cienki, Alan. 2005. "Metaphor in the 'strict father' and 'nurturant parent' cognitive models: Theoretical issues raised in an empirical study”. Cognitive Linguistics 16 (2): 279-312. 
Degani, Marta, 2015. Framing the Rhetoric of a Leader: An Analysis of Obama's Election Campaign Speeches. Basingstoke: Palgrave Macmillan.

Degani, Marta. 2016. "Endangered intellect: A case study of Clinton vs Trump campaign discourse”. Iperstoria 8: 131-145.

De Landtsheer, Christ'l, Philippe De Vries \& Dieter Vertessen. 2008. "Political impression management: How metaphors, sound bites, appearance effectiveness, and personality traits can win elections". Journal of Political Marketing 7 (3-4): 217-238.

Demata, Massimiliano. 2017. “'A great and beautiful wall.' Donald Trump's populist discourse on immigration." Journal of Language Aggression and Conflict 5 (2): 274-294.

Edelman, Murray. 1964. The Symbolic Uses of Politics. Urbana: University of Illinois Press.

Ezrahi, Yaron. 1995. "The theatrics and mechanics of action: The theater and the machine as political metaphors”. Social Research 62 (2): 299-322.

Ferrari, Federica. 2007. "Metaphor at work in the analysis of political discourse: Investigating a 'preventive war' persuasion strategy”. Discourse E Society 18 (5): 603 - 625.

Gibbs, Raymond W. Jr. 2015. “The allegorical character of political metaphors in discourse”. Metaphor and the Social World 5 (2): 264-282.

Johnson, Paul E. 2017. “The art of masculine victimhood: Donald Trump's demagoguery”. Women's Studies in Communication 40 (3): 229-250.

Kreis, Ramona. 2017. “\#refugeesnotwelcome: Anti-refugee discourse on Twitter”. Discourse $\mathcal{E}$ Communication 11(5): 498-514.

Lakoff, George. 1996. Moral politics: What Conservatives know that Liberals don't. Chicago: University of Chicago Press.

Lakoff, George \& Mark Johnson. 1980. Metaphors We Live by. Chicago, IL: University of Chicago Press.

Lakoff, George \& Mark Turner. 1989. More Than Cool Reason: A Field Guide to Poetic Metaphor. Chicago \& London: The University of Chicago Press.

Lakoff, Robin T. 2017. "The hollow man. Donald Trump, populism, and post-truth politics". Journal of Language and Politics 16 (4): 595-606.

Lau, Richard R., \& David P. Redlawsk. 2001. "Advantages and disadvantages of cognitive heuristics in political decision making”. Journal of Political Science 45 (4): 951-971.

Martin, James. 2013. Politics and rhetoric: A critical introduction. London: Routledge.

Mio, Jeffery S. 1997. "Metaphor and politics". Metaphor and Symbol 12 (2): 113-133.

Montgomery, Martin. 2017. "Post-truth politics? Authenticity, populism and the electoral discourses of Donald Trump". Journal of Language and Politics 16 (4): 619-639.

Musolff, Andreas. 2010. Metaphor, Nation and Holocaust: The Concept of the Body Politic. London $\&$ New York: Routledge.

Oliver, Eric J., \& Wendy M. Rahn. 2016. "Rise of the Trumpenvolk: Populism in the 2016 election". The Annals of the American Academy 667: 189-206.

Pawelec, Andrzej. 2006. “The death of metaphor”. Studia Linguistica 123: 117-122.

Pragglejaz Group. 2007. "MIP: A method for identifying metaphorically used words in discourse". Metaphor and Symbol 22 (1): 1-39.

Santa Ana, Otto. 1999. “Like an animal I was treated': Anti-immigrant metaphor in US public discourse”. Discourse E Society 10 (2): 191-224. 
Shafer, Jessica G. 2017. “Donald Trump’s 'political incorrectness': Neoliberalism as frontstage racism on social media”. Social Media + Society, July-September: 1-10. doi: 10.1177/205630511 7733226

Schoor, Carola. 2015. "Political metaphor, a matter of purposeful style. On the rational, emotional and strategic purposes of political metaphor". Metaphor and the Social World 5 (1): 82-101.

Steen, J. Gerard. 2007. "Finding metaphor in discourse: Pragglejaz and beyond". Culture, Language and Representation 5: 9-25.

Stone, Deborah A. 1988. Policy paradox and political reason. Glenview: IL: Scott, Foresman. Van Dijk, Teun, A. 2006. Discourse and manipulation. Discourse E Society 17 (3): 359-383. Van Dijk, Teun A. 1998. Ideology: A multidisciplinary approach. Newbury Park, CA: Sage.

Wodak, Ruth. 2015. The politics of fear: What right-wing populist discourses mean. London: SAGE Publications.

\section{Primary data}

"Victory speech". CNN. 9 Nov. 2016.

Accessed at http://edition.cnn.com/2016/11/09/politics/donald-trump-victory-speech/ "Inaugural Address" CNN. 21 Jan. 2017.

Accessed at http://edition.cnn.com/2017/01/20/politics/trump-inaugural-address/.

"Address accepting the presidential nomination".

Accessed at http://www.presidency.ucsb.edu/ws/index.php?pid=117935 


\section{Appendix A}

\section{Metaphor Frequency}

Total Number: 346 metaphors;

Unique Metaphors: 235 metaphors (67.9\%)

\begin{tabular}{lrrr}
\hline Speech & Number of metaphors & Number of words & Metaphor frequency in speech \\
\hline \hline Acceptance speech & 211 & 5,114 & 1 metaphor per 24.2 words (4.13\%) \\
Victory speech & 65 & 1,617 & 1 metaphor per 24.9 words (4,02\%) \\
Inauguration speech & 70 & 1,444 & 1 metaphor per 20.63 words (4.85\%) \\
\hline
\end{tabular}

\section{Basic Frequency Findings}

\begin{tabular}{|c|c|c|c|c|c|}
\hline \# & Metaphor & $\begin{array}{r}\text { Total } \\
\text { number }\end{array}$ & $\begin{array}{r}\text { Acceptance } \\
\text { speech }\end{array}$ & $\begin{array}{r}\text { Victory } \\
\text { speech }\end{array}$ & $\begin{array}{r}\text { Inauguration } \\
\text { speech }\end{array}$ \\
\hline \multirow{2}{*}{\multicolumn{2}{|c|}{ Person Metaphors }} & 57 & 27 & 8 & 22 \\
\hline & & $(16.47 \%)$ & & & \\
\hline 1. & A NATION IS A PERSON & 26 & 12 & 5 & 9 \\
\hline 2. & POLITICIANS ARE SERVANTS & 3 & 1 & 2 & 0 \\
\hline 3. & HISTORY IS A PERSON & 2 & 2 & 0 & 0 \\
\hline 4. & THE MILITARY IS A PERSON & 2 & 1 & 0 & 1 \\
\hline 5. & A PLANET IS A PERSON & 2 & 0 & 0 & 2 \\
\hline 6. & A TRADE DEAL IS AN IMMORAL PERSON & 2 & 2 & 0 & 0 \\
\hline 7. & OTHER NATIONS ARE THIEVES & 2 & 0 & 0 & 2 \\
\hline 8. & A NATION IS A THIEF & 1 & 1 & 0 & 0 \\
\hline 9. & A POLITICAL SYSTEM IS A PERSON & 1 & 1 & 0 & 0 \\
\hline 10. & A POLICY IS A PERSON & 1 & 1 & 0 & 0 \\
\hline 11. & ECONOMY IS A PERSON & 1 & 0 & 1 & 0 \\
\hline 12. & A TRADE DEAL IS A MURDERER & 1 & 1 & 0 & 0 \\
\hline 13. & LAWS ARE PEOPLE & 1 & 1 & 0 & 0 \\
\hline 14. & JOBS ARE PEOPLE & 1 & 1 & 0 & 0 \\
\hline 15. & BUILDINGS ARE PEOPLE & 1 & 0 & 0 & 1 \\
\hline 16. & ALLIES ARE FAMILY RELATIONS & 1 & 1 & 0 & 0 \\
\hline 17. & PATRIOTISM IS A DOCTOR & 1 & 0 & 0 & 1 \\
\hline 18. & PATRIOTISM IS A VISITOR & 1 & 0 & 0 & 1 \\
\hline 19. & A PRESIDENT IS A PREACHER & 1 & 1 & 0 & 0 \\
\hline 20. & THE MILITARY PERSONNEL ARE SERVANTS & 1 & 1 & 0 & 0 \\
\hline
\end{tabular}




\begin{tabular}{llrrrr}
\hline$\#$ & Metaphor & Total & Acceptance & Victory & Inauguration \\
speech & number & speech & speech \\
\hline \hline
\end{tabular}

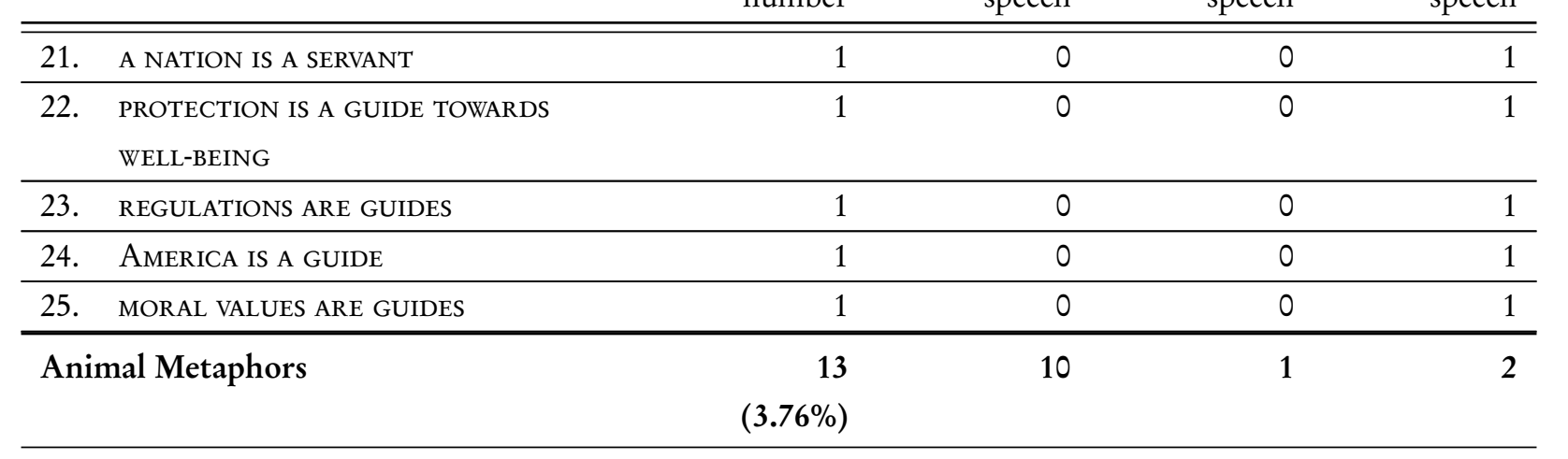

\begin{tabular}{llllll}
\hline 1. & IMMIGRANTS ARE ANIMALS & 4 & 4 & 0 & 0 \\
\hline 2. & PEOPLE ARE ANIMALS & 1 & 0 & 0 & 0 \\
\hline 3. & TERRORISM IS AN ANIMAL & 1 & 1 & 1 & 0 \\
\hline 4. & A TERRORIST IS AN ANIMAL & 1 & 1 & 0 & 0 \\
\hline 5. & TERRORISTS ARE INSECTS & 1 & 1 & 0 & 0
\end{tabular}
TO AN ANIMAL

\begin{tabular}{llllll}
\hline 7. & CLINTON IS A PIG & 1 & 1 & 0 & 0 \\
\hline 8. & COMPANIES ARE LIONS & 1 & 1 & 0 & 0 \\
\hline 9. & TALENTS ARE DRAFT HORSES & 1 & 0 & 1 & 0 \\
\hline 10. & ENERGIES, INDUSTRIES, AND & 1 & 0 & 0 & 1
\end{tabular}
TECHNOLOGIES ARE DRAFT HORSES

\begin{tabular}{lrrrr}
\hline Object Metaphors & 65 & 40 & 21 & 4 \\
\hline
\end{tabular}

\begin{tabular}{llllll}
\hline 1. & AN OATH IS AN OBJECT & 5 & 4 & 1 & 0 \\
\hline 2. & PEOPLE ARE OBJECTS & 4 & 2 & 2 & 0 \\
\hline 3. & POLITICAL POWER IS AN OBJECT & 4 & 0 & 4 & 0 \\
\hline 4. & A NATION IS AN OBJECT & 3 & 3 & 0 & 0 \\
\hline 5. & A JOB IS AN OBJECT & 3 & 2 & 1 & 0 \\
\hline 6. & SUPPORT IS AN OBJECT & 2 & 2 & 2 & 0 \\
\hline 7. & TIME IS AN OBJECT & 2 & 0 & 0 \\
\hline 8. & LOVE IS AN OBJECT & 2 & 2 & 0 & 0 \\
\hline 9. & A DREAM IS AN OBJECT & 2 & 0 & 0 & 0 \\
\hline 10. & CONTROL IS AN OBJECT & 1 & 1 & 0 & 0 \\
\hline 11. & A PLAN IS AN OBJECT & 1 & 1 & 0 & 0 \\
\hline 12. & E-MAILS ARE OBJECTS & 1 & 1 & 0 & 0 \\
\hline 13. & SECRETS ARE OBJECTS & 1 & 1 & 0 & 0 \\
\hline 14. & SUCCESS IS AN OBJECT & 1 & 1 & 0 & 0 \\
\hline
\end{tabular}




\begin{tabular}{|c|c|c|c|c|c|}
\hline$\#$ & Metaphor & $\begin{array}{r}\text { Total } \\
\text { number }\end{array}$ & $\begin{array}{r}\text { Acceptance } \\
\text { speech }\end{array}$ & $\begin{array}{r}\text { Victory } \\
\text { speech }\end{array}$ & $\begin{array}{r}\text { Inauguration } \\
\text { speech }\end{array}$ \\
\hline 15. & ACTIONS ARE OBJECTS & 1 & 1 & 0 & 0 \\
\hline 16. & POLICY IS AN OBJECT & 1 & 1 & 0 & 0 \\
\hline 17. & GOALS ARE OBJECTS & 1 & 1 & 0 & 0 \\
\hline 18. & EXPENDITURE IS AN OBJECT & 1 & 1 & 0 & 0 \\
\hline 19. & PAIN IS AN OBJECT & 1 & 1 & 0 & 0 \\
\hline 20. & RESPECT IS AN OBJECT & 1 & 1 & 0 & 0 \\
\hline 21. & VOICE IS AN OBJECT & 1 & 1 & 0 & 0 \\
\hline 22. & VICTORY IS AN OBJECT & 1 & 1 & 0 & 0 \\
\hline 23. & GUIDANCE AND HELP IS AN OBJECT & 1 & 0 & 1 & 0 \\
\hline 24. & A MOVEMENT IS AN OBJECT & 1 & 0 & 1 & 0 \\
\hline 25. & CHALLENGE IS AN OBJECT & 1 & 0 & 1 & 0 \\
\hline 26. & GRATITUDE IS AN OBJECT & 1 & 0 & 1 & 0 \\
\hline 27. & DESTINY IS AN OBJECT & 1 & 0 & 0 & 1 \\
\hline 28. & WEALTH IS AN OBJECT & 1 & 0 & 1 & 0 \\
\hline 29. & PREJUDICE IS AN OBJECT & 1 & 0 & 1 & 0 \\
\hline 30. & AN ELECTION CAMPAIGN IS AN OBJECT & 1 & 1 & 0 & 0 \\
\hline 31. & A TALENT IS AN OBJECT & 1 & 0 & 1 & 0 \\
\hline 32. & CRIME AND VIOLENCE IS A MOVING OBJECT & 1 & 1 & 0 & 0 \\
\hline 33. & A CONVENTION IS AN OBJECT & 1 & 1 & 0 & 0 \\
\hline 34. & A NOMINATION IS AN OBJECT & 1 & 1 & 0 & 0 \\
\hline 35. & IDEAS ARE POSSESSIONS & 1 & 1 & 0 & 0 \\
\hline 36. & LIFE IS A VALUABLE POSSESSION & 1 & 0 & 1 & 0 \\
\hline 37. & SOLIDARITY IS AN OBJECT TO BE PURSUED & 1 & 0 & 0 & 1 \\
\hline 38. & POVERTY IS A TRAP & 1 & 0 & 0 & 1 \\
\hline 39. & BAD POLITICS IS CHAINS & 1 & 1 & 0 & 0 \\
\hline 40. & PEOPLE ARE LINKS OF A CHAIN & 1 & 0 & 0 & 1 \\
\hline 41. & PROBLEMS ARE FABRIC & 1 & 1 & 0 & 0 \\
\hline 42. & FAMILIES ARE FABRIC & 1 & 1 & 0 & 0 \\
\hline 43. & WEALTH IS A FABRIC & 1 & 0 & 1 & 0 \\
\hline 44. & $\begin{array}{l}\text { POLITICAL CORRECTNESS IS AN EXPENSIVE } \\
\text { ITEM }\end{array}$ & 1 & 1 & 0 & 0 \\
\hline 45. & $\begin{array}{l}\text { LIES ARE SKILLFULLY MANUFACTURED } \\
\text { GOODS }\end{array}$ & 1 & 1 & 0 & 0 \\
\hline 46. & RESULTS ARE PRODUCTS & 1 & 1 & 0 & 0 \\
\hline 47. & $\begin{array}{l}\text { WAGES AND UNEMPLOYMENT ARE } \\
\text { PRODUCTS }\end{array}$ & 1 & 1 & 0 & 0 \\
\hline
\end{tabular}




\begin{tabular}{|c|c|c|c|c|c|}
\hline$\#$ & Metaphor & $\begin{array}{l}\text { Total } \\
\text { number }\end{array}$ & $\begin{array}{r}\text { Acceptance } \\
\text { speech }\end{array}$ & $\begin{array}{r}\text { Victory } \\
\text { speech }\end{array}$ & $\begin{array}{r}\text { Inauguration } \\
\text { speech }\end{array}$ \\
\hline \multicolumn{2}{|c|}{ Physical Suffering Metaphors } & $9(2.6 \%)$ & 5 & 1 & 3 \\
\hline 1. & SOCIAL DIVISION IS A WOUND & 2 & 0 & 1 & 1 \\
\hline 2. & IMMIGRATION IS PAIN & 1 & 1 & 0 & 0 \\
\hline 3. & $\begin{array}{l}\text { EMOTIONAL SUFFERING IS A PHYSICAL } \\
\text { WOUND }\end{array}$ & 1 & 1 & 0 & 0 \\
\hline 4. & PROBLEMS ARE PHYSICAL SUFFERING & 1 & 0 & 0 & 1 \\
\hline 5. & FINANCIAL LOSS IS BLEEDING & 1 & 0 & 0 & 1 \\
\hline 6. & CRIME AND VIOLENCE IS A DISEASE & 1 & 1 & 0 & 0 \\
\hline 7. & BAD AGREEMENTS ARE PAIN & 1 & 1 & 0 & 0 \\
\hline 8. & TAXES ARE PAIN & 1 & 1 & 0 & 0 \\
\hline \multicolumn{2}{|c|}{ Force Metaphors } & $\begin{array}{r}16 \\
(4.62 \%) \\
\end{array}$ & 13 & 0 & 3 \\
\hline 1. & DIFFICULTIES ARE OPPOSING FORCES & 4 & 2 & 0 & 2 \\
\hline 2. & RESISTANCE IS REMAINING UPRIGHT & 2 & 2 & 0 & 0 \\
\hline 3. & A PROBLEM IS A DESTRUCTIVE FORCE & 1 & 2 & 0 & 0 \\
\hline 4. & IMMIGRANTS ARE A DESTRUCTIVE FORCE & 1 & 1 & 0 & 0 \\
\hline 5. & A TRADE DEAL IS A DESTRUCTIVE FORCE & 1 & 1 & 0 & 0 \\
\hline 6. & A MISTAKE IS A DESTRUCTIVE FORCE & 2 & 1 & 0 & 0 \\
\hline 7. & OBAMACARE IS A DESTRUCTIVE FORCE & 1 & 1 & 0 & 0 \\
\hline 8. & $\begin{array}{l}\text { TRANSPORTATION SECURITY } \\
\text { ADMINISTRATION IS A DESTRUCTIVE FORCE }\end{array}$ & 1 & 1 & 0 & 0 \\
\hline 9. & $\begin{array}{l}\text { CURRENCY MANIPULATION IS A } \\
\text { DEVASTATING FORCE }\end{array}$ & 1 & 1 & 0 & 0 \\
\hline 10. & PATRIOTISM IS A FORCE & 1 & 0 & 0 & 1 \\
\hline 11. & AUTHORITY IS PHYSICAL POWER & 1 & 1 & 0 & 0 \\
\hline \multicolumn{2}{|c|}{ Building Metaphors } & $\begin{array}{r}24 \\
(6.94 \%) \\
\end{array}$ & 16 & 2 & 6 \\
\hline 1. & A NATION IS A BUILDING & 5 & 2 & 1 & 2 \\
\hline 2. & PEACE IS STABILITY & 2 & 2 & 0 & 0 \\
\hline 3. & PEACE IS A BUILDING & 1 & 1 & 0 & 0 \\
\hline 4. & SAFETY IS A BUILDING & 1 & 1 & 0 & 0 \\
\hline 5. & CRIME IS A BUILDING & 1 & 1 & 0 & 0 \\
\hline 6. & THE WORLD IS A BUILDING & 1 & 1 & 0 & 0 \\
\hline 7. & COMMUNITIES ARE BUILDINGS & 1 & 1 & 0 & 0 \\
\hline 8. & LAW AND ORDER IS A BUILDING & 1 & 1 & 0 & 0 \\
\hline 9. & LIFE IS A BUILDING & 1 & 1 & 0 & 0 \\
\hline
\end{tabular}




\begin{tabular}{|c|c|c|c|c|c|}
\hline$\#$ & Metaphor & $\begin{array}{l}\text { Total } \\
\text { number }\end{array}$ & $\begin{array}{r}\text { Acceptance } \\
\text { speech }\end{array}$ & $\begin{array}{r}\text { Victory } \\
\text { speech }\end{array}$ & $\begin{array}{r}\text { Inauguration } \\
\text { speech }\end{array}$ \\
\hline 10. & ISIS IS A BUILDING & 1 & 1 & 0 & 0 \\
\hline 11. & SOCIAL CLASS IS A BUILDING & 1 & 1 & 0 & 0 \\
\hline 12. & TRANSACTION IS A BUILDING & 1 & 1 & 0 & 0 \\
\hline 13. & THE MILITARY IS A BUILDING & 1 & 1 & 0 & 0 \\
\hline 14. & A MOVEMENT IS A BUILDING & 1 & 0 & 1 & 0 \\
\hline 15. & DESOLATION IS A RUSTED BUILDING & 1 & 0 & 0 & 1 \\
\hline 16. & A PROMISE IS A BUILDING & 1 & 0 & 0 & 1 \\
\hline 17. & POLITICS IS A BUILDING & 1 & 0 & 0 & 1 \\
\hline 18. & HEART IS A HOME & 1 & 0 & 0 & 1 \\
\hline 19. & BORDERS ARE DOORS TO A BUILDING & 1 & 1 & 0 & 0 \\
\hline \multicolumn{2}{|c|}{ Container Metaphors } & $8(2.31 \%)$ & 4 & 0 & 4 \\
\hline 1. & A COUNTRY IS A CONTAINER & 2 & 2 & 0 & 0 \\
\hline 2. & COMMUNITIES ARE CONTAINERS & 1 & 1 & 0 & 0 \\
\hline 3. & POVERTY IS A CONTAINER & 1 & 1 & 0 & 0 \\
\hline 4. & MEANING IS SUBSTANCE IN A CONTAINER & 1 & 0 & 0 & 1 \\
\hline 5. & THE HEART IS A CONTAINER & 1 & 0 & 0 & 1 \\
\hline 6. & PEOPLE ARE CONTAINERS & 1 & 0 & 0 & 1 \\
\hline 7. & $\begin{array}{l}\text { THE UNKNOWN IS THE CONTENTS OF A } \\
\text { LOCKED CHEST }\end{array}$ & 1 & 0 & 0 & 1 \\
\hline \multicolumn{2}{|c|}{ Machine Metaphors } & $8(2.31 \%)$ & 8 & 0 & 0 \\
\hline 1. & SOLVING PROBLEMS IS FIXING A MACHINE & 5 & 5 & 0 & 0 \\
\hline 2. & THE POLITICAL SYSTEM IS A MACHINE & 1 & 1 & 0 & 0 \\
\hline 3. & $\begin{array}{l}\text { TRANSPORTATION SECURITY } \\
\text { ADMINISTRATION IS A MACHINE }\end{array}$ & 1 & 1 & 0 & 0 \\
\hline 4. & IMMIGRATION IS A MACHINE & 1 & 1 & 0 & 0 \\
\hline \multicolumn{2}{|c|}{ Motion and Journey Metaphors } & $\begin{array}{r}23 \\
(6.64 \%) \\
\end{array}$ & 17 & 2 & 4 \\
\hline 1. & CHANGE IS MOTION & 8 & 5 & 1 & 2 \\
\hline 2. & TIME IS MOTION & 3 & 2 & 0 & 1 \\
\hline 3. & $\begin{array}{l}\text { A CHARACTERISTIC IS A PARTICULAR } \\
\text { ROTATION }\end{array}$ & 1 & 1 & 0 & 0 \\
\hline 4. & $\begin{array}{l}\text { REACHING A GOAL IS MOTION ALONG A } \\
\text { PATH TOWARDS A DESTINATION }\end{array}$ & 1 & 1 & 0 & 0 \\
\hline 5. & TIME IS A MOVING VEHICLE & 1 & 1 & 0 & 0 \\
\hline 6. & REFUSING IS GOING AWAY & 1 & 1 & 0 & 0 \\
\hline 7. & DAMAGE IS FALLING & 1 & 0 & 0 & 1 \\
\hline
\end{tabular}




\begin{tabular}{|c|c|c|c|c|c|}
\hline \# & Metaphor & $\begin{array}{r}\text { Total } \\
\text { number }\end{array}$ & $\begin{array}{r}\text { Acceptance } \\
\text { speech }\end{array}$ & $\begin{array}{r}\text { Victory } \\
\text { speech }\end{array}$ & $\begin{array}{r}\text { Inauguration } \\
\text { speech }\end{array}$ \\
\hline
\end{tabular}

\begin{tabular}{llllll}
\hline \hline 8. & LIFE IS A JOURNEY & 3 & 3 & 0 & 0 \\
\hline 9. & AN ELECTION CAMPAIGN IS A JOURNEY & 2 & 2 & 1 & 0 \\
\hline $\begin{array}{l}\text { 10. } \\
\quad \begin{array}{l}\text { HUMAN SMUGGLING AND VIOLENCE IS A } \\
\text { (NEVE-ENDING) JOURNEY }\end{array}\end{array}$ & 1 & 1 & 0 & 0 \\
\hline $\begin{array}{l}\text { POVERTY IS A (NEVER-ENDING) JOURNEY } \\
\text { Spatial Metaphors }\end{array}$ & 1 & 1 & $\mathbf{0}$ & 0 \\
\hline
\end{tabular}

$(8.96 \%)$

\begin{tabular}{llllll}
\hline 1. & SUPPORT IS PROXIMITY & 4 & 4 & 0 & 0 \\
\hline 2. & MORE IS UP & 3 & 3 & 1 & 0 \\
\hline 3. & DISAPPOINTMENT IS DOWN & 2 & 0 & 1 & 1 \\
\hline 4. & FUTURE IS AHEAD & 2 & 0 & 0 & 0 \\
\hline 5. & STRONG IS UP & 1 & 1 & 1 & 0 \\
\hline 6. & SUPPORTING IS LIFTING UP & 1 & 0 & 1 & 0 \\
\hline 7. & HEAVEN IS UP & 1 & 0 & 0 & 0 \\
\hline 8. & HONOR IS UP & 1 & 0 & 0 & 0 \\
\hline 9. & GOOD IS UP & 1 & 1 & 0 & 0 \\
\hline 10. & LESS IS DOWN & 1 & 1 & 1 & 0 \\
\hline 11. & HUMILIATION IS DOWN & 1 & 1 & 1 & 0 \\
\hline 12. & ATTENTION IS PROXIMITY & 1 & 1 & 0 & 0
\end{tabular}

LOCATIONS

\begin{tabular}{llllll}
\hline 16. & BAD SCHOOLS ARE A DANGEROUS LOCATION & 1 & 1 & 0 & 0 \\
\hline 17. & AGREEING IS SETTLING AT A LOCATION & 1 & 0 & 1 & 0 \\
\hline 18. & LOYALTY IS A LOCATION & 1 & 0 & 1 & 0 \\
\hline 19. & TIME IS SPACE & 1 & 0 & 1 & 0 \\
\hline 20. & DUTY IS AN ORDERLY SPATIAL & 1 & 1 & 0
\end{tabular}

ARRANGEMENT

\begin{tabular}{llllll}
\hline 21. & EMOTIONAL INTENSITY IS DEPTH & 1 & 1 & 0 & 0 \\
\hline 22. & IMPORTANT IS CENTRAL & 1 & 0 & 0 & 1 \\
\hline 23. & $\begin{array}{l}\text { REDUCING THE PRICE OF A PRODUCT IS } \\
\text { DECREASING VERTICAL ELEVATION }\end{array}$ & 1 & 1 & 0 & 0 \\
\hline $24 . \quad$ INCREASE IN QUANTITY IS INCREASE IN SIZE & 1 & 0 & 1 & 0 \\
\hline Plant Metaphors & $\mathbf{9 ( 2 . 6 \% )}$ & $\mathbf{2}$ & $\mathbf{2}$ & $\mathbf{5}$ \\
\hline 1. & A NATION IS A PLANT & 2 & 0 & 1 & 1 \\
\hline
\end{tabular}




\begin{tabular}{|c|c|c|c|c|c|}
\hline$\#$ & Metaphor & $\begin{array}{l}\text { Total } \\
\text { number }\end{array}$ & $\begin{array}{r}\text { Acceptance } \\
\text { speech }\end{array}$ & $\begin{array}{r}\text { Victory } \\
\text { speech }\end{array}$ & $\begin{array}{r}\text { Inauguration } \\
\text { speech }\end{array}$ \\
\hline 2. & A CITY IS A PLANT & 2 & 0 & 0 & 2 \\
\hline 3. & ECONOMY IS A PLANT & 1 & 0 & 1 & 0 \\
\hline 4. & MONEY ARE CROPS & 1 & 0 & 0 & 1 \\
\hline 5. & TERRORISM IS A WEED & 1 & 0 & 0 & 1 \\
\hline 6. & $\begin{array}{l}\text { A LOT OF MONEY IS AN ABUNDANCE OF } \\
\text { LEAVES }\end{array}$ & 1 & 1 & 0 & 0 \\
\hline 7. & KILLING IS CUTTING DOWN GRASS & 1 & 1 & 0 & 0 \\
\hline \multicolumn{2}{|c|}{ Money Metaphors } & $6(1.7 \%)$ & 2 & 4 & 0 \\
\hline 1. & TIME IS MONEY & 3 & 1 & 2 & 0 \\
\hline 2. & GRATITUDE IS MONEY & 1 & 0 & 1 & 0 \\
\hline 3. & $\begin{array}{l}\text { PUNISHMENT IS PAYING EXCESSIVE } \\
\text { AMOUNTS OF MONEY }\end{array}$ & 1 & 1 & 0 & 0 \\
\hline 4. & PERSONAL RELATIONS ARE BUSINESS & 1 & 0 & 1 & 0 \\
\hline \multicolumn{2}{|c|}{ Liquid Metaphors } & $\begin{array}{r}12 \\
(3.47 \%)\end{array}$ & 7 & 2 & 3 \\
\hline 1. & $\begin{array}{l}\text { DRUGS ARE AN UNCONTAINED FLOW OF } \\
\text { WATER }\end{array}$ & 1 & 1 & 0 & 0 \\
\hline 2. & MONEY IS FLOWING WATER & 1 & 1 & 0 & 0 \\
\hline 3. & MONEY IS WATER & 1 & 0 & 0 & 1 \\
\hline 4. & WAR IS A FLOOD & 1 & 1 & 0 & 0 \\
\hline 5. & IMMIGRATION IS A FLOOD & 1 & 1 & 0 & 0 \\
\hline 6. & DEBTS ARE A DEADLY FLOOD & 1 & 1 & 0 & 0 \\
\hline 7. & VIOLENCE IS AN OVERFLOWING LIQUID & 1 & 1 & 0 & 0 \\
\hline 8. & SOUL IS A LIQUID & 1 & 0 & 0 & 1 \\
\hline 9. & POTENTIAL IS A LIQUID & 1 & 0 & 1 & 0 \\
\hline 10. & PRIDE AND JOY ARE LIQUIDS & 1 & 0 & 1 & 0 \\
\hline 11. & A SCANDAL IS A SUBSTANCE & 1 & 1 & 0 & 0 \\
\hline 12. & MEANING IS SUBSTANCE IN A CONTAINER & 1 & 0 & 0 & 1 \\
\hline \multicolumn{2}{|c|}{ Competition Metaphors } & $\begin{array}{r}15 \\
(4.34 \%)\end{array}$ & 8 & 5 & 2 \\
\hline 1. & ELECTIONS ARE A COMPETITION & 4 & 2 & 2 & 0 \\
\hline 2. & ELECTIONS ARE A WAR & 2 & 2 & 0 & 0 \\
\hline 3. & TRUMP IS A WARRIOR & 2 & 1 & 0 & 1 \\
\hline 4. & ELECTIONS ARE FIGHTS & 2 & 0 & 2 & 0 \\
\hline 5. & POLITICS IS A COMPETITION & 2 & 2 & 0 & 0 \\
\hline 6. & AN ELECTION CAMPAIGN IS A HORSERACE & 1 & 0 & 1 & 0 \\
\hline
\end{tabular}




\begin{tabular}{|c|c|c|c|c|c|}
\hline$\#$ & Metaphor & $\begin{array}{r}\text { Total } \\
\text { number }\end{array}$ & $\begin{array}{r}\text { Acceptance } \\
\text { speech }\end{array}$ & $\begin{array}{r}\text { Victory } \\
\text { speech }\end{array}$ & $\begin{array}{r}\text { Inauguration } \\
\text { speech }\end{array}$ \\
\hline 7. & DEALING WITH PROBLEMS IS FIGHTING & 1 & 1 & 0 & 0 \\
\hline 8. & DEALING WITH POVERTY IS FIGHTING & 1 & 0 & 0 & 1 \\
\hline \multicolumn{2}{|c|}{ Seeing Metaphors } & $8(2.31 \%)$ & 7 & 0 & 1 \\
\hline 1. & $\begin{array}{l}\text { BEING CONFRONTED WITH STHG. IS } \\
\text { LOOKING AT STHG. }\end{array}$ & 3 & 3 & 0 & 0 \\
\hline 2. & BELIEVING IS SEEING & 2 & 2 & 0 & 0 \\
\hline 3. & HAVING A PLAN IS SEEING & 1 & 1 & 0 & 0 \\
\hline 4. & $\begin{array}{l}\text { IGNORING A PROBLEM IS INTENTIONALLY } \\
\text { NOT SEEING }\end{array}$ & 1 & 1 & 0 & 0 \\
\hline 5. & LOSING IS MOVING OUT OF SIGHT & 1 & 0 & 0 & 1 \\
\hline \multicolumn{2}{|c|}{ Holding Metaphors } & $5(1.45 \%)$ & 3 & 2 & 0 \\
\hline 1. & UNDERSTANDING IS HOLDING & 2 & 2 & 0 & 0 \\
\hline 2. & POSSESSION IS HOLDING & 2 & 0 & 2 & 0 \\
\hline 3. & $\begin{array}{l}\text { ENFORCING LEGISLATION IS HOLDING UP } \\
\text { AN OBJECT }\end{array}$ & 1 & 1 & 0 & 0 \\
\hline \multicolumn{2}{|c|}{ Other Metaphors } & $\begin{array}{r}37 \\
(10.7 \%)\end{array}$ & 26 & 4 & 7 \\
\hline 1. & $\begin{array}{l}\text { TWO DIFFERENT OPINIONS ARE TWO HANDS } \\
\text { OF THE BODY }\end{array}$ & 3 & 3 & 0 & 0 \\
\hline 2. & BEING THE BEST IS BEING FIRST & 2 & 2 & 0 & 0 \\
\hline 3. & REFORMS ARE DRAWINGS & 2 & 2 & 0 & 0 \\
\hline 4. & GOOD IS LIGHT & 2 & 0 & 1 & 1 \\
\hline 5. & INTELLIGENT IS BRIGHT & 2 & 1 & 1 & 0 \\
\hline 6. & TRUTH IS PLAIN & 2 & 2 & 0 & 0 \\
\hline 7. & $\begin{array}{l}\text { A CHARACTERISTIC MESSAGE IS A } \\
\text { SIGNATURE }\end{array}$ & 1 & 1 & 0 & 0 \\
\hline 8. & $\begin{array}{l}\text { A CHARACTERISTIC FEATURE IS A } \\
\text { SIGNATURE }\end{array}$ & 1 & 1 & 0 & 0 \\
\hline 9. & INTELLIGENT IS SHARP & 1 & 0 & 1 & 0 \\
\hline 10. & BEING UNDER CONTROL IS BEING A PUPPET & 1 & 1 & 0 & 0 \\
\hline 11. & $\begin{array}{l}\text { MANIPULATING IS PULLING STRINGS OF A } \\
\text { PUPPET }\end{array}$ & 1 & 1 & 0 & 0 \\
\hline 12. & $\begin{array}{l}\text { LOSING JOBS AND WEALTH IS BECOMING } \\
\text { NAKED }\end{array}$ & 1 & 1 & 0 & 0 \\
\hline 13. & DESTROYING JOBS IS BURNING & 1 & 1 & 0 & 0 \\
\hline 14. & EXISTENCE IS BEING ON A MAP & 1 & 1 & 0 & 0 \\
\hline
\end{tabular}




\begin{tabular}{|c|c|c|c|c|c|}
\hline \# & Metaphor & $\begin{array}{r}\text { Total } \\
\text { number }\end{array}$ & $\begin{array}{r}\text { Acceptance } \\
\text { speech }\end{array}$ & $\begin{array}{r}\text { Victory } \\
\text { speech }\end{array}$ & $\begin{array}{r}\text { Inauguration } \\
\text { speech }\end{array}$ \\
\hline 15. & INFLUENCE IS VOICE & 1 & 1 & 0 & 0 \\
\hline 16. & PROJECTS ARE SHIPS & 1 & 0 & 1 & 0 \\
\hline 17. & AMERICA IS A SHIP & 1 & 0 & 0 & 1 \\
\hline 18. & BIG IS GOOD & 1 & 0 & 0 & 1 \\
\hline 19. & BEGINNING IS BIRTH & 1 & 0 & 0 & 1 \\
\hline 20. & UNITY IS SHARING & 1 & 0 & 0 & 1 \\
\hline 21. & EXPRESSING ONE'S OPINION IS PREACHING & 1 & 1 & 0 & 0 \\
\hline 22. & DEATH IS LOSS & 1 & 1 & 0 & 0 \\
\hline 23. & $\begin{array}{l}\text { OPEN BORDERS ARE AN ALTAR FOR RITUAL } \\
\text { SACRIFICE }\end{array}$ & 1 & 1 & 0 & 0 \\
\hline 24. & SERIOUS PROBLEMS ARE SLAUGHTER & 1 & 0 & 0 & 1 \\
\hline 25. & EMOTION IS TEMPERATURE & 1 & 1 & 0 & 0 \\
\hline 26. & KIND IS WARM & 1 & 1 & 0 & 0 \\
\hline 27. & RESTRICTIONS ARE WEIGHT & 1 & 1 & 0 & 0 \\
\hline 28. & A FINANCIAL OBLIGATION IS PRESSURE & 1 & 1 & 0 & 0 \\
\hline 29. & EXPENSES ARE BAGGAGE & 1 & 0 & 0 & 1 \\
\hline 30. & TRUTH IS STRAIGHT & 1 & 1 & 0 & 0 \\
\hline
\end{tabular}




\section{Appendix B}

\section{Metaphors in Trump's Discourse}

\begin{tabular}{|c|c|c|c|}
\hline \# & Text passage & Metaphor & Speech \\
\hline \multicolumn{4}{|c|}{ Person Metaphors } \\
\hline 1. & $\begin{array}{l}\text { a country of generosity and } \\
\text { warmth }\end{array}$ & A NATION IS A PERSON & Acceptance speech \\
\hline 2. & $\begin{array}{l}\text { the crime and violence that today } \\
\text { afflicts our nation }\end{array}$ & A NATION IS A PERSON & Acceptance speech \\
\hline 3. & $\begin{array}{l}\text { Iraq was seeing a big, big } \\
\text { reduction in violence }\end{array}$ & A NATION IS A PERSON & Acceptance speech \\
\hline 4. & $\begin{array}{l}\text { Iran was being choked by } \\
\text { sanctions }\end{array}$ & A NATION IS A PERSON & Acceptance speech \\
\hline 5. & Muslim brotherhood & ALLIES ARE FAMILY RELATIONS & Acceptance speech \\
\hline 6. & $\begin{array}{l}\text { political system lacks the will, or } \\
\text { the courage, or the basic decency }\end{array}$ & A POLITICAL SYSTEM IS A PERSON & Acceptance speech \\
\hline 7. & a nation in mourning & A NATION IS A PERSON & Acceptance speech \\
\hline 8. & $\begin{array}{l}\text { our laws will finally receive the } \\
\text { respect they deserve }\end{array}$ & LAWS ARE PEOPLE & Acceptance speech \\
\hline 9. & $\begin{array}{l}\text { fair trade policy that protects our } \\
\text { jobs and stands up to countries } \\
\text { that cheat }\end{array}$ & A NATION IS A PERSON & Acceptance speech \\
\hline 10. & job killing trade deal & A TRADE DEAL IS A MURDERER & Acceptance speech \\
\hline 11. & horrible and unfair trade deals & $\begin{array}{l}\text { A TRADE DEAL IS AN IMMORAL } \\
\text { PERSON }\end{array}$ & Acceptance speech \\
\hline 12. & $\begin{array}{l}\text { I will make individual deals with } \\
\text { individual countries }\end{array}$ & A NATION IS A PERSON & Acceptance speech \\
\hline 13. & country that cheats & A NATION IS A PERSON & Acceptance speech \\
\hline 14. & China's outrageous theft & A NATION IS A PERSON & Acceptance speech \\
\hline & job-killers & JOBS ARE PEOPLE & Acceptance speech \\
\hline & our depleted military & MILITARY IS A PERSON & Acceptance speech \\
\hline 17. & History is watching us now. & HISTORY IS A PERSON & Acceptance speech \\
\hline 18. & It's waiting to see [about history] & HISTORY IS A PERSON & Acceptance speech \\
\hline 19. & $\begin{array}{l}\text { America is still free and } \\
\text { independent and strong }\end{array}$ & A NATION IS A PERSON & Acceptance speech \\
\hline & $\begin{array}{l}\text { We Will Make America Strong } \\
\text { Again }\end{array}$ & A NATION IS A PERSON & Acceptance speech \\
\hline
\end{tabular}




\begin{tabular}{|c|c|c|c|}
\hline \# & Text passage & Metaphor & Speech \\
\hline \multicolumn{4}{|c|}{ Person Metaphors } \\
\hline 21. & $\begin{array}{l}\text { We Will Make America Proud } \\
\text { Again }\end{array}$ & A NATION IS A PERSON & Acceptance speech \\
\hline 22. & $\begin{array}{l}\text { now it is time for America to bind } \\
\text { the wounds of division }\end{array}$ & A NATION IS A PERSON & Victory speech \\
\hline 23. & $\begin{array}{l}\text { the strongest economy anywhere } \\
\text { in the world }\end{array}$ & ECONOMY IS A PERSON & Victory speech \\
\hline 24. & $\begin{array}{l}\text { we will have great relationships } \\
\text { (with other nations) }\end{array}$ & A NATION IS A PERSON & Victory speech \\
\hline 25. & $\begin{array}{l}\text { we expect to have great, great } \\
\text { relationships }\end{array}$ & A NATION IS A PERSON & Victory speech \\
\hline 26. & $\begin{array}{l}\text { we must reclaim our country's } \\
\text { destiny }\end{array}$ & A NATION IS A PERSON & Victory speech \\
\hline 27. & $\begin{array}{l}\text { we will always put America's } \\
\text { interests first }\end{array}$ & A NATION IS A PERSON & Victory speech \\
\hline 28. & depletion of our military & THE MILITARY IS A PERSON & Inauguration speech \\
\hline 29. & $\begin{array}{l}\text { the crime and gangs and drugs } \\
\text { that have stolen too many lives } \\
\text { and robbed our country of so } \\
\text { much unrealized potential }\end{array}$ & A NATION IS A PERSON & Inauguration speech \\
\hline 30. & $\begin{array}{l}\text { the wealth, strength, and } \\
\text { confidence of our country has } \\
\text { disappeared over the horizon }\end{array}$ & A NATION IS A PERSON & Inauguration speech \\
\hline 31. & $\begin{array}{l}\text { the factories shuttered and left our } \\
\text { shores }\end{array}$ & BUILDINGS ARE PEOPLE & Inauguration speech \\
\hline 32. & $\begin{array}{l}\text { We must protect our borders from } \\
\text { the ravages of other countries }\end{array}$ & OTHER NATIONS ARE THIEVES & Inauguration speech \\
\hline 33. & $\begin{array}{l}\text { (other countries) stealing our } \\
\text { companies and destroying our } \\
\text { jobs }\end{array}$ & OTHER NATIONS ARE THIEVES & Inauguration speech \\
\hline 34. & $\begin{array}{l}\text { we will seek friendship and } \\
\text { goodwill with the nations of the } \\
\text { world }\end{array}$ & A NATION IS A PERSON & Inauguration speech \\
\hline & $\begin{array}{l}\text { the right of all nations to put their } \\
\text { own interests first }\end{array}$ & A NATION IS A PERSON & Inauguration speech \\
\hline 36. & $\begin{array}{l}\text { a nation is only living as long as it } \\
\text { is striving }\end{array}$ & A NATION IS A PERSON & Inauguration speech \\
\hline & the face of the Earth & A PLANET IS A PERSON & Inauguration speech \\
\hline
\end{tabular}




\begin{tabular}{|c|c|c|c|}
\hline$\#$ & Text passage & Metaphor & Speech \\
\hline \multicolumn{4}{|c|}{ Person Metaphors } \\
\hline 38. & $\begin{array}{l}\text { no challenge can match the heart } \\
\text { and fight and spirit of America }\end{array}$ & NATION (AMERICA) IS A PERSON & Inauguration speech \\
\hline 39. & $\begin{array}{l}\text { to free the Earth from the miseries } \\
\text { of disease }\end{array}$ & A PLANET IS A PERSON & Inauguration speech \\
\hline 40. & $\begin{array}{l}\text { a new national pride will stir our } \\
\text { souls, lift our sights, and heal our } \\
\text { divisions }\end{array}$ & PATRIOTISM IS A DOCTOR & Inauguration speech \\
\hline 41. & $\begin{array}{l}\text { we will make America strong } \\
\text { again }\end{array}$ & A NATION IS A PERSON & Inauguration speech \\
\hline 42. & $\begin{array}{l}\text { we will make America wealthy } \\
\text { again }\end{array}$ & A NATION IS A PERSON & Inauguration speech \\
\hline 43. & $\begin{array}{l}\text { we will make America proud } \\
\text { again }\end{array}$ & A NATION IS A PERSON & Inauguration speech \\
\hline 44. & $\begin{array}{l}\text { when you open your heart to } \\
\text { patriotism }\end{array}$ & PATRIOTISM IS A VISITOR & Inauguration speech \\
\hline 45. & $\begin{array}{l}\text { fair trade policy that protects our } \\
\text { jobs and stands up to countries } \\
\text { that cheat }\end{array}$ & A POLICY IS A PERSON & Acceptance speech \\
\hline 46. & $\begin{array}{l}\text { trade deals that strip us of our } \\
\text { jobs, and strip us of our wealth as } \\
\text { a country }\end{array}$ & $\begin{array}{l}\text { A TRADE DEAL IS AN IMMORAL } \\
\text { PERSON }\end{array}$ & Acceptance speech \\
\hline 47. & $\begin{array}{l}\text { trade deals that strip us of our } \\
\text { jobs, and strip us of our wealth as } \\
\text { a country }\end{array}$ & A NATION IS A PERSON & Acceptance speech \\
\hline 48. & $\begin{array}{l}\text { who has used the pulpit of the } \\
\text { presidency }\end{array}$ & A PRESIDENT IS A PREACHER & Acceptance speech \\
\hline
\end{tabular}

\begin{tabular}{llll}
\hline Servant Metaphors & & \\
\hline 49. & $\begin{array}{l}\text { my opponent would rather } \\
\text { protect bureaucrats than serve } \\
\text { American children }\end{array}$ & POLITICIANS ARE SERVANTS & Acceptance speech \\
\hline 50. & those who serve this country & $\begin{array}{l}\text { THE MILITARY PERSONNEL ARE } \\
\text { SERVANTS }\end{array}$ & Acceptance speech \\
\hline 51. & her service to our country & POLITICIANS ARE SERVANTS & Victory speech \\
\hline 52. & nation exists to serve its citizens & A NATION IS A SERVANT & Inauguration speech \\
\hline 53. & who want and expect our & POLITICIANS ARE SERVANTS & Victory speech \\
\hline
\end{tabular}




\begin{tabular}{llll}
\hline Guide Metaphors & & \\
\hline 54. & $\begin{array}{l}\text { protection will lead to great } \\
\text { prosperity and strength }\end{array}$ & $\begin{array}{l}\text { PROTECTION IS A GUIDE TOWARDS } \\
\text { WELL-BEING }\end{array}$ & Inauguration speech \\
\hline 55. & we will follow two simple rules & REGULATIONS ARE GUIDES & Inauguration speech \\
\hline 56. & $\begin{array}{l}\text { to impose our way of life on } \\
\text { anyone, but rather to let it shine as } \\
\text { an example for everyone to follow }\end{array}$ & AMERICA IS A GUIDE & Inauguration speech \\
\hline 57. & $\begin{array}{l}\text { your courage and goodness and } \\
\text { love will forever guide us along } \\
\text { the way }\end{array}$ & MORAL VALUES ARE GUIDES & Inauguration speech \\
\hline
\end{tabular}

\begin{tabular}{llll}
\hline \multicolumn{2}{l}{ Animal Metaphors } & & \\
\hline 58. & $\begin{array}{l}\text { illegal immigrants with criminal } \\
\text { records (ordered deported from } \\
\text { our country) are tonight roaming } \\
\text { free }\end{array}$ & IMMIGRANTS ARE ANIMALS & Acceptance speech \\
\hline 59. & $\begin{array}{l}\text { they are being released (by the } \\
\text { tens of thousands into our } \\
\text { communities) with no regard for } \\
\text { the impact on public safety or } \\
\text { resources }\end{array}$ & IMMIGRANTS ARE ANIMALS & Acceptance speech \\
\hline 60. & stamping out Islamic terrorism & TERRORISTS ARE INSECTS & Acceptance speech \\
\hline 61. & $\begin{array}{l}\text { one such border-crosser was } \\
\text { released }\end{array}$ & IMMIGRANTS ARE ANIMALS & Acceptance speech \\
\hline 62. & they are throwing money at her & $\begin{array}{l}\text { WASTING IS THROWING A PRECIOUS } \\
\text { OBJECT TO AN ANIMAL }\end{array}$ & Acceptance speech \\
\hline 63. & they are throwing money at her & $\begin{array}{l}\text { CLINTON IS A PIG [CASTING PEARLS } \\
\text { BEFORE SWINE] }\end{array}$ & Acceptance speech \\
\hline 64. & brutal Islamic terrorism & TERRORISM IS AN ANIMAL & Acceptance speech \\
\hline 65. & $\begin{array}{l}\text { Americans were savagely } \\
\text { murdered by an Islamic terrorist }\end{array}$ & A TERRORIST IS AN ANIMAL & Acceptance speech \\
\hline
\end{tabular}




\begin{tabular}{llll}
\hline$\# \quad$ Text passage & Metaphor & Speech \\
\hline \hline Animal Metaphors & & \\
\hline 66. & $\begin{array}{l}\text { (On Monday, we heard from three } \\
\text { parents whose children were } \\
\text { killed by illegal immigrants Mary }\end{array}$ & & IMMIGRANTS ARE ANIMALS \\
& $\begin{array}{l}\text { Ann Mendoza, Sabine Durden, } \\
\text { and my friend Jamiel Shaw. They speech } \\
\text { are just three brave representatives } \\
\text { of many thousands who have }\end{array}$ & & \\
& $\begin{array}{l}\text { suffered so gravely). } \\
\text { Americans who have been so } \\
\text { brutally murdered, and who have } \\
\text { suffered so so horribly }\end{array}$ & & \\
\hline 67. & $\begin{array}{l}\text { companies and new jobs to come } \\
\text { roaring back into our country }\end{array}$ & COMPANIES ARE LIONS & Acceptance speech \\
\hline 68. & $\begin{array}{l}\text { I will harness the creative talents } \\
\text { of our people }\end{array}$ & TALENTS ARE DRAFT HORSES & Victory speech \\
\hline 69. & $\begin{array}{l}\text { mothers and children trapped in } \\
\text { poverty }\end{array}$ & PEOPLE ARE ANIMALS & Inauguration speech \\
\hline 70. & $\begin{array}{l}\text { to harness the energies, industries } \\
\text { and technologies of tomorrow }\end{array}$ & ENERGIES, INDUSTRIES, AND \\
\hline
\end{tabular}

\section{Object Metaphors}

\begin{tabular}{llll}
\hline 71. & $\begin{array}{l}\text { (I humbly and gratefully) accept } \\
\text { your nomination }\end{array}$ & A NOMINATION IS AN OBJECT & Acceptance speech \\
\hline 72. & $\begin{array}{l}\text { (the crime and violence that today } \\
\text { afflicts our nation) come to an end }\end{array}$ & $\begin{array}{l}\text { CRIME AND VIOLENCE IS A MOVING } \\
\text { OBJECT }\end{array}$ & Acceptance speech \\
\hline 73. & $\begin{array}{l}\text { the Democrats are holding their } \\
\text { convention next week }\end{array}$ & A CONVENTION IS AN OBJECT & Acceptance speech \\
\hline 74. & he took office & A JOB IS AN OBJECT & Acceptance speech \\
\hline 75. & $\begin{array}{l}\text { (President Obama) took his oath } \\
\text { of office }\end{array}$ & AN OATH IS AN OBJECT & Acceptance speech \\
\hline 76. & $\begin{array}{l}\text { to put Hillary Clinton in charge } \\
\text { of America's foreign policy }\end{array}$ & PEOPLE ARE OBJECTS & Acceptance speech \\
\hline 77. & to retake control & CONTROL IS AN OBJECT & Acceptance speech \\
\hline 78. & $\begin{array}{l}\text { (I will) share with you my plan of } \\
\text { action }\end{array}$ & A PLAN IS AN OBJECT & Acceptance speech \\
\hline 79. & our plan will put America first & A NATION IS AN OBJECT & Acceptance speech \\
\hline 80. & put America first & A NATION IS AN OBJECT & Acceptance speech \\
\hline
\end{tabular}




\begin{tabular}{|c|c|c|c|}
\hline \# & Text passage & Metaphor & Speech \\
\hline \multicolumn{4}{|c|}{ Object Metaphors } \\
\hline 81. & $\begin{array}{l}\text { a Secretary of State illegally stores } \\
\text { her emails }\end{array}$ & E-MAILS ARE OBJECTS & Acceptance speech \\
\hline 82. & $\begin{array}{l}\text { (a Secretary of State) puts our } \\
\text { country at risk }\end{array}$ & A NATION IS AN OBJECT & Acceptance speech \\
\hline 83. & $\begin{array}{l}\text { (the Secretary of State was } \\
\text { "extremely careless" and } \\
\text { "negligent,") in handling our } \\
\text { classified secrets }\end{array}$ & SECRETS ARE OBJECTS & Acceptance speech \\
\hline 84. & $\begin{array}{l}\text { we will bring the same economic } \\
\text { success to America }\end{array}$ & SUCCESS IS AN OBJECT & Acceptance speech \\
\hline 85. & when I take the oath of office & AN OATH IS AN OBJECT & Acceptance speech \\
\hline 86. & $\begin{array}{l}\text { every action I take, I will ask } \\
\text { myself }\end{array}$ & ACTIONS ARE OBJECTS & Acceptance speech \\
\hline 87. & $\begin{array}{l}\text { the failed policy of nation } \\
\text { building and regime change that } \\
\text { Hillary Clinton pushed in Iraq, } \\
\text { Libya, Egypt and Syria }\end{array}$ & POLICY IS AN OBJECT & Acceptance speech \\
\hline 88. & share our goal & GOALS ARE OBJECTS & Acceptance speech \\
\hline 89. & $\begin{array}{l}\text { the United States has been picking } \\
\text { up the cost }\end{array}$ & EXPENDITURE IS AN OBJECT & Acceptance speech \\
\hline 90. & share in their pain & PAIN IS AN OBJECT & Acceptance speech \\
\hline 91. & to send them our love & LOVE IS AN OBJECT & Acceptance speech \\
\hline 92. & $\begin{array}{l}\text { our laws will finally receive the } \\
\text { respect they deserve }\end{array}$ & RESPECT IS AN OBJECT & Acceptance speech \\
\hline 93. & $\begin{array}{l}\text { from the moment I take the oath } \\
\text { of office }\end{array}$ & AN OATH IS AN OBJECT & Acceptance speech \\
\hline 94. & the day I take the oath of office & AN OATH IS AN OBJECT & Acceptance speech \\
\hline 95. & $\begin{array}{l}\text { I am going to bring our jobs back } \\
\text { to Ohio and Pennsylvania and } \\
\text { New York and Michigan and all } \\
\text { of America }\end{array}$ & A JOB IS AN OBJECT & Acceptance speech \\
\hline 96. & intellectual property & IDEAS ARE POSSESSIONS & Acceptance speech \\
\hline 97. & $\begin{array}{l}\text { to put the great miners and steel } \\
\text { workers of our country out of } \\
\text { work }\end{array}$ & PEOPLE ARE OBJECTS & Acceptance speech \\
\hline 98. & $\begin{array}{l}\text { Ten Point Plan has received } \\
\text { tremendous veteran support }\end{array}$ & SUPPORT IS AN OBJECT & Acceptance speech \\
\hline
\end{tabular}




\begin{tabular}{|c|c|c|c|}
\hline \# & Text passage & Metaphor & Speech \\
\hline \multicolumn{4}{|c|}{ Object Metaphors } \\
\hline 99. & the support they have given me & SUPPORT IS AN OBJECT & Acceptance speech \\
\hline 100. & their voice has been taken away & VOICE IS AN OBJECT & Acceptance speech \\
\hline 101. & I will always give you my love & LOVE IS AN OBJECT & Acceptance speech \\
\hline 102. & deliver a victory & VICTORY IS AN OBJECT & Acceptance speech \\
\hline 103. & $\begin{array}{l}\text { I'm reaching out to you for your } \\
\text { guidance and your help }\end{array}$ & GUIDANCE AND HELP IS AN OBJECT & Victory speech \\
\hline 104. & $\begin{array}{l}\text { it is a movement comprised of } \\
\text { Americans from all races, } \\
\text { religions, backgrounds, and beliefs }\end{array}$ & A MOVEMENT IS AN OBJECT & Victory speech \\
\hline 105. & $\begin{array}{l}\text { we will put millions of our people } \\
\text { to work }\end{array}$ & PEOPLE ARE OBJECTS & Victory speech \\
\hline 106. & no dream is too big & A DREAM IS AN OBJECT & Victory speech \\
\hline 107. & no challenge is too great & CHALLENGE IS AN OBJECT & Victory speech \\
\hline 108. & I would like to take this moment & TIME IS AN OBJECT & Victory speech \\
\hline 109. & $\begin{array}{l}\text { I want to give a very special } \\
\text { thanks }\end{array}$ & GRATITUDE IS AN OBJECT & Victory speech \\
\hline 110. & transfer of power & POLITICAL POWER IS AN OBJECT & Victory speech \\
\hline 111. & $\begin{array}{l}\text { transferring power from one } \\
\text { administration to another }\end{array}$ & POLITICAL POWER IS AN OBJECT & Victory speech \\
\hline 112. & $\begin{array}{l}\text { we are transferring power from } \\
\text { Washington, D.C. }\end{array}$ & POLITICAL POWER IS AN OBJECT & Victory speech \\
\hline 113. & giving it [power] back to you & POLITICAL POWER IS AN OBJECT & Victory speech \\
\hline 114. & $\begin{array}{l}\text { this moment is your moment: it } \\
\text { belongs to you }\end{array}$ & TIME IS AN OBJECT & Victory speech \\
\hline 115. & $\begin{array}{l}\text { the crime and gangs and drugs } \\
\text { that have stolen too many lives } \\
\text { and robbed our country of so } \\
\text { much unrealized potential }\end{array}$ & LIFE IS A VALUABLE POSSESSION & Victory speech \\
\hline 116. & $\begin{array}{l}\text { we share one heart, one home, } \\
\text { and one glorious destiny }\end{array}$ & DESTINY IS AN OBJECT & Victory speech \\
\hline 117. & the oath of office I take today & AN OATH IS AN OBJECT & Victory speech \\
\hline 118. & we will bring back our jobs & A JOB IS AN OBJECT & Victory speech \\
\hline 119. & we will bring back our wealth & WEALTH IS AN OBJECT & Victory speech \\
\hline 120. & we will bring back our dreams & A DREAM IS AN OBJECT & Victory speech \\
\hline 121. & $\begin{array}{l}\text { we will get our people off of } \\
\text { welfare and back to work }\end{array}$ & PEOPLE ARE OBJECTS & Victory speech \\
\hline 122. & room for prejudice & PREJUDICE IS AN OBJECT & Victory speech \\
\hline
\end{tabular}




\begin{tabular}{|c|c|c|c|}
\hline \# & Text passage & Metaphor & Speech \\
\hline \multicolumn{4}{|c|}{ Object Metaphors } \\
\hline 123. & $\begin{array}{l}\text { major donors are lining up behind } \\
\text { the campaign of my opponent }\end{array}$ & $\begin{array}{l}\text { AN ELECTION CAMPAIGN IS AN } \\
\text { OBJECT }\end{array}$ & Acceptance speech \\
\hline 124. & $\begin{array}{l}\text { to leverage their tremendous } \\
\text { talent }\end{array}$ & A TALENT IS AN OBJECT & Victory speech \\
\hline 125. & $\begin{array}{l}\text { mothers and children trapped in } \\
\text { poverty }\end{array}$ & POVERTY IS A TRAP & Inauguration speech \\
\hline 126. & pursue solidarity & $\begin{array}{l}\text { SOLIDARITY IS AN OBJECT TO BE } \\
\text { PURSUED }\end{array}$ & Inauguration speech \\
\hline 127. & $\begin{array}{l}\text { we must break free from the petty } \\
\text { politics of the past }\end{array}$ & BAD POLITICS IS CHAINS & Acceptance speech \\
\hline 128. & $\begin{array}{l}\text { we, the citizens of America, are } \\
\text { now joined in a great national } \\
\text { effort }\end{array}$ & PEOPLE ARE LINKS OF A CHAIN & Inauguration speech \\
\hline 129. & $\begin{array}{l}\text { (her bad instincts and her bad } \\
\text { judgment) are what caused so } \\
\text { many of the disasters unfolding } \\
\text { today }\end{array}$ & PROBLEMS ARE FABRIC & Acceptance speech \\
\hline 130. & families ripped apart & FAMILIES ARE FABRIC & Acceptance speech \\
\hline 131. & $\begin{array}{l}\text { the wealth of our middle class has } \\
\text { been ripped from their homes }\end{array}$ & WEALTH IS A FABRIC & Victory speech \\
\hline 132. & $\begin{array}{l}\text { we cannot afford to be so } \\
\text { politically correct anymore }\end{array}$ & $\begin{array}{l}\text { POLITICAL CORRECTNESS IS AN } \\
\text { EXPENSIVE ITEM }\end{array}$ & Acceptance speech \\
\hline 133. & the carefully-crafted lies & $\begin{array}{l}\text { LIES ARE SKILFULLY MANUFACTURED } \\
\text { GOODS }\end{array}$ & Acceptance speech \\
\hline 134. & to produce a change in outcomes & RESULTS ARE PRODUCTS & Acceptance speech \\
\hline 135. & $\begin{array}{l}\text { decades of record immigration } \\
\text { have produced lower wages and } \\
\text { higher unemployment }\end{array}$ & $\begin{array}{l}\text { WAGES AND UNEMPLOYMENT ARE } \\
\text { PRODUCTS }\end{array}$ & Acceptance speech \\
\hline
\end{tabular}

\section{Physical Suffering Metaphors}

\begin{tabular}{llll}
\hline 136. & $\begin{array}{l}\text { the crime and violence that today } \\
\text { afflicts our nation }\end{array}$ & CRIME AND VIOLENCE IS A DISEASE & Acceptance speech \\
\hline 137. & wounded American families & $\begin{array}{l}\text { EMOTIONAL SUFFERING IS A } \\
\text { PHYSICAL wOUND }\end{array}$ & Acceptance speech \\
\hline 138. & $\begin{array}{l}\text { relief from uncontrolled } \\
\text { immigration }\end{array}$ & IMMIGRATION IS PAIN & Acceptance speech \\
\hline 139. & agreement that hurts our workers & BAD AGREEMENTS ARE PAIN & Acceptance speech \\
\hline
\end{tabular}




\begin{tabular}{llll}
\hline$\#$ & Text passage & Metaphor & Speech \\
\hline \hline Physical Suffering Metaphors & & \\
\hline 140. & $\begin{array}{l}\text { (middle-income Americans and } \\
\text { businesses) will experience } \\
\text { profound relief }\end{array}$ & TAXES ARE PAIN & Acceptance speech \\
\hline 141. & $\begin{array}{l}\text { now it is time for America to bind } \\
\text { the wounds of division }\end{array}$ & SOCIAL DIVISION IS A WOUND & Victory speech \\
\hline 142. & their pain is our pain & PROBLEMS ARE PHYSICAL SUFFERING & Inauguration speech \\
\hline 143. & $\begin{array}{l}\text { subsidized the armies of other } \\
\text { countries while allowing for the } \\
\text { very sad depletion of our military }\end{array}$ & FINANCIAL LOSS IS BLEEDING & Inauguration speech \\
\hline 144. & $\begin{array}{l}\text { a new national pride will stir our } \\
\text { souls, lift our sights, and heal our } \\
\text { divisions }\end{array}$ & SOCIAL DIVISION IS A WOUND & Inauguration speech \\
\hline
\end{tabular}

\section{Force Metaphors}

\begin{tabular}{llll}
\hline 145. & $\begin{array}{l}\text { they are being released (by the } \\
\text { tens of thousands into our } \\
\text { communities) with no regard for } \\
\text { the impact on public safety or } \\
\text { resources }\end{array}$ & $\begin{array}{l}\text { IMMIGRANTS ARE A DESTRUCTIVE } \\
\text { FORCE }\end{array}$ & Acceptance speech \\
\hline 146. & the problems we face now & RESISTANCE IS REMAINING UPRIGHT & Acceptance speech \\
\hline 147. & $\begin{array}{l}\text { (a Secretary of State) faces no } \\
\text { consequence }\end{array}$ & DIFFICULTIES ARE OPPOSING FORCES & Acceptance speech \\
\hline 148. & $\begin{array}{l}\text { the powerful can no longer beat } \\
\text { up on people }\end{array}$ & AUTHORITY IS PHYSICAL POWER & Acceptance speech \\
\hline 149. & $\begin{array}{l}\text { the growing threats we face from } \\
\text { outside the country }\end{array}$ & DIFFICULTIES ARE OPPOSING FORCES & Acceptance speech \\
\hline 150. & $\begin{array}{l}\text { fair trade policy that protects our } \\
\text { jobs and stands up to countries } \\
\text { that cheat }\end{array}$ & RESISTANCE IS REMAINING UPRIGHT & Acceptance speech \\
\hline 151. & $\begin{array}{l}\text { devastating currency } \\
\text { manipulation }\end{array}$ & $\begin{array}{l}\text { CURRENCY MANIPULATION IS A } \\
\text { DEVASTATING FORCE }\end{array}$ & Acceptance speech \\
\hline 152. & we will face challenges & DIFFICULTIES ARE OPPOSING FORCES & Inauguration speech \\
\hline 153. & we will confront hardships & DIFFICULTIES ARE OPPOSING FORCES & Inauguration speech \\
\hline 154. & $\begin{array}{l}\text { a new national pride will stir our } \\
\text { souls, lift our sights, and heal our } \\
\text { divisions }\end{array}$ & PATRIOTISM IS A FORCE & Inauguration speech \\
\hline 155. & domestic disaster & A PROBLEM IS A DESTRUCTIVE FORCE & Acceptance speech \\
\hline
\end{tabular}




\begin{tabular}{|c|c|c|c|}
\hline \# & Text passage & Metaphor & Speech \\
\hline \multicolumn{4}{|c|}{ Force Metaphors } \\
\hline 156. & $\begin{array}{l}\text { (her bad instincts and her bad } \\
\text { judgment) are what caused so } \\
\text { many of the disasters unfolding } \\
\text { today }\end{array}$ & A MISTAKE IS A DESTRUCTIVE FORCE & Acceptance speech \\
\hline 157. & disastrous trade deals & $\begin{array}{l}\text { A TRADE DEAL IS A DESTRUCTIVE } \\
\text { FORCE }\end{array}$ & Acceptance speech \\
\hline 158. & colossal mistakes and disasters & A MISTAKE IS A DESTRUCTIVE FORCE & Acceptance speech \\
\hline 159. & $\begin{array}{l}\text { we will repeal and replace } \\
\text { disastrous Obamacare }\end{array}$ & $\begin{array}{l}\text { OBAMACARE IS A DESTRUCTIVE } \\
\text { FORCE }\end{array}$ & Acceptance speech \\
\hline 160. & $\begin{array}{l}\text { and we will fix TSA at the } \\
\text { airports which is a total disaster }\end{array}$ & $\begin{array}{l}\text { TRANSPORTATION SECURITY } \\
\text { ADMINISTRATION IS A } \\
\text { DESTRUCTIVE FORCE }\end{array}$ & Acceptance speech \\
\hline
\end{tabular}

\section{Building Metaphors}

\begin{tabular}{llll}
\hline 161. & safety will be restored & SAFETY IS A BUILDING & Acceptance speech \\
\hline 162. & bringing down crime & CRIME IS A BUILDING & Acceptance speech \\
\hline 163. & the world is far less stable & THE WORLD IS A BUILDING & Acceptance speech \\
\hline 164. & the world is far less stable & PEACE IS STABILITY & Acceptance speech \\
\hline 165. & Libya was stable & $\begin{array}{l}\text { A NATION IS A BUILDING } \\
\text { PEACE IS STABILITY }\end{array}$ & Acceptance speech \\
\hline 166. & $\begin{array}{l}\text { communities crushed by our } \\
\text { horrible and unfair trade deals }\end{array}$ & COMMUNITIES ARE BUILDINGS & Acceptance speech \\
\hline 167. & rebuild America & A NATION IS A BUILDING & Acceptance speech \\
\hline 168. & $\begin{array}{l}\text { I will restore law and order to our } \\
\text { country }\end{array}$ & LAW AND ORDER IS A BUILDING & Acceptance speech \\
\hline 169. & lives ruined & LIFE IS A BUILDING & Acceptance speech \\
\hline 170. & destroying ISIS & ISIS IS A BUILDING & Acceptance speech \\
\hline 171. & Peace will be restored & PEACE IS A BUILDING & Acceptance speech \\
\hline 172. & destroying our middle class & SOCIAL CLASS IS A BUILDING & Acceptance speech \\
\hline 173. & no longer will we enter into these & TRANSACTION IS A BUILDING & Acceptance speech \\
& $\begin{array}{l}\text { massive transactions, with many } \\
\text { countries }\end{array}$ & & \\
\hline 174. & $\begin{array}{l}\text { (we will completely) rebuild our } \\
\text { depleted military }\end{array}$ & THE MILITARY IS A BUILDING & Acceptance speech \\
\hline 175. & rebuilding our nation & A NATION IS A BUILDING & Victory speech \\
\hline 176. & our work on this movement & A MOVEMENT IS A BUILDING & Victory speech \\
\hline
\end{tabular}




\begin{tabular}{|c|c|c|c|}
\hline \# & Text passage & Metaphor & Speech \\
\hline \multicolumn{4}{|c|}{ Building Metaphors } \\
\hline 177. & $\begin{array}{l}\text { rebuilding our country with } \\
\text { American hands and American } \\
\text { labor }\end{array}$ & A NATION IS A BUILDING & Inauguration speech \\
\hline 178. & rusted-out factories & DESOLATION IS A RUSTED BUILDING & Inauguration speech \\
\hline 179. & $\begin{array}{l}\text { to rebuild our country and to } \\
\text { restore its promise }\end{array}$ & $\begin{array}{l}\text { A NATION IS A BUILDING / A } \\
\text { PROMISE IS A BUILDING }\end{array}$ & Inauguration speech \\
\hline 180. & At the bedrock of our politics & POLITICS IS A BUILDING & Inauguration speech \\
\hline 181. & $\begin{array}{l}\text { when you open your heart to } \\
\text { patriotism }\end{array}$ & HEART IS A HOME & Inauguration speech \\
\hline 182. & $\begin{array}{l}\text { (one more child to sacrifice) on } \\
\text { the order and on the altar of open } \\
\text { borders }\end{array}$ & $\begin{array}{l}\text { BORDERS ARE DOORS TO A } \\
\text { BUILDING }\end{array}$ & Acceptance speech \\
\hline
\end{tabular}

\section{Container Metaphors}

\begin{tabular}{llll}
\hline 183. & children are living in poverty & POVERTY IS A CONTAINER & Acceptance speech \\
\hline 184. & $\begin{array}{l}\text { existing massive refugee flows } \\
\text { coming into our country }\end{array}$ & A COUNTRY IS A CONTAINER & Acceptance speech \\
\hline $\begin{array}{l}\text { 185. } \\
\text { to stop the drugs from pouring } \\
\text { into our communities }\end{array}$ & COMMUNITIES ARE CONTAINERS & Acceptance speech \\
\hline 186. & $\begin{array}{l}\text { trillions of dollars will start } \\
\text { flowing into our country }\end{array}$ & A COUNTRY IS A CONTAINER & Acceptance speech \\
\hline 187. & the time for empty talk is over & MEANING IS SUBSTANCE IN A & Inauguration speech \\
\hline 188. & to unlock the mysteries of space & $\begin{array}{l}\text { THE UNKNOWN IS THE CONTENTS } \\
\text { OF A LOCKED CHEST }\end{array}$ & Inauguration speech \\
\hline 189. & $\begin{array}{l}\text { they fill their heart with the same } \\
\text { dreams }\end{array}$ & THE HEART IS A CONTAINER & Inauguration speech \\
\hline 190. & $\begin{array}{l}\text { they are infused with the breath of } \\
\text { life }\end{array}$ & PEOPLE ARE CONTAINERS & Inauguration speech \\
\hline
\end{tabular}

\section{Machine Metaphors}

\begin{tabular}{llll}
\hline 191. & we're going to fix that & $\begin{array}{l}\text { SOLVING PROBLEMS IS FIXING A } \\
\text { MACHINE }\end{array}$ & Acceptance speech \\
\hline 192. & I alone can fix it & $\begin{array}{l}\text { SOLVING PROBLEMS IS FIXING A } \\
\text { MACHINE }\end{array}$ & Acceptance speech \\
\hline
\end{tabular}




\begin{tabular}{llll}
\hline$\#$ & Text passage & Metaphor & Speech \\
\hline \hline Machine Metaphors & & \\
\hline 193. & we will fix his biggest single issue & $\begin{array}{l}\text { SOLVING PROBLEMS IS FIXING A } \\
\text { MACHINE }\end{array}$ & Acceptance speech \\
\hline 194. & $\begin{array}{l}\text { to fix the system so it works justly } \\
\text { for each and every American }\end{array}$ & $\begin{array}{l}\text { THE POLITICAL SYSTEM IS A } \\
\text { MACHINE }\end{array}$ & Acceptance speech \\
\hline 195. & we can fix this problem so quickly & SOLVING PROBLEMS IS FIXING A & Acceptance speech \\
& & MACHINE & Acceptance speech \\
\hline 196. & we will fix TSA at the airports & $\begin{array}{l}\text { TRANSPORTATION SECURITY } \\
\text { ADMINISTRATION IS A MACHINE }\end{array}$ & Acceptance speech \\
\hline 197. & to fix our inner cities & SOLVING PROBLEMS IS FIXING A & Acceptance speech \\
\hline 198. & $\begin{array}{l}\text { to fix the system so it works justly } \\
\text { for each and every American }\end{array}$ & POLITICAL SYSTEM IS A MACHINE & Acceptance speech \\
\hline 199. & $\begin{array}{l}\text { decades of record immigration } \\
\text { have produced lower wages and } \\
\text { higher unemployment }\end{array}$ & IMMIGRATION IS A MACHINE & \\
\hline
\end{tabular}

\begin{tabular}{|c|c|c|c|}
\hline \multicolumn{4}{|c|}{ Journey Metaphors } \\
\hline 200. & way of life & LIFE IS A JOURNEY & Acceptance speech \\
\hline 201. & $\begin{array}{l}\text { he ended the life of an innocent } \\
\text { young girl }\end{array}$ & LIFE IS A JOURNEY & Acceptance speech \\
\hline 202. & $\begin{array}{l}\text { the cycle of human smuggling and } \\
\text { violence }\end{array}$ & $\begin{array}{l}\text { HUMAN SMUGGLING AND VIOLENCE } \\
\text { IS A (NEVER-ENDING) JOURNEY }\end{array}$ & Acceptance speech \\
\hline 203. & $\begin{array}{l}\text { to escape the tremendous cycle of } \\
\text { poverty that they're going } \\
\text { through }\end{array}$ & $\begin{array}{l}\text { POVERTY IS A (NEVER-ENDING) } \\
\text { JOURNEY }\end{array}$ & Acceptance speech \\
\hline 204. & $\begin{array}{l}\text { young people just starting out } \\
\text { their adult lives }\end{array}$ & LIFE IS A JOURNEY & Acceptance speech \\
\hline 205. & in this journey & $\begin{array}{l}\text { AN ELECTION CAMPAIGN IS A } \\
\text { JOURNEY }\end{array}$ & Acceptance speech \\
\hline 206. & this 18 -month journey & $\begin{array}{l}\text { AN ELECTION CAMPAIGN IS A } \\
\text { JOURNEY }\end{array}$ & Victory speech \\
\hline
\end{tabular}

\section{Motion Metaphors}

207. the crime and violence that today

TIME IS MOTION

Acceptance speech afflicts our nation come to an end 


\begin{tabular}{|c|c|c|c|}
\hline \# & Text passage & Metaphor & Speech \\
\hline \multicolumn{4}{|c|}{ Motion Metaphors } \\
\hline \multirow[t]{2}{*}{208.} & the corporate spin & A CHARACTERISTIC IS A PARTICULAR & Acceptance speech \\
\hline & & ROTATION & \\
\hline 209. & rollback of criminal enforcement & CHANGE IS MOTION & Acceptance speech \\
\hline 210. & it will go down in history & TIME IS MOTION & Acceptance speech \\
\hline \multirow[t]{3}{*}{211.} & on the path to nuclear weapons & REACHING A GOAL IS MOTION & Acceptance speech \\
\hline & & ALONG A PATH TOWARDS A & \\
\hline & & DESTINATION & \\
\hline 212. & $\begin{array}{l}\text { she will keep our rigged system in } \\
\text { place }\end{array}$ & CHANGE IS MOTION & Acceptance speech \\
\hline 213. & the time for action has come & TIME IS A MOVING VEHICLE & Acceptance speech \\
\hline 214. & a true step in the right direction & CHANGE IS MOTION & Acceptance speech \\
\hline 215. & $\begin{array}{l}\text { we'll walk away (if we don't get } \\
\text { the deal that we want) }\end{array}$ & REFUSING IS GOING AWAY & Acceptance speech \\
\hline 216. & $\begin{array}{l}\text { ours was not a campaign but } \\
\text { rather an incredible and great } \\
\text { movement }\end{array}$ & CHANGE IS MOTION & Victory speech \\
\hline 217. & $\begin{array}{l}\text { America's infrastructure has fallen } \\
\text { into disrepair and decay }\end{array}$ & DAMAGE IS FALLING & Inauguration speech \\
\hline 218. & $\begin{array}{l}\text { You came by the tens of millions } \\
\text { to become part of a historic } \\
\text { movement }\end{array}$ & CHANGE IS MOTION & Inauguration speech \\
\hline 219. & at the center of this movement & CHANGE IS MOTION & Inauguration speech \\
\hline 220. & now arrives the hour of action & TIME IS MOTION & Inauguration speech \\
\hline 221. & $\begin{array}{l}\text { but his supporters will join our } \\
\text { movement }\end{array}$ & CHANGE IS MOTION & Acceptance speech \\
\hline 222. & $\begin{array}{l}\text { Democrats will join our } \\
\text { movement }\end{array}$ & CHANGE IS MOTION & Acceptance speech \\
\hline 223. & $\begin{array}{l}\text { (you came by the tens of millions) } \\
\text { to become part of a historic } \\
\text { movement }\end{array}$ & CHANGE IS MOTION & Inauguration speech \\
\hline 224. & at the center of this movement & CHANGE IS MOTION & Inauguration speech \\
\hline
\end{tabular}

\begin{tabular}{llll}
\hline \multicolumn{2}{l}{ Spatial Metaphors } & \\
\hline 225. & killings have risen by 50 percent & MORE IS UP & Acceptance speech \\
\hline 226. & they are up nearly 60 percent & MORE IS UP & Acceptance speech \\
\hline
\end{tabular}




\begin{tabular}{|c|c|c|c|}
\hline \# & Text passage & Metaphor & Speech \\
\hline \multicolumn{4}{|c|}{ Spatial Metaphors } \\
\hline 227. & $\begin{array}{l}\text { the number of police officers } \\
\text { killed in the line of duty has risen } \\
\text { by almost } 50 \text { percent }\end{array}$ & MORE IS UP & Acceptance speech \\
\hline 228. & $\begin{array}{l}\text { we will lead our country back to } \\
\text { safety, prosperity, and peace }\end{array}$ & $\begin{array}{l}\text { SAFETY AND PROSPERITY AND } \\
\text { PEACE ARE LOCATIONS }\end{array}$ & Acceptance speech \\
\hline 229. & the line of duty & $\begin{array}{l}\text { DUTY IS AN ORDERLY SPATIAL } \\
\text { ARRANGEMENT }\end{array}$ & Acceptance speech \\
\hline 230. & household incomes are down & LESS IS DOWN & Acceptance speech \\
\hline 231. & $\begin{array}{l}\text { our sailors being forced to their } \\
\text { knees }\end{array}$ & HUMILIATION IS DOWN & Acceptance speech \\
\hline 232. & $\begin{array}{l}\text { major donors are lining up behind } \\
\text { the campaign of my opponent }\end{array}$ & SUPPORT IS PROXIMITY & Acceptance speech \\
\hline 233. & $\begin{array}{l}\text { to have at my side the next Vice } \\
\text { President of the United States }\end{array}$ & SUPPORT IS PROXIMITY & Acceptance speech \\
\hline 234. & $\begin{array}{l}\text { tonight, this candidate and the } \\
\text { whole nation stand in their corner } \\
\text { to support them }\end{array}$ & SUPPORT IS PROXIMITY & Acceptance speech \\
\hline 235. & $\begin{array}{l}\text { nothing has affected me more } \\
\text { deeply }\end{array}$ & EMOTIONAL INTENSITY IS DEPTH & Acceptance speech \\
\hline 236. & to listen very very closely & ATTENTION IS PROXIMITY & Acceptance speech \\
\hline 237. & $\begin{array}{l}\text { we will rescue kids from failing } \\
\text { schools }\end{array}$ & $\begin{array}{l}\text { BAD SCHOOLS ARE A DANGEROUS } \\
\text { LOCATION }\end{array}$ & Acceptance speech \\
\hline 238. & to have at my side my wife & SUPPORT IS PROXIMITY & Acceptance speech \\
\hline 239. & if we will rise to the occasion & STRONG IS UP & Acceptance speech \\
\hline 240. & $\begin{array}{l}\text { to leverage their tremendous } \\
\text { talent }\end{array}$ & SUPPORTING IS LIFTING UP & Victory speech \\
\hline 241. & $\begin{array}{l}\text { we will get along with all other } \\
\text { nations willing to get along with } \\
\text { us }\end{array}$ & SYMPATHY IS PROXIMITY & Victory speech \\
\hline 242. & $\begin{array}{l}\text { America will no longer settle for } \\
\text { anything less than the best }\end{array}$ & $\begin{array}{l}\text { AGREEING IS SETTLING AT A } \\
\text { LOCATION }\end{array}$ & Victory speech \\
\hline 243. & we will seek common ground & AGREEMENT IS PROXIMITY & Victory speech \\
\hline 244. & $\begin{array}{l}\text { I want to thank my parents, who I } \\
\text { know are looking down on me } \\
\text { right now }\end{array}$ & HEAVEN IS UP & Victory speech \\
\hline 245. & $\begin{array}{l}\text { he is highly respected in } \\
\text { Washington }\end{array}$ & HONOR IS UP & Victory speech \\
\hline
\end{tabular}




\begin{tabular}{llll}
\hline$\#$ & Text passage & Metaphor & Speech \\
\hline \hline Spatial Metaphors & & \\
\hline 246. & that I will not let you down & DISAPPOINTMENT IS DOwN & Victory speech \\
\hline 247. & $\begin{array}{l}\text { I look very much forward to } \\
\text { being your president }\end{array}$ & FUTURE IS AHEAD & Victory speech \\
\hline 248. & $\begin{array}{l}\text { at the end of two years or three } \\
\text { years or four years or maybe even } \\
\text { eight years }\end{array}$ & TIME IS SPACE & Victory speech \\
\hline 249. & $\begin{array}{l}\text { we will rediscover our loyalty to } \\
\text { each other }\end{array}$ & LOYALTY IS A LOCATION & Victory speech \\
\hline 250. & at the center of this movement & IMPORTANT IS CENTRAL & Inauguration speech \\
\hline 251. & we are looking only to the future & FUTURE IS AHEAD & Inauguration speech \\
\hline 252. & I will never, ever let you down & DISAPPOINTMENT IS DOWN & Inauguration speech \\
\hline 253. & $\begin{array}{l}\text { A new national pride will stir our } \\
\text { souls, lift our sights, and heal our }\end{array}$ & GOOD IS UP & Inauguration speech \\
& divisions & & \\
\hline 254. & product dumping & REDUCING THE PRICE OF A & Acceptance speech \\
& & PRODUCT IS DECREASING VERTICAL & \\
\hline 255. & we will double our growth & INCREASE IN QUANTITY IS INCREASE & Victory speech \\
& & IN SIZE & \\
\hline
\end{tabular}

\begin{tabular}{llll}
\hline Plant & Metaphors & & \\
\hline 256. & $\begin{array}{l}\text { Secretary of State rakes in millions } \\
\text { and millions of dollars }\end{array}$ & $\begin{array}{l}\text { A LOT OF MONEY IS AN ABUNDANCE } \\
\text { OF LEAVES }\end{array}$ & Acceptance speech \\
\hline 257. & $\begin{array}{l}\text { men, women and children } \\
\text { viciously mowed down }\end{array}$ & KILING IS CUTTING DOWN GRASS & Acceptance speech \\
\hline 258. & $\begin{array}{l}\text { we will embark upon a project of } \\
\text { national growth and renewal }\end{array}$ & A NATION IS A PLANT & Victory speech \\
\hline 259. & we will double our growth & ECONOMY IS A PLANT & Victory speech \\
\hline 260. & $\begin{array}{l}\text { a small group in our nation's } \\
\text { Capital has reaped the rewards of } \\
\text { government }\end{array}$ & MONEY ARE CROPS & Inauguration speech \\
\hline 261. & Washington flourished & A CITY IS A PLANT & Inauguration speech \\
\hline 262. & $\begin{array}{l}\text { radical Islamic terrorism, which } \\
\text { we will eradicate completely }\end{array}$ & TERRORISM IS A WEED & Inauguration speech \\
\hline 263. & $\begin{array}{l}\text { our country will thrive and } \\
\text { prosper again }\end{array}$ & A NATION IS A PLANT & Inauguration speech \\
\hline 264. & the urban sprawl of Detroit & A CITY IS A PLANT & Inauguration speech \\
\hline
\end{tabular}




\begin{tabular}{llll}
\hline Money Metaphors & & \\
\hline 265. & $\begin{array}{l}\text { especially when others who have } \\
\text { done far less, have paid so dearly }\end{array}$ & $\begin{array}{l}\text { PUNISHMENT IS PAYING EXCESSIVE } \\
\text { AMOUNTS OF MONEY }\end{array}$ & Acceptance speech \\
\hline 266. & $\begin{array}{l}\text { time I have spent with the } \\
\text { mothers and fathers }\end{array}$ & TIME IS MONEY & Acceptance speech \\
\hline 267. & $\begin{array}{l}\text { we owe her a major debt of } \\
\text { gratitude }\end{array}$ & GRATITUDE IS MONEY & Victory speech \\
\hline 268. & spent my entire life in business & TIME IS MONEY & Victory speech \\
\hline 269. & the time I've spent with them & TIME IS MONEY & Victory speech \\
\hline 270. & we will deal fairly with everyone & PERSONAL RELATIONS ARE BUSINESS & Victory speech \\
\hline
\end{tabular}

\begin{tabular}{llll}
\hline Liquid Metaphors & & \\
\hline 271. & Syria is engulfed in a civil war & WAR IS A FLOOD & Acceptance speech \\
\hline 272. & $\begin{array}{l}\text { existing massive refugee flows } \\
\text { coming into our country }\end{array}$ & IMMIGRATION IS A FLOOD & Acceptance speech \\
\hline 273. & violence spilling across our border & $\begin{array}{l}\text { VIOLENCE IS AN OVERFLOwING } \\
\text { LIQUID }\end{array}$ & Acceptance speech \\
\hline 274. & $\begin{array}{l}\text { to stop the drugs from pouring } \\
\text { into our communities }\end{array}$ & $\begin{array}{l}\text { DRUGS ARE AN UNCONTAINED FLOw } \\
\text { OF WATER }\end{array}$ & Acceptance speech \\
\hline 275. & $\begin{array}{l}\text { trillions of dollars will start } \\
\text { flowing into our country }\end{array}$ & MONEY IS FLOWING WATER & Acceptance speech \\
\hline 276. & $\begin{array}{l}\text { students who are drowning in } \\
\text { debt }\end{array}$ & DEBTS ARE A DEADLY FLOOD & Acceptance speech \\
\hline 277. & $\begin{array}{l}\text { my opponent dismissed the VA } \\
\text { scandal as being not widespread }\end{array}$ & A SCANDAL IS A SUBSTANCE & Acceptance speech \\
\hline 278. & flush with cash & MONEY IS WATER & Inauguration speech \\
\hline 279. & the time for empty talk is over & MEANING IS SUBSTANCE IN A & Inauguration speech \\
\hline 280. & $\begin{array}{l}\text { a new national pride will stir our } \\
\text { souls, lift our sights, and heal our } \\
\text { divisions }\end{array}$ & SOUL IS A LIQUID & Inauguration speech \\
\hline 281. & the untapped potential & POTENTIAL IS A LIQUID & Victory speech \\
\hline 282. & source of pride and joy & PRIDE AND JOY ARE LIQUIDS & Victory speech \\
\hline
\end{tabular}

\section{Competition Metaphors}

\begin{tabular}{llll}
\hline 283. & let's defeat her in November & ELECTIONS ARE A wAR & Acceptance speech \\
\hline 284. & in this race for the White House & ELECTIONS ARE A COMPETITION & Acceptance speech \\
\hline
\end{tabular}




\begin{tabular}{llll}
\hline$\#$ & Text passage & Metaphor & Speech \\
\hline \hline Competition Metaphors & & \\
\hline 285. & struggling citizens & $\begin{array}{l}\text { DEALING WITH PROBLEMS Is } \\
\text { FIGHTING }\end{array}$ & Acceptance speech \\
\hline 286. & presidential race & ELECTIONS ARE A COMPETITION & Acceptance speech \\
\hline 287. & $\begin{array}{l}\text { we don't win anymore, but we are } \\
\text { going to start winning }\end{array}$ & POLITICS IS A COMPETITION & Acceptance speech \\
\hline 288. & we love defeating those people & ELECTIONS ARE A WAR & Acceptance speech \\
\hline 289. & $\begin{array}{l}\text { I can be your champion in the } \\
\text { White House }\end{array}$ & POLITICS IS A COMPETITION & Acceptance speech \\
\hline 290. & $\begin{array}{l}\text { I will fight for you, and I will win } \\
\text { for you }\end{array}$ & TRUMP IS A WARRIOR & Acceptance speech \\
\hline 291. & hard-fought campaign & ELECTIONS ARE FIGHTS & Victory speech \\
\hline 292. & she fought very hard & ELECTIONS ARE FIGHTS & Victory speech \\
\hline 293. & $\begin{array}{l}\text { and while they celebrated in our } \\
\text { nation's capital, there was little to } \\
\text { celebrate for struggling families all } \\
\text { across our land }\end{array}$ & $\begin{array}{l}\text { DEALING WITH POVERTY IS } \\
\text { FIGHTING }\end{array}$ & Inauguration speech \\
\hline 294. & $\begin{array}{l}\text { I will fight for you with every } \\
\text { breath in my body }\end{array}$ & TRUMP IS A WARRIOR & Inauguration speech \\
\hline 295. & very historic victory & ELECTIONS ARE A COMPETITION & Victory speech \\
\hline 296. & unless we win it & $\begin{array}{l}\text { ELECTIONS ARE A COMPETITION } \\
\text { track at Belmont }\end{array}$ & Victory speech \\
\hline 297. & AN ELECTION CAMPAIGN IS A & Victory speech \\
\hline
\end{tabular}

\begin{tabular}{llll}
\hline Seeing Metaphors & & \\
\hline 298. & look the other way & $\begin{array}{l}\text { IGNORING A PROBLEM IS } \\
\text { INTENTIONALLY NOT SEEING }\end{array}$ & Acceptance speech \\
\hline 299. & $\begin{array}{l}\text { (a Secretary of State) faces no } \\
\text { consequence }\end{array}$ & $\begin{array}{l}\text { BEING CONFRONTED wITH STHG. Is } \\
\text { LOOKING AT STHG. }\end{array}$ & Acceptance speech \\
\hline 300. & $\begin{array}{l}\text { facing justice for her terrible } \\
\text { terrible crimes }\end{array}$ & $\begin{array}{l}\text { BEING CONFRONTED WITH STHG. Is } \\
\text { LOOKING AT STHG. }\end{array}$ & Acceptance speech \\
\hline 301. & $\begin{array}{l}\text { the growing threats we face from } \\
\text { outside the country }\end{array}$ & $\begin{array}{l}\text { BEING CONFRONTED WITH sTHG. Is } \\
\text { LOOKING AT STHG. }\end{array}$ & Acceptance speech \\
\hline 302. & I have a different vision & HAVING A PLAN IS SEEING & Acceptance speech \\
\hline 303. & a person of similar views & BELIEVING IS SEEING & Acceptance speech \\
\hline 304. & political views & BELIEVING IS SEEING & Acceptance speech \\
\hline
\end{tabular}




\begin{tabular}{lll}
\hline$\# \quad$ Text passage & Metaphor & Speech \\
\hline \hline Seeing Metaphors & & \\
\hline $305 . \quad \begin{array}{l}\text { the wealth, strength, and } \\
\text { confidence of our country has } \\
\text { disappeared over the horizon }\end{array}$ & LOSING IS MOVING OUT OF SIGHT & Inauguration speech \\
& & \\
\hline
\end{tabular}

\begin{tabular}{llll}
\hline Holding Metaphors & & \\
\hline 306. & who does not grasp this danger & UNDERSTANDING IS HOLDING & Acceptance speech \\
\hline 307. & how out of touch she really is & UNDERSTANDING IS HOLDING & Acceptance speech \\
\hline 308. & $\begin{array}{l}\text { uphold our laws and our } \\
\text { Constitution }\end{array}$ & $\begin{array}{l}\text { ENFORCING LEGISLATION IS } \\
\text { HOLDING UP AN OBJECT }\end{array}$ & Acceptance speech \\
\hline 309. & $\begin{array}{l}\text { I'm reaching out to you for your } \\
\text { guidance and your help }\end{array}$ & POSSESSION IS HOLDING & Victory speech \\
\hline 310. & beyond our reach & POSSESSION IS HOLDING & Victory speech \\
\hline
\end{tabular}

\section{Other Metaphors}

\begin{tabular}{llll}
\hline 311. & number one in her class & BEING THE BEST IS BEING FIRST & Acceptance speech \\
\hline 312. & Third World condition & BEING THE BEST IS BEING FIRST & Acceptance speech \\
\hline 313. & ISIS was not even on the map & EXISTENCE IS BEING ON A MAP & Acceptance speech \\
\hline 314. & thousands of lives lost & DEATH IS LOSS & Acceptance speech \\
\hline 315. & I will outline reforms & REFORMS ARE DRAWINGS & Acceptance speech \\
\hline 316. & reforms that I will outline & REFORMS ARE DRAWINGS & Acceptance speech \\
\hline 317. & She is their puppet & BEING UNDER CONTROL IS BEING A & Acceptance speech \\
& & PUPPET & \\
\hline 318. & they pull the strings & MANIPULATING IS PULLING STRINGS & Acceptance speech \\
\hline 319. & no longer have a voice & OF A PUPPET & \\
\hline 320. & trade deals that strip us of our & INFLUENCE IS VOICE & Acceptance speech \\
\hline & jobs, and strip us of our wealth as & BECOMING NAKED & Acceptance speech \\
& a country & & \\
\hline 321. & the best and brightest prosecutors & INTELLIGENT IS BRIGHT & Acceptance speech \\
\hline 322. & a signature message & A CHARACTERISTIC MESSAGE IS A & Acceptance speech \\
& & SIGNATURE & \\
\hline 323. & signature feature & A CHARACTERISTIC FEATURE IS A & Acceptance speech \\
\hline 324. & brighter future & SIGNATURE & Victory speech \\
\hline
\end{tabular}




\begin{tabular}{|c|c|c|c|}
\hline \# & Text passage & Metaphor & Speech \\
\hline \multicolumn{4}{|c|}{ Other Metaphors } \\
\hline 325. & $\begin{array}{l}\text { we will embark upon a project of } \\
\text { national growth and renewal }\end{array}$ & PROJECTS ARE SHIPS & Victory speech \\
\hline 326. & $\begin{array}{l}\text { we will call upon the best and } \\
\text { brightest }\end{array}$ & INTELLIGENT IS BRIGHT & Victory speech \\
\hline 327. & $\begin{array}{l}\text { they're sharp (about Secret } \\
\text { Service people) }\end{array}$ & INTELLIGENT IS SHARP & Victory speech \\
\hline 328. & $\begin{array}{l}\text { we must think big and dream even } \\
\text { bigger }\end{array}$ & BIG IS GOOD & Inauguration speech \\
\hline 329. & $\begin{array}{l}\text { we stand at the birth of a new } \\
\text { millennium }\end{array}$ & BEGINNING IS BIRTH & Inauguration speech \\
\hline 330. & $\begin{array}{l}\text { we share one heart, one home, } \\
\text { and one glorious destiny }\end{array}$ & UNITY IS SHARING & Inauguration speech \\
\hline 331. & on the other hand & $\begin{array}{l}\text { TWO DIFFERENT OPINIONS ARE TWO } \\
\text { HANDS OF THE BODY }\end{array}$ & Acceptance speech \\
\hline 332. & on the other hand & $\begin{array}{l}\text { TWO DIFFERENT OPINIONS ARE TWO } \\
\text { HANDS OF THE BODY }\end{array}$ & Acceptance speech \\
\hline 333. & on the other hand & $\begin{array}{l}\text { TWO DIFFERENT OPINIONS ARE TWO } \\
\text { HANDS OF THE BODY }\end{array}$ & Acceptance speech \\
\hline 334. & $\begin{array}{l}\text { firing their employees along the } \\
\text { way }\end{array}$ & DESTROYING JOBS IS BURNING & Acceptance speech \\
\hline 335. & $\begin{array}{l}\text { we will determine the course of } \\
\text { America }\end{array}$ & AMERICA IS A SHIP & Inauguration speech \\
\hline 336. & $\begin{array}{l}\text { to impose our way of life on } \\
\text { anyone, but rather to let it shine as } \\
\text { an example for everyone to follow }\end{array}$ & GOOD IS LIGHT & Inauguration speech \\
\hline 337. & $\begin{array}{l}\text { prevent you from speaking your } \\
\text { minds from your own pulpits }\end{array}$ & $\begin{array}{l}\text { EXPRESSING ONE'S OPINION IS } \\
\text { PREACHING }\end{array}$ & Acceptance speech \\
\hline 338. & $\begin{array}{l}\text { (one more child to sacrifice) on } \\
\text { the order and on the altar of open } \\
\text { borders }\end{array}$ & $\begin{array}{l}\text { OPEN BORDERS ARE AN ALTAR FOR } \\
\text { RITUAL SACRIFICE }\end{array}$ & Acceptance speech \\
\hline 339. & $\begin{array}{l}\text { this American carnage stops right } \\
\text { here and stops right now }\end{array}$ & SERIOUS PROBLEMS ARE SLAUGHTER & Inauguration speech \\
\hline 340. & $\begin{array}{l}\text { a country of generosity and } \\
\text { warmth }\end{array}$ & EMOTION IS TEMPERATURE & Acceptance speech \\
\hline 341. & $\begin{array}{l}\text { she was strong, but also warm and } \\
\text { fair-minded }\end{array}$ & KIND IS WARM & Acceptance speech \\
\hline
\end{tabular}




\begin{tabular}{llll}
\hline$\#$ & Text passage & Metaphor & Speech \\
\hline \hline Other Metaphors & & \\
\hline 342. & $\begin{array}{l}\text { to lift the restrictions on the } \\
\text { production of American energy }\end{array}$ & RESTRICTIONS ARE WEIGHT & Acceptance speech \\
\hline 343. & take the pressure off & A FINANCIAL OBLIGATION IS & Acceptance speech \\
& & PRESSURE & \\
\hline 344. & people have borne the cost & EXPENSES ARE BAGGAGE & Inauguration speech \\
\hline 345. & it is finally time for a & TRUTH IS STRAIGHT & Acceptance speech \\
& straightforward assessment of the & & \\
& state of our nation & & Acceptance speech \\
\hline 346. & I will present the facts plainly & TRUTH IS PLAIN & Acceptance speech \\
\hline 347. & plain facts & TRUTH IS PLAIN &
\end{tabular}




\title{
Srbohrvaški asimetrični deseterec $\mathbf{v}$ slovenskih prevodih
}

Aleksander Bjelčevič*

\begin{abstract}
Slovene translations of serbocroatian folk songs, written in scr. deseterac metrum, began in 1831 with the translation of Hasanaginica; this and all the following translations were made in trochaic decasyllable. I compard the rhythm of six Slovene and one German translation with scr. corpus of seven folk songs by the following rhythmic parameters: accentuation of syllabic positions, non-metric accents, borders between phonetic words, verse endings, caesura after the $4^{\text {th }}$ syllable and zeugma after the $3^{\text {rd }}$ and $9^{\text {th }}$ syllable.
\end{abstract}

Key words: comparative metrics, syllabotonic verse, syllabic verse, trochaic phrasing, caesura, zeugma

*University of Ljubljana, Filozofska fakulteta v Ljubljani; Aleksander.Bjelcevic@ff.uni-lj.si 


\subsection{Začetki prevajanja srbohrvaških ljudskih pesmi}

$\mathrm{V}$ tem članku bom primerjal ritmiko srbohrvaškega ${ }^{1}$ (odslej shr.) asimetričnega deseterca $(4+6)$ in trohejskega deseterca $(-\mathrm{U}-\mathrm{U}-\mathrm{U}-\mathrm{U}-\mathrm{U})$ slovenskih prevodov iz srbohrvašcine. Vsi slovenski prevajalci so kot najustreznejši ekvivalent shr. desetercu izbrali trohejski deseterec, ker asimetričnega deseterca $\mathrm{v}$ slovenski ljudski pesmi ni, pesmi $\mathrm{v}$ desetercih se pojejo le med Srbi v Beli krajini (objavljene so v SLP 1, 2 in 3 in v Terseglav 1996). Tudi trohejski deseterec je bil slovenski ljudski in umetni poeziji do $30-i h$ let 19. stoletja tuj in se je pojavil šele s prevodi srbohrvaških ljudskih pesmi, ki so jim sledile izvirne knjižne epske pesmi v trohejskem desetercu (npr. Pegam in Lambergar Franca Cegnarja, 1858, wikivir/wikisource, pesnitvi Mustaf-Aga in Smrt Hasan-Bega, 1866, Janka Pajka).

Za shr. ljudski deseterec se po raziskavah Svetozarja Petrovića (1971) in posebej Mirjane Stefanović (1992), ki je raziskala celotni ohranjeni korpus shr. ljudskih pesmi 17. in 18. stoletja (npr. Erlangenski rukopis iz l. 1725), torej iz časa preden je shr. ljudske pesmi zapisal Vuk Stefanović Karadžić ${ }^{2}$, lahko z gotovostjo reče, da niha med čisto silabičnim verzom in verzom s trohejsko ali daktilsko tendenco. Toda slovenski, nemški (npr. Goethe ${ }^{3}$ ), ruski (Rastov) in celo poljski (Jastrzebiec-Kozłowski; prim. prevod Kosorwska dziewczina na http://www.rastko.rs/) prevajalci so posegali po troheju, čeprav je npr. na poljskem silabična tradicija veliko močnejša od silabotonične.

Za slovensko prevajanje shr. ljudskega (silabičnega) deseterca v izrazit trohej obstaja več razlogov. Prvič, četrtina shr. ljudskih pesmi ima trohejsko tendenco; drugič, že Vuk Karadžić je shr. deseterec označil za trohej (pri tem je poudaril, da predvsem takrat, ko se poje $)^{4}$, posledično so tudi takratni slovenski literarni kritiki kot Fran Levstik (1831 - 1887) trdili, da je shr. deseterec trohejski (Levstik 1956 (1868), 343); in tretjič, ker silabični verz v slovenski knjižni poeziji ni imel tradicije.

Pri Slovencih je prevajanja in posvajanje deseterca posledica južnoslovanske kulturnopolitične orientacije v 19. stoletju. Začelo se je s prevodom Hasanaginice (pod naslovom Asan-aginka v pesniškem almanahu Kranjska čbelica leta 1832; že leta 1831 je v istem časopisu France Prešeren predelal slovensko ljudsko pesem Lepa Vida v trohejske deseterce. Do konca 50-ih se je prevedlo skoraj deset shr. ljudskih pesmi, vse v trohejskom desetercu, npr. Kraljević Marko i vila 1849 v časopisu Slovenija, Marko Kraljevič i Musa kesedžija 1852, Smert Marka Kraljevića 1853, Oranje Kraljevića Marka 1853 v Kmetijskih in rokodelskih novicah, Marko ukida svabarinu 1858 (pod naslovom Serbska narodna pesem), 1889-e je Ivan Mohorčić prevedel veliko pesmi o kosovskem ciklu za knjigo Srbske

\footnotetext{
1 Ta izraz uporabljam brez politične konotacije.

2 Karadžić je objavil dve zbirki ljudskih pesmi, največja, Narodne srpske pjesme je izšla v štirih knjigah v Leipzigu in na Dunaju 1823-33.

3 O Goethejevih razlogih za izbiro troheja gl. npr. Čurćin 2010 (1905).

4 V uvodu k drugi izdaji Narodne srbske pjesnarice l. 1824 in v IV. knjigi Narodnih srpskih pjesmi (cit. po Franičević 1957: 30, Martinović 1969: 8, Źganec 1964, 3).
} 
narodne pesmi o boju na Kosovem, originalne srbske pesmi pa so izšle v knjigi že leta 1865 (ur. Janko Pajk). V 60-ih letih je duhovnik Štefan Kociančič (1818-1883) prevedel 287 makedonskih in bolgarskih ljudskih pesmi iz zbornika bratov Miladinovih (1861), ki pa so ostale v rokopisu (Stefanija 1984, 5-6).

\subsection{Gradivo}

Slovensko: a) prevodi šestih shr. ljudskih pesmi (536 verzov) različnih prevajalcev iz različnih desetletji in sicer Serpske pokrajnčene in Hasanaginica (iz Krajnske čbelice 1831 in 1832), Kraljevič Marko in Musa kesedžija (prevedel Fran Cegnar), Smrt Marka Kraljevića (prevajalec ni podpisan), Marko nkida svadbarinu (prevedel Jurij Kobe) in Zidanje Ravanice (prevedel Ivan Mohorčić); 500 trohejskih desetercev s cezuro (T 10) iz izvirnih pesmi Antona Aškerca (1851-1912) in Ivana Cankarja (1876 -1918), c) 100 odlomkov iz proze Josipa Jurčiča in Josipa Stritarja, ki so po ritmični zgradbi enaki cezurnemu T 10.

Srbohrvaško gradivo: a) Franičevićeva analiza (1957: 86, 96, 1976: 122) sedmih ljudskih pesmi (1495 verzov, Smrt majke Jugovića, Omer i Merima, Predrag i Nenad, Hasanaginica, Zidanje Skadra, Dioba Jakšića in Ropstvo Janković Stojana), Petrovićeva (1971, 70) analiza ljudskih pesmi Smrt Kraljevića Marka, b) knjižni T 10 sočasnih srbskih in hrvaških pesnikov Jovana J. Zmaja (Stefanović 1995: 239) in Petra Preradovića (416 verzov, Franičević 1975: 96) in c) in korpus ljudskih pesmi 17. in 18.stoletja (13.353 verzov, Stefanović 1992); za ilustracijo pa še Goethejev (1778) prevod Hasanaginice.

\subsection{Cilji in definicije}

Zanima nas, katere od ritmičnih konstant, dominant in tendenc shr. deseterca se $\mathrm{v}$ prevodnem trohejskem 10-ercu ohranijo in katere se ne ter kaj so specifične lastnosti slovenskega trohejskega 10-erca v primerjavi s srbohrvaškim. Primerjava bo potekala po teh ritmično-metričnih parametrih:

a) naglašenost metričnih položajev v verzu (teh je deset), t.i. naglasni profil verza

b) naglašanje šibkih metričnih položajev (položajev, označenih z U) oz. t. i. tonizacija

c) tonizacija šibkih položajev z večzložnimi besedami, t.j. potencialna nemetričnost verza

d) meje med naglasnimi enotami oz. frazami, t.i. fraziranje

e) (̌̌enska) verzna klavzula

f) cezura za 4. zlogom

g) zevgma med 3. in 4. ter 9. in 10. zlogom

Definirajmo pojme. Naglasne enote in meje med njimi so dejanski gradniki ritma: naglasno enoto tvorita naglašena beseda in morebitna klitika. V verzu »Al' su snjezi /, al' su labudovi? « (Hasanaginica) sta le dve, v Goethejevem prevodu »Ist es Schnée wohl /, óder / sind es Schwáene?« pa tri. Nasprotno pa stopice niso gradniki ritma, ampak 
le merske enote (tako kot kilometri niso gradniki cest): trohejski verz »Ist es Schnée wohl /, óder / sind es Schwáene? « je res dolg pet stopic, dejansko pa je sestavljen iz treh ritmičnih enot, njegov ritem tvorijo tri naglasne enote in ne petero stopic.

Fraziranje je ritem, ki ga verzu dajejo meje med naglasnimi enotami (odslej NEmeje). V shr. in sl. desetercih so za šibkimi položaji (na mejah stopic) pogostejše kot za krepkimi položaji (ikti), zato ga imenujejo kar trohejsko fraziranje (T-fraziranje, Taranovski 1954, 47-49); ritmično še pomembneje pa je, da NE-meje ne stojijo sredi stopic oz. meje med stopicami ne stojijo sredi NE, saj to povzroča nasprotno, jambsko fraziranje. Grafični prikaz (/ je meja med NE, | pa meja med stopicami):

trohejsko fraziranje $-\mathrm{U} /|-\mathrm{U} /|-\mathrm{U} /|-\mathrm{U} /|-\mathrm{U}$ (meje med NE sovpadajo z mejami stopic)

netrohejsko fraziranje $-/ \mathrm{U}|-/ \mathrm{U}|-/ \mathrm{U}|-/ \mathrm{U}|-\mathrm{U}$ (meje med NE so sredi stopic)

Primer za T-fraziranje (iz slovenskega prevoda Kraljević Marko in Musa Kesedžija) je „Víno |/píje |/ Músa |/Arbanásec« in ko verz skandiramo tako, da na mejah stopic za kratek hip pomolčimo "Víno/ píje/ Músa/ Arba/násec«, se skandiranje sliši smiselno, ker se oboje meje pokrivajo. Skandiranje verza z netrohejskim fraziranjem »Na primórju zídati terdnjávo«, kjer so si oboje meje navzkriž, pa bo zvenelo nesmiselno: »Napri morju zida titerd njavo«.

Cezura ni pavza, ampak stoodstotna meja med besedami (imenoval jo bom slovenska cezura), v shr. verzu pa tudi stoodstotna meja med naglasnimi enotami: na 4. zlogu nikoli ne bo proklitike, na 5. nikoli enklitike; 4. in 5. zlog nista nikoli zasedena z eno večzložno besedo (ni možno »onde je pa|la krvca od junaka«, ampak le »onde j’ pala | krvca od junaka«; Kosovka djevojka).

Zevgma je prepoved NE-mej med 3. in 4. zlogom ter med 9. in 10. zlogom: 3. in 4. zlog vedno pripadata isti naglasni enoti, med njima ni NE-meje; enako 9. in 10. zlog: »Što se bjeli | u gori zelenoj? « (Hasanaginica), »umiva ga | hlađanom vodicom« (Kosovka devojka).

\section{Problem ritma shr. deseterca}

Ko odprete poljubno antologijo shr. ljudskih pesmi, bo prav vsaka deseterska pesem sledila tem pravilom, ker guslarji ${ }^{5}$ vedno poskrbijo za tri metrične konstante $(1,2,3)$, eno dominanto (4) in dve šibki tendenci $(5,6)$.

\footnotetext{
${ }^{5}$ Ljudske pesmi se pojejo ob goslih ali zgolj pripovedujejo (Žganec 1964, 3).
} 


\subsection{Konstante in dominante}

1. 4. in 10. zlog sta vedno nenaglašena (kar je znak za konec polverza in konec verza). Njuna nenaglašenost ni zgolj posledica dejstva, da je zadnji zlog večzložnih besede $\mathrm{v}$ novoštokavščini vedno nenaglašen: guslar bi na 4 . in 10. zlog lahko postavil naglašeno enozložnico, ampak noče.

2. Za četrtim zlogom je cezura (označujem jo z $\mid$ ), obvezna meja med naglasnimi enotami.

3. Posledično je med 3. in 4. zlogom in med 9. in 10. zlogom vedno zevgma/most. ${ }^{6}$

4. Kvantitativna klavzula: kadar je 9. zlog naglašen, je ta vokal dolgonaglašeni in ne kratkonaglašeni, 7. in 8. vokal pa sta, kadar sta naglašena, kratkonaglašena.

\subsection{Deseterčeve ritmične tendence: silabizem ali silabotonizem?}

V nekaterih, a zdaleč ne vseh pesmih pa so tudi trohejske tendence po dveh parametrih:

5. naglašenost neparnih metričnih položajev

6. trohejsko fraziranje.

Vprašanje, ali je tendenco k trohejskosti, torej k silabotoničnosti, dovolj močna, da ima smisel govoriti o silabotoničnosti, ali pa je shr. deseterec zgolj silabični verz, je 200 let stara debata (Franičević 1957, Petrović 1971, Stefanović 1992). Gre za vprašanje, kdaj je deseterec še silabični, kdaj pa že silabotonični, t. j. trohejski. Med silabizmom srbskega deseterca in silabotonizmom slovenskega trohejskega deseterca je namreč kontinuum brez jasne meje, ob kateri bi lahko rekli: tu pa se začenja silabotonizem. Številke v vseh spodnjih tabelah so ilustracija te dileme. Ključno pri tem je, ali je takšna ritmična struktura namerna pevčeva stilizacija ali pa je, zaradi srbohrvaškega paroksitoničnega naglasa, normalna posledica členjenja na dva polverza, $\mathrm{v}$ katerih je zadnji zlog nenaglašen (Petrović 1971: 68; Stefanović 1992: 197). Če je stilizacija namerna, je verz trohejski, v nasprotnem pa ni. O pevčevi intenci pa lahko sklepamo le iz verzne zgradbe.

\subsubsection{Naglašanje metričnih položajev}

Trohejskost so na podlagi analize nekaterih pesmi zagovarjali Jakobson (1932), Taranovski $(1949-50,1950,1954)$ in do neke mere Franičević (1957). Toda Petrović (1971) je pokazal, da trohejsko tendenco kažejo zgolj nekatere pesmi, druge pa ne in da je to odvisno od posameznega guslarja. Drugače pa je v srbskem in hrvaškem knjižnem desetercu, ki je resnično trohej: hrvaški (npr. Petar Preradović) in srbski (npr. Jovan J. Zmaj) knjižni trohejski deseterec ima drugačen naglasni profil od ljudskega (rezultati za sedem ljudskih pesmi so iz Franičević 1957: 96), kar kaže ta tabela:

\footnotetext{
${ }^{6}$ Kako fascinanten občutek za melodijo jezika, pri stotinah guslarjev in stoletjih tradicije. Pomislimo: v desettisočih verzov desetin pevcev ne bo na 4. zlogu nikoli proklitike, na 5. pa nikoli enklitike.
} 


\begin{tabular}{lrrrrrrrrrr}
\hline zlog & 1. & 2. & 3. & 4. & 5. & 6. & 7. & 8. & 9. & 10. \\
\hline \hline Petar Preradović & $\mathbf{6 4}$ & 23 & $\mathbf{6 6}$ & 0 & 74 & 23 & $\mathbf{4 5}$ & 24 & 70 & 0 \\
Jovan J. Zmaj & $\mathbf{6 9}$ & 16 & $\mathbf{7 2}$ & 0 & $\mathbf{6 7}$ & 26 & $\mathbf{4 4}$ & 8 & $\mathbf{8 3}$ & 0 \\
7 shr. ljudskih pesmi & $\mathbf{6 1}$ & 34 & $\mathbf{5 1}$ & 0 & $\mathbf{7 9}$ & 21 & 34 & 38 & $\mathbf{4 2}$ & 0 \\
\hline
\end{tabular}

Tabela 1: Naglašenost metričnih položajev ( $\mathrm{v}$ odstotkih) v knjižnem trohejskem desetercu Preradovića, Zmaja in v sedmih ljudskih pesmih (krepki tisk v vseh tabelah označuje krepke položaje v verzu)

Krepki položaji, zlasti 7. in 9. zlog, so v ljudskem verzu redkeje naglašene kot v knjižnem, šibki položaji pa pogosteje, povrhu je 8. zlog (4. šibki položaj) pogosteje naglašen od 7. (4. krepki položaj), zato je drugi polverz v ljudskih pesmih redkeje trohejski kot v knjižnih.

Raziskava Mirjane Stefanović na korpusu 13.353 verzov potrjuje Petrovićeve rezultate: shr. pesmi je mogoče razdeliti na šest različnih ritmičnih skupin (Stefanović 1992: 189-195): zgolj 24\% pesmi ima trohejsko tendenco; $v$ ostalih je prvi polverz ali trohejski ali silabični, drugi polverz pa ali daktilski ali silabični. Poglejmo tri reprezentativne skupine oz. tipe:

\begin{tabular}{lcccccccccc}
\hline zlog & 1. & 2. & 3. & 4. & 5. & 6. & 7. & 8. & 9. & 10. \\
\hline \hline $\begin{array}{l}\text { korpus shr. ljudskih pesmi } \\
\text { 17. in 18. stoletja }\end{array}$ & 45 & 36 & 53 & 0,4 & 71 & 26 & 33 & 40 & 41 & 0 \\
I. skupina: 24 \% verzov & 47 & 32 & $\mathbf{5 8}$ & 0,15 & $\mathbf{7 2}$ & 25 & 40 & 30 & 47 & 0 \\
II. skupina: 26 \% verzov & 49 & 35 & $\mathbf{5 2}$ & 0,26 & $\mathbf{7 0}$ & 28 & 30 & 49 & 35 & 0 \\
VI skupina: 11\% verzov & 38 & 44 & 44 & 0,33 & $\mathbf{7 2}$ & 26 & 33 & 41 & 41 & 0 \\
\hline
\end{tabular}

Tabela 2: Naglašenost metričnih položajev v treh od šestih skupin v korpusu shr. ljudskih pesmi 17. in 18. stoletja

Rezultati v tabeli so jasni:

a v celotnem korpusu ima le prvi polverz trohejsko tendenco;

b dosledno trohejsko tendenco ima le I. skupina, t. j. le $24 \%$ pesmi. Odgovor na vprašanje, ali je shr. ljudski deseterec trohejski, se glasi: le 24

c V II. skupini ima trohejsko tendenco le prvi polverz, v drugem polverzu pa je namesto 7. zloga pogosto naglašen 8. zlog, zato ima ta polverz daktilsko tendenco: -UU-UU $(70,28,30,49,35,0)$.

d Verzi VI. skupine so povsem silabični. 


\subsubsection{Trohejsko fraziranje}

Za Taranovskega (1954, 48-49; 1950, 125; 1949-50, 145, 152) je trohejsko fraziranje (Tfraziranje) glavni ritmični princip shr. ljudskega deseterca in je pomembnejši od trohejskega razporeda naglasov. Statistika Taranovskega kaže, da guslar iz slovarja štokavskih besed izbira (nezavedno) predvsem dvo- in štirizložne naglasne enote, ki takšno fraziranje omogočajo (teh je v prozi $50 \%$, v desetercu pa kar $81 \%$ ), redkeje pa izbira enozložne in trizložne naglasne enote (trizložnih je v prozi $36 \%$; verzu pa le $16 \%$, Taranovski 1949-50, 145). Posledično postane deseterec razčlenjen na niz parnozložnih naglasnih enot, npr. $2+2 \mid 2+2+2$ in $4 \mid 2+4$ in $2+2 \mid 2+4$ itd. (številke pomenijo dolžine naglasnih enot, znak | pa pomeni cezuro), parnozložne enote pa s tem ${ }^{7}$ napovedujejo prihod krepkega položaja.

Toda analiza Stefanovićeve (1992: 197-205) kaže manj trohejsko sliko. Od prej omenjenih šest ritmičnih skupin imajo dosledno trohejsko fraziranje le tri (kar je $53 \%$ od vseh verzov v korpusu), ostali tri skupine ( $47 \%$ verzov) pa ga imajo le v prvem polverzu. Poglejmo I. skupino, kjer je T-Fraziranje dosledno, in II. skupino, kjer je T-Fraziranje le v prvem polverzu:

\begin{tabular}{lcccccccccc}
\hline & 1. & 2. & 3. & 4. & 5. & 6. & 7. & 8. & 9. & 10. \\
\hline \hline I. skupina: $24 \%$ verzov & 3 & 34 & 0,1 & 100 & 4 & 53 & 19 & 36 & 0 & 100 \\
II. skupina: 26 \% verzov & 4 & 31 & 0,2 & 100 & 3,5 & 49 & 30 & 27 & 0 & 100 \\
\hline
\end{tabular}

Tabela 3: Fraziranje v dveh v od šestih skupin v korpusu shr. ljudskih pesmi 17. in 18. stoletja

Zato Stefanović (1992: 203-205) trdi, shr. ljudski deseterec nima enotnega ritma: tendenco $\mathrm{k}$ trohejskemu fraziranju ima le prvi polverz, kar je posledica njegove kračine, prepovedi naglašanja 4. zloga in štokavskega paroksitoničnega naglasa. Drugi polverz pa ima v mnogih pesmih tudi trizložno $3+3$ fraziranje, ki ni trohejsko.

Shr. deseterec je torej glede naglašanja in glede fraziranja predvsem silabični verz z različnimi ritmičnimi tendencami.

\section{Primerjava slovenskega trohejskega deseterca s shr. desetercem}

Najprej bomo primerjali slovenske prevode Hasanaginice in Smrti Marka Kraljevića (Stefanović 1992: 194; Petrović 1971, 70), za ilustracijo pa še Goethejev (1775) prevod Hasa-

7 Zato ker so štokavske dvozložne besede vedno naglašene na prvem zlogu. 
naginice. Za ostale štiri srbohrvaške ljudske pesmi (Serpske pokrajnčene, Kraljević Marko i Musa kesedžija, Marko ukida svadbarinu in Zidanje Ravanice) nimam statističnih podatkov o naglašenosti in fraziranju, zato bom primerjal rezultate šestih slovenskih prevodov z rezultati sedmih shr. ljudskih pesmi (Franičević 1957).

\subsection{Hasanaginica in Smrt Marka Kraljevića}

\subsubsection{Naglašenost metričnih položajev}

\begin{tabular}{lccccccccccc}
\hline zlog & 1. & 2. & 3. & 4 & 5. & 6. & 7 & 8. & 9. & 10. & Količnik S:W \\
\hline \hline shr. Hasanaginica & 53 & $\underline{32}$ & 60 & 0 & 77 & $\underline{23}$ & 35 & $\underline{32}$ & $\underline{52}$ & 0 & $3,2: 1$ \\
slovenski prevod & 74 & $\underline{2}$ & 89 & $\underline{3}$ & 80 & $\underline{2}$ & 42 & $\underline{2}$ & 99 & 1 & $39: 1$ \\
nemški prevod & 60 & $\underline{5}$ & 84 & $\underline{9}$ & 68 & $\underline{3}$ & 78 & 1 & 100 & $\underline{1}$ & $20: 1$ \\
\hline \hline shr. Smrt Marka Kraljevića & 81 & $\underline{21}$ & 67 & $\underline{0}$ & 79 & $\underline{23}$ & 38 & $\underline{28}$ & 51 & 0 & $4,4: 1$ \\
slovenski prevod & 73 & $\underline{1}$ & 91 & $\underline{2}$ & 64 & $\underline{5}$ & 48 & $\underline{0}$ & 99 & 1 & $41,7: 1$ \\
\hline \hline Aškerc in Cankar & 68 & $\underline{3}$ & 92 & $\underline{4}$ & 70 & $\underline{4}$ & 63 & $\underline{2}$ & 98 & 0 & $30: 1$ \\
\hline
\end{tabular}

Tabela 4: Naglašenost metričnih položajev v shr. Hasanaginici in Smrti Marka Kraljevića $\mathrm{v}$ slovenskih in nemških prevodih in v izvirnih Aškerčevih in Cankarjevih pesmih. Podčrtani so šibki položaji. Količnik $\mathrm{S}$ : W je razmerje med naglašenostjo krepkih položajev (S) in naglašenostjo šibkih položajev (W).

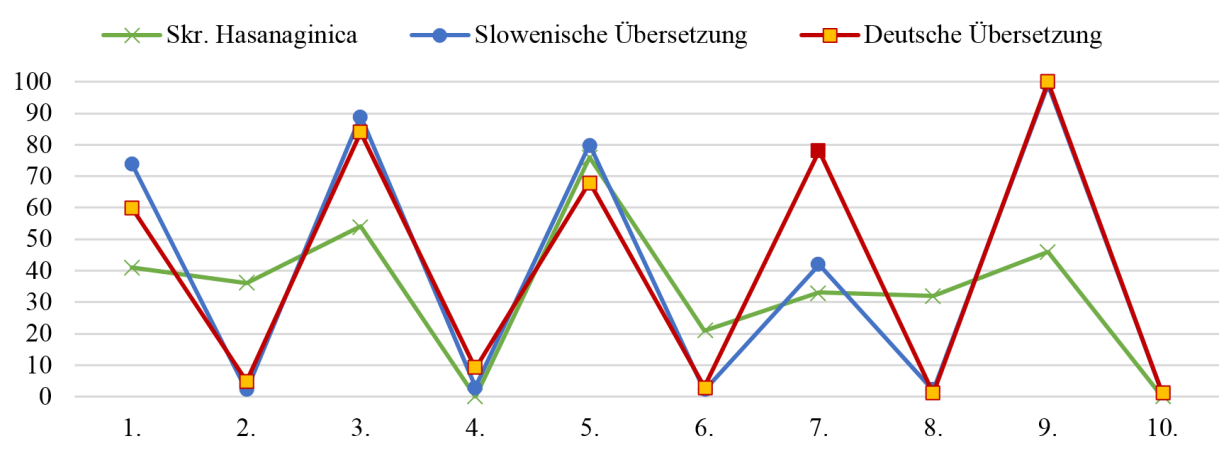

Slika 1: Naglašenost metričnih položajev v shr. Hasanaginici in v dveh prevodih ${ }^{8}$

a) Naglasna profila shr. Hasanaginice in Smrti Marka Kraljevića kažeta zgolj (šibko) tendenco k trohejskosti, slovenski in nemški prevod pa sta tipična troheja, kjer je naj-

${ }^{8}$ Krivulji za slovenski in za nemški verz se med 8. in 10. zlogom prekrivata, ker so statistični rezultati enaki. 
pomembneje, da so šibki položaji v primerjavi z originali izjemno redko naglašeni, največkrat z enozložnimi besedami, predvsem z zaimki in nikalnico ni, nekoliko redkeje s polnopomensko besedo, npr. s prislovom (podčrtano so ikti) »od peterih me otrok próč goni«, števnikom »v čelo kušnila dvá sina svoja« in glagolom »hčerama dá celiga mezlana«, nemški pa npr. »Und läßt durch dies Blatt dich höchlich bitten«, redko s samostalnikom, npr »Znadeš li, zakaj kónj omahuje«.

b) Obvezno nenaglašeni 4. metrični položaj je v obeh prevodih sicer lahko naglašen, toda večinoma le z nepolnopomenskimi enozložnimi besedami: slovenski z enozložnima zaimkoma to, naš in prislovom prot ‘ (»ide z njo prót’ beli domovini«), nemški z besedami wohl (»ist es Schnee wohl oder sind der Schwäne«), nicht, dies (»als die Frau dies harte Wort vernommen«), redkeje s polnopomensko besedo, npr. zna (»naj mi Bóg zna, dobrega ne bode«, Smrt Marka Kraljevića), g'nug (»kurze zeit g'nug; von viel großen Herren«) in sah (»das beiseit sah Vater Asan Aga«) (Hasanaginica). Ampak to ne pomeni, da so hoteli prevajalci čim manj odstopati od originala, saj enako postopajo tudi pri naglašanju preostalih šibkih položajev: slovenska prevajalca sta zgolj sledila normi slovenske silabotonike.

c) Tonizacija šibkih položajev z večzložnimi besedami. V shr. verzu so 2., 6. in 8 . zlog (potencialno šibki položaji) pogosto naglašeni z večzložno besedo, v shr. Hasanaginici je kar $27 \%$ vseh potencialno šibkih položajev naglašenih z večzložnico (npr. »Šta se bjeli u gori zelenoj«, »Da su snjezi, već bi okopnuli«). Tudi tu se prevoda ne ozirata na original, ampak sledita slovenski in nemški silabotonski normi, ki tonizacijo z večzložnicami smatrata za nemetričen pojav. V slovenskih prevodih Hasanaginice in Smrti Marka Kraljeviča se tonizacija z večzložnico zgodi le dvakrat oz. štirikrat, npr. »jéli teptát konji po dvoriši« (Hasanaginica) ali »Tam med njima izvíra studenec« (Der $T o d)$, v nemškem nikoli. Torej je v slovenščini in nemščini tonizacija z večzložnicami nemetričen pojav.

č) ) V nemškem in slovenskem prevodu je zadnji krepki položaj, to je 9. zlog, je skoraj $100 \%$ naglašen, česar v shr. verzu ni: slovenski T 10 ima izrazito naglašeno klavzulo, kar je namerna pesnikova stilizacija naravne jezikovne tendence (saj je večina slovenskih večzložnic paroksitonična).

d) V slovenskih prevodih ( $v$ nemškem pa ne) se vpliv shr. ritma kaže le v enem: v atonizaciji 7. zloga (4. ikta). 7. zlog, ki v shr. desetercu zaradi redke naglašenosti ruši trohejski ritem, je tudi v slo. prevodih naglašen najredkeje in sicer veliko redkeje kot $\mathrm{v}$ izvirnih slovenskih pesmih Aškerca in Cankarja (kar za 21 \% oz. 15 \% manj).

e) Stopnjo troheizacije lahko izmerimo s količnikom med naglašenostjo krepkih položajev in naglašenostjo šibkih položajev: v slovenskem in nemškem troheju (prevodnem in izvirnem) so krepki položaji zelo pogosto naglašeni, šibki pa zelo redko, zato je količnik visok (od 20 do 41,7); v srbohrvaškem je to razmerje bistveno manjše (od 3,2 do $4,4)$ 


\subsubsection{Trohejsko fraziranje}

\begin{tabular}{lrrrrrrrrrrrl}
\hline zlog & 1. & 2. & 3. & 4. & 5. & 6. & 7. & 8. & 9. & 10. & sl. cezura & količnik W : S \\
\hline \hline & - & $\mathrm{U}$ & - & $\mathrm{U}$ & - & $\mathrm{U}$ & - & $\mathrm{U}$ & - & $\mathrm{U}$ & & \\
shr. Hasanaginica & 4,5 & 40 & 0 & 100 & 2 & 56 & 23 & 37 & 0 & 100 & 100 & $11,3: 1$ \\
slovenski prevod & 15 & 50 & 20 & 66 & 16 & 50 & 39 & 46 & 0 & 100 & 82 & $3,8: 1$ \\
nemški prevod & 23 & 34 & 29 & 62 & 17 & 52 & 17 & 66 & 1 & 100 & 95 & $3,7: 1$ \\
\hline
\end{tabular}

Tabela 5: Meje med naglasnimi enotami $\mathrm{v}$ shr. Hasanaginici in $\mathrm{v}$ slovenskem in nemškem prevodu. "Sl. cezura« pomeni 'slovensko' cezuro (blizu 100-procentna meja med besedami). Količnik W : S je razmerje med deležem mej za šibkimi položaji (na mejah stopic) in deležem mej za krepkimi položaji.
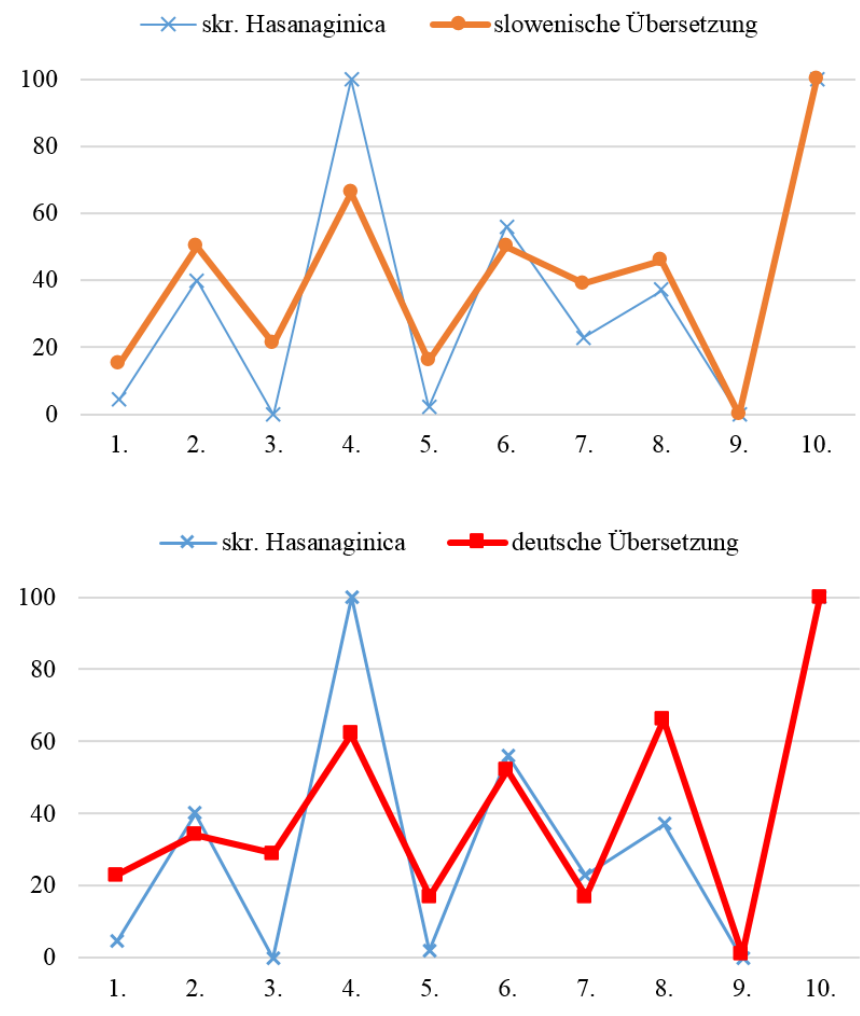

Slika 2: T-fraziranje $\mathrm{v}$ shr. Hasanaginici in $\mathrm{v}$ dveh prevodih

Vsa tri besedila imajo trohejsko fraziranje (meje med naglasnimi enotami so na mejah stopic bolj pogoste kot znotraj stopic), toda v izvirni shr. Hasanaginici je močnejše, kar kaže tudi količnik: a) bistvena razlika je, da so v shr. tekstu meje med naglasnimi 
enotami za neparnimi zlogi (sredi stopic) zelo redke, $v$ obeh prevodih pa so veliko pogostejše (v tabeli podčrtano), b) za parnimi zlogi (na meji stopic) pa jih je v prevodih povprečno manj kot $\mathrm{v}$ originalu. Ker je za T-fraziranje parameter (a) pomembnejši od Parametra (b), lahko rečemo, da je T-fraziranje za slovenski in nemški tekst ${ }^{9}$ manj pomembno kot za srbohrvaškega.

\subsubsection{Sklep}

Primerjave procentov po obeh parametrih (po naglašenosti in mejah med naglasnimi enotami) kažeta: v srbohrvaški Hasanaginici o trohejski tendenci odločajo predvsem meje med naglasnimi enotami; te so ritmotvornejše od naglasa. V slovenskem in nemškem prevodu pa odločajo predvsem naglasi; ti so ritmotvornejši od mej. Vsota obeh ritmotvornih dejavnikov pa najbrž kaže, da sta izbrani shr. ljudski pesmi manj trohejski od prevodov.

\subsection{Primerjava šestih sl. prevodov s sedmimi shr. ljudskimi pesmimi}

Ker za štiri od šestih pesmi nimam statističnih podatkov, sem statistiko šestih pesmi primerjal statistiko sedmih drugih srbohrvaških pesmi, ki ga je analiziral Franičević 1957, 86). Primerjal sem sledeče, za shr. deseterec značilne konstante in tendence: 1) naglašanje metričnih položajev, 2) trohejsko fraziranje, 3) cezuro in 4) zevgmo. Prevodi so v vseh štirih parametrih drugačni, skoraj nasprotni od shr. ljudskih pesmi: naglašanje je izrazitejše, fraziranje šibkejše, cezura je pretvorjena v tendenco, prva zevgma je ukinjena.

Tudi ta primerjava pokaže, da se vpliv shr. ritma kaže zgolj v pogostejši tonizaciji šibkih položajev $\mathrm{z}$ večzložnicami in $\mathrm{v}$ atonizaciji 7 . zloga, $\mathrm{v}$ ostalem pa so prevodi skladni s slovensko silabotonsko normo 19. stoletja, kot jo izkazuje trohejski deseterec izvirnih pesmi Aškerca in Cankarja. Shr. izvirniku je najbližji Kobetov prevod pesmi Marko ukida svadbarinu, zato so podatki zanj navedeni posebej.

\footnotetext{
9 Zanimivo bi bilo raziskati, zakaj je v slovenskem prevodu fraziranje močnejše na začetku verzov, v nemškem pa proti koncu.
} 


\subsubsection{Naglašanje metričnih položajev}

\begin{tabular}{lrrrrrrrrrrrr}
\hline zlog & 1. & 2. & 3. & 4. & 5. & 6. & 7. & 8. & 9. & 10. & količnik S:W \\
\hline \hline 6 slovenskih prevodov & $\mathbf{6 4}$ & $\mathbf{3}$ & $\mathbf{8 3}$ & $\mathbf{3}$ & $\mathbf{7 0}$ & $\mathbf{7}$ & $\mathbf{4 4}$ & $\mathbf{2}$ & $\mathbf{9 7}$ & 0,4 & $23: 1$ \\
prevod Marko ukida svadbarinu & $\mathbf{5 8}$ & $\mathbf{8}$ & $\mathbf{8 0}$ & $\mathbf{4}$ & $\mathbf{6 2}$ & $\mathbf{1 8}$ & 24 & $\mathbf{5}$ & 94,6 & 0,4 & $9: 1$ \\
7 shr. ljudskih pesmi & $\mathbf{6 1}$ & $\mathbf{3 4}$ & $\mathbf{5 1}$ & $\mathbf{0}$ & $\mathbf{7 9}$ & $\mathbf{2 1}$ & 34 & $\mathbf{3 8}$ & $\mathbf{4 2}$ & 0 & $3: 1$ \\
Aškerc in Cankar & $\mathbf{6 8}$ & $\mathbf{3}$ & $\mathbf{9 2}$ & $\mathbf{4}$ & $\mathbf{7 0}$ & $\mathbf{4}$ & $\mathbf{6 3}$ & $\mathbf{2}$ & $\mathbf{9 8}$ & 0 & $30: 1$ \\
\hline
\end{tabular}

Tabela 6: Naglašenost metričnih položajev v šestih slovenskih prevodih (kumulativno) in v sedmih shr. ljudskih pesmih (Franičević 1957: 96) ter v izvirnih pesmi Aškerca in Cankarja

Ritem prevodov se od ritma shr. ljudskih pesmi loči v sledečem:

a) Zaradi redkega naglašanja šibkih metričnih položajev so prevodi izrazito trohejski (gl. količnike), shr. pesmi pa imajo le (šibko) trohejsko tendenco (šibki položaji so v tabeli podčrtani).

b) 4. zlog je lahko naglašen.

c) 9. zlog je naglašen skoraj $100 \%$, česar v shr. verzu ni - slovenski deseterec ima izrazito naglasno klavzulo. Ta ni posledica naravne lastnosti slovenskega akcenta, čeprav ta teži k paroksitoničnosti, ampak je pesnikova intenca. Podoben proces je sočasno nastajal v srbskih in hrvaških knjižnih desetercih (gl. Tabelo 1).

Vpliv prevodov:

a) Šibki položaji so v prevodih naglašeni ne le z enozložnimi, ampak tudi z večzložnimi besedami. Presenetljivo pa je, da je slednjih več kot prvih, kar je v nasprotju s slovensko silabotonsko normo in torej nedvomen vpliv prevodov. Teh primerov je v pesmih Hasanaginica, Smrt Kraljeviča Marka, Kraljevič Marko in Musa kesedžija in Zidanje Ravanice (skupaj 508 verzov) dvajset (3,9\%), npr. »Téžko méni váte poglédati«. Največ pa jih je v Kobetovem prevodu pesmi Marko nkida svadbarinu (ki ima 240 verzov), okoli petdeset (21\%).

b) 7. zlog, ki v shr. desetercu razbija trohejski ritmični profil, je tudi v prevodih nadpovprečno redko naglašen (najredkeje v Kobetovem prevodu Marko ukida svadbarinu), kar je vpliv shr. ritma.

\subsubsection{Trohejsko fraziranje}

Ker so slovenske dvo- in večzložne besede lahko naglašene tudi na zadnjem zlogu, členitev verza na parnozložne naglasne enote ne povzroča trohejskega fraziranja $v$ taki meri kot $\mathrm{v}$ shr. desetercu: 


\begin{tabular}{lrrrrrrrrrrrr}
\hline zlog & 1. & 2. & 3. & 4. & 5. & 6. & 7. & 8. & 9. & 10. & sl. cezura & količnik W:S \\
\hline \hline & - & $\mathrm{U}$ & - & $\mathrm{U}$ & - & $\mathrm{U}$ & - & $\mathrm{U}$ & - & $\mathrm{U}$ & & \\
6 slovenskih prevodov & 9 & 41 & $\underline{11}$ & $\mathbf{7 5}$ & $\underline{17}$ & 43 & 30 & 39 & 0,4 & 100 & 88 & 4,5 \\
prevod Marko ukida svadbarinu & 2 & 44 & $\underline{0}$ & $\mathbf{9 7}$ & $\underline{5}$ & 34 & 41 & 30 & 1 & 100 & 100 & 6,2 \\
7 shr. ljudskih pesmi & 8 & 37 & $\underline{0}$ & 100 & $\underline{5}$ & 49 & 26 & 38 & 0 & 100 & 100 & 8,3 \\
\hline
\end{tabular}

Tabela 7: Meje med naglasnimi enotami v šestih sl. prevodih in sedmih shr. ljudskih pesmih.

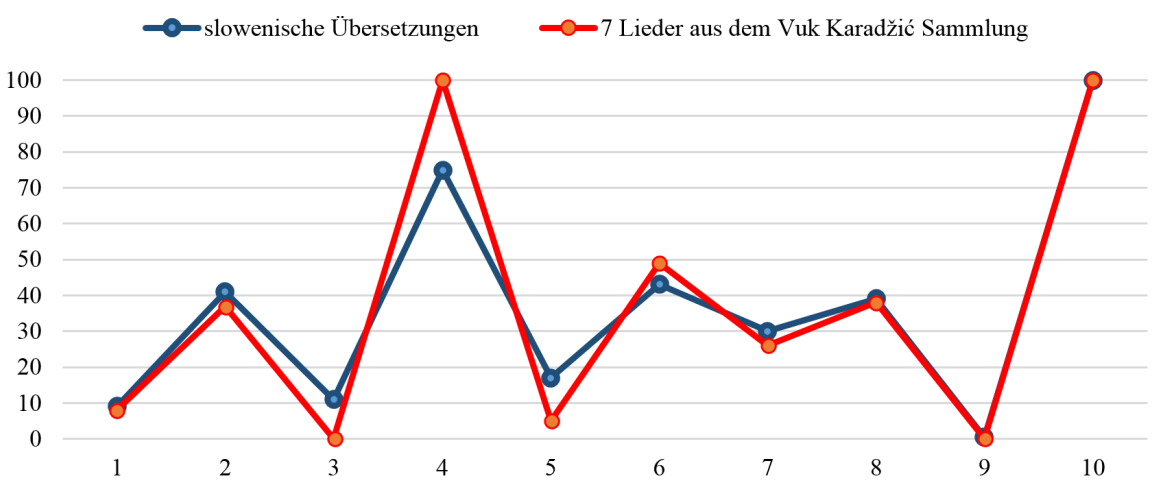

Slika 3: Meje med naglasnimi v šestih sl. prevodih in sedmih shr. ljudskih pesmih

Čeprav primerjamo različne tekste, sta si krivulji v splošnem poteku sicer podobni. Toda bistvenih podrobnostih je trohejsko fraziranje v slovenskih prevodih šibkejše: a) za krepkimi položaji (torej sredi stopice) je mej več (v tabeli podčrtano), b) za šibkimi položaji (na mejah stopic) pa manj kot v srbohrvaških pesmih. Med vsemi prevodi se je izvirniku najbolj približal Kobetov prevod Marko ukida svadbarinu.

Fraziranje slovenskega T 10 pa ni rezultat avtorjeve intence, ampak je posledica součinkovanja slovenskega pretežno paroksitoničnega naglasa in pogostega naglašanja krepkih položajev. To lahko dokažemo tako, da preverimo fraziranje $\mathrm{v}$ stavkih iz proze, ki so po ritmični zgradbi enaki trohejskemu desetercu s cezuro (kjer so naglašeni vsaj trije neparni zlogi, npr. »Še nikóli nísem bil na kónju« iz romana Deseti brat):

\begin{tabular}{lcccccccccc}
\hline zlog & 1. & 2. & 3. & 4. & 5. & 6. & 7. & 8. & 9. & 10. \\
\hline \hline $\begin{array}{l}\text { prozni trohejski segmenti s } \\
\text { cezuro }\end{array}$ & 9 & 48 & 11 & 80 & 10 & 49 & 34 & 39 & 0 & 100 \\
\hline
\end{tabular}

Tabela 8: Meje med naglasnimi enotami v trohejskih segmentih $\mathrm{v}$ prozi (100 odlomkov iz proze Josipa Jurčiča in Josipa Stritarja) 
Tudi ti prozni stavki imajo trohejsko fraziranje. Torej res drži, da je T-fraziranje za slovenski prevodni trohejski deseterec ritmično manj pomembno kot za srbohrvaški deseterec, ker je to pričakovana posledica slovenskega naglasa.

$$
* * *
$$

Razen v naglašanju in fraziranju so med shr. desetercem in slovenskim trohejskim desetercem velike razlike tudi v konstantah: v cezuri za 4. zlogom in prvi zevgmi (med 3. in 4. zlogom).

\subsection{Cezura za 4. zlogom}

Slovenski in nemški prevodi nimajo take cezure kot shr. deseterec: nimajo $100 \%$ meje med naglasnimi enotami, ampak le tendenco od $43 \%$ do $81 \%$, v povprečju $75 \%$, Goethejev pa $62 \%$ (gl. tabeli 5 in 7). V shr. ljudskem desetercu ni na 4. zlogu nikoli proklitike, na 5. pa nikoli enklitike, $v$ slovenskem in nemškem prevodu pa je to dovoljeno, npr. v Hasanaginici »da srce ne | poči revi meni« (proklitika ne), »Ne počakaj | me u beli hiši« (enklitika me), v nemščni npr. »'S ist der Glanz der | Zelten Asan Aga«, »Ihn besucht die | Mutter und die Schwester«(proklitiki der in die). Izjema je zopet Kobetov prevod Marko ukida svadbarinu, ki je zaradi upoštevanja srbohrvaške cezure nekaj izjemnega $\mathrm{v}$ okviru slovenske silabotonike nasploh.

Slovenska in nemška cezura, kadar jo pesem sploh ima, je drugačna: to je $100 \%$ meja med besedami - zgolj med besedami. "Slovensko-nemško« cezuro imata prevoda Smrt Marka Kralajevića in seveda Marko ukdia svadbarinu, Goethejev prevod ima zelo močno tendenco $95 \%$, ostali štirje slo. prevodi pa nimajo niti te, ampak le tendenco od 82 do $88 \% .{ }^{10}$ Zanimivo je, da Goethejev prevod Hasanaginice takšno cezuro ignorira le petkrat, npr. »Ausgeferti | get den Brief der Scheidug«(| je položaj neuresničene cezure), medtem ko slovenski kar 16-krat, npr. »Tam leži ne |vsmiljeno izranjen«.

\subsection{Zevgma (Brücke)}

Zevgma je v shr. verzu konstanta in pomeni, da 3. in 4. zlog (ter 9. in 10. zlog) vedno pripadata isti naglasni enoti, t.j. vsak polverz se zaključuje $z$ večzložno besedo ali pa z enklitiko, nikoli pa s proklitiko ali z naglašeno enozložnico. Primeri zevgme (podčrtano):

Vino pije | Musa Arbanasa

al' tako mi $\mid$ moje vjere tvrde

(Kraljević Marko i Musa kesedžija)

\footnotetext{
${ }^{10}$ Niti drugi slovenski prevajalci shr. deseterca vse do danes ne za srbohrvaško ne za slovensko cezuro nimajo posluha (npr. trije različni prevodi Njegoševega Gorskega venca iz 1907, 1947 in 1983).
} 
Kršenja zevgme za 3. zlogom je v slovenskih prevodih veliko, npr. v Hasanaginici jih je 19 (saj je 16-krat brez slovenske cezure), v nemškem prevodu okoli 27, v vseh šestih slovenskih prevodih pa $11 \%$, zgodi pa se na tri načine:

a) da stoji na 4. zlogu proklitika, npr. »'S ist der Glanz der | Zelten Asan Aga, Hasanaginica«;

b) ali pa naglašena enozložnica, npr. »das beiseit sáh | Vater Asan Aga (Hasanaginica), »Ali sem píl | snoči mnogo vina« (Kraljević Marko i Musa Kesedžija);

c) ali ko 4. in 5. zlog celo pripadata isti besedi in verz nima cezure, npr. »Ausgeferti|get den Brief der Scheidug« (Hasanaginica).

Zevgmo za 3. zlogom ima spet le Kobetov prevod Marko ukida svadbarinu. Zevgmo za 9. zlogom pa imajo vsi prevodi (vsak verz se konča z večzložno besedo ali, skrajno redko, z enklitiko, »da sede nektere dni krepčam se«, Marko Kraljevič in Musa kesedžija) in sicer zato, ker verzi nimajo enjambementov, da bi na 10. zlogu stala proklitika, in ker 10. zlog ni (skoraj) nikoli naglašen.

\subsection{Klavzula}

Shr. deseterec teži h kvantitativni klavzuli: kadar je 9. zlog naglašen (v povprečju 41 \%), je večinoma dolg (v 67 \% primerov; Stefanović 1992), 10. zlog pa kratek. Klavzula slovenskega in nemškega T 10 pa je tonska in sicer ženska: 9. zlog je naglašen (skoraj) $100 \%$, 10. zlog pa (skoraj) nikoli, posledično je klavzula često kvantitativna, ker so mnogi slovenski naglašeni zlogi dolgi, nenaglašeni zlogi pa so kratki.

\section{Zaključek}

Pokazale so se naslednje razlike med shr. ljudskim desetercem in slovenskim trohejskim desetercem: Naglašanje krepkih položajev in nenaglašanje šibkih je v slovenskem T 10 dominantna lastnost, $v$ shr. ljudskem desetercu pa se javlja kot (šibka) tendenca; trohejsko fraziranje je $\mathrm{v}$ slovenskem verzu šibkejše in ritmično manj pomembno kot $\mathrm{v}$ srbohrvaškem, ker je posledica slovenske prozodije; tonizacija šibkih položajev z večzložnimi besedami je v shr. verzu standarden pojav, v slovenskem verzu pa zelo redek in torej nemetričen. Cezura je v shr. verzu konstanta, $\mathrm{v}$ slovenskem pa tendenca ali dominanta; prevodi ohranjajo le drugo od dveh zevgem. Prevodi dobijo žensko klavzulo, ki je shr. ljudski deseterec nima.

Med prevodi se Kobetov prevod Marko ukida svadbarinu po vseh parametrih najbolj približa shr. desetercu. Jurij Kobe (1807-1858) je bil namreč folklorist in takrat najboljši slovenski poznavalec shr. epike, doma iz Bele krajine, kjer v srbski enklavi še živijo srbske narodne pesmi. Edino on je že v 50-ih letih 19. stoletja opazil vse ritmične nianse shr. deseterca: srbohrvaško cezuro, vso kompleksnost zevgme in ni se podredil nastajajoči silabotonski normi, ki je prepovedovala naglašanje šibkih položajev z večzložnimi besedami. 


\section{Povzetek}

Ko se je leta 1831 na Slovenskem začelo prevajati srbohrvaške ljudske pesmi, so epski (nerimani) deseterec prevajali v (nerimani) trohejski deseterec ( $\mathrm{T} 10$ ), čeprav shr. deseterec ni vedno trohejski. Zgradba shr. deseterca je kompleksna:

(a) za 4. zlogom ima cezuro (100-procentno mejo med naglasnimi enotami),

(b) 4. in 10. zlog sta vedno nenaglašena,

(c) za 3. in za 9. zlogom ni nikoli meje med naglasnimi enotami (zevgma);

(d) le četrtina pesmi tendira $\mathrm{k}$ trohejskemu razporedu naglasov, 70

(e) potencialni šibki položaji ( = parni zlogi) so naglašeni zelo pogosto (do 40

(f) polovica pesmi pa ima tendenco k trohejskemu fraziranju (členitev na 2- in 4zložne naglasne enote), ki je pomembnejši ritmični princip od trohejskega naglašanja;

(g) tendenca h kvantitativni klavzuli.

Po naštetih ritmičnih parametrih smo primerjali slovenske prevode šestih shr. ljudskih pesmi in Goethejev prevod Hasanaginice s korpusom sedmih shr. pesmi in ugotovili, da je slovenski prevodni trohejski deseterec tipični trohej, ki je ritmično enak desetercu izvirnih slovenskih pesmi in se ravna po pravilih slovenske silabotonike; podobno Goethejev prevod. Prevodi se od shr. deseterca razlikujejo v vseh parametrih:

(a) pet od šestih slovenskih prevodov cezure ne upošteva, vendarle pa imata dva od njih in Goethejev prevod Hasanaginice nekakšno cezuro, namreč 100-procentno mejo med besedami,

(b) 4. zlog je lahko naglašen, čeprav redko (do $3 \%$ ),

(c) le eden od prevodov upošteva zevgmo za 3. zlogom (Marko ukida svadbarinu),

(d) vse pesmi imajo dosleden trohejski ritem,

(e) šibki položaji so zelo redko naglašeni (0 do $5 \%$ ),

(f) fraziranje je šibkejše in je naravna posledica slovenskega pretežno paroksitoničnega akcenta,

(g) slovenski T 10 ima tonsko klavzulo (9. zlog je naglašen $100 \%$ ).

Shr. deseterec je na prevode vplival v naslednjem: 4. ikt (7. zlog) je naglašen najredkeje, naglašanje šibkih položajev $\mathrm{z}$ večzložnimi besedami je nad normo slovenske silabotonike.

Med prevodi se je Kobetov prevod Marko ukda svadbarinu po vseh parametrih najbolj približal shr. desetercu. 


\section{Uporabljena literatura}

Milan Čurćin 2010 (1905): Petostopni (srpski) trohej. V: Srpski trohej. Ur. Mirjana D. Stefanović. Beograd: Službeni glasnik.

Epske narodne pjesme (ur. Salko Nazečić). Sarajevo: Svetlost, 1954.

Marin Franičević 1957: O nekim problemima našeg ritma. Zagreb: Jugoslavenska akademija znanosti i umjetnosti. (Rad JAZU 313.)

Marin Franičević 1985: Trohejski i jampski stihovi Jovana J. Zmaja u odnosi na hrvatski stih XIX. stoljeća. Zmajev stih. Novi Sad: Vojvođanska akademija nauka i umetnosti. (Colloquia litteraria: metrica et poetica I.)

Roman Jakobson 1932 (1966): Über den Versbau der serbokroatishen Volksepen. Selected Writings IV: Slavic Epic Studies. The Hague: Mouton.

Fran Levstik 1956: O metriki srbskih narodnih pesmi. Rokopis iz 1. 1868. V: Zbrano delo Frana Levstika 6. Ljubljana: Državna založba Slovenije.

Svetozar Petrović 1971: Jedno sporno pitanje u opisu srpskohrvatsog epskog deseterca. V: Metryka stowiańska. Ur. Zdzysława Kopczyńska in Lucylla Pszczołowska. Warszava, Krakow itd.: Ossolineum in Polska akademia nauk.

SLP Slovenske ljudske pesmi 1, 2, 3. Ljubljana: Slovenska matica, 1971, 1981, 1992.

Tone Pretnar 1997: Iz zgodovine slovenskega verznega oblikovanja. Ljubljana: Filozofska fakulteta.

Dragi Stefanija (ur.) 1984: Brata Miladinova. Ljubljana: Goriški narodni muzej, Narodni muzej Struga, Znanstveni inštitut Filozofske fakultete v Ljubljani.

Mirjana Stefanović 1992: Struktura srpskohrvatskog asimetričnog deseterca u starijim zapisima (XVIXVIII stoleće). Beograd: Institut za književnost i umetnost.

Kiril Taranovski 1949-50: O tonskoj metrici Prof Košutića. V: O srpskom stihu. Ur. Mirjana Stefanović. Beograd: Službeni glasnik, 2010.

Kiril Taranovski 1954: Principi srpskohrvatske verzifikacije. V: O srpskom stibu. Ur. Mirjana Stefanović. Beograd: Službeni glasnik, 2010.

Kiril Taranovski 1950: O jednosložnim rečima u srpskom stihu. V: O srpskom stihu. Ur. Mirjana Stefanović. Beograd: Službeni glasnik, 2010.

Marko Terseglav 1996: Uskoška pesemska dedišcina Bele krajine. Ljubljana: ZRC SAZU. Dostopno tudi na google books. 


\title{
Language.Literature.Politics. 1918-2018. (Un)doing Nationalism and Resistance
}

\author{
Colloquium Editorial Board
}

The Open Access journal Colloquium: New Philologies, the Alpen-Adria-Universität Klagenfurt and the Alps-Adriatic-Rectors' Conference organised the $3^{\text {rd }}$ AARC PhD Students' Conference entitled Language.Literature.Politics. 1918-2018. (Un)doing Nationalism and Resistance. The conference took place from Thursday, $20^{\text {th }}$ to Saturday, $22^{\text {nd }}$ September 2018 in Klagenfurt (Austria), at the Alpen-Adria-Universität Klagenfurt.

Selected paper abstracts form the Perspectives section of this Colloquium issue. Revised and amended versions of the papers will be published as a Special Issue.

Preface of the conference programme: Although it may seem to many as a case of déjà vu, we actually bear witness to a cyclical turn of events in history. The world shortly after World War I seems very similar in many ways to the current state of affairs in the sense that another major push against multinationalism, multiculturalism, and globalism is clearly evident. Mirroring 1918 and the nationalist movements of the time, 2018 seems to bring a strong (or at least a loud) return to nationalism. After a long general movement into globalization, unification, and multiculturalism that has marked the period succeeding World War II, nationalism, particularly in the Western World, seems more pronounced today than anytime in the last 70 years. It is particularly rampant in the political discourse of today. On the other hand, supranational entities such as the EU, seem to be deriving new motivation precisely from the revival of these nationalistic tendencies. A thorough look is hence needed into the languages not only of nationalisms, but also of critique and resistance to them, especially into their narrative, rhetoric, and argumentative strategies, as well as their use of metaphors, images, and other devices of communication.

Conference Website: https://conference.aau.at/event/150 


\title{
The phenomenon of propaganda as reflected in Victor Pelevin's novel S.N.U.U.F
}

Tomas Cenys*

\begin{abstract}
The aim of this paper is to draw a parallel between today's situation - not only political and military, but also between the ideological confrontation between Russia and the Western world and the religious wars, which were waged during the Reformation, and Counterreformation in Europe in the $17^{\text {th }}$ century. Epoch when arguably wars were waged not only for the military domination in Europe, but also, and most importantly, for the minds of people. Jose Antonio Maravall in his book "Culture of Baroque: Analysis of Historical Structure" describes the means of influencing audiences, calling this influence a "Baroque mechanism". The connection between the modern times and the epoch of Baroque is also described in Greg Lambert's book "The Return of the Baroque in Modern Culture". Lambert is comparing the alliance between politics and culture present in the modern world to that of Baroque epoch. Recent developments in Russian history and its reflection by the state propaganda and television quite often make the citizens feel that it is almost impossible to tell where fictional tragedy ends and a real one starts. The occupation of Crimea by the Russian Federation and the sanctions that followed gave rise to a new spiral of Russian propaganda which gave an impetus to a new wave of nationalism on the government-sponsored television and created the so called "Olgin Trolls" on the internet. This policy of state-sponsored ideology and propaganda found its reflection in Russian literature. Prominent contemporary writers, such as Viktor Pelevin and Vladimir Sorokin, gained almost prophetic status for their ability to predict developments in Russian politics albeit in a satirical and provocative form. By describing the present, Pelevin models the future and for this reason he is often credited with prophetic qualities. It seems that he manages to foresee not only the general outline of events, but also the smallest details. While reading Pelevin, one cannot help returning back to the title page and double check the date - it's hard to believe that the book has been written not in the wake of the Chechen wars (Generation II) or the hybrid war
\end{abstract}

* Vilnius University, Lithuania 
with Ukraine (S.N.U.F.F.) but anticipated the events and provided their astonishingly accurate description. As a rule, Pelevin's books outpace the historic events by about five to six years. Presumably we are not dealing here with a mystical providence, but with Pelevin's unique ability to observe and his brilliant capacity for analysis. The aim of this paper is to analyze Viktor Pelevin's novel S.N.U.F.F. This post apocalyptic novel was published in 2011 and predicted the confrontation between Russia and the Western world, which began after 2014. Pelevin suggested even the name of Ukraine, albeit in a distorted form - Urkaina, which is a derivative of укры (the term which became to serve as a pejorative name for Ukranians in Russia), орки (Orks by Tolkien) and урки (prisoners in the prison jargon). Although the book describes a dystopian future, one can clearly establish a connection with modern day realities. One of main discourses of the book is a fusion of ideology and art. The research based on works by Greg Lambert and Jose Antonio Maravall will be mainly focused on the analysis of the system, created in Pelevin's book. In this system society is based on the films it is itself producing. The films are divided in two halves: one part of the film is a pornographic footage, and other part is a footage of killing during war, hence both the book and the films are called snuffs. The films relentlessly fed to the public serve to educate it and to offer it news.

In this way they are the only source of information in Pelevin's dystopia. The connection discussed in this paper will show that these films carry out not only an educational and information functions, they also become the main object of a religious cult and are an integral part of ideological and religious propaganda.

The results of our analysis will hopefully show the mechanisms and effects of such forceful cultural pressure on individuals and how they can cope with and resist the pressure of goverment-controlled media. 


\title{
Competitive Nationalism vs. Cooperative Nationalism: Re-reading Rabindranath Tagore in Times of War
}

\author{
Debabrata Das*
}

\section{Summary}

The proposed paper intends to discuss Rabindranath Tagore's idea of Nationalism and why he is the man the world should look up to for guidance at a time of violence and war threatening to destroy humanity. The proposed paper also intends to identify the loopholes in the traditional theories of Nationalism and to understand the logic behind Tagore's rejection of the same in favour of a more inclusive and humanistic approach to nationalism. Tagore's well-known debate with Mahatma Gandhi on the subject of nationalism will also be touched upon in order to highlight the uniqueness of his thoughts.

\section{Content}

"As I look around I see the crumbling ruins of a proud civilization... and yet I shall not commit the grievous sin of losing faith in Man" (Tagore 1941) was the unequivocal utterance of a man whose strong faith in the ideals of humanism never quivered, even in the face of an all-sweeping storm of modernism that came along with an extremely powerful philosophy of nationalism in the first half of the twentieth century. It is a wellestablished practice in the Indian subcontinent to assimilate Tagore into their brand of postcolonialism where his staunch critique of the discourse of nationalism is often rendered as his oppositional attitude towards the European models of nationalism which arose out of the divisive principles of the European Enlightenment. The obvious danger of such reductionist reading of Tagore lies in the fact that this kind of crippled understanding of Tagore's critique of nationalism leads to the construction of narrow ideological walls which is the hallmark of the traditional discourse of nationalism, against

* Rabindra Bharati University, India 
which Tagore protested in many of his creative and critical writings including Nationalism (1917). A serious problem with the intellectuals who have worked on Tagore's idea of nationalism so far is that they have treated his idea of nationalism as a monolith whereas the truth is his idea of nationalism was always in a state of flux and it did not remain where it was when he had started writing on/reacting to the discourse of nationalism. Having said that, one cannot unaccept the fact that there runs a common strain in all that he wrote on nationalism, and a clear understanding of that common strain is most important in order to effectively understand his otherwise baffling concept of nationalism. Several theories of nationalism have come into being over decades across the globe to analyse the history of nationalism, the rise of the nation-state as a result of man's collective will to call something their own and the interrelation between man and the nation. During the Enlightenment era, an intellectual, as well as cultural, void was created in the minds of the younger generation who unconditionally submitted their faith to the philosophy of Enlightenment which resulted in the breakdown of older social orders causing psychological crisis among the members of the younger generation. This deep psychological crisis, Elie Kedourie believes, had made this generation desperate to look for an alternative space which could provide a sense of stability to them. They finally found the much needed "stability" in a "coherent and stable community" of the "nation" (Kedourie 1960). Ernest Gellner links the rise of nation and the feeling of nationalism to the rise of industrial society. He believes that the ulterior motive behind the formation of the nation-state was to create a nation of citizen-workers. Control over state apparatuses through which to express power is what Karl Deutsch claims to be the criterion by which nationalism transforms itself into "nations". Anderson, in Imagined Communities, defines "nation" as "an imagined political community that is both inherently limited and sovereign" (Anderson 1983). In a postcolonial response to Anderson, Partha Chatterjee dismisses the theory of "imagined community" by stating that the theory had originated in the West and can be applied to the western nation-states only as it fails to explain the reality of the "inner domain" of the Asian and the African people which is the basis of anticolonial nationalism. Several other theories have been originated to extend the scope of nationalism, especially following the infamous incident of $9 / 11$, but one thing remains constant in all these apparently contesting theories of nationalism, i.e. the attempt to uphold national identity as something different from the identity of "other". Tagore's objection to this entire discourse of nationalism lies in the attempt to try to project a nation as distinct from all other nations, which is, according to him, the root-cause of violence and war in all ages. Tagore was one of those very few public intellectuals who sought an alternative to the available model of nationalism which would be completely free of "any Enlightenment concept of freedom" and would uphold a "distinctively civilizational concept of nationalism embedded in the tolerance encoded in various traditional ways of life in a highly diverse plural society" (Nandy 1994). A close reading of Tagore's three political novels - Ghare Baire (The Home and the World), Gora (Gora) and Char Adhyay (Four Chapters) - 
enables the reader to clearly get the quintessential point of Tagore's unique brand of nationalism which is independent of the influences of the western theories and which shifts the focus completely from competitive nationalism to cooperative nationalism. His famous debate with Mahatma Gandhi on the subject of nationalism bears a clear witness to this. Like a true humanist, in his last public speech - "Crisis in Civilization" - Tagore proudly declares: "A day will come when unvanquished Man will... win back his lost human heritage” (Tagore 1941). We all are waiting for that day to come! 


\section{Resisting Nationalism: Postnational Visions in Thomas Pynchon's Against the Day}

Ali Dehdarirad*

\section{Summary}

I aim to investigate how Pynchon's Against the Day depicts a postnational vision that questions the metanarrative of "nation-ness" (Pöhlmann, 7). My discussion is informed by Sascha Pöhlmann's enlightening study of postnationalism in Pynchon's fiction. Here, the postnational is anything that "works towards dismantling the hegemony of nationness as a metanarrative” (8). Nonetheless, although Pöhlmann brilliantly analyzes Gravity's Rainbow and Mason \& Dixon, he dedicates few pages to discuss Against the Day. Drawing and building upon Pöhlmann's theoretical study of postnationalism, I endeavor to show how Pynchon's alternative worlds in Against the Day manifest the potential of other "modes of being" (McHale, 10) which instantiate a trans/post-national insight, resisting the rooted hegemony of "nation-ness" in our life worlds.

\section{Content}

In 1996, Geoff Eley and Ronald Grigor Suny assessed, rather optimistically, the condition of "belonging to a nation" (32) as a state of "cultural recovery" which could potentially bring about "acceptance, even celebration of difference." They observed that "Being national is the condition of our times." Nevertheless, with the rise of the nationalist movements in the U.S., and elsewhere, in recent years, many racial, ethnic, and social groups have been the target of intolerance. Such a condition calls, ipso facto, for a rethinking of the notions of nation and community. In today's world, nation-states and politics are not anymore the only sites of sovereign power. Indeed, Michael Hardt and Antonio Negri have argued that "the concept of national sovereignty is losing its effectiveness" (307). As the "State functions and constitutional elements" effectively undergo change, a "system of transnational command" assimilates the government and politics.

\footnotetext{
* Sapienza University of Rome, Italy
} 
Several significant factors have played a role in highlighting the (un)making narratives of (trans/post)nationalism in the U.S. Fiction has always been influential in the representation of protest and dissent against hegemonic structures of socio-political power, impacting our quotidian "lived spaces," to speak like Henri Lefebvre. In this respect, Thomas Pynchon has been very salient in creating the so-called alternative worlds which challenge the dominance of nation-state and undermine the legitimacy of nationalism as the single form of ordering our life worlds. Pynchon's alternative worlds reflect upon the spatiality of our lives in the way it constructs national identities and boundaries and is used to exert social power and surveillance over "a political body of governable people" (Pöhlmann, 177). A hegemonic narrative, nation-state has made it very diffcult to imagine other (im)possible worlds, in the sense of "way of life, life-experience" (McHale, 79), for almost as long as the last 200 years

In light of this brief introduction, my paper aims at investigating how Pynchon's Against the Day depicts a postnational vision that questions the metanarrative of "nationness" (Pöhlmann, 7), which refers to the concept of nation as distinguished from nationality. My discussion is informed by Sascha Pöhlmann's enlightening study of postnationalism in Pynchon's fiction, which takes issue with those scholars, such as Paul Giles, who favor a transnational attitude in American studies, dismissing a postnational perspective. Here, the postnational is anything that "works towards dismantling the hegemony of nation-ness as a metanarrative" (8). Nonetheless, although Pöhlmann brilliantly analyzes Gravity's Rainbow and Mason \& Dixon at great length, he dedicates few pages to discuss the topic in Against the Day. An "interstice" (361) between the two other novels, he observes that Against the Day is "nothing like Mason \&; Dixon or Gravity's Rainbow in many respects." At the same time, however, the novel evinces similar "postnational traits" and "constitutes another part of Pynchon's postnational imagination.” Drawing and building upon Pöhlmann's theoretical study of postnationalism, I endeavor to show how Pynchon's alternative worlds in Against the Day manifest the potential of other "modes of being" (McHale, 10) which instantiate a trans/post-national insight, resisting the rooted hegemony of "nation-ness" in our life worlds

For example, in the novel Darby explains that, during the sieges of Paris, some of the balloonists came to realize "how much the modern State depended for its survival on maintaining a condition of permanent siege" (19). Pöhlmann argues that the elevated viewpoint of these balloonists allowed them to broaden their "framework of thought" (362) by way of observing the big picture of "politics and society that could not remain within the accepted national categories." In effect, with the end of the sieges, the balloonists were set free "of the political delusions" and decided to fly "far above fortress walls and national boundaries" (20). Realizing the problematic nature of "nation-ness," they seek to feed "the hungry" and shelter "the sick and persecuted," irrespective of nationalities or boundaries. On the cusp of a war that is nationalized, they are trying to develop a transnational attitude in the hope of peace in the world. Their good will, 
however, is fiercely antagonized "because it violates the dictates of national politics and identity" (Pöhlmann, 363).

Moving from a trans/post-national point of view, this, and other similar scenarios in the novel, can be analyzed in suggesting how the alternative worlds of Against the Day demonstrate an imagination which calls into question the dominant sovereignty of "nation-ness" and national identity by way of setting in motion other ways of epistemological thinking and organizing our world. 


\title{
Identity and Contemporary Fashion
}

\author{
Ana Gruic*
}

\begin{abstract}
Fashion, defined as a cultural phenomenon provides one of the most ready means through which individuals can make powerful visual statement about their identity. This thesis seeks to explore the issue of multiculturalism with special attention to work of contemporary fashion designers, starting from Karl Lagerfeld and controversial example of two confronted ideas of freedom, Arabic-inspired dress. Fashion plays a vital role in construction and expression of identity. Multiculturalism can be defined as a dialogue between cultures which results in acknowledgement of certain ethic and national groups. It is a political compromise to maintain cultural identity. However, culture is in a changing position. The transition starts from the point where culture was trying to extend humanity values to the point that defines culture as an instrument of political differentiation.
\end{abstract}

* Faculty of Humanities and Social Sciences, Program of doctoral studies in literature, performing arts, film and culture, Croatia 


\title{
Beyond Nationalism: Faith Movements as Transnational Communities
}

\author{
Himani Kapoor*
}

\section{Summary}

The paper will argue that Faith Movements in India like the Ramakrishna Mission, the Self Realization Fellowship and The Art of Living Foundation can be looked at as transnational communities in their own right by offering cosmopolitan religiosity rather than religious universalism as their ideal.

\section{Content}

Theoretical Preliminaries: A shared tenet of many of the disparate strands in the discourse concerning cosmopolitanism that looks beyond the boundaries of the nationstate, is the desire to reconfigure world society as a community joined by a common thread of social justice, and common good which could be articulated as "emergent social order that extends political rights beyond exclusivist territorial boundaries" ( $\mathrm{Pa}-$ pastergiadis 2011) or "universal political communion with justice" (Jazeel 2011) etc. In this context, the paper will posit religious communities of transnational social movements, such as the New Religious Movements in India as imagined communities where national boundaries do not matter. Ulrich Beck in his book A God of One's Own: Religion's Capacity for Peace and Potential for Violence (2010) offers, as a part of the framework of "reflexive modernization", a strong case for individualization and cosmopolitization of religion. He suggests that as globalization erodes cultural boundaries and exposes people to diverse faiths, a de-territorialization of the traditional cultural systems takes place and the rigidity of institutionalized religions is resisted in favour of more personal, "individualized" religion(s). This radicalized religious freedom also offers a new definition of God, who is "a personal God who has a firm place and a clear voice in the intimate heart of one's own life". Beck also foregrounds here, the

* Delhi University, India 
peace-building capacity of religion in the modern world. Although Beck mostly focuses on Christianity in the west, he indicates that a cross-cultural research is required before judgments can be made about the wider applicability of his thesis. In the proposed paper therefore, I would like to explore the resonances of Beck's theory with the Indian religious public sphere. For this I will consider three New Religious Movements- The Art of Living Foundation, Ramakrishna Mission and Self Realization Fellowship to understand these religious social movements as transnational communities in their own right. These religious societies are all regionally rooted and globally connected through sophisticated urban channels wherein identity formation and perceived common good is the intended outcome. Their geographical footprint and the ideological underpinnings will be looked into, in order to ascertain the function played by them in contemporary society. The paper will thereby inquire religiously inspired cosmopolitan consciousness in the light of the various critical perspectives on cosmopolitanism. Tentative Arguments The paper will thus argue that Faith Movements in India like the Ramakrishna Mission, the Self Realization Fellowship and The Art of Living Foundation can be looked at as transnational communities in their own right by offering cosmopolitan religiosity rather than religious universalism as their ideal. These transnational imagined communities are formed around the figure of the guru, who serves as a godhead and the organization, with its own set of sacred geography, philosophy and iconography; and an element of Seva or service to humanity as a tenet associated with each. All these elements come together and serve as a binding force around which the community defines itself and its place in the society. The paper will inquire into these movements for their potential in inspiring a "cosmopolitan consciousness" by trying to remain preeminently multicultural, while also emphasizing upon the moral sensibility and issues of social concern. What is significant about the above mentioned faith based groups is that they do not go with an isolated orthodox view, cut away from contemporary reason and rationality, rather they represent themselves as modern day organizations, by highlighting the scientific elements in of Yoga, and meditation. Beck calls this attitude "post-modern" religiosity as the individuals, instead of having to choose between religion or rationality, appropriate both the aspects together, or "a new equality between religious and scientific knowledge” (Beck 2010, 134). Furthermore, the paper will also look into Beck's work on the role of religion in modern, "post secular" European society, with the ideas of "cosmopolitan constellation", "cosmopolitan religiosity" and "post-modern religiosity" etc and discuss a wider applicability of his thesis, especially in the Indian context. Finally the paper will also try to question the assumptions associated with religious nationalism in India and try to demonstrate that different publics may indeed be attracted to different elements within the same religious community. Whilst there can be many counterpoints to this argument, for instance such Faith Movements have often been looked at as signifiers of globalized Hinduism, the paper, taking a consideration to these issues will try to understand the various reasons associated with the rise of such Faith 
based movements like the rising middle class in India, capital flows, western education and seek to measure their potential in creating a cosmopolitan consciousness.

\section{References}

Beck, Ulrich, and Rodney Livingstone. 2010. A God of One’s Own. Religion's Capacity for Peace and Potential for Violence. Polity Press.

Jazeel, Tariq. 2011. "Spatializing Difference beyond Cosmopolitanism: Rethinking Planetary Futures" Theory, Culture \& Society, vol. 28, no. 5, pp. 75-97.

Papastergiadis, Nikos. 2011. "Cultural translation, cosmopolitanism and thevoid", Translation Studies, vol. 4, no. 1, pp 1-20 


\title{
Conceptual Blending in Social Issue Advertisements
}

\author{
Anela Mulahmetovic Ibrisimovic ${ }^{*} \&$ Nerma Pezerović-Ridić**
}

\section{Summary}

The aim of the paper is to examine the extent to which conceptual integration theory can be applied to the analysis of social issue advertisements. Taking into consideration that we live in a visually-dominated culture, visual resources such as advertisements, cartoons, and memes have been used in crafting short, eye-catching messages, seeking the biggest impact with a limited amount of space. In recent years, there has been an enormous interest in the way conceptual integration theory can be used to explain how the mentioned resources are formed and what message they convey. More precisely, CIT will be used to show a glimpse of the intricate mental processes that are involved in the creation and understanding of social-issues advertisements.

\section{Content}

\section{Theoretical outline}

Conceptual integration theory, commonly known as blending, has emerged as an offspring of Fauconnier's mental spaces theory. In one of his works, Fauconnier (1994: xxvii) states that meaning construction or conceptualization is inseparable from the context since sentences serve as cues for the construction of mental spaces. Mental spaces are said to be "structured, incrementable sets, that is, sets with elements (...) and relations holding between them (...) such that new elements can be added to them and new relations established between their elements (ibid:16). In other words, mental spaces are temporary containers of information created for the purpose of better comprehension of a spoken or a written discourse.

\footnotetext{
* Tuzla University, Bosnia and Herzegovina

** Tuzla University, Bosnia and Herzegovina
} 
Mental spaces get integrated in a conceptual integration network as a model of how meaning is mentally constructed. The network encompasses minimally four mental spaces that are structured by many different domains, namely two input spaces connected by counterpart matching or cross-mappings that is indicated by solid lines in the diagram, a generic space, and a blended space. The link between the generic space and input spaces is bidirectional. The generic space inherits elements from the inputs creating a less detailed structure than the one found in the input spaces, which is in turn mapped onto its counterparts in the inputs. There is a partial projection from the inputs into the blended space marked by the broken lines in the diagram. What emerges in the blend is a novel structure that remains connected to the inputs, as the blend "contains generic structure captured in the generic space but also contains more specific structure, and it can contain structure that is impossible for the inputs (...)" (Fauconnier and Turner 2002:47).

\section{Methodology}

It has been suggested that the creation of meaning in an advertisement can be explained by applying conceptual integration theory (Lundmark 2003, Ruiz 2006, Joy et al. 2008, Delibegovic Dzanic and Berberovic 2012). The paper tries to prove that social-issue advertisements are no exception. The three social-issue advertisements that were analyzed in the paper were randomly selected from "the most powerful social-issue advertisements that make you stop and think" (Digital Synopsis 2016). The first social - issue advertisement was part of the 2010 campaign by the French LICRA (Ligue Internationale Contre le Racisme et l'Antisémitism) against racism and anti-Semitism. The campaign slogan "Your skin color. Shouldn't dictate your future" had cognitive and emotional appeal and served as a call for action. The second social- issue advertisement was taken from the 2014 "Liking is not helping. Be a volunteer. Change a life" campaign developed by Publicis Singapore for Crisis Relief Singapore. Finally, the third UN social- issue advertisement tried to bring attention to the issues of discrimination, gender inequality, and women's rights. On their website, UN women (2013) stated that the intent of the campaign was to "expose negative sentiments ranging from stereotyping as well as outright denial of women's rights".

- Social-issue advertisement 1 Source: http://www.ufunk.net/en/publicite/contre-le-racisme-et-lantisemitisme/

- Social-issue advertisement 2 Source: https://digitalsynopsis.com/inspiration/60-public-service-announcements-socialissue-ads/

- Social-issue advertisement 3 Source: http://www.unwomen.org/en/news/stories/2013/10/women-should-ads

In all three examples, conceptual integration network is established by opening mental spaces on the basis of verbal and/or linguistic element, cobbling them together and cre- 
ating the blend. The blended space contains a structure that represents an incongruity that needs to be solved. What ensues is the unpacking of the blend and reconstructing the input spaces by relying once again on visual and verbal components that serve as cues for the viewers to arrive at the intended meaning. Following the reconstruction, the backward projection to the input spaces highlights the contrast between the emergent structure in the blend and the elements in the inputs and, as Delibegovic Dzanic and Berberovic (2010:210) notice, "reinforce[s] construals in input spaces in accordance with the new structure created in the blend ". In this way, viewers are able to grasp the main idea behind the advertisement.

\section{Tentative Results}

The paper presents an analysis of social-issue advertisements within the framework of conceptual integration theory. The main goal of the paper was shedding light on the meaning construction in social issue advertisements, as well as the comprehension of central ideas behind them. It needs to be pointed out that texts, images and social context play a vital role in the understanding of social-issue advertisements. Thus, in the first advertisement, the image of babies in cribs opens a mental space that comprises a newborn nursery. Furthermore, the advertising slogan, as well as the social context in which the advertisement was created, evokes the concept of racial segregation in the French society.

Selective projections from the two input spaces give rise to the blend in which black babies in a nursery wear uniforms that symbolize lower-paid and lower-status jobs, as opposed to white babies whose future has not been predetermined.

In that sense, we are able to understand the central message behind the advertisement, that is, the provision of tougher support against racial discrimination.

In the second advertisement, verbal and visual components prompt the opening of mental spaces comprising the domain of war and Facebook, respectively. In the blend, a dying boy is gently held in his mother's arms, as the Facebook users are giving the thumbs up. Since the blend itself represents an incongruity that needs to be accounted for, the unpacking of the blend enables the backward projection and reconstruction of the input spaces. It is suggested that posting a courageous status/photo and getting thousands of virtual likes will be rendered ineffective unless users take prompt action. The blend ridicules the social setting in which virtuality is being treated as a substitute of reality, rather than its supplement.

In the third example, input space one contains women around the world that differ in race, nation, and ethnicity, and the concept of women's rights. The second input space utilizes a Google search engine and a list of the most denigrating searched phrases on women suggested by the Google autocomplete search function. Lastly, input space three comprises the notion of restraint that is metonymically symbolized by duct tape. Projections to the blended space result in the blend containing four women with the duct tape over their mouth which has been merged with the Google queries. Backward 
projections point out that women are unable to voice their opinion but have sexist attitudes imposed on them. The advertisement puts the spotlight on the fact that the notion of women's rights is still met with resistance around the world, contravening the entitlement to equality with men.

Taking everything into account, it can be concluded that conceptual integration theory can be applied to the analysis of social- issue advertisements. The paper confirmed the hypothesis by showing that visual and verbal resources are exploited in an advertisement in order to grab attention, aid the creation of meaning, and incite people to act. It can be suggested that, to a certain extent, conceptual integration theory explains how human beings think. 


\section{Unification, Nationalism and/or Brexit? The impact of the Nationalisms and the Northern Irish Good Friday Agreement 1998-2018 on local media discourse}

Sarah Ritt*

\section{Background}

In 2018, on the twentieth anniversary of the 1998 Good Friday Agreement, the treaty that formally ended the civil war in Northern Ireland, three very different kinds of nationalistic ideologies (the term 'nationalist' in this context is mainly used for Irish republicans) are shaping Northern Irish public discourse. The first and perhaps the most widely known is linked to the outcome and consequences of the British 'Brexit' vote. The most prominent and symbolic aspect of this, the possible re-introduction of a hard border between the Republic of Ireland and Northern Ireland is speculated to undermine peace efforts and only feed into the ideologies and actions of republican paramilitaries.

The second is the just mentioned republicans, who see Northern Ireland as part of the Republic of Ireland, away from the UK. This is the side of the ideological spectrum where parties like Sinn Féin and the paramilitary IRA are situated. In the Good Friday Agreement, this side has committed to reaching their means of a united Ireland solely by democratic means (for example a referendum). The third is the unionists, who are content with the status quo of Northern Ireland being a part of the UK, which does however not automatically mean that they approve Brexit. They see themselves as British and although Northern Ireland does not currently (early April 2018) have a government, the main unionist party (the DUP) was the winner of last year's general election.

Despite this, there is a growing amount of people on all sides, that want to work towards a shared future for their country and, despite having their socio-cultural beliefs,

* University of Vienna, Austria 
try to resist the often black-and-white stereotypes invoked by nationalistic thinking patterns. All of these different takes on nationalism and the ideal national state, which influence the handling and implementation of the Good Friday Agreement and the attention it is getting twenty years after it was signed, will be the topic of this talk: How do they influence each other? How are the individual strands of nationalism portrayed in the source texts (which can be found below)? Is a mediated form of nationalism even possible in a place, where the population is about equally split into two groups, one who in essence wants to be part of the Republic of Ireland and the other wants to remain within the UK? How is this tension picked up and treated by media outlets, who both point back to the original signing date of the Good Friday Agreement and speculating on how and if it can survive in a post-Brexit UK? And, most importantly: How much attention/agency is given to people who are trying to overcome these nationalist tensions?

\section{Methodology}

Although it is neither possible nor practical to aim for a corpus that is anywhere near 'complete', I will be taking both a multimodal (cf. Kress 2010) and a multimedial approach to the keyword 'nationalism' in connection with the Good Friday Agreement, which will be generating a rather large number of individual items, such as newspaper articles, videos, speeches and perhaps more.

The search itself will be restricted by date: two weeks before and after Good Friday (29th April 2018). Following these criteria, the following media outlets will be searched (for content of all types, not only written articles):

- The online versions of the Belfast Telegraph and the News Letter, two unionistleaning Northern Irish newspapers

- The Irish Times, from the Republic of Ireland

- The Guardian, from England

In order to be able to focus on the sub-discourse of nationality in these sources, I will be following the general notion of Critical Discourse Studies (cf. Wodak and Meyer 2016) but as this is a very broad term which characterizes a critical, aware and multidisciplinary approach to one's data and research, I will additionally be making use of the DIMEAN-Model (cf. Spitzmüller/Warnke 2011) to limit the output I am generating by focusing on the traits in the model's 'upper level', the transtextual level, which deals with (among a handful of other factors) with intertextuality, frames and - this is probably the most important aspect for this analysis - historicity.

Tentative outcomes: The - at this point in time very tentative - outcomes of this media survey will most likely be pointing at a climate of tension, the rather unique 
situation of Northern Ireland within the EU, where there is not one (like in Hungary or Poland) but two nationalistic groups opposing each other, in addition to the statechanging and unpredictable consequences of Brexit. This tension and the prospect of twenty years of more or less sustainable peace-building attempts being either eradicated or lessened by the change in circumstances that comes with the UK leaving the EU is surely visible in media coverage, and it will most likely show in the usage of topoi related to division of the civic society, hints to a violent past and symbolism of terror and unrest. I do not expect to find many attempts to deal with the topic from a nonnationalistic view.

\section{References}

Kress, Gunther and Theo van Leeuven. 2010. Reading Images. 1996. London: Routledge Kress, Gunther: Multimodality. London: Routledge.

Spitzmüller, Jürgen and Ingo Warnke. 2011. Diskurslinguistik. Berlin: De Gruyter Mouton.

Wodak, Ruth and Michael Meyer (eds.). 2016. Methods of Critical Discourse Studies. Los Angeles: Sage.

Wodak, Ruth. 2015. The politics of fear: what right-wing populist discourses mean. Los Angeles: Sage. 


\title{
Neologisms at historical turning points: Czech example
}

\author{
Tena Šinjori*
}

\begin{abstract}
Neologisms that had never entered official dictionaries present valuable research topic, proving the velocity of social changes. Several such examples are mentioned by V. Dvořácková in an article about supplements (Dodatky) to the Encyclopaedic Dictionary of Czech Language (PSJČ). Supplements had never been published (mostly because of the fact the vast majority of changes it contained were included in the SSJČ, a new dictionary being prepared simultaneously with supplements to PSJČ). Among neologisms Dvořáčková had sorted out were words which had never become dictionary entries, such as a pejorative term černoprdelník, meaning the priest, that reflects attitudes of political regime of the time towards the Church. Dvořácková states that words such as černoprdelník are of great significance in exploring social changes in the Czech society of the time (1940-1950). Having in mind the iconic connection of lexicographic work and ideology, T. Dickins points out that not only the users of language understand the importance of dictionary of their national language, but so do the governing structures. Dictionaries are not only a window into the patriotic thought, but also in the dynamics of power. Therefore dictionaries are social facts filled with traces of influence (and pressure) of political regimes and also of attitudes (and resistance) towards them. The analysis of neologisms occurring during the turning points of a nation's history provides a valuable insight into the users' attitudes towards their language and nation. In the first part of my paper I will discuss this claim based on the examples from Czech lexicography throughout the $20^{\text {th }}$ century by using relevant monolingual dictionaries, dictionaries of neologism published within Czech Language Institute and chosen examples of neologism and neosemanticism. In the second part of my paper an analysis of Czech neologism published in the database of Czech neologism Neomat will be presented. The published database contains of corpus excerpted 2013-2018. Special attention will be dedicated to the words belonging to political discourse (e.g. those
\end{abstract}

* Faculty of Humanities and Social Sciences Zagreb, Croatia 
containing prefix euro- or words whose meaning is related to the question of migrant crisis).

\section{Content}

Chosen examples of Czech neologisms occurring during the historical turning points of $20^{\text {th }}$ century.

Analysis of Czech neologisms published in the database Neomat 2013-2018 concerning political changes of current time. 


\title{
'The opposite of hatred': Undoing nationalism in Joyce's Ulysses
}

Nataša Tučev*

\begin{abstract}
The epitome of chauvinist narrow-mindedness in Joyce's Ulysses is the drunken brawler and anti-Semite depicted in the novel's twelfth chapter, 'Cyclops'. Using his mockheroic approach as one of the essential stylistic devices in Ulysses, and one of the chief sources of humour in the text, Joyce connects his character to the one-eyed giant Polyphemus of the original Homeric epic. As Randall Stevenson suggests in his study Modernist Fiction (1992), Joyce uses the allusion to Cyclops to warn his readers of any 'one-eyed', narrow or single-minded view of reality (such as nationalism) and the dangerous patterns of behaviour that might ensue from it. However, Joyce's intention is not just to repudiate or mock nationalism, but also to offer an alternative, a way of resisting the dangerous mindset embodied in Cyclops. Stevenson argues that Joyce accomplishes this by the very narrative method his novel employs: with its constantly shifting perspectives, its myriad styles and points of view, it successfully fights against any narrowing of vision - and so, by implication, against any tendency towards localism, division, ethnic or religious hatred. The key word for understanding this strategy in the novel is 'parallax', one of the scientific concepts that Joyce's protagonist Bloom speculates about, referring to the effect whereby the position of an object seems to change when viewed from different points of observation. As Stevenson points out, Joyce uses parallax to fight against paralysis - by which he means the paralysis of Dublin's drab, unimaginative middle-class, and their myopic political views. In her study Upheavals of Thought: The Intelligence of Emotions (2001), Martha Nussbaum likewise focuses on the twelfth chapter of Ulysses in order to analyse the novel's political stance and its repudiation of nationalist and religious bigotry. In Nussbaum's opinion, however, Joyce's strategy in dealing with these issues is inseparable from one of the major motifs in the novel, i.e., the author's celebration of physical love. Namely, Nussbaum argues that hating the Other may be psychologically connected to self-hatred - which stems
\end{abstract}

* University of Niš, Serbia 
from our inability to embrace our human experience in its totality, including its bodily, disorderly and mundane aspects. Especially sexuality, as Nussbaum maintains, tends to become metonymic and imply everything in our life which defies control. Accepting only the controllable, rational and orderly portion of our being may lead us to project the undesirable psychic contents onto the Other, thus making him/her the object of our hatred. Such self-hatred - eventually leading to the hatred of the Other - may even be prompted by certain works of art, those which, according to Nussbaum, constitute the so-called 'ascent' tradition. These works (written by Plato, Augustine, Dante, Spinoza, Whitman or Proust) project a sublimated image of love and life, constructing in the reader's mind some idealized version of his or her own self, removed from the messiness of one's ordinary existence and one's "real-life body with its hungers and thirsts and fantasies" (Nussbaum 2001). As a result, Nussbaum argues, these works create a wide gap between the constructed reader and the real-life reader, which may cause us anger and self-disgust when we return from the experience of reading and discover that we are still ourselves. Joyce's Ulysses, on the other hand, closes the selfsame gap with the narrative method which Nussbaum calls 'transfiguration of everyday life' and 'the descent of love'. Nussbaum explains it primarily as a descent into the chaos and disorder of erotic love. Joyce's novel, in her opinion, seems to argue that it is only through love (and bodily love at that) that human beings can find an exit from solipsism and connect with the reality of another life. Furthermore, since bodily needs are universal, focusing on bodily love may be an important step towards embracing our common humanity and adopting a cosmopolitan view. Cosmopolitanism is also explicitly advocated by Joyce's protagonist Leopold Bloom. In the twelfth chapter, standing up to 'Cyclops', Bloom points out that insult and hatred cannot constitute a proper 'life for men and women', and 'it's the very opposite of that that is really life'. Militant nationalism, as a chief source of insult and hatred, is the opposite of love and therefore of life. Using Stevenson's and Nussbaum's insights as a starting point, the paper will proceed to explore Joyce's ethical and political preoccupations in Ulysses in order to outline the predominant narrative strategies which the author employs in undoing nationalism. 


\title{
The Role of Language in the Definition of National Character: A Case Study of Identity Discourse in Contemporary Japan
}

Elisa Vitali*

\begin{abstract}
After the defeat in WWII the Japanese experienced a twenty-year period of identity crisis in which they searched for a new ideology that could enable them to face the threat of "spiritual vacuum" (Befu 2001), economic instability and strong criticisms from the West. In such a chaotic environment the identity discourse known as Nihonjinron (Theories on the Japanese) flourished and became hegemonic. Nihonjinron successfully dominates the Japanese panorama even now, thanks to the influence of academic and popular literature, mass media, a powerful cultural industry, politics, and a national, genuine interest for the "Japaneseness". The discussion on the alleged Japanese uniqueness, that is, the existence of unbridgeable racial and cultural differences between the 'Japanese' and the 'Other' - the West - is precisely the core of Nihonjinron. As Dale (1986), Befu, Sugimoto (1986) and Yoshino (1992) argue, the underlying assumptions of Nihonjinron could be summed up as follows: a racial and cultural homogeneity of Japanese people; a conceptual equation between Nation/Race/Ethnicity/Language/Culture/Blood considered as monolithic, natural features, that is, a primordialist or essentialist perspective (Eriksen 2010, Geertz 1963); a "race thinking” or racialism; a belief in the validity of emic judgments only over etic analyses on Japaneseness and ethnocentrism. The historical roots of the Nihonjinron phenomenon can be traced back to the Meiji period (1868-1912), when the first theories on the origins of the Japanese nation emerged in reaction to the shocking encounter with the West and the introduction of Western science (Oguma 2002). Interestingly, the myth of a homogeneous, pureblooded state-nation coexisted from its birth with another typology of nationalism, the so called 'mixed nation theory'. This theory prevailed during the Taishō (1912-1926) and part of the Showa (1926-1989) periods until the 1945 defeat, serving as the basis of the multinational paradigm of the imperialistic and expansionistic ideology and as
\end{abstract}

* University of Milan, Italy 
a justification of the aggressive expansionism into China. However, as a result of the surrender, the Japanese government could no longer advocate the logic of the past and the previous assimilationist discourse was abandoned. A vision of Japan as an isolated, remote and peaceful insular nation, homeland to no aliens but inhabited from time immemorial by a homogeneous and harmonious agricultural people, with no skill for war, was thus reactivated to serve in the new context. These images of Japanese identity based on a myth of homogeneity and on discourse of cultural exceptionalism culminated in the 1960s and 1970s, in correspondence with the economic growth and the gain of self-confidence in the international society. Moreover, despite the socioeconomical changes from the end of 1980s, Japan succeeded in adjusting her paradigm of cultural nationalism through the medium of cultural capitalism, as the spread of her soft power policies throughout the world shows. My contribution will focus on an outstanding example of Nihonjinron* and of its temporal continuity, namely the works of Watanabe Shōichi (1930-2017), a professor emeritus of English literature, a political and cultural critic and a historical revisionist. Despite its carrier background, from the half of the 1970s until well into the 2000s Watanabe was surprisingly prolific in the nihonjinron field, enthusiastically propagating the establishment's ideology (Watanabe 1974a, 1977, $1980,2000,2007)$. In this respect, Watanabe's essays provide a significant insight into two aspects of Japanese contemporary society which I will discuss: the role of language as the most effective expression of ethnic identity and the existence of a widespread set of peculiar Japanese expressions (un)consciously conveying the underlying ideology. Watanabe connects the uniqueness of Japanese culture to the particularism of the language, as revealed by a number of untranslatable aesthetical concepts and native words conveying a "Japanese spirit", a vast range of lexical items and idiomatic expressions appealing directly to the emotionality of the Japanese. My purpose is to present and analyze a specific example of the ideological distinction that Watanabe intentionally develops, namely the lexical dichotomy between the stratum of the supposed "native lexicon" and that of "foreign loans". Watanabe refers to the former by means of a variety of words and expressions related to the concepts of "authenticity", "primitivity" and "naturalness", associated with attributes such "indigenous", "pure", "irrational", "emotional”, "soft/maternal", "inward-looking”. The latter lexicon is instead related to negative notions such "foreignness", "corruption" and "artifice", and to attributes such "alien”, "contaminated”, "logical”, "detached”, "hard/masculine”, "outward-looking” (Watanabe 1974a). I will examine likewise the language of the feelings that each linguistic category is supposed to evoke: while native words should evoke a primordial ethnic memory of harmonious, peaceful, delicate and moving sensations, foreign loanwords provoke aggressive, euphoric states of mind, alien to the "true" Japanese spirit. My contribution will provide an insight into the close relationship between language and ideology. The role that language plays in the definition of Japanese national identity may help understand the importance of language in vehiculating and slyly imposing ideology, power, identity paradigms and distorted realities to the minds of social actors. 
This is all the more actual in the contemporary world, where the spread of nationalisms and ethnic conflicts is sustained by a scattered usage of rhetoric and ideological narratives. 


\section{(Un)doing nationalism through familial metaphors: a case of Taiwan}

Jennifer Meei Yau Wei*

\section{Summary}

Combining corpus-assisted method and discourse analysis, this paper aims to study familial metaphors such as mother, wife, and parents and analyze how ideals of gender roles are intersected with socio-political transitions in testing times.

\section{Content}

Ideals of femininities and masculinities (to a lesser extent) are often used to mobilize citizens in testing socio-political times. Familial roles such as mothers and wives are prime targets for politicians crafting ideals of nationalism. In this presentation, I use political speeches delivered by female politicians in Chinese/Taiwanese modern history, namely, Mme. Chiang Kai Shek, and Annette Lu, to argue that ideal familial roles always intersected with cultural and political transitions. Moreover, these ideals parallel changes in a society through feudalistic, modern, and authoritarian to democracy. Combining both corpus assisted method and discourse analysis and studying the argumentative strategies and familial metaphors such as mothers, wives and parents, I offer a comprehensive view on how gender, nation, and family values have been articulated in times of transitions on the island in the 20th century.

Taiwan situated in the strategic center in the Pacific Ocean can offer an interesting case study as it has experienced brief colonization by the Dutch and the Spanish in the 16th century and was included as one of the prefatory to Fujian, one of the provinces in China during the Qing dynasty (the last Chinese dynasty). At the beginning of the 20th century, Taiwan became the first colony of Japan (1894-1945) as a result of the first SinoJapanese War, experienced a 50 year authoritarian rule as the then ruling party KMT (Kuomintang) to the island as it lost the civil war to the Chinese communists in the late

\footnotetext{
* Soochow University, English Department, Taipei, Taiwan
} 
1940s. In the late 1980s, the island started to democratize rapidly with much opposition demanding changes and direct elections. In 1996, the island held the first presidential election in Chinese history, in 2000 the then opposition party, DPP (Democratic Progressive Party) won the election and ended the 50 year monopoly of KMT. Since the turn of the 21st century, the island has experienced three party successions.

Following Brownell and Wasserstrom (2002), Chang (2002) and Li (2011), I see gender and politics as mutually intertwined and I am interested in the following questions: 1) Do political transitions from feudal society to modern state and from authoritarianism to democracy change the way we view gender roles and expectations? 2) If gender and politics are mutually embedded, do shifts in political ideology change the way candidates and voters view issues? 3 ) Does Confucian stress on women's subordination and subservience still pervade $21^{\text {st }}$-century Taiwan? Our results show that Mme. Chiang Kai Shek in the period of modern China saw women's subordinate status and illiteracy as one of the major culprits for China's malaise. Ways to advance women's status and the emphasis on women's education were incorporated into Chinese nationalism and patriotism where women were shown to lead in all spheres in society and their potentials were boundless. Women were discursively constructed as strong and rebellious and their defiance to Chinese patriarchy was allowed so long as it was an act of patriotism. Gender socialization was emphasized, and their well-bounded familial roles paralleled China's transition from a feudal society to a modern state and emphasized the importance of Chinese nationalism which had reigned in Taiwan from the 1940s to the 1980s.

Annette $\mathrm{Lu}$ was one of the most forceful feminists and human rights advocators in Taiwan. Her belief that gender equality is a fundamental human right served as one of the driving forces for her political convictions. By embedding her gender ideals with democratic appeals, her rhetoric constantly tested the limitations of tolerance when Taiwan was under martial law. Her stress on being human and then learning how to become men or women echoed much of the mistreatment of women in Taiwan in the 1950s, a society where Chinese patriarchal beliefs saw the dependence and obedience of women to men as the holy grail dictating gender relations. Lu's stress on the agency and independence of gender roles resonated well in the Taiwanese society when being submissive to Chinese patriarchy and Chinese nationalism was rampant.

By studying the rhetoric of these prominent politicians in time, we should get a better understanding of how changing ideas and ideals for gender, nation, and family can serve as resources for testing theories on gender, politics and language. 


\title{
The Postmodern Turkish Novel's Resistance to the Return of Nationalism
}

\author{
Barış Yilmaz*
}

\begin{abstract}
Postmodern Turkish Novel's Resistance to the Return of the Nationalism The emergence of the first wave of nationalism in the late $18^{\text {th }}$, the early $19^{\text {th }}$ century was underpinned not only by traditional historiography but also by the historical novels written to verify the legitimacy assertions of the nationhood ideals. Although at that time historical novels were not considered as passable as history books whose faculty to represent the facts was not in question, still, they served in the gathering of the people on the distant peripheries around the same central idea of commonality, perhaps, even more effectively than historiography did. The novel, along with the newspapers, as Benedict Anderson and the others argued, was the most efficient medium in concretizing the ambiguous nation imagination with the effective use of vernacular, the function to employ different writing styles, and the inherent claim to represent every member of the nation. The utilization of the novel, especially of the romantic novel, in strengthening the foundations of the nation-state, first had started in the Western countries and then spread to the all the world, including the colonies of those Western countries. This kind of utilization of the novel continued after the end of the World War II, by drawing the new borders for the new nation-states and new colonies in the world. Turkey, once a big empire with many multi-national possessions, experienced the binary positions of nationalism, during and after its Independence War (1919-1922) against the Allied Powers. Before the World War I, as Ottoman Empire, it had strived to protect its vast territories with the help of the ideal of Ottomanism that referred to the equality of every citizen of the Empire without any religious or ethnic division. But, in the end, this and other overarching ideas, such as 'Islamism' or 'Westernism', could not hold against the nationalism's aura. Primarily, Ottoman Empire started to lose its elements in the Balkans subsequent to a series of nationalistic revolts, then the heavy loss of the World War I came. The intelligentsia was already offering the solution as Pan-Turkism; the attempts of imperial powers to share the fields of the country among its neighbors and
\end{abstract}

* University of Szeged, Hungary 
stateless subjects, and then to colonize the remaining parts, only helped to consolidate them around nationhood ideal. Winning the Independence War, the founder of Turkish Republic, Mustafa Kemal Atatürk (1881-1938) and his staff officers established the Turkish Republic in 1923 upon the base of one nation (Turks), one religion (Islam), and one sect (Sunnism). The concept was similar to the other nation-state building processes; initially, the deportation/extermination of the elements having a different religious identity, and the assimilation of the elements having a different ethnicity, or a different sect of Islam, in the melting pot of Turk-Islamism. The role of the novelists was crucial in fulfilment of the theoretical, moreover, it was expected to show a parallelism with the suggestions of historiographers. The expectation was met, but, it also created a problem of representation. Because the presupposed real being represented was the reality of the dominant subject. However, there was still a significant amount of cultural, ethnic, and religious minorities living in the country, yet excluded from the circuit of representation. The emergence of postmodernism has shifted this paradigm which was preoccupied with the reproduction of the discourse of the dominant. Against the canonized robustness of the modernist representation and referentiality, postmodern fiction, by availing of post-structuralism, offers to turn the tables in favor of the oppressed ones. Postmodernist literature has redefined the concept of the historical fiction by diverting its course from a central, singular, and homogeneous position to a peripheral, plural, and heterogeneous direction. Postmodern historical fiction, or by the term "historiographic metafiction" as Linda Hutcheon has coined, designates a narration with two predominant features; a) It is principally a retelling of a historical occurrence from a counter-position against the supposed factuality of the original story, and b) It contains the self-reflexivity of its author which enables him/her to question boundary between fact and fiction, if there is any at all. Obviously, Hutcheon's conception upon this particular category of postmodern fiction was mainly derived from the approach which stresses the inherent narratological characteristics in history writing, argued by Hayden White, and other theoreticians. What is my research question in this work is how successfully historiographic metafiction is utilized by postmodern writers in Turkish literature. Has postmodernism been able to challenge the traditional admissions of representation in Turkey? What kind of resistance can provide postmodern literature after the return of the second big wave of nationalism, especially, in a strongly nationalist country, like Turkey? In order to respond to these questions, I offer to analyze a certain postmodern text, The Black Book ("Kara Kitap" 1990; in English 1994), written by acclaimed contemporary Turkish writer Orhan Pamuk (1952-). 


\title{
Ernst Bloch's Ungleichzeitigkeit then and now - About a political term and its reflection in literary texts of the past and present
}

\author{
Manuel Theophil*
}

\begin{abstract}
The term Ungleichzeitigkeit, taken from the philosophy of Ernst Bloch, shows itself as an analytic tool that helps understanding the emergence of nationalism both in the past and present. The objective of the presentation is not only to compare ungleichzeitige developments then and now but also to show in which ways this political term is reflected within contemparary literary texts as well as in novels from the past.
\end{abstract}

\section{Content}

„They seized their prey among people who got lost" - with these words the German philosopher Ernst Bloch described in his book Erbschaft dieser Zeit (1935) the strategy of the Nazis to gain power during the 1920s and 30s. According to Bloch the nationalist propaganda was first and foremost successful due to capitalizing on - what Bloch called - Ungleichzeitigkeit. With this term he encompassed the situation of all milieus and classes which did not stand at the forefront of modernity (especially the petty bourgeois and the peasantry). In contrast to social democratic and communist parties the Nazis were willing and also able to grasp (and henceforward to manipulate) the phantasies and desires of these groups of people.

Mutatis mutandis the concept of Ungleichzeitigkeit uncovers a similar situation for the present (always having in mind that today there is no political group like the Nazis). Citizens, particularly those living in small towns and villages, were politically ignored

* Universität Koblenz Landau, Germany 
for a long time, leaving them exposed to the propaganda of right wing parties and movements. The words used to gain back trust among these people often ring hollow. However, in contrast to the past - and this will be one central hypothesis of my presentation - there seems to be more awareness today among artists, especially writers, that Ungleichzeitigkeiten within a society are likely to cause soft spots which make attacks on the democracy easier. Authors like Klaus Mann or Hans Fallada captured the Ungleichzeitigkeiten of the 1920s and 30s in their novels when the consequences (or even the aftermath) of the National Socialist empowerment were already visible. They considered the downfall of democracy when it was already deceased. Today, writers like Juli Zeh or Saša Stanišić seem to be more conscious towards reality. In their novels they consider the living conditions, problems and dreams of people living in rural areas, thus making it harder for the rest of the population as well as for politics to ignore potential threats that go along with developments that are characterized by Ungleichzeitigkeit.

As the paragraph above already indicates, the notion of Ungleichzeitigkeit from the philosophy of Ernst Bloch will be methodologically crucial for my presentation. I did not translate the term Ungleichzeitigkeit because in my judgement transmissions like non-simultaneity or non-parallelism focus too much on the negation. Bloch did not want to describe people living in Ungleichzeitigkeit only as reactionary or backward; he also wanted to stress that there is nevertheless an anticapitalistic impulse that connects for example the peasant with the proletarian (and that of course disappears when nationalist movements get hold of these people). In short, the Gleichzeitigkeit within the Ungleichzeitigkeit is also very important to Bloch. (The same phenomenon is for example true for the term deconstruction.) Following Marxist thinking Bloch used the concept of Ungleichzeitigkeit to capture differing developments of social classes. The peasant for instance, bound to his own clod of earth, with the means of production in his own hands has not much in common with his fellow citizens living in the cities. These groups share the present but nevertheless live in totally different times. However, they are both pressured by the same economic development which can lead to the above mentioned anticapitalistic impulse. Because this impulse is not very clear and precise, particularly for those affected by Ungleichzeitigkeit, these people need to be addressed in a specific way by left wing politicians and thinkers. According to Bloch this was not done during the time of the Weimar Republic.

When it comes to this failure and to the Nazis who used it for their own purposes Klaus Mann's novel Mephisto in part almost seems like a reflection of Bloch's theoretical concept. Especially analysing the character of Hans Miklas - a young actor coming from rural Bavaria to Hamburg who struggles to make a living and eventually turns towards the Nazis - will be fruitful in this context. As already mentioned neither is there such a party as the Nazis in the present nor did we witness an antidemocratic takeover in politics. But nonetheless Ungleichzeitigkeiten are still in place and play a major role in the emergence of today's nationalist movements. Against this backdrop novels like Juli Zeh's Unter Leuten or Saša Stanišićc's Vor dem Fest seemingly appear like a reminder 
that there are people who should not be forgotten. Analysing these novels with Bloch's concept of Ungleichzeitigkeit and at the same time comparing them with literary texts from the past potentially reveal that they can be a powerful means in undoing (or at least in pushing back) antidemocratic movements of the present. 